\title{
SIMULATION AND VALIDATION OF TWO-COMPONENT FLOW IN A VOID RECIRCULATION SYSTEM
}

\author{
A Thesis \\ presented to \\ the Faculty of California Polytechnic State University, \\ San Luis Obispo
}

\author{
In Partial Fulfillment \\ of the Requirements for the Degree \\ Master of Science in Mechanical Engineering
}

by

Oscar Eduardo Daza

May 2011 
(C) 2008

Oscar Eduardo Daza

ALL RIGHTS RESERVED 


\section{COMMITTEE MEMBERSHIP}

TITLE:

AUTHOR:

DATE SUBMITTED:

COMMITTEE CHAIR:

COMMITTEE MEMBER:

COMMITTEE MEMBER:
Simulation and Validation of Two-Component Flow in a Void Recirculation System

Oscar Eduardo Daza

May 2011
Dr. Kim A. Shollenberger, Professor

Dr. Glen E. Thorncroft, Professor 


\begin{abstract}
Simulation and Validation of Two-Component Flow in a Void Recirculation System Oscar Eduardo Daza
\end{abstract}

Nuclear power plants rely on the Emergency Core Cooling System (ECCS) to cool down the reactor core in case of an accident. Occasionally, air is entrained into the suction piping of ECCS causing voids that decrease pumping efficiency, and consequently damage the pumps. In an attempt to minimize the amount of voids entering the suction side of the pump in ECCS, a Void Recirculation System (VRS) experiment was conducted for a proof of concept purpose. While many studies have been oriented in studying two-component flow behavior in ECCS, none of them propose a solution to minimize air entrainment. As a consequence, there are no simulation models that use computational fluid dynamics to address gas entrainment solutions in ECCS. The objectives of this thesis are to (1) simulate and investigate two-component air-water flow in a VRS that minimizes the amount of air in piping systems, using RELAP5/MOD3 as the computational tool, and (2) to validate the numerical results with respect to experimental results and observations.

A one-dimensional model of the VRS was built in RELAP5, in which eight different scenarios (replicating those from the VRS experiment) were simulated for a period of 150 seconds. Four Froude numbers of 0.8, 1.0, 1.3 and 1.6 were evaluated in two different pipe configurations, and the experimental data obtained from the VRS experiment was used to validate the numerical results obtained from these simulations. It was concluded that air recirculation occurs indefinitely throughout the entire 150 seconds of the simulation for Froude numbers up to 1.3; while for a Froude number of 1.6, air recirculation occurs for approximately 100 seconds and ceases after 125 seconds of the simulation. An average air reduction effectiveness of $90 \%$ was found for all simulation scenarios. The VRS model was successfully validated and can be used to investigate the effects of air entrainment in suction piping.

Keywords: Two-component flow, air-water, void fraction, RELAP5, CFD simulation. 


\section{ACKNOWLEDGMENTS}

I would like to thank and acknowledge the advice given by Dr. Christopher Pascual, thesis advisor. I also thank Dr. Kim Shollenberger's guidance and the graduate committee members.

My sincere gratitude to Anderson Lin, who believed in my talent and gave me the opportunity to work in this beautiful project. I also thank Jerry Ballard for the technical support provided in using RELAP5.

I feel deeply appreciated with Nereida Figueroa for her continuous support, words of patience and love.

This thesis is dedicated to my parents Oscar H. Daza and Trinidad de Daza, to my brother Alejandro Daza and his family, who opened new doors to my life and encouraged me to achieve challenging milestones. 


\section{TABLE OF CONTENTS}

Page

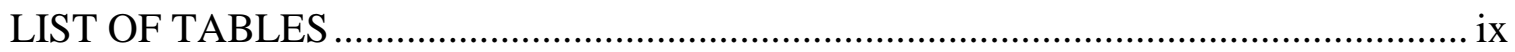

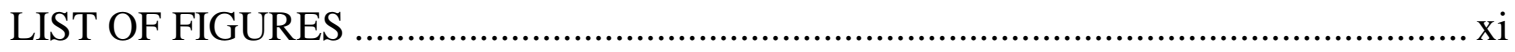

NOMENCLATURE ...................................................................................

Chapter 1. INTRODUCTION AND LITERATURE REVIEW …………………….... 1

1.1. Emergency Core Cooling System …………………………………………..... 1

1.2. ECCS Gas Entrainment Solutions and Void Recirculation System...................... 3

1.3. Review of existing ECCS models .............................................................. 5

1.4. Review of existing Two-Phase flow models ...................................................... 8

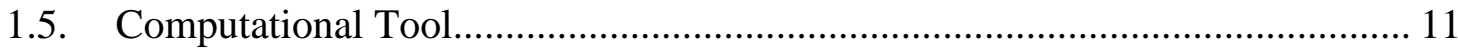

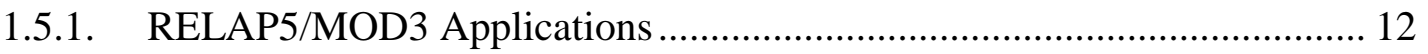

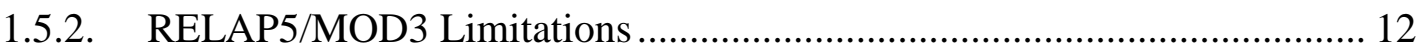

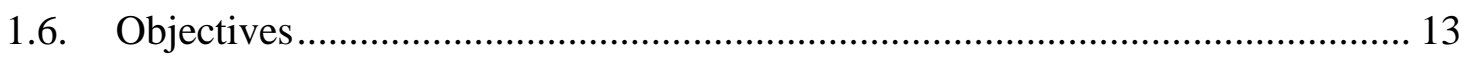

Chapter 2. COMPUTATIONAL MODEL ………………...................................... 14

2.1. Two-Fluid General Definitions .................................................................... 14

2.1.1. Froude Number .............................................................................. 14

2.1.2. Void Fraction ……………………………………………………….... 15

2.1.3. Superficial Velocity ………………………….................................... 16

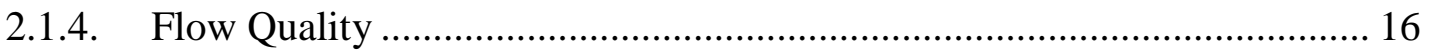

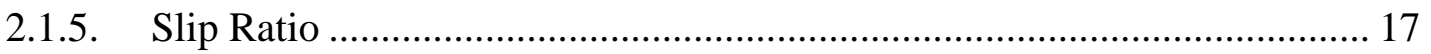

2.2. Two-Fluid Flow Model used in RELAP5 …………........................................ 17

2.2.1. One-Dimensional Two-Fluid Conservation Equations ....................................... 18

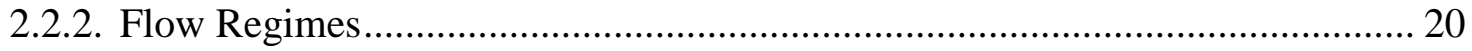

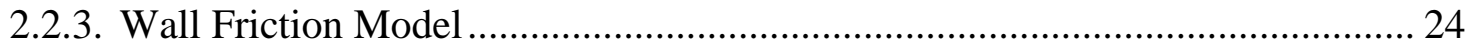




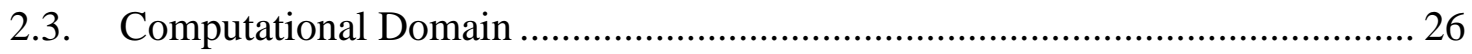

2.3.1. VRS Model Geometry ……………………….................................... 26

2.3.2. VRS Model Boundary Conditions ............................................................... 37

2.3.3. VRS Model Thermal/Hydraulic settings ...................................................... 41

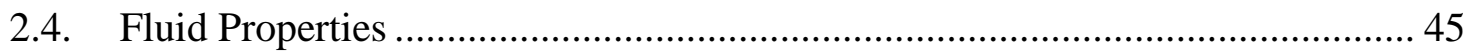

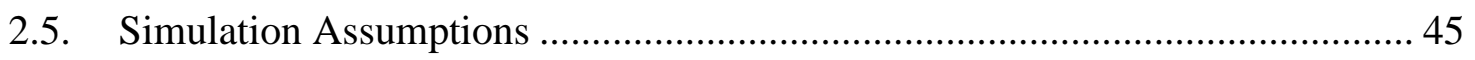

Chapter 3. SIMULATION SCENARIOS, RESULTS AND DISCUSSION ................ 47

3.1. Void Recirculation Experiment....................................................................... 47

3.1.1. Experiment Description ........................................................................... 47

3.1.2. Experiment Observations ....................................................................... 51

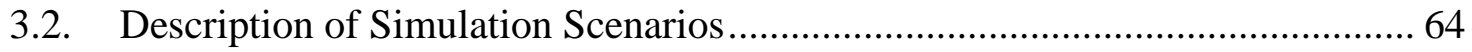

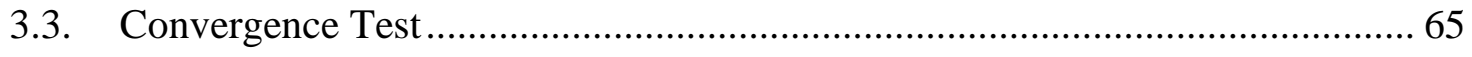

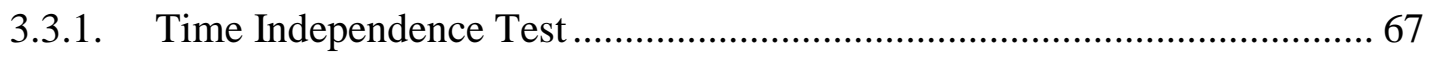

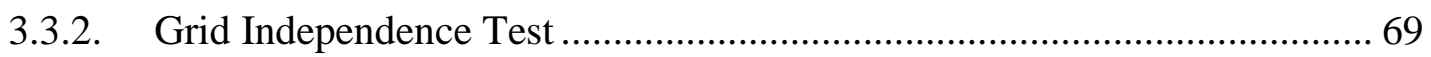

3.4. Simulation Validation, Results and Discussion ............................................... 73

3.4.1. Mass Flow Rate Analysis.......................................................................... 74

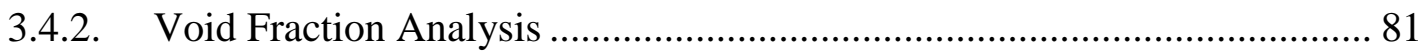

3.4.3. Simulation and Experimental Void Fraction Validation ............................. 92

Chapter 4. CONCLUSIONS AND RECOMMENDATIONS ……………………....... 96

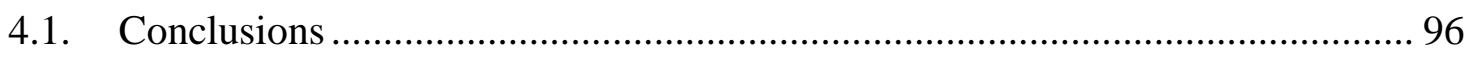

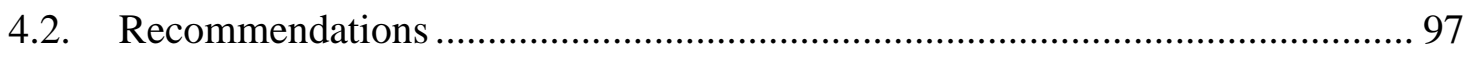

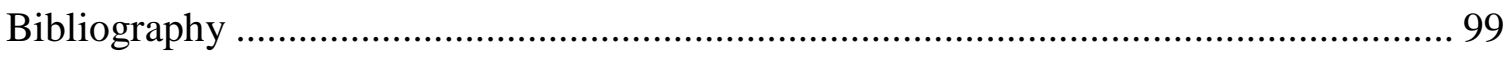

Appendix A - VRS Piping Drawings ……………………………………………..... 102

Appendix B - VRS Pipe Data................................................................................. 104

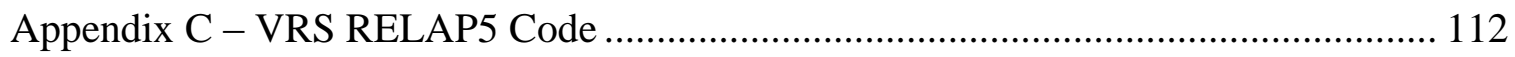




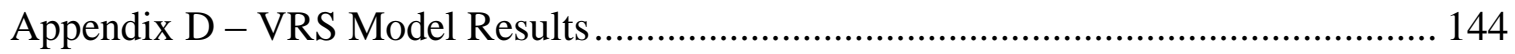

Appendix D.1. Mass Flow Rate Results ............................................................... 144

Appendix D.2. Void Fraction Results....................................................................... 148

Appendix E - VRS Simulation and Experimental Void Fraction Validation ................ 152 


\section{LIST OF TABLES}

Page

Table 2.1. List of the main hydrodynamic building blocks used in the VRS model. 30

Table 2.2. VRS pipe specifications and elbow resistance coefficients 32

Table 2.3. Enlargement and contraction loss coefficient values for various reducing bushings. 34

Table 2.4. Regular tee loss coefficient values. 35

Table 2.5. Summary of the simulated pump flow rates as a function of the Froude number. 38

Table 2.6. Air injection scheme for various Froude numbers in the four-inch pipe, yielding a minimum initial void fraction of seven-percent. 40

Table 2.7. Air injection scheme for various Froude numbers in the six-inch pipe, yielding a minimum initial void fraction of seven-percent.

Table 2.8. Summary of the control flags used for various VRS model components.

Table 2.9. Summary of the controls flags used for various VRS model reducing tees.

Table 3.1. List of simulation scenarios for the RELAP5 VRS model. 65

Table 3.2. List of convergence tests for the RELAP5 VRS model. 66

Table 3.3. Discretization error results based on the RE method 70

Table 3.4. Modified Discretization error results based on the RE method, using $p$ $=2.00$. 73 
Table 3.5. Numerical results for the average percent air removed between

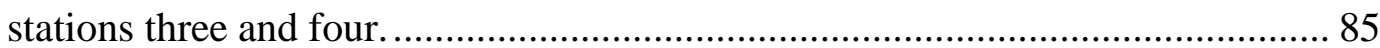




\section{LIST OF FIGURES}

Page

Figure 1.1. Schematic Diagram of the Emergency Core Cooling System. (Diablo Canyon Power Plant, PG\&E, 2009) ...................................................... 1

Figure 1.2. Void migration schematic in the suction piping of the ECCS....................... 3

Figure 1.3. Generic schematic of the Void Recirculation System device to be

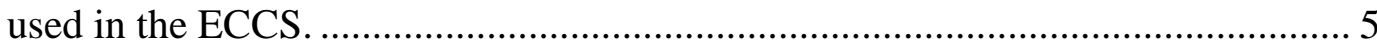

Figure 2.1. Horizontal flow regimes with brief description (Chisholm D. , 1983). ........ 21

Figure 2.2. Horizontal flow regime map used in RELAP5 (RELAP5/MOD3.2,

Code Manual Volume I: Code Structure, System Models, and Solution Methods, 1995).

Figure 2.3. Upwards vertical flow regimes with brief description (Chisholm D. , $1983)$

Figure 2.4. Vertical flow regime map used in RELAP5 (RELAP5/MOD3.2,

Code Manual Volume I: Code Structure, System Models, and Solution

Methods, 1995). 23

Figure 2.5. Isometric drawing of the VRS (Daza, Fong, Rosas, \& Wong, 2009). 27

Figure 2.6. Computational schematic of the $4 \times 4 \times 3$-inch VRS model. ........................... 28

Figure 2.7. Computational schematic of the $6 \times 6 \times 4$ " VRS model................................... 29

Figure 3.1. Experimental setup of the Void Recirculation System................................ 47

Figure 3.2. Lower pipe configurations used during the VRS experiment. ..................... 49

Figure 3.3. Sections of experimental interest for the Void Recirculation System........... 51 
Figure 3.4. Horizontal stratified flow regime observed in the four and six-inch pipes.

Figure 3.5. Downward bubbly flow regime observed in the four and six-inch pipes 54

Figure 3.6. Wavy horizontal stratified flow observed in the four and six-inch

pipes 55

Figure 3.7 Bubbly and slug flow observed in the four and six-inch pipes. 56

Figure 3.8. Slug flow observed at station three in the four and six-inch pipes. 57

Figure 3.9. Wavy horizontal stratified and bubbly flow transition observed at station three in the four and six-inch pipes. 58

Figure 3.10. Bubbly flow observed at station four in the four and six-inch pipes. 60

Figure 3.11. Upwards slug flow observed at the VRP for the four and six-inch pipe configurations. 61

Figure 3.12. Upwards bubbly flow observed at the VRP for the four and six-inch pipe configurations.. 62

Figure 3.13. Taylor Bubble Train Flow Regime (Flow Regime Sample Movies). 62

Figure 3.14. Air settling before the check valve in the six-inch branch. 64

Figure 3.15. Void fraction behavior for scenario one at station three for different time steps.

Figure 3.16. Void fraction behavior for scenario one at station three for different mesh sizes. 69

Figure 3.17. Mass flow rate behavior for simulation scenario one: 4x4x3-inch, $F r=0.81$ 75 
Figure 3.18. Mass flow rate and void fraction behavior at the recirculation pipe, for simulation scenario one: $4 \times 4 \times 3$-inch, $F r=0.81$. 76

Figure 3.19. Mass flow rate and void fraction behavior at the recirculation pipe, for simulation scenario eight: $6 \times 6 \times 4$-inch, $F r=1.60$. 78

Figure 3.20. Mass flow rate behavior for simulation scenario five: $6 \times 6 \times 4$-inch,

$F r=0.81$ 80

Figure 3.21. Void fraction behavior for simulation scenario one: $4 \times 4 \times 3$-inch, $\mathrm{Fr}$ $=0.81$. 83

Figure 3.22. Slip ratio and void fraction behavior at stations three and four, for simulation scenario one: $4 \times 4 \times 3$-inch, $F r=0.81$. 86

Figure 3.23. Void fraction behavior for simulation scenario eight: $6 \times 6 \times 4$-inch,

$F r=1.60$.

Figure 3.24. Slip ratio and void fraction behavior at pipe section after lower elbow, for simulation scenario one: $4 \times 4 \times 3$-inch, $F r=0.81$ 90

Figure 3.25. Slip ratio and void fraction behavior at pipe section after lower elbow, for simulation scenario eight: $6 \times 6 \times 4$-inch, $F r=1.6$. 91

Figure 3.26. Void fraction validation of the VRS model for simulation scenario one: $4 \times 4 \times 3$-inch, $F r=0.81$. 93

Figure 3.27. Schematic of a pipe partially filled with water 94

Figure A.1. 4x4x3-inch VRS Pipe Configuration Drawing.................................... 102

Figure A.2. 6x6x4" VRS Pipe Configuration Drawing. .......................................... 103

Figure D.1. Mass flow rate behavior for scenario one $(4 \times 4 \times 3$-inch, $F r=0.81) \ldots \ldots \ldots \ldots . . . .144$

Figure D.2. Mass flow rate behavior for scenario two $(4 \times 4 \times 3$-inch, $F r=0.96)$. 144 
Figure D.3. Mass flow rate behavior for scenario three $(4 \times 4 \times 3$-inch, $F r=1.29)$........ 145

Figure D.4. Mass flow rate behavior for scenario four $(4 \mathrm{x} 4 \mathrm{x} 3$-inch, $F r=1.60) \ldots \ldots \ldots . . .145$

Figure D.5. Mass flow rate behavior for scenario five $(6 \mathrm{x} 6 \mathrm{x} 4$-inch, $F r=0.81) \ldots \ldots \ldots . .146$

Figure D.6. Mass flow rate behavior for scenario six $(6 x 6 x 4-i n c h, F r=1.10) \ldots \ldots \ldots \ldots . .146$

Figure D.7. Mass flow rate behavior for scenario seven $(6 \times 6 \times 4$-inch, $F r=1.38)$....... 147

Figure D.8. Mass flow rate behavior for scenario eight $(6 \times 6 \times 4$-inch, $F r=1.60)$........ 147

Figure D.9. Void fraction behavior for scenario one $(4 \mathrm{x} 4 \mathrm{x} 3$-inch, $F r=0.81) \ldots \ldots \ldots \ldots . . .148$

Figure D.10. Void fraction behavior for scenario two $(4 \times 4 \times 3$-inch, $F r=0.96) \ldots \ldots \ldots . . .148$

Figure D.11. Void fraction behavior for scenario three $(4 \times 4 \times 3$-inch, $F r=1.29) \ldots \ldots \ldots . .149$

Figure D.12. Void fraction behavior for scenario four $(4 \times 4 \times 3$-inch, $F r=1.60) \ldots \ldots \ldots . . .149$

Figure D.13. Void fraction behavior for scenario five (6x6x4-inch, $F r=0.81) \ldots \ldots \ldots . .150$

Figure D.14. Void fraction behavior for scenario six (6x6x4-inch, $F r=1.10) \ldots \ldots \ldots \ldots . .150$

Figure D.15. Void fraction behavior for scenario seven (6x6x4-inch, $F r=1.38) \ldots \ldots \ldots 151$

Figure D.16. Void fraction behavior for scenario eight $(6 \mathrm{x} 6 \mathrm{x} 4$-inch, $\mathrm{Fr}=1.60) \ldots \ldots \ldots . .151$

Figure E.1. Void fraction validation for scenario one $(4 \times 4 \times 3$-inch, $F r=0.81) \ldots \ldots \ldots \ldots . . . .152$

Figure E.2. Void fraction validation for scenario two $(4 \mathrm{x} 4 \mathrm{x} 3$-inch, $F r=0.96) \ldots \ldots \ldots \ldots . . . .152$

Figure E.3. Void fraction validation for scenario three $(4 \times 4 \times 3$-inch, $F r=1.29) \ldots \ldots \ldots . .153$

Figure E.4. Void fraction validation for scenario four $(4 \times 4 \times 3$-inch, $F r=1.60)$.......... 153

Figure E.5. Void fraction validation for scenario five (6x6x4-inch, $F r=0.81) \ldots \ldots \ldots \ldots . . . .154$

Figure E.6. Void fraction validation for scenario six $(6 \mathrm{x} 6 \mathrm{x} 4$-inch, $F r=1.10) . \ldots \ldots \ldots \ldots . . . .154$

Figure E.7. Void fraction validation for scenario seven (6x6x4-inch, $F r=1.38) \ldots \ldots \ldots .155$

Figure E.8. Void fraction validation for scenario eight $(6 \times 6 \times 4$-inch, $F r=1.60) \ldots \ldots \ldots . .155$ 


\section{NOMENCLATURE}

\begin{tabular}{|c|c|}
\hline$A$ & Pipe cross-sectional area $\left(\mathrm{ft}^{2}\right)$ \\
\hline$C_{V}$ & Flow Coefficient \\
\hline$D$ & Pipe Diameter (in) \\
\hline $\mathrm{Fr}$ & Froude Number \\
\hline$g$ & Gravitational constant $\left(\mathrm{ft} / \mathrm{s}^{2}\right)$ \\
\hline$j$ & Fluid superficial velocity $(\mathrm{ft} / \mathrm{s})$ \\
\hline$K$ & Loss coefficient \\
\hline$L$ & Pipe length (ft) \\
\hline$\dot{m}$ & Mass flow rate $(\mathrm{lb} / \mathrm{s})$ \\
\hline$P$ & Pressure (psi) \\
\hline$q$ & Volumetric flow rate (gpm) \\
\hline $\operatorname{Re}$ & Reynolds number \\
\hline$S$ & Slip ratio \\
\hline$t$ & Time (s) \\
\hline$V$ & Fluid velocity $(\mathrm{ft} / \mathrm{s})$ \\
\hline$x$ & Flow quality \\
\hline$X$ & Lockhart-Martinelli parameter \\
\hline$Z$ & Volume centroid elevation $(\mathrm{ft})$ \\
\hline
\end{tabular}




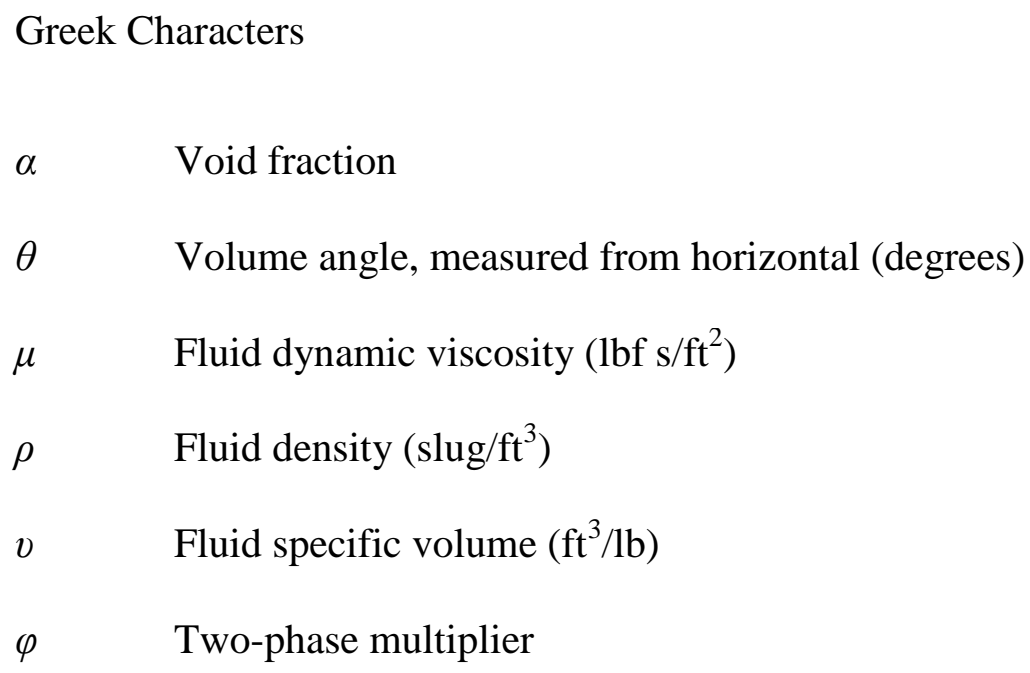




\section{Chapter 1. INTRODUCTION AND LITERATURE REVIEW}

\subsection{Emergency Core Cooling System}

Nuclear power plants rely on various protection systems that must be ready to operate in case of a nuclear reactor failure. One of the most important protection plans is the Emergency Core Cooling System (ECCS), which ultimately prevents a nuclear meltdown by means of transferring heat from the reactor to the borated water, which is a neutron absorber. When the ECCS is activated, borated water stored in a tank and subject to atmospheric pressure, is pumped to the nuclear reactor as shown in Figure 1.1.
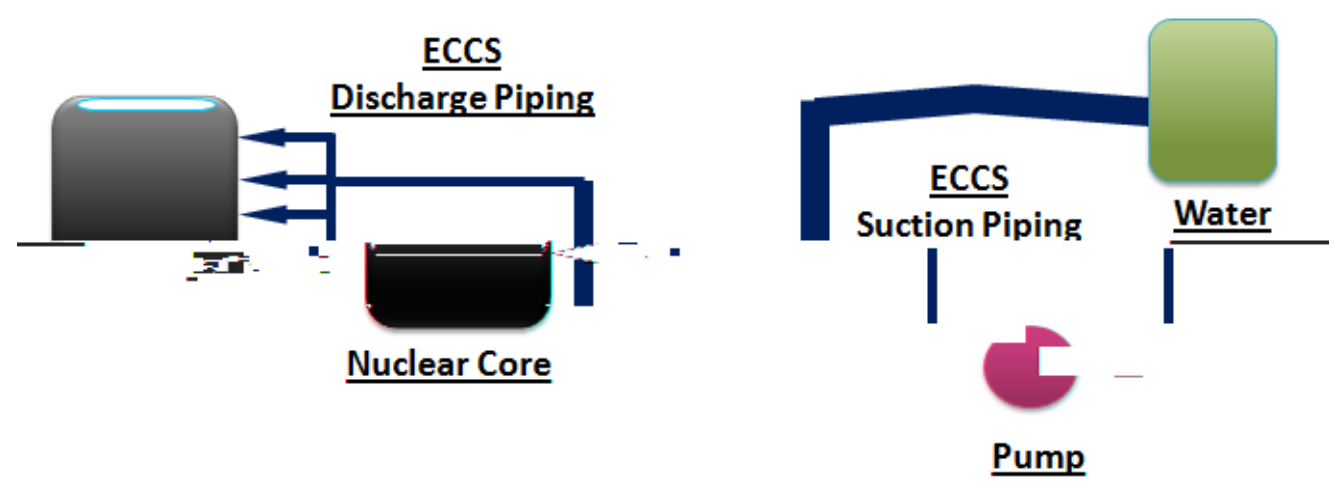

Figure 1.1. Schematic Diagram of the Emergency Core Cooling System. (Diablo Canyon Power Plant, PG\&E, 2009)

While this method has been used for many years and in many power plants, it has been common to see dissolved gas being transported into the ECCS piping system. An information notice from the Nuclear Regulatory Commission (NRC) was published regarding the entrainment of gas into the ECCS and containment spray systems of three main nuclear power plants (Nuclear Regulatory Commission, 2006). The source of 
entrained gas in these three events was due to different conditions, but produced the same problem throughout. For example, NRC's inspection at Palo Verde Nuclear Generating Station determined that gas was being entrained because the water level fell below the suction piping. The second event described in the NRC's inspection was at the Waterford Steam Electric Station, Unit 3, where it was determined that lack of adjustments to the outside containment isolation valve led to loss of suction supply, thus leading to a medium to large Loss of Coolant Accident (LOCA), creating large gas voids within the suction piping. The last event described in this inspection was at the Clinton Power Station, where it was determined that an inappropriate method was used to calculate vortexing at the pump's intake. Another reason for the entrainment of gas into ECCS piping systems, which is not discussed in this information notice from the NRC and was specifically reported at the Diablo Canyon Power Plant (Avila Beach, CA), is a consequence of the depressurization of the gas in the water tank. Gas depressurization occurs when the local pressure falls below the saturation pressure of the gas. When this happens, a water-gas flow is generated and later transported into the piping system creating gas voids as specifically shown in Figure 1.2. Large voids in the suction side of the pump can create cavitation, thus decreasing pump efficiency, lifetime, while adding to the maintenance and repair costs. Even though some gas voids can be vented using relief valves, other gas voids exist near the nuclear reactor where these types of valves cannot be installed for safety purposes. For this reason, a series of solutions have been proposed in the nuclear industry to minimize or eliminate the gas voids present in the ECCS piping system. These solutions are discussed in the next section and are intended to inform the reader about possible and existing solutions. 


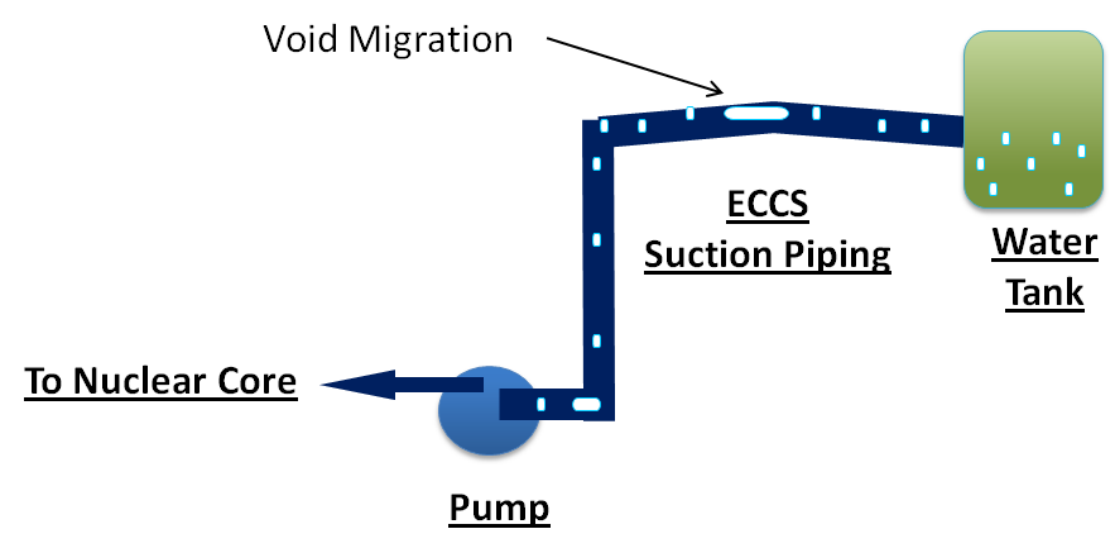

Figure 1.2. Void migration schematic in the suction piping of the ECCS.

\subsection{ECCS Gas Entrainment Solutions and Void Recirculation System}

Possible solutions proposed by the NRC in a Generic Safety Issue Report (Nuclear Regulatory Commission, 2010) to minimize or prevent damage due to entrained gas into ECC systems are as follows:

a) Install gas sensors in the suction piping to prevent pump startup or valve opening. Emergency operations are to be resumed once single-phase flow (i.e. water flow) has been fully established in the pipes.

b) Control the sequencing of the pumps during ECCS startup.

c) Align one of the suction pipes to the condensate storage tank.

d) Install anti-vortexing devices to suction strainers in the location of the water source.

While these ideas still need to be carefully thought due to their practicality and cost effectiveness, other power plants need to mitigate the problem immediately. Recently, Westinghouse Electric Company LLC published a report on the investigation of a 
simplified equation for gas transport in ECCS (Westinghouse Electric Company LLC, 2011). The simplified equation (SE) helps to find the maximum amount of gas volume in pump suction piping, as a function of gas volume high points, system pressures and flows. Even though the SE is based on a variety of assumptions and is limited to specific pump suction piping configurations and flow regimes, it allows the ECCS to be activated safely without risking pump damage. In fact, the Diablo Canyon Power Plant (DCPP) has been one of the first plants to successfully use this SE, and is currently updating safety procedures to keep the ECCS under normal operating conditions. In addition of using the SE, DCPP has also been proactive at minimizing the amount of gas entrained by installing a "void header" that traps the air in a collector tank. Unfortunately, this tank needs to be vented periodically by an operator, thus adding to the cost of labor and time.

With the intention of solving this problem without the need of frequent human interaction, California Polytechnic State University (San Luis Obispo, CA) partnered with DCPP to develop a self-contained system. This device, called a "Void Recirculation System" (VRS), consists of a vertical pipe connecting the lower and upper main suction piping allowing gas recirculation with the use of a check valve to prevent water back flow (Daza, Fong, Rosas, \& Wong, 2009). Figure 1.3 describes a generic schematic for the VRS device, where gas voids migrate from the water tank and through the upper suction piping, then transported down through a 90 degree elbow, a vertical downcomer, another 90 degree elbow and a lower horizontal suction pipe. The void recirculation pipe is to be placed before the pump, where gas recirculates upwards and around the main suction piping as depicted in the green arrows. 


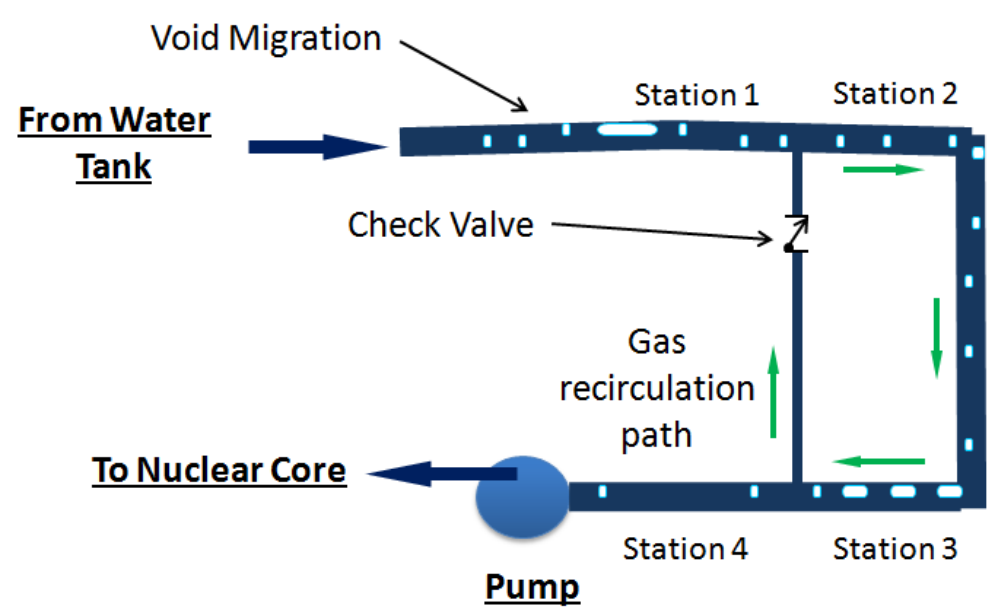

Figure 1.3. Generic schematic of the Void Recirculation System device to be used in the ECCS.

This device was tested under different flow rates, initial void quantities, and bottom pipe configurations. Air was injected in the system by using an air compressor and the VRS was tested on the discharge side of the pump, rather than on the suction side, for the sake of the experiment. Void fraction measurements were taken at stations one (before the upper tee), two (after the upper tee), three (before the lower tee) and four (after the lower tee). The objective of this experiment was to verify the design of the VRS and to select the best bottom piping configuration for each of the tested scenarios. The data recorded from this experiment will be used in this thesis to validate the VRS concept using a thermal-hydraulic computer code called RELAP5/Mod3.

\subsection{Review of existing ECCS models}

There are several investigators who have modeled a variety of scenarios in ECCS and have contributed to the analysis and prediction of LOCAs. The main objective in 
these contributions is to provide better management and operating procedures in case of nuclear accidents. Sarrette and Bestion, for example, investigated the potential release of nitrogen gas dissolved in water during depressurization in the accumulator of the ECCS at the Loviisa Nuclear Power Plant (Sarrette \& Bestion, 2003). The first part of their work consisted of performing a series of degassing tests in order to find the time constant associated with the nitrogen gas release in a vertical pipe. Then, a non-condensable gas dissolution-release model was created using CATHARE (Code Avancé de Thermohydraulique pour Accidents de Réacteur à Eau), a thermal-hydraulic code for the nuclear safety analysis of Pressurized Water Reactors (PWR). An interfacial friction model consistent with the flow configuration seen in the experimental results, along with the gas-release time constant previously found, was later implemented in CATHARE. Finally, the code was used to investigate the effects of nitrogen degassing for LOCA scenarios. Numerical results showed better agreement with experimental results for the case of delayed degassing than for faster degassing.

A similar work at DCPP, where the effect of nitrogen gas entrained was studied in ECCS piping systems, was the effort done by Phillips in his water hammer simulation using RELAP5 (Phillips, 2003). During the pump startup operation, pressure waves can be generated if gas voids are present in the piping system. This effect, commonly known as a water hammer, can create high pipe stresses in elbows due to rapid change in direction, thus leading to pipe damage and possible ECCS failure. Pipe stresses modeled in RELAP5, measured as hydraulic forces, were subject to $100 \%$ and $50 \%$ void models in order to fully analyze the water hammer effect. Even though the model provided a 
reasonable prediction of hydraulic forces, the maximum calculated values continue to be under the safety order of magnitude during a LOCA.

Other investigators have focused their research in different LOCA scenarios in order to develop severe accident management guidelines, and to provide better insight on the ECCS fluid transport model. For instance, a RELAP5 model was developed to analyze the steam-zirconium oxidation and pipe rupture in the ECCS at the Ignalina Nuclear Power Plant (Kaliatka \& Uspuras, 2008). Zirconium is used as a cladding material for nuclear rods due to its low thermal absorbance and high corrosion resistance. However, steam can oxidize the zirconium cladding at high temperatures (approximately at $1200^{\circ} \mathrm{C}$ ) by producing an exothermic reaction (release of heat), accompanied by the release of hydrogen gas. If this oxidation is not controlled, pipe rupture can occur. The code results were first validated against existing data in the RBMK (for Russian reaktor bolshoy moshchnosti kanalniy) type reactors at the Leningrad Nuclear Power Plant and later used at the Ignalina plant for the development of accident management guidelines. The results obtained in RELAP5 were determined to be acceptable for plant operating procedures. In another investigation, Groudev and Gencheva studied the advantages and disadvantages of main loop isolating valves in case of a steam generator tube rupture (Groudev \& Gencheva, 2004). The thermal-hydraulic results, modeled in RELAP5, showed that the use of main isolation valves is achievable, and the operator can bring the plant to safe running conditions.

It is important to note that few investigators, such as Sarrette, Bestion and Phillips, have actually dealt with gas entrainment models. However, during the literature research, no publication was found that discussed neither the implementation of gas 
entrainment solutions nor the modeling of possible solutions in ECCS piping systems. For this reason, the motivation of using RELAP5/MOD3 to build a computational model, representing the experimental setup of the VRS, was initiated to simulate gas entrainment solutions in ECCS. The numerical results obtained were used to evaluate the practicality of one of the first gas entrainment solutions, and were validated against the results obtained from the VRS experiment. This one involves the subject of two-phase flow in pipes, for which a literature review of these models will be discussed in the next section.

\subsection{Review of existing Two-Phase flow models}

Since the VRS experiment mainly focused on the void fraction behavior at the upper and lower main pipes, and not the effects that elbows had on the recirculation path,

the following literature research also focuses on two-phase horizontal flows and flow separation at tee junctions. Moreover, the research will be limited to horizontal stratified flows since this was the flow regime that was observed during the VRS experiments.

The investigation and analysis of two-phase flows has been carried out by numerous researchers depending upon the conditions of interest. The contributions done by Ishii and Mishima have been of great value to the multi-phase community because they have formalized all equations to be used for mass, momentum and energy conservation (Ishii, 1975; Ishii \& Mishima, 1984). Other researchers such as Taitel, Dukler and Chisholm have also contributed to this immense field by providing theoretical approaches to the prediction of pressure drop in pipelines (Taitel \& Dukler, 1976; Chisholm, 1968). 
With the introducton of today's powerful computational techniques, it has been possible to better predict many variables of interest for two-phase flow (e.g. void fraction, pressure drop, flow regimes, etc.). For instance, Newton and Behnia (2001) developed a numerical model for horizontal stratified wavy gas-liquid pipe flow, that predicted liquid holdup, pressure drop, wall and interfacial shear stresses. The main objective of this numerical model was to gain independence of empirical closure relations, by providing a bipolar coordinate system, along with a $\kappa-\epsilon$ turbulunce model at low Reynolds numbers, allowing the solution of the governing equations for each phase without inputting empirical wall functions. The proposed numerical model was then compared to existing mechanisitc models, and the prediction of the measured values were in acceptable agreement with the experimental data. In a similar investigation, a model was proposed using the Reynolds-averaged Navier-Stokes (RANS) equations, with the $\kappa-\omega$ turbulence model for fully developed horizontal stratified flow in pipes (de Sampaio, Faccini, \& Su, 2008). This model used a finite element mesh, bipolar coordinates, the Newton-Raphson root finding scheme, and focused on simulating the wall and interfacial shear stresses to provide better insight on the interaction of gas-liquid flows, with the objective of validating the use of the $\kappa-\omega$ turbulence model. The predicted values were then compared to experimental data, showing that the turbulence model was suitable for horizontal stratified flows. Yet another numerical simulation was carried out using FLUENT to deterimine the interfacial friction factor for horizontal stratified gas-liquid 3D flows (Sidi-Ali \& Gatignol, 2010). Velocity profiles, wall-gas shear stresses and interfacial shear stresses numerical results were compared to seven different experiments and one numerical model. The results comparison showed to be in excellent agreement 
for velocity profiles, and acceptable agreement for wall-gas and interfacial shear stresses, confirming the validity of the turbulence model used.

Simulation of the bottom horizontal tee for the VRS experiment can be seen as a form of two-phase separator, with the exception that the gas recirculation path is actually connected to the same main pipe loop. The orientation of the tee, where there is a horizontal run and a vertical branch (with upwards flow), is of particular interest for the validation of the VRS device and hence the computational model presented in this thesis. In the attempt of analyzing this specific type of flow configuration, Margaris (2007) proposed a mathematical algorithm to model the separation of gas-liquid two-phase flow at a tee junction. The experimental and numerical models both assumed a horizontal straight pipe before the tee junction with slug flow at the tee inlet, the air was separated through the vertical branch and the water continued its path through the horizontal run. The vertical branch then connected to a horizontal settling pipe, where further separation was allowed. The air continued its path into an independent gas line, and the water fell downwards into the lower main horizontal pipeline through a vertical pipe. Air and water mass flow rates were compared, as well as void fraction and pressure drop at the tee junction and at the settling pipe. The numerical results obtained showed satisfactory results with respect to the experimental data, and the mathematical algorithm was successfully validated. Margaris also suggested the implementation of this algorithm into other computer codes due to its easy incorporation of one-dimensional multiphase flow. Other similar investigations carried out by Ottens et al. (2001) and Baker et al. (2008), studied the transient effects in gas-liquid separators by using different pipe configurations and tee orientations. Nonetheless, the experiments carried out in both works showed that 
the different phases were completely separated in different pipelines, as was the case for the research done by Margaris.

\subsection{Computational Tool}

Numerical simulations for nuclear power plant systems can be done in a variety of computational fluid dynamic (CFD) solvers depending upon the specific problem to be analyzed. Software such as FLUENT (by ANSYS), SolidWorks Flow Simulation and Flow-3D could potentially be used to solve two-phase flow simulation problems. The software selection mainly depends on the computational domain to be solved, being either a small subsystem (e.g. flow around an object), or the analysis of a complete system (e.g. power plant thermal and hydraulic systems). Since this thesis analyzes airwater flow in nuclear power plant pipelines that change both in diameter and orientation, then the current study will use RELAP5/MOD3 to simulate the VRS device.

RELAP5 stands for Reactor Excursion and Leak Analysis Program, and is the fifth version of all RELAP codes. It is a thermal/hydraulic computer code developed for the U.S. NRC for the use of rulemaking, operating guidelines and as nuclear plant analyzer. Hence, it is the only code accepted by the NRC if simulation data is to be presented in any form of publication. In addition, DCPP uses this code to analyze the plant, and the code developed in this study can potentially be used at their site for further development. RELAP5 computer code is written in FORTRAN 77 and uses onedimensional two-fluid conservation equations that are formulated in terms of volume and 
time-averaged parameters. The code also uses a semi-implicit finite-difference technique to solve the computational domain and is first-order accurate in space and time.

\subsubsection{RELAP5/MOD3 Applications}

The computer code RELAP, being in its fifth version, has a variety of co-current and new models that are used to simulate and analyze specific nuclear plant systems such as steady-state and transient problems, Emergency Core Cooling mixing component model, Zirconium-water reaction model, correlations for interfacial friction in all geometries, an improved cross flow model and many more (RELAP5/MOD3.2, Code Manual Volume I: Code Structure, System Models, and Solution Methods, 1995). In general, RELAP5 is commonly used to simulate LOCA's, loss of feed-water, station blackout and turbine trip. It can also be used to simulate mixtures of steam, water, and non-condensable gases.

\subsubsection{RELAP5/MOD3 Limitations}

As previously mentioned, it is wise to carefully choose the CFD tool to be used for each problem since not all software is capable of analyzing an entire scope of computational domains. In the case of RELAP5, the code has two main limitations that were depicted during the learning phase of the program. First, the code cannot be used to analyze flows around objects. For example, the analysis of variables such as pressure and temperature gradients, streamlines, and velocities cannot be done on the problem of flow through an orifice. Second, the process of nodalization is limited to the $L / D$ ratio $(L$ is 
the volume length and $D$ is the volume diameter) for numerical stability. There are other limitations depending upon the models to be used within the program, and is strongly suggested to review the components to be used, along with their limitations, before deciding to use RELAP5.

\subsection{Objectives}

The objectives of this thesis are to (1) simulate and investigate two-component air-water flow in a void recirculation system that minimizes the amount of air in piping systems, using RELAP5/MOD3 as the computational tool, and (2) to validate the numerical results obtained from the void recirculation system model with respect to experimental results and observations.

The objectives previously mentioned will be approached in Chapter 2, where the computational model is explained from both the theoretical and geometrical viewpoints; and in Chapter 3, where the results from the model are discussed and validated against experimental results. Chapter 4 highlights the most significant achievements of this work and provides recommendations for future work. 


\section{Chapter 2. COMPUTATIONAL MODEL}

\subsection{Two-Fluid General Definitions}

The two-fluid flow model used in RELAP5, which will be discussed in the next section, requires the definition of unique parameters that are pertinent to this field of study. It is important to note that there are several parameters used in two-fluid flow, but only the concepts of interest will be defined.

\subsubsection{Froude Number}

The Froude number is a dimensionless parameter representing the ratio of inertia to gravitational forces. In general, it can be applied to open-channel flow (Jain, 2001), where the free surface of the water is subject to atmospheric pressure; and in pipe flow, where gaseous and liquid phases interact with each other (i.e. two-fluid flow). The Froude number equation is as follows:

$$
F r=\frac{V_{l}}{\sqrt{\frac{\left(\rho_{l}-\rho_{g}\right)}{\rho_{l}} g D}}
$$

where $V_{l}$ represents the liquid velocity, $\rho_{l}$ the liquid density, $\rho_{g}$ the gas density, $g$ the gravitational constant and $D$ the inside pipe diameter. Because $\rho_{l} \gg \rho_{g}$, for the case of water and air as the main working fluids, then:

$$
F r \cong \frac{V_{l}}{\sqrt{g D}}
$$


The Froude number categorizes the flow in three main regimes: $F r<1$ for subcritical flow, $F r=1$ for critical flow and $F r>1$ for supercritical flow (Fox, McDonald, \& Pritchard, 2006). Previous works, for example, analyzed the influence of the Froude number in determining the frequency at which air-water horizontal slug flow occurs (Woods \& Hanratty, 1999). In this analysis, it was determined that Froude numbers less than unity led to gravity waves upstream, caused by the formation of slug flows. In a similar example, the Froude number was used to characterize and predict the transition from horizontal stratified to slug flow (Kadri, Mudde, Oliemans, Bonizzi, \& Andreussi, 2009). Because of the Froude number significance in the industry, this paper will use the parameter in discussion for flow regime predictions and void fraction calculations.

Other basic parameters used in two-fluid flow are void fraction, superficial velocity, slip ratio and flow quality (Ghiaasiaan, 2008). These will be discussed in more detail in the following sections, will be used in different models and correlations, and assume the form of composite-averaged parameters.

\subsubsection{Void Fraction}

The void fraction can be defined as the ratio of the area occupied by the gas to the total cross-sectional area as follows:

$$
\alpha=\frac{A_{g}}{A}
$$

where $A_{g}$ is the area occupied by the gas and $A$ is the total cross-sectional area of the pipe. 


\subsubsection{Superficial Velocity}

The superficial velocity of each fluid is defined as the mean velocity if only that fluid flowed in the pipe, thus,

$$
\begin{gathered}
j_{l}=\frac{q_{l}}{A} \\
j_{g}=\frac{q_{g}}{A}
\end{gathered}
$$

where $q_{l}$ and $q_{g}$ are the liquid and gas flow rates, respectively.

The mixture center-of-volume velocity is the sum of both superficial fluid velocities, then

$$
j=j_{l}+j_{g}
$$

In the same way, the superficial fluid velocities are related to their fluid intrinsic velocities as follows:

$$
\begin{gathered}
j_{l}=(1-\alpha) V_{l} \\
j_{g}=\alpha V_{g}
\end{gathered}
$$

The superficial velocities are used to generalize flow regime maps and calculate void fraction values.

\subsubsection{Flow Quality}

The flow quality is the ratio of the gas to mixture mass flow rates as follows: 


$$
x=\frac{\dot{m}_{g}}{\dot{m}_{g}+\dot{m}_{l}}
$$

where $\dot{m}_{g}$ and $\dot{m}_{l}$ represent the gas and liquid mass flow rates, respectively. This parameter will also be used to calculate both void fraction and two-fluid pressure drop values.

\subsubsection{Slip Ratio}

The slip ratio is a relationship between the gas and liquid velocities that allows describing velocity differences between the phases or components as follows:

$$
S=\frac{V_{g}}{V_{l}}
$$

The slip ratio has a direct and indirect proportional relationship with the gas and liquid velocities, respectively. More specifically, as the gas velocity decreases, the slip ratio decreases as well, implying that the gaseous phase or component moves slower than the liquid component. This parameter will be used to validate numerical results.

\subsection{Two-Fluid Flow Model used in RELAP5}

Two-fluid flow is concerned with the simultaneous flow of two fluids in a given space. It can occur in many industrial applications such as boiling and pressurized water reactors, evaporators, condensers, jet pumps and many more. This concept can be divided into two subcategories for which they are well known in the industry (Wallis, 1969): 
1. Two-Phase flow, in which the fluids can be of the same component but of different states of matter, such as gas, liquid or solid.

2. Two-Component flow, in which the fluids do not consist of the same chemical substance, such as water and air.

These three terms will be used interchangeably throughout this paper depending on the matters to be discussed, but all mathematical notions and derivations are identical. Another term used in different references, and which will not be discussed in this paper, is Multi-Phase flow, which concerns the simultaneous flow of more than two phases or components.

\subsubsection{One-Dimensional Two-Fluid Conservation Equations}

Two-fluid flows follow the same laws as those described in fluid dynamics, and in fact are derived from single-phase or single-fluid conservation equations, though they are more complex and numerous since more variables have to be accounted for. The basic field one-dimensional equations for the two-fluid model consists of two continuity equations, two momentum equations and two energy equations as follows (RELAP5/MOD3.2, Code Manual Volume I: Code Structure, System Models, and Solution Methods, 1995):

Continuity Equation:

$$
\frac{\partial}{\partial t}\left(\alpha_{k} \rho_{k}\right)+\frac{1}{A} \frac{\partial}{\partial x}\left(\alpha_{k} \rho_{k} V_{k} A\right)=\Gamma_{k}
$$


where the subscript $k$ denotes the phase or component of interest, that is $k=g$ for the gas phase and $k=l$ for the liquid phase; and $\Gamma$ is the gas or liquid generation depending on the phase of interest.

Momentum Equation:

$$
\begin{aligned}
\alpha_{k} \rho_{k} A \frac{\partial V_{k}}{\partial t}+ & \frac{1}{2} \alpha_{k} \rho_{k} A \frac{\partial V_{k}^{2}}{\partial x} \\
& =-\alpha_{k} \mathrm{~A} \frac{\partial P}{\partial x}+\alpha_{k} \rho_{k} B_{x} A-\left(\alpha_{k} \rho_{k} A\right) F W_{k}\left(V_{k}\right)+\Gamma_{k} A\left(V_{k i}-V_{k}\right) \\
& -\left(\alpha_{k} \rho_{k} A\right) F I_{k}\left(V_{k}-V_{j}\right) \\
& -C \alpha_{k} \alpha_{j} \rho_{m} A\left[\frac{\partial\left(V_{k}-V_{j}\right)}{\partial t}+V_{j} \frac{\partial V_{k}}{\partial x}-V_{k} \frac{\partial V_{j}}{\partial x}\right]
\end{aligned}
$$

where the subscript $i$ is the interface between the phases, $j$ is the opposite phase of interest, and $m$ represents the flow mixture. Also,

$$
\begin{aligned}
& P=\text { Pressure } \\
& B=\text { Body force (i.e. gravity and pump head) } \\
& F W=\text { Wall frictional drag coefficient } \\
& F I=\text { Interface frictional drag coefficient } \\
& C=\text { Virtual mass coefficient }
\end{aligned}
$$


Energy Equation:

$$
\begin{aligned}
\frac{\partial}{\partial t}\left(\alpha_{k} \rho_{k} U_{k}\right)+ & \frac{1}{A} \frac{\partial}{\partial x}\left(\alpha_{k} \rho_{k} U_{k} V_{k} A\right) \\
& =-P \frac{\partial \alpha_{k}}{\partial t}-\frac{P}{A} \frac{\partial}{\partial x}\left(\alpha_{k} V_{k} A\right)+Q_{w k}+Q_{i k}+\Gamma_{i k} h_{k}^{*}+\Gamma_{w} h_{k}^{\prime} \\
& +D^{\prime S S} S_{k}
\end{aligned}
$$

where,

$$
\begin{aligned}
& U=\text { Specific internal energy } \\
& Q_{w k}=\text { Phasic wall heat transfer } \\
& Q_{i k}=\text { Interfacial heat transfer } \\
& h_{k}^{*}=\text { Phasic enthalpy associated with bulk interface mass transfer } \\
& h_{k}^{\prime}=\text { Phasic enthalpy associated with wall interface mass transfer } \\
& D I S S=\text { Phasic energy dissipation (sums of wall friction and pump effects) }
\end{aligned}
$$

\subsubsection{Flow Regimes}

Two-phase flow patterns or regimes can occur in many ways depending upon volume orientation, diameter, flow rates, fluid density, fluid viscosity, surface tension, and other parameters. The main flow regimes seen in horizontal flow are bubbly, plug, stratified, stratified-wavy, slug and annular flow (Chisholm, 1983). Figure 2.1 briefly describes the most common horizontal flow regimes seen in two-phase flow. The regimes are organized in ascending gas flow rates such that bubbly flow has the lowest gas flow rate, and annular flow has the highest gas flow rate. In order to determine the type of flow regime, RELAP5 uses a specific horizontal flow regime map that is based on several empirical correlations, and only applies to volume orientations between $0^{\circ}$ and 
$45^{\circ}$. Figure 2.2 shows the horizontal flow regime map used in RELAP5, consisting of horizontally stratified, bubbly, slug, annular mist, and mist-pre-CHF (critical heat flux) regimes. The shaded regions seen in the figure are the flow regime transition areas that also follow a set of criterions and are a function of void fraction limits, mass flux ranges, superficial velocities and fluid properties.

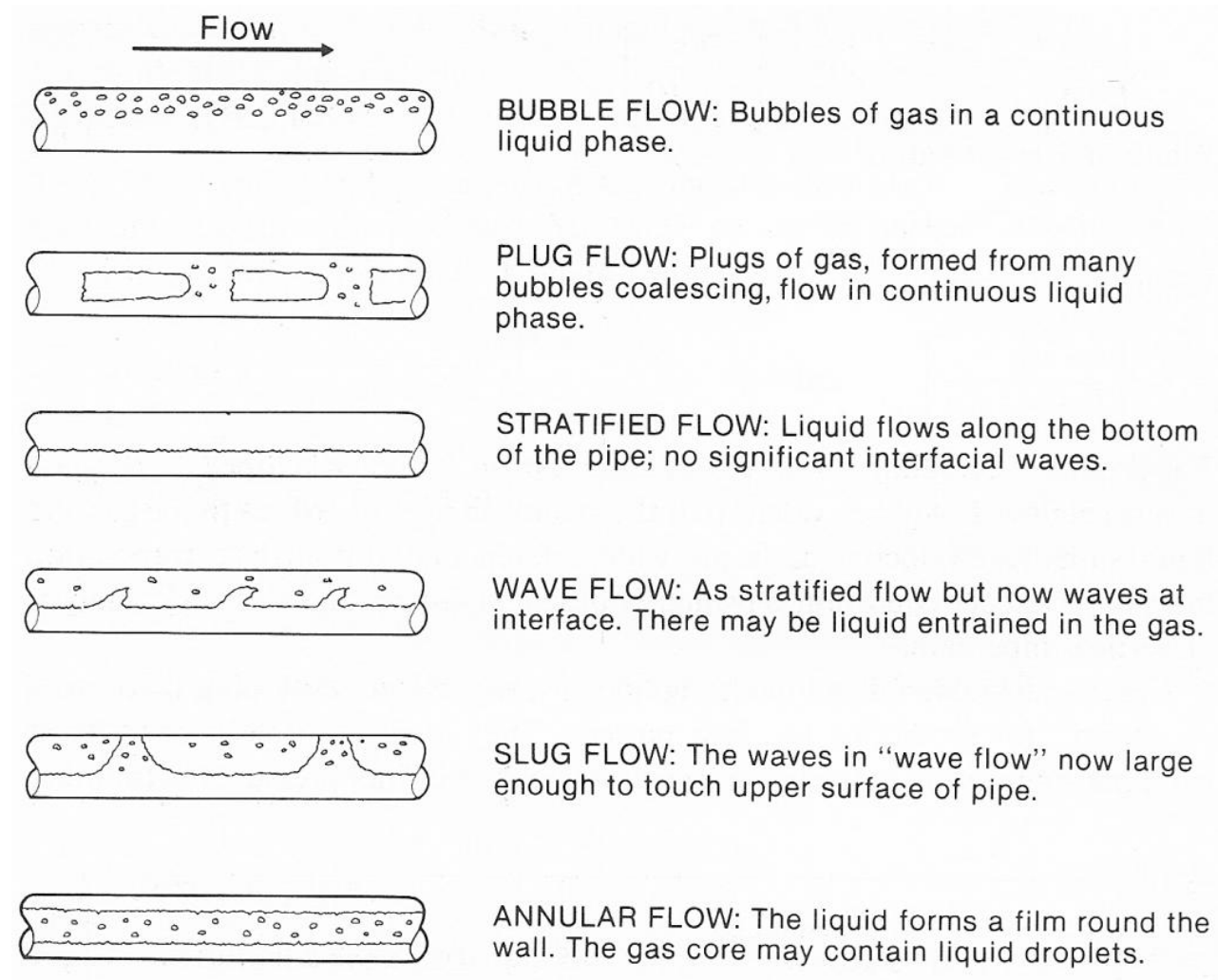

Figure 2.1. Horizontal flow regimes with brief description (Chisholm, 1983). 


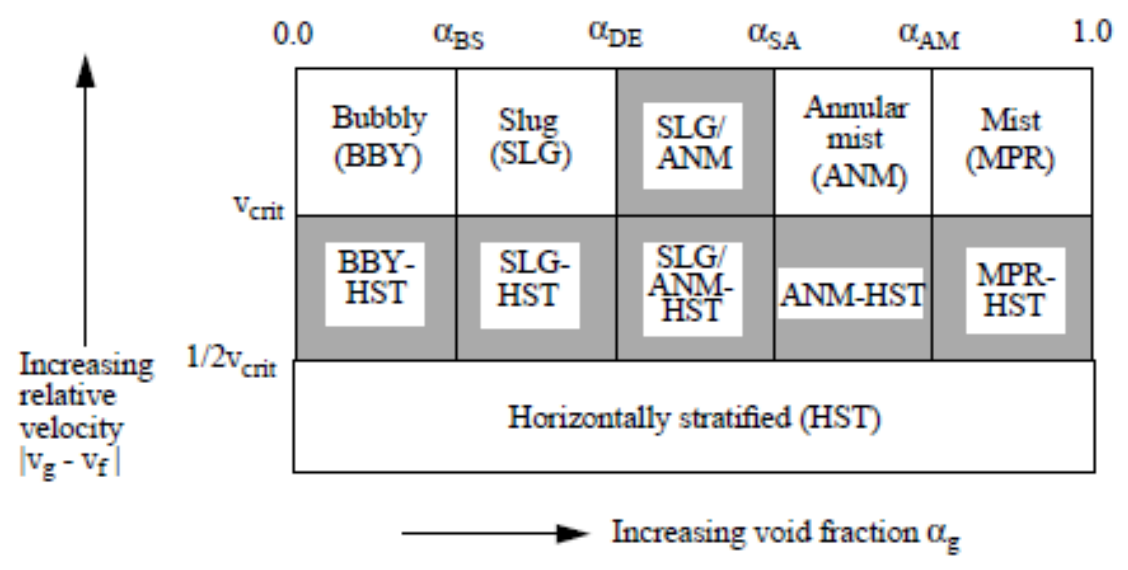

Figure 2.2. Horizontal flow regime map used in RELAP5 (RELAP5/MOD3.2, Code Manual Volume I: Code Structure, System Models, and Solution Methods, 1995).

Similarly, a variety of two-phase flow regimes can be found in vertically oriented channels. The most common vertical flow regimes are bubbly, churn, slug and annular (Chisholm, 1983). These regimes are depicted in Figure 2.3, followed by a brief description for each flow regime. Downwards vertical flows share the same flow regimes as upwards flows. As was the case for the horizontal flow regime map, RELAP5 also uses a specific vertical flow regime map that only applies to volume orientations between $45^{\circ}$ and $90^{\circ}$, and are also based on several empirical correlations. Figure 2.4 describes the vertical flow regime map used in RELAP5, consisting of vertically stratified, bubbly, slug, annular mist, inverted annular, inverted slug and mist regimes. The shaded regions in the figure are the flow regime transition areas and are subject to a similar set of criteria, as previously described in the horizontal flow regime section. 


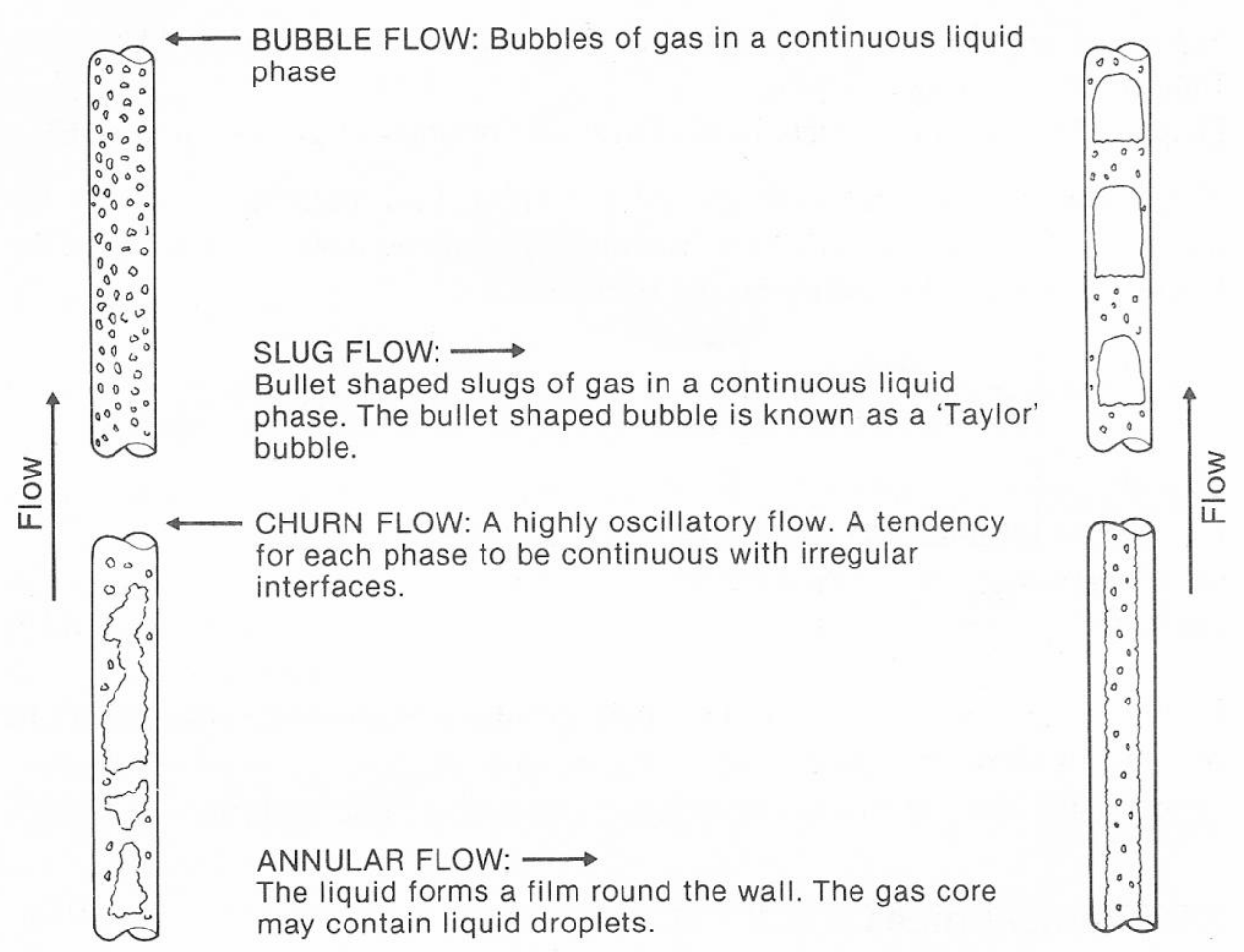

Figure 2.3. Upwards vertical flow regimes with brief description (Chisholm, 1983).

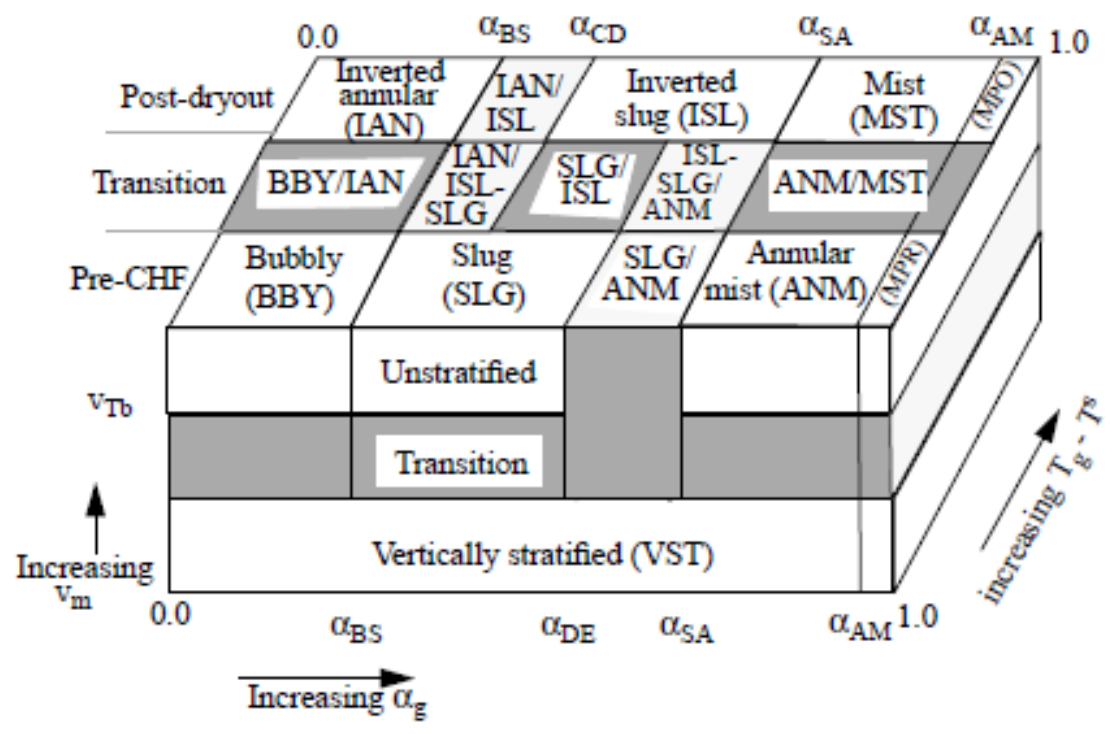

Figure 2.4. Vertical flow regime map used in RELAP5 (RELAP5/MOD3.2, Code Manual Volume I: Code Structure, System Models, and Solution Methods, 1995). 


\subsubsection{Wall Friction Model}

The wall friction calculated in RELAP5 is based on the flow regime maps previously discussed, in that each flow regime provides a criterion to determine the wall friction for each phase. It is essential to note that only wall shear effects are included, losses due to enlargement and contraction devices are calculated using mechanistic models, and losses due to elbows are modeled using flow loss coefficients that must be input by the code user.

The wall friction model is based on the two-phase multiplier approach, where the Heat Transfer and Fluid Flow Service (HTFS)-modified Baroczy correlation (RELAP5/MOD3.2, Code Manual Volume I: Code Structure, System Models, and Solution Methods, 1995) is used to find the two-phase multiplier. The total friction pressure drop in terms of the pure phasic wall friction pressure drop is

$$
\left(\frac{d P}{d x}\right)_{2 \phi}=\phi_{k}^{2}\left(\frac{d P}{d x}\right)_{k}
$$

where $\phi_{k}$ is the pure phase (fluid or gas) two-phase multiplier, and $2 \phi$ is short for twophase. The phasic wall friction pressure gradient is as follows:

$$
\left(\frac{d P}{d x}\right)_{k}=\frac{\lambda_{k}^{\prime}\left(R e_{k}^{\prime}\right) \dot{m}_{k}}{2 D \rho_{k} A^{2}}
$$

where $\lambda$ is the single-phase friction factor, the prime denotes the pure liquid or pure gas condition, and $R e_{k}^{\prime}$ is the Reynolds number defined as

$$
R e_{k}^{\prime}=\frac{\dot{m}_{k} D}{\mu_{k} A}
$$


where $\mu_{k}$ is the dynamic viscosity. The mass flow rate as a function of phasic void fraction, density, velocity and area can be expressed as

$$
\dot{m}_{k}=\alpha_{k} \rho_{k} V_{k} A R e_{k}^{\prime}=\frac{\dot{m}_{k} D}{\mu_{k} A}
$$

Finally, the Lockhart-Martinelli parameter can be defined as the ratio of the pure twophase multipliers, and are related to their pure phasic wall pressure drop as follows:

$$
X^{2}=\frac{\left(\frac{d P}{d x}\right)_{l}}{\left(\frac{d P}{d x}\right)_{g}}=\frac{\phi_{g}^{2}}{\phi_{l}^{2}}
$$

The respective pure liquid and gas two-phase multipliers can be found by using the HTFS-modified Baroczy correlation:

$$
\begin{gathered}
\phi_{l}^{2}=1+\frac{C}{X}+\frac{1}{X^{2}} \\
\phi_{g}^{2}=X^{2}+C X+1
\end{gathered}
$$

where $C$ is the correlation coefficient and is a function of the scalar mass flux and other dimensionless parameters (RELAP5/MOD3.2, Code Manual Volume I: Code Structure, System Models, and Solution Methods, 1995). 


\subsection{Computational Domain}

\subsubsection{VRS Model Geometry}

The computational domain analyzed in this study was based on the experimental fixture of the VRS, which can be fully appreciated in Figure 2.5. The test fixture consisted of a 1000 gallon tank, a six-inch trash pump and three main pipe subassemblies: four-inch, six-inch and eight-inch. Due to the limited air injection power available to the project, the eight-inch pipe was not able to be tested with the initial amount of void fraction requested by DCPP. For this reason, only the four and six-inch pipe subassemblies were able to be tested, which are consequently the experimental scenarios to be modeled in RELAP5. The flow path starts at the tank, where the pump is drawing water through the six-inch suction pipe and later discharged to the main six-inch pipe. The flow path is then directed upwards where it is divided into three main pipe subassemblies or branches. Only one main branch is allowed to operate during the experiment by opening the ball valve that corresponds to the branch of interest. The flow path then continues through the main branch until it encounters the main return line, which ultimately leads to the same tank. Air was injected with a two-horsepower, 33 gallon, 150 maximum psi compressor, at locations before the upper tee. 


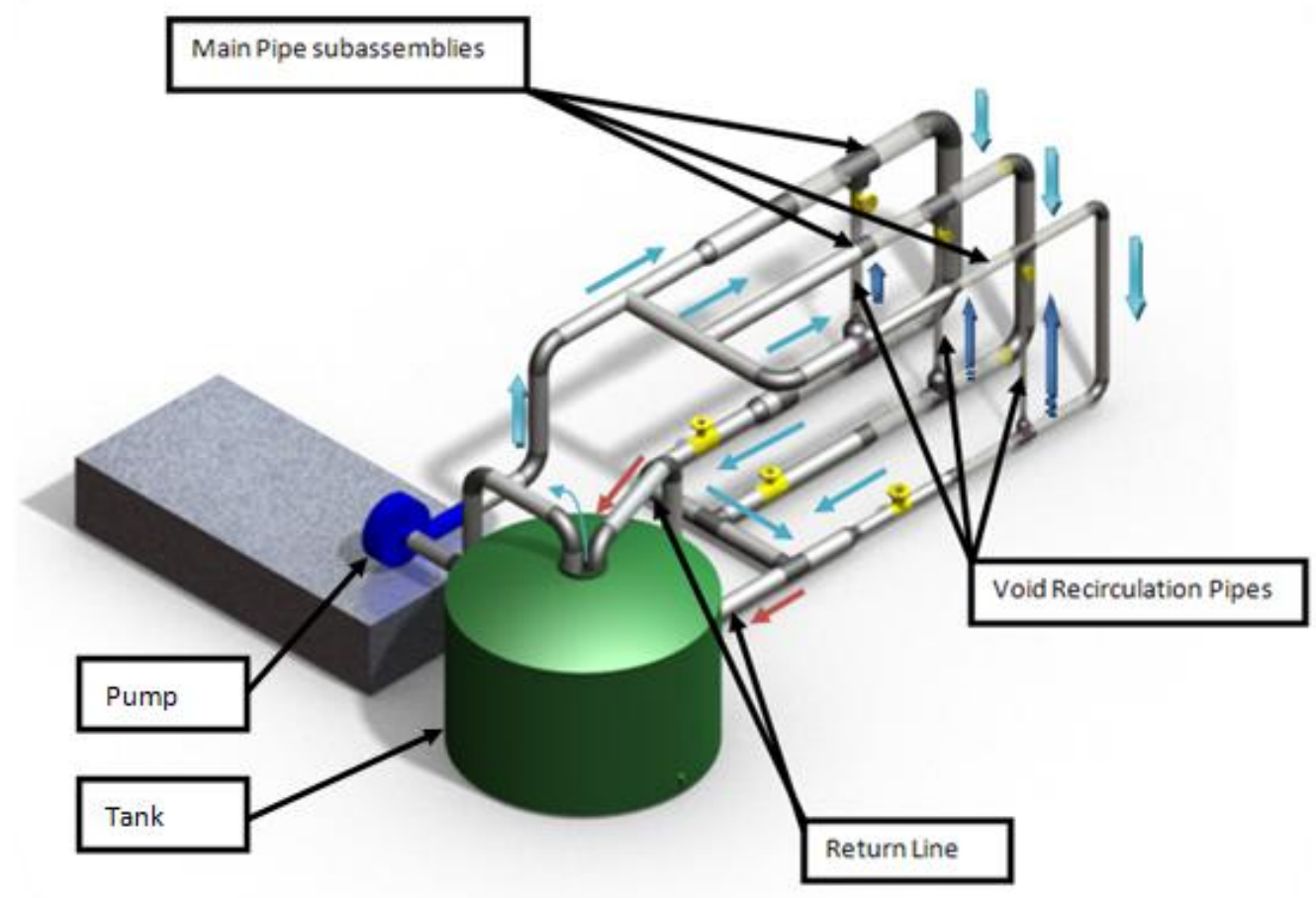

Figure 2.5. Isometric drawing of the VRS (Daza, Fong, Rosas, \& Wong, 2009).

The test fixture configuration was then coded into RELAP5 with the same physical hydrodynamic characteristics, such as pipe lengths, pipe roughness, fittings, loss coefficients, etc. Because there were several bottom tee configurations tested during the experiment, this study will only focus on the pipe configurations that yielded more air removal from the system. In particular, the bottom tees $4 \times 4 \times 3$-inch and $6 \times 6 \times 4$-inch configurations will be analyzed in the code. Figure 2.6 and Figure 2.7 show the computational schematic representation of the VRS that was used to build the code in RELAP5. The component number selection was based on the flow path direction, and all pipe data was condensed under a single spreadsheet, as seen in Appendix B - VRS Pipe Data. 


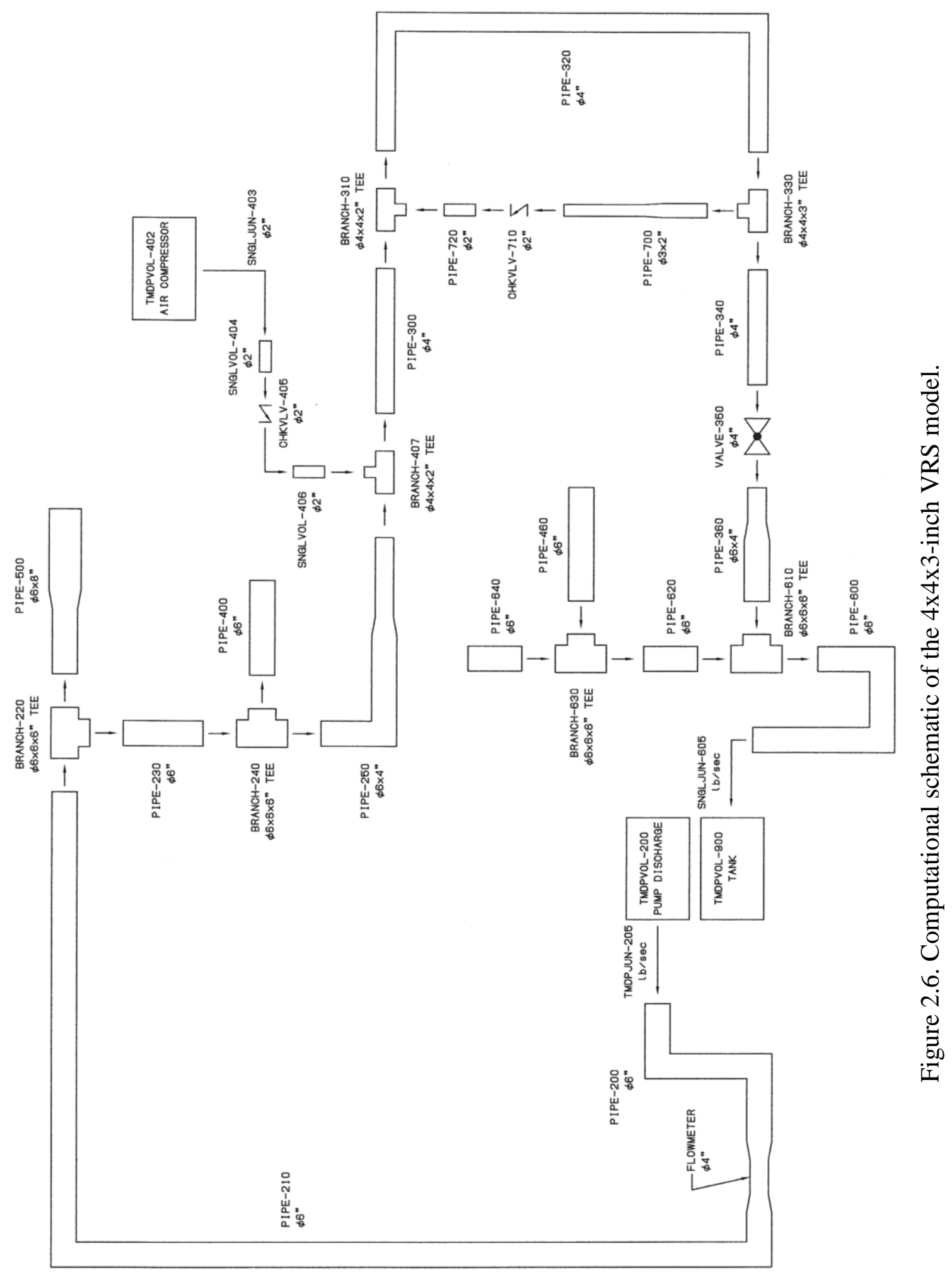




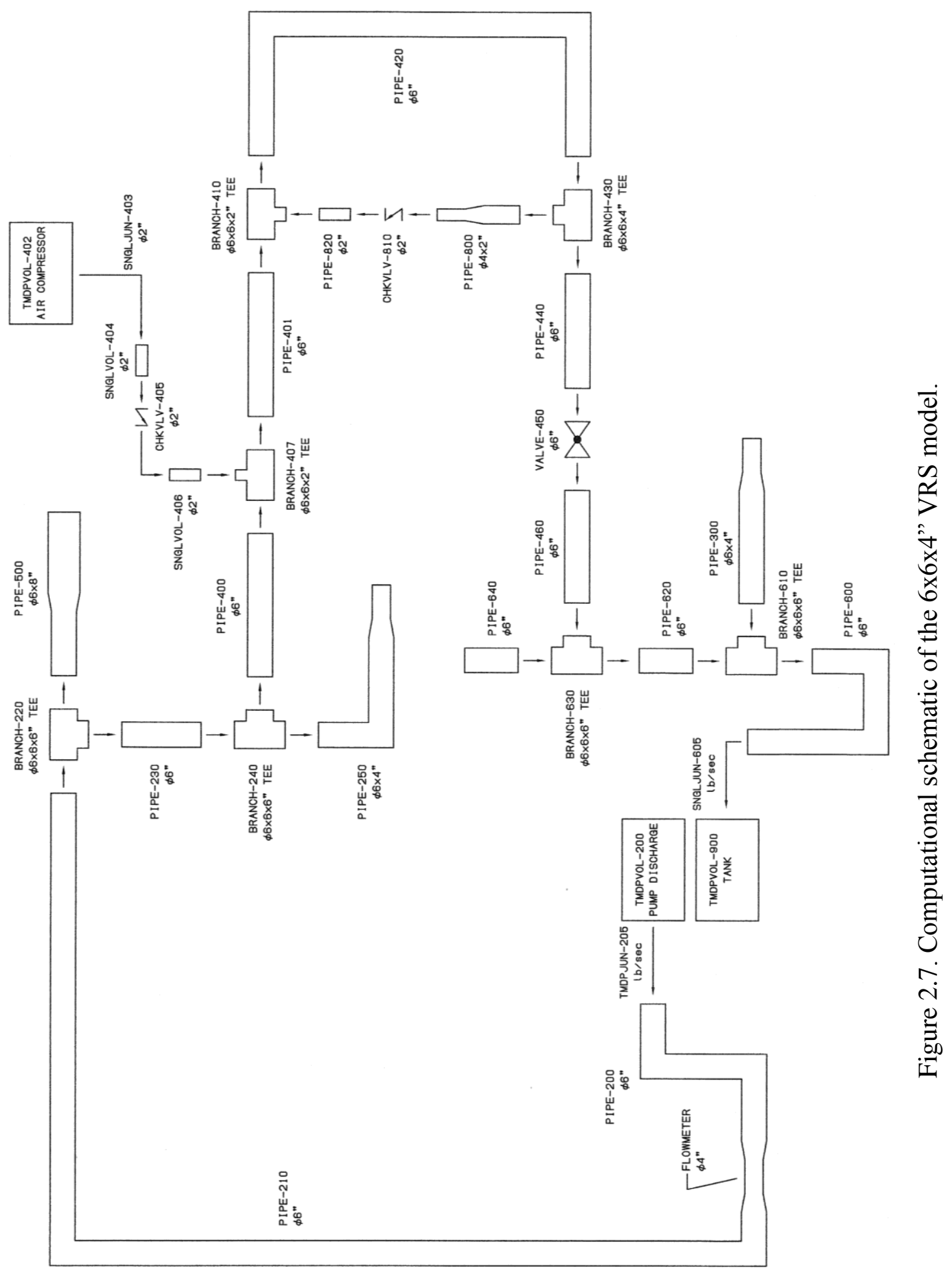


A list of the experimental hydrodynamic components along with the chosen hydrodynamic building blocks to be modeled in RELAP5 can be seen in Table 2.1. A label and brief description of the building block function accompanies the hydrodynamic components for clarity. The VRS code built in RELAP5 can be seen in Appendix C VRS RELAP5 Code.

Table 2.1. List of the main hydrodynamic building blocks used in the VRS model.

\begin{tabular}{|c|c|c|l|}
\hline $\begin{array}{c}\text { Hydrodynamic } \\
\text { Experiment } \\
\text { Component }\end{array}$ & $\begin{array}{c}\text { Hydrodynamic } \\
\text { Building block }\end{array}$ & Label & \multicolumn{1}{|c|}{ Function } \\
\hline Tank & $\begin{array}{c}\text { Time-dependent } \\
\text { volume }\end{array}$ & TMDPVOL & $\begin{array}{l}\text { Simulates a reservoir with } \\
\text { constant water level. }\end{array}$ \\
\hline Pipe & Pipe & PIPE & $\begin{array}{l}\text { Simulates a pipe in the } \\
\text { system. }\end{array}$ \\
\hline Pump & $\begin{array}{c}\text { Time-dependent } \\
\text { junction }\end{array}$ & TMDPJUN & $\begin{array}{l}\text { Connects two blocks and } \\
\text { specifies boundary } \\
\text { conditions. }\end{array}$ \\
\hline Tee & Branch & BRANCH & $\begin{array}{l}\text { Connects three or more } \\
\text { blocks in a system. }\end{array}$ \\
\hline Check Valve & Valve & VALVE & $\begin{array}{l}\text { Connects two blocks and } \\
\text { simulates a valve action. }\end{array}$ \\
\hline Ball Valve & Valve & VALVE & $\begin{array}{l}\text { Connects two blocks and } \\
\text { simulates a valve action. }\end{array}$ \\
\hline- & Single junction & SNGLJUN & Connects two blocks. \\
\hline & & &
\end{tabular}




\subsubsection{VRS Tank/Pump Model}

As described in Table 2.1, the water tank (component 200 from Figure 2.6) was modeled as a TMDPVOL to represent a water reservoir with constant water level (or constant pressure), and temperature. The pump was modeled using a combination of both the TMDPVOL and TMDPJUN (component 205) in order to set the boundary conditions for the VRS model. The pump model boundary conditions are a function of time, pressure, temperature and mass flow rate.

\subsubsection{VRS Pipe Model}

All pipe components and fittings, such as elbows, tees and bushing reducers, were modeled using the PIPE component in RELAP5. Appendix B summarizes the entire pipe data used in the code, consisting of the following main parameters: component name, subcomponent name, pipe length, pipe diameter, length/diameter ratio, flow area, resistance coefficient, volume angle, quality, volume centroid elevation and volume centroid pressure.

All piping information was obtained from the senior project experiment report (Daza, Fong, Rosas, \& Wong, 2009), following the piping diagrams and computational schematics as references. The length/diameter ratio, which has to be greater than unity for numerical stability, is the relationship between the sub volume length to total pipe diameter. 
Pipe diameters, flow area and elbow resistance coefficients were obtained by using the pipe specifications in Table 2.2. The elbow loss coefficient $(K)$ was obtained by performing the following calculation (Crane Corporation, 1988):

$$
K=30 f_{T}
$$

where $f_{T}$ is the pipe friction factor, and 30 is the coefficient for an elbow.

Table 2.2. VRS pipe specifications and elbow resistance coefficients.

\begin{tabular}{|c|c|c|c|c|c|c|}
\hline $\begin{array}{c}\text { Nominal } \\
\text { pipe size } \\
\text { (in) }\end{array}$ & $\begin{array}{c}\text { Mean } \\
\text { outside } \\
\text { diameter } \\
\text { (in) }\end{array}$ & $\begin{array}{c}\text { Minimum } \\
\text { Wall } \\
\text { thickness (in) }\end{array}$ & $\begin{array}{c}\text { Inner } \\
\text { Diameter } \\
\text { (in) }\end{array}$ & $\begin{array}{c}\text { Flow } \\
\text { Area } \\
\left(\mathrm{ft}^{2}\right)\end{array}$ & $\begin{array}{c}\text { Pipe } \\
\text { Friction } \\
\text { Factor } f_{T}\end{array}$ & $\begin{array}{c}90^{\circ} \\
\text { Elbow } \\
K\end{array}$ \\
\hline 2 & 2.375 & 0.154 & 2.067 & 0.0233 & 0.019 & 0.570 \\
\hline 3 & 3.500 & 0.216 & 3.068 & 0.0513 & 0.018 & 0.540 \\
\hline 4 & 4.500 & 0.237 & 4.026 & 0.0884 & 0.017 & 0.510 \\
\hline 6 & 6.625 & 0.280 & 6.065 & 0.2006 & 0.015 & 0.450 \\
\hline 8 & 8.625 & 0.322 & 7.981 & 0.3474 & 0.014 & 0.420 \\
\hline
\end{tabular}

Even though the $K$ values for a $90^{\circ}$ elbow were used throughout the code, it is important to note that the two elbows associated with pipe components 320 and 420 were modeled as $45^{\circ}$ elbows, by keeping the former elbow loss. This was done after a simulation sensitivity analysis, where the measurements of interest were in better agreement with respect to the experimental results. In addition, it allows the code to calculate all conservation equations with a smoother transition between horizontal and vertical planes.

The volume angles, varying from $90^{\circ}$ to $-90^{\circ}$, represent the pipe orientation for flow direction specification. The quality is a ratio of the non-condensable mass to the system's total mass, similar to the concept of flow quality previously explained. This 
value was defined as zero throughout all piping networks since there was no initial air in the system. Instead, air was injected into the pipes at steady-state conditions.

The volume centroid elevation and pressure were calculated using the following expressions:

$$
\begin{aligned}
Z_{i}=Z_{i-1}+ & 0.5 L_{i} \sin \theta_{i}+0.5 L_{i-1} \sin \theta_{i-1}+0.5 \frac{D_{i+1}}{12} \cos \theta_{i+1} \\
& +0.5 \frac{D_{i-1}}{12} \cos \theta_{i-1} \\
P_{i} & =P_{i-1}+\left[\frac{\left(Z_{i-1}-Z_{i}\right)}{\left(1-\alpha v_{g}\right)}+\alpha_{l} v_{l}\right] / 144
\end{aligned}
$$

where $\quad Z_{i}=$ elevation of the $i$ th volume centroid $(\mathrm{ft})$

$L_{i}=$ length of the $i$ th volume $(\mathrm{ft})$

$\theta_{i}=$ angle of the $i$ th volume measured from horizontal (degrees)

$D_{i}=$ diameter of the $i$ th volume (in)

$P_{i}=$ pressure of the $i$ th volume $(\mathrm{psi})$

$v_{k}=$ phasic specific volume of the $i$ th volume $\left(\mathrm{ft}^{3} / \mathrm{lb}\right)$

The volume centroid elevation and pressure will remain the same if the volume angle is zero.

Enlargements and contractions (reducing bushings) were modeled by inputting the forward and reverse loss coefficients into the PIPE model. Forward and reverse loss coefficients are used for co-current and counter-current flows, respectively. The loss 
coefficient $(K)$ for enlargements and contractions, were calculated by using the following expressions (Crane Corporation, 1988):

$$
\begin{gathered}
K=\frac{\left(1-\beta^{2}\right)^{2}}{\beta^{4}}-\text { enlargement } \\
K=\frac{0.5 \sqrt{\sin \frac{\omega}{2}}\left(1-\beta^{2}\right)}{\beta^{4}}-\text { contraction }
\end{gathered}
$$

where $\beta$ is the ratio of diameters of the small $\left(D_{l}\right)$ to large $\left(D_{2}\right)$ pipes, and $\omega$ is the angle of divergence measured in radians. The divergence angle must satisfy the condition $45^{\circ}<\omega \leq 180^{\circ}$ and was calculated as:

$$
\omega=\tan ^{-1}\left(\frac{D_{2}-D_{1}}{N}\right)
$$

Where $N$ is the socket to socket bottom dimension (Spears Manufacturing Company, 2010). Table 2.3 summarizes all loss coefficient values for several enlargement and contraction devices used in the VRS model.

Table 2.3. Enlargement and contraction loss coefficient values for various reducing bushings.

\begin{tabular}{|c|c|c|c|c|c|c|}
\hline $\begin{array}{c}\text { Large } \\
\text { diameter } \\
D_{2} \text { (in) }\end{array}$ & $\begin{array}{c}\text { Small } \\
\text { diameter } \\
D_{1} \text { (in) }\end{array}$ & $\begin{array}{c}\text { Reducing } \\
\text { Bushing }\end{array}$ & $\begin{array}{c}\text { Dimension } \\
N(\text { in) }\end{array}$ & $\omega$ (rad) & $\begin{array}{c}\text { Enlargement } \\
K\end{array}$ & $\begin{array}{c}\text { Contraction } \\
K\end{array}$ \\
\hline 3 & 2 & $3 \times 2$ & 0.563 & 1.058 & 0.309 & 0.999 \\
\hline 4 & 2 & $4 \times 2$ & 1.031 & 1.095 & 0.563 & 4.328 \\
\hline 4 & 3 & $4 \times 3$ & 0.469 & 1.132 & 0.191 & 0.506 \\
\hline 6 & 2 & $6 \times 2$ & 2.156 & 1.076 & 0.790 & 25.774 \\
\hline 6 & 3 & $6 \times 3$ & 1.625 & 1.074 & 0.563 & 4.292 \\
\hline 6 & 4 & $6 \times 4$ & 1.563 & 0.908 & 0.309 & 0.931 \\
\hline
\end{tabular}




\subsubsection{VRS Tee Model}

Tee fittings were simulated by using the BRANCH model as indicated in Table 2.1. Each branch component had three junctions, thus connecting three pipes as necessary. The $K$ value for regular tees were calculated in the same way as was the case for elbows (Crane Corporation, 1988):

$$
K=C f_{T}
$$

Were $C$ is 20 or 60 for the flow through the run and branch, respectively. Table 2.4 summarizes all regular tee loss coefficient values for several nominal pipe diameters that were used in the VRS model.

Table 2.4. Regular tee loss coefficient values.

\begin{tabular}{|c|c|c|c|}
\hline $\begin{array}{c}\text { Large } \\
\text { diameter } \\
D_{2} \text { (in) }\end{array}$ & $\begin{array}{c}D_{2} \\
\text { friction } \\
\text { factor } \\
f_{T}\end{array}$ & $\begin{array}{c}\text { Flow through } \\
\text { run } K\end{array}$ & $\begin{array}{c}\text { Flow through } \\
\text { branch } K\end{array}$ \\
\hline 4 & 0.017 & 0.340 & 1.020 \\
\hline 4 & 0.017 & 0.340 & 1.020 \\
\hline 4 & 0.017 & 0.340 & 1.020 \\
\hline 6 & 0.015 & 0.300 & 0.900 \\
\hline
\end{tabular}

Reducing tee loss coefficients (for BRANCH components 310, 330, 410 and 430) were calculated by adding the regular tee and contraction $K$ values, depending upon the direction of the flow through the run or branch. 


\subsubsection{VRS Valve Model}

The two-inch check valves (components 710 and 810) were simulated by using the VALVE model as indicated in Table 2.1. The VALVE functions as a junction between two pipes for the VRS model in specific. The minimum opening pressure is approximately $0.5 \mathrm{psi}$ and the loss coefficient was calculated using a lift check valve coefficient of 600 and a pipe friction factor of 0.019 (Crane Corporation, 1988):

$$
K=600 f_{T}=11.4
$$

All ball valves (components 350 and 450) were also simulated using the VALVE model as previously described. However, the loss coefficient values were obtained by using the flow coefficient $\left(C_{V}\right)$ specified by manufacturer's standards as follows (Crane Corporation, 1988):

$$
K=\left(\frac{29.9 D^{2}}{C_{V}}\right)^{2}
$$

The flow coefficient values for the four-inch and six-inch ball valves were $3129 \mathrm{gpm} / \mathrm{psi}$ and $7942 \mathrm{gpm} / \mathrm{psi}$, respectively. The loss coefficients for the four-inch and six-inch ball valves were 0.024 and 0.019 , respectively.

The single junction (SNGLJUN) was utilized to connect PIPE-600 to the tank component 900 . The forward and reverse $K$ values for the pipe exit were set to unity and 0.75 , respectively. 


\subsubsection{VRS Air Compressor Model}

The air compressor was simulated by using one TMDPVOL, one TMDPJUN, two SNGLVOL and one VALVE block as shown in Figure 2.6. This system was then connected to BRANCH 407, where air was injected under steady-state conditions.

\subsubsection{VRS Pipe Nodalization}

The nodalization process was carried out by using the $L / D$ ratio, which was set to be greater than unity for numerical stability. Not all pipe volumes had the same length due to their characteristic diameter, hence $L>0.3355 \mathrm{ft}$ for a four-inch pipe and $L>$ $0.5054 \mathrm{ft}$ for a six-inch pipe. Appendix B contains all the data pertaining to this ratio.

\subsubsection{VRS Model Boundary Conditions}

\subsubsection{VRS Tank/Pump Model}

The boundary condition for the tank/pump model was specified by using a combination of a TMDPVOL and a TMDPJUN. TMDPVOL-200 (tank) conditions were set with a constant pressure and temperature of $65 \mathrm{psi}$ and $70^{\circ} \mathrm{F}$, respectively. TMDPJUN-205 (pump) conditions were set to various mass flow rates as seen in Table 2.5, which were directly obtained from experimental results and are a function of the Froude numbers tested, being approximately 0.8, 1.0, 1.3 and 1.6. 
Table 2.5. Summary of the simulated pump flow rates as a function of the Froude number.

\begin{tabular}{|c|c|c|c|c|c|}
\hline$q(\mathrm{gpm})$ & $\begin{array}{c}\dot{m}_{l} \\
(\mathrm{lb} / \mathrm{sec})\end{array}$ & $V\left(4^{\prime \prime}\right)(\mathrm{ft} / \mathrm{s})$ & $V\left(6^{\prime \prime}\right)(\mathrm{ft} / \mathrm{s})$ & $\operatorname{Fr}(4 ")$ & $\operatorname{Fr}\left(6^{\prime \prime}\right)$ \\
\hline 105 & 14.540 & 2.646 & $\mathrm{n} / \mathrm{a}$ & 0.805 & $\mathrm{n} / \mathrm{a}$ \\
\hline 125 & 17.310 & 3.151 & $\mathrm{n} / \mathrm{a}$ & 0.959 & $\mathrm{n} / \mathrm{a}$ \\
\hline 168 & 23.265 & 4.234 & $\mathrm{n} / \mathrm{a}$ & 1.288 & $\mathrm{n} / \mathrm{a}$ \\
\hline 208 & 28.804 & 5.242 & $\mathrm{n} / \mathrm{a}$ & 1.595 & $\mathrm{n} / \mathrm{a}$ \\
\hline 294 & 40.713 & $\mathrm{n} / \mathrm{a}$ & 3.265 & $\mathrm{n} / \mathrm{a}$ & 0.809 \\
\hline 400 & 55.392 & $\mathrm{n} / \mathrm{a}$ & 4.442 & $\mathrm{n} / \mathrm{a}$ & 1.101 \\
\hline 500 & 69.240 & $\mathrm{n} / \mathrm{a}$ & 5.553 & $\mathrm{n} / \mathrm{a}$ & 1.376 \\
\hline 582 & 80.596 & $\mathrm{n} / \mathrm{a}$ & 6.464 & $\mathrm{n} / \mathrm{a}$ & 1.602 \\
\hline
\end{tabular}

The averaged flow rates $(q)$ were obtained from the experimental results, and the mass flow rates $\left(\dot{m}_{l}\right)$ were calculated by using the following expression:

$$
\dot{m}_{l}=\frac{q \rho_{l}}{448.8 \frac{g a l}{\frac{f t^{3}}{s}}}
$$

where $\rho_{l}$ is the water density and its value corresponds to $62.15 \mathrm{lb} / \mathrm{ft}^{3}$ at $70^{\circ} \mathrm{F}$.

Note that TMDPVOL-900 is modeled with the same boundary conditions as TMDPVOL-200, and in fact, simulate the same tank. However, RELAP5 only allows connecting one component to a TMDPVOL. 


\subsubsection{VRS Air Compressor Model}

The boundary conditions for the air compressor model follow the same methodology as the tank/pump model, except that air is injected for 15 seconds at a specific time range. Table 2.6 and Table 2.7 show the air injection scheme used for the four-inch and 6-inch pipes to guarantee a minimum initial void fraction of seven-percent, at various Froude numbers. Many other initial void fractions were performed during the experiment, though this value was chosen to guarantee a sound comparison, since the initial void fractions between both pipes were similar. Even though the experimental initial void fractions were six and five-percent for the four-inch and six-inch pipes respectively, it was necessary to guarantee the previously mentioned void fraction value of seven-percent to account for a physical behavior not modeled by RELAP5 called kinematic shock (Westinghouse Electric Company, LLC, 2010). This phenomenon specifically occurs when the gas is transported into the downstream of the downturned elbow, resulting in a "waterfall" effect, where a vertically downward stratified flow pattern occurs. The void fraction or amount of air being transported into the bottom horizontal pipe highly depends on the kinematic shock location, and as a consequence, is a function of the vertical pipe length to pipe diameter $(L / D)$ ratio. Assuming steady-state flow conditions, the void fraction decreases as it travels downwards through the vertical pipe, or as the $L / D$ ratio increases (Marshall, 2003). Since the kinematic shock was indeed observed during the experiment and occurred typically at half the vertical pipe distance $(L / 2 D)$ by allowing more air to travel downwards, then an extra quantity of void had to be added into the computational model to account for the amount of air being formed in the downcomer pipe. 
Table 2.6. Air injection scheme for various Froude numbers in the four-inch pipe, yielding a minimum initial void fraction of seven-percent.

\begin{tabular}{|c||c|c|c|c|}
\cline { 2 - 5 } \multicolumn{1}{c||}{} & \multicolumn{4}{c|}{ Air Flow Rate (lb/s) - 4" pipe } \\
\hline Injection Time (s) & Fr =0.81 & Fr =0.96 & Fr = 1.29 & Fr = 1.60 \\
\hline $0-15$ & 0 & 0 & 0 & 0 \\
\hline 16 & 0 & 0 & $5.00 \mathrm{E}-04$ & $1.00 \mathrm{E}-03$ \\
\hline 17 & 0 & $5.00 \mathrm{E}-04$ & $1.00 \mathrm{E}-03$ & $2.00 \mathrm{E}-03$ \\
\hline 18 & $5.00 \mathrm{E}-04$ & $1.00 \mathrm{E}-03$ & $2.00 \mathrm{E}-03$ & $3.00 \mathrm{E}-03$ \\
\hline 19 & $1.00 \mathrm{E}-03$ & $2.50 \mathrm{E}-03$ & $3.00 \mathrm{E}-03$ & $4.00 \mathrm{E}-03$ \\
\hline $20-35$ & $3.00 \mathrm{E}-03$ & $3.30 \mathrm{E}-03$ & $3.80 \mathrm{E}-03$ & $4.50 \mathrm{E}-03$ \\
\hline 36 & $2.80 \mathrm{E}-03$ & $3.00 \mathrm{E}-03$ & $3.50 \mathrm{E}-03$ & $4.00 \mathrm{E}-03$ \\
\hline 37 & $2.60 \mathrm{E}-03$ & $2.00 \mathrm{E}-03$ & $3.00 \mathrm{E}-03$ & $3.00 \mathrm{E}-03$ \\
\hline 38 & $2.40 \mathrm{E}-03$ & $1.00 \mathrm{E}-03$ & $2.00 \mathrm{E}-03$ & $2.00 \mathrm{E}-03$ \\
\hline 39 & $2.00 \mathrm{E}-03$ & $5.00 \mathrm{E}-04$ & $1.00 \mathrm{E}-03$ & $1.00 \mathrm{E}-03$ \\
\hline 40 & $1.60 \mathrm{E}-03$ & 0 & $5.00 \mathrm{E}-04$ & $5.00 \mathrm{E}-04$ \\
\hline 41 & $1.20 \mathrm{E}-03$ & 0 & 0 & 0 \\
\hline 42 & 0 & 0 & 0 & 0 \\
\hline
\end{tabular}

Table 2.7. Air injection scheme for various Froude numbers in the six-inch pipe, yielding a minimum initial void fraction of seven-percent.

\begin{tabular}{|c||c|c|c|c|}
\multicolumn{1}{c||}{} & \multicolumn{4}{c|}{ Air Flow Rate (lb/s) - 6" pipe } \\
\hline Injection Time (s) & Fr $=0.81$ & Fr $=1.10$ & Fr $=1.38$ & Fr $=1.60$ \\
\hline $0-15$ & 0 & 0 & 0 & 0 \\
\hline 16 & 0 & 0 & 0 & $1.00 \mathrm{E}-03$ \\
\hline 17 & $1.00 \mathrm{E}-03$ & $1.00 \mathrm{E}-03$ & $1.00 \mathrm{E}-03$ & $5.00 \mathrm{E}-03$ \\
\hline 18 & $3.00 \mathrm{E}-03$ & $3.00 \mathrm{E}-03$ & $5.00 \mathrm{E}-03$ & $7.00 \mathrm{E}-03$ \\
\hline 19 & $5.00 \mathrm{E}-03$ & $5.00 \mathrm{E}-03$ & $7.00 \mathrm{E}-03$ & $1.20 \mathrm{E}-02$ \\
\hline $20-35$ & $7.80 \mathrm{E}-03$ & $9.70 \mathrm{E}-03$ & $1.20 \mathrm{E}-02$ & $1.48 \mathrm{E}-02$ \\
\hline 36 & $5.00 \mathrm{E}-03$ & $6.00 \mathrm{E}-03$ & $6.00 \mathrm{E}-03$ & $6.00 \mathrm{E}-03$ \\
\hline 37 & $3.00 \mathrm{E}-03$ & $3.00 \mathrm{E}-03$ & $3.00 \mathrm{E}-03$ & $3.00 \mathrm{E}-03$ \\
\hline 38 & $1.00 \mathrm{E}-03$ & $1.00 \mathrm{E}-03$ & $1.00 \mathrm{E}-03$ & $1.00 \mathrm{E}-03$ \\
\hline 39 & 0 & 0 & 0 & 0 \\
\hline 40 & 0 & 0 & 0 & 0 \\
\hline
\end{tabular}




\subsubsection{VRS Model Thermal/Hydraulic settings}

RELAP5 uses two different set of control flags that allow the calculation of specific thermal/hydraulic models (RELAP5/MOD3.2, Code Manual Volume II: User's Guide and Input Requirements, 1995). It is up to the user to use them accordingly depending upon the simulation being carried. The first set of control flags consist of the packed format tlpvbfe, which allows the processing of the following models:

$t$ - Thermal front tracking model: used to improve the accuracy calculations when a warm fluid layer appears above a cold fluid.

$l$ - Mixture level tracking model: used to calculate the void fractions (above and below level) and level velocity in a volume.

$p$ - Water packing scheme: used to model a pressurizer.

$v$ - Vertical stratification model: used to model a pressurizer.

$b$ - Interphase friction model: used to model the pipe or rod bundle interphase friction.

$f$ - Wall friction model: used to specify if the wall friction effects are to be accounted for.

$e$ - Non-equilibrium model, used to specify the non-equilibrium or equilibrium model. This option is provided for the comparison between other codes.

The second set of control flags consist of the packed format efvcahs, which allows the processing of the following models: 
$e$-modified $P V$ (pressure-volume) term: used to specify if the $P V$ term is to be applied.

$f$ - Counter-current Flow Limitation (CCFL) model: used specifically for vertical volumes, gas-liquid phases and counter-current flow (liquid flowing down, gas flowing up).

$v$ - Horizontal stratification model, used to model a BRANCH component.

$c$ - Choking model: recommended to be used for modeling relief valves. Removal of the choking model may be recommended to avoid internal oscillations.

$a$ - Abrupt area model: used when sharp edged area changes occur; recommended to be used in a BRANCH component.

$h$ - Non-homogenous model: used to specify the non-homogeneous (two-velocity momentum equations) or homogenous (single-velocity momentum equation) options.

$s$ - Momentum flux model: used in BRANCH components; specifies the use of the momentum flux in the BRANCH junctions.

Table 2.8 shows the summary of the control flags used in the main VRS model components, including the tank/pump, pipe, regular tees, check valves and ball valves. The letter ' $\mathrm{X}$ ' is used to symbolize that the current model is being used. The letters ' $\mathrm{N}$ E', 'N-H', 'S', and 'A' stand for non-equilibrium, non-homogenous, smooth area change, and abrupt area change, respectively. 
Table 2.8. Summary of the control flags used for various VRS model components.

\begin{tabular}{|c|c|c|c|c|c|}
\hline & \multicolumn{5}{|c|}{ VRS Model Component } \\
\hline Control Flag & Tank/Pump & Pipe & Regular Tee & Check Valve & Ball Valve \\
\hline$t$ & & & & & \\
\hline$l$ & & & & & \\
\hline$p$ & & & & & \\
\hline$v$ & & $\mathrm{X}$ & & & \\
\hline$b$ & Pipe Friction & Pipe Friction & Pipe Friction & Pipe Friction & Pipe Friction \\
\hline$f$ & & $\mathrm{X}$ & $\mathrm{X}$ & $\mathrm{X}$ & $\mathrm{X}$ \\
\hline$e$ & $\mathrm{~N}-\mathrm{E}$ & $\mathrm{N}-\mathrm{E}$ & N-E & $\mathrm{N}-\mathrm{E}$ & $\mathrm{N}-\mathrm{E}$ \\
\hline$e$ & & & & & \\
\hline$f$ & & & & & \\
\hline$v$ & & & & & \\
\hline$c$ & & & & $\mathrm{X}$ & \\
\hline$a$ & & $\mathrm{~S}$ & A & $\mathrm{S}$ & $\mathrm{S}$ \\
\hline$h$ & & $\mathrm{~N}-\mathrm{H}$ & $\mathrm{N}-\mathrm{H}$ & $\mathrm{N}-\mathrm{H}$ & $\mathrm{N}-\mathrm{H}$ \\
\hline$s$ & & & & & \\
\hline
\end{tabular}

Table 2.9 shows the summary of the control flags used in the reducing tees of the VRS model. The listed reducing tees refer specifically to the BRANCH components 310 (four-inch upper tee), 410 (six-inch upper tee), 330 (four-inch lower tee) and 430 (sixinch lower tee). The large and small diameters mentioned in Table 2.9 refer to the main pipe connections (four or six-inch pipes) and the reduced void recirculation pipes (three or four-inch pipes) connections, respectively. The same letters apply as before, with the addition of the letters ' $\mathrm{H}$ ', ' $\mathrm{D}$ ' and ' $\mathrm{U}$ ', which stand for homogeneous equation, downwards and upwards oriented junctions, respectively. Important differences lie between the different reducing tees and are worth mentioning for the sake of the VRS model. While the large diameters of 310/410 and 330/430 use the same control flags, the small diameters of 310/410 and 330/430 have one main distinction: the use of the ' $\mathrm{D}$ ' and ' $U$ ' models. Specifically, the small diameter of 310 and 410 uses the downwards 
oriented junction since it connects to the top of pipe components 720 and 820 , respectively, which come from the bottom. In contrast, the small diameter of 330 and 430 uses the upwards oriented junction since this one connects to the bottom of pipe components 700 and 800, which are placed directly above the main lower pipe.

Table 2.9. Summary of the controls flags used for various VRS model reducing tees.

\begin{tabular}{|c|c|c|c|c|}
\hline & \multicolumn{4}{|c|}{ VRS Model Component } \\
\hline & $\begin{array}{c}310,410 \\
\text { Reducing Tees }\end{array}$ & $\begin{array}{c}310,410 \\
\text { Reducing Tees }\end{array}$ & $\begin{array}{c}330,430 \\
\text { Reducing Tees }\end{array}$ & $\begin{array}{c}330,430 \\
\text { Reducing Tees }\end{array}$ \\
\hline $\begin{array}{l}\text { Control } \\
\text { Flag }\end{array}$ & Large Diameter & Small Diameter & Large Diameter & Small Diameter \\
\hline \multicolumn{5}{|l|}{$t$} \\
\hline \multicolumn{5}{|l|}{$l$} \\
\hline \multicolumn{5}{|l|}{$p$} \\
\hline \multicolumn{5}{|l|}{$v$} \\
\hline$b$ & Pipe Friction & Pipe Friction & Pipe Friction & Pipe Friction \\
\hline$f$ & $\mathrm{X}$ & $\mathrm{X}$ & $\mathrm{X}$ & $\mathrm{X}$ \\
\hline$e$ & $\mathrm{~N}-\mathrm{E}$ & N-E & $\mathrm{N}-\mathrm{E}$ & N-E \\
\hline \multicolumn{5}{|l|}{$e$} \\
\hline$f$ & & $X$ & & $X$ \\
\hline$v$ & & $\mathrm{D}$ & & $\mathrm{U}$ \\
\hline \multicolumn{5}{|l|}{$c$} \\
\hline$a$ & A & A & A & A \\
\hline$h$ & $\mathrm{H}$ & $\mathrm{N}-\mathrm{H}$ & $\mathrm{H}$ & $\mathrm{N}-\mathrm{H}$ \\
\hline$s$ & & & & \\
\hline
\end{tabular}

Other control flag configurations were attempted during the sensitivity analysis of the VRS model. However, the decision on using this specific arrangement was based both on the RELAP5 code recommendation for numerical stability, and on results that yielded most realistic behavior. 


\subsubsection{VRS Valve Model}

The valve model only uses the packed format efvcahs, where the choking model (c) is only used for the check valve, recommendation done by RELAP5 for relief valves. All other process models were not used on both check and ball valves.

\subsection{Fluid Properties}

The fluids used in the VRS model are water for the liquid phase and air (noncondensable) for the gas phase. Both fluids were set at a temperature of $70^{\circ} \mathrm{F}$, and at different pressures depending on the component used. RELAP5 automatically calculates all fluid properties once the types of fluids, temperatures and pressures have been specified.

\subsection{Simulation Assumptions}

The VRS model, built in RELAP5, was created under the following assumptions:

- All simulations happen on the discharge side of the pump, rather than on the suction side. These simulations are intended to be benchmarked with the experimental results, which were also carried on the discharge side of the pump.

- Air injection occurs when the main flow is steady-state, assuming the pump has been running for a certain amount of time. 
- The Froude number parameters, which are meant to describe the water velocities, are assumed to be referenced to the main four and six-inch pipes, with water occupying the entire cross-section of the pipe.

- The VRS tank is modeled as a water reservoir, having a constant pressure.

- The VRS pump is modeled with a constant supply of water, rather than using a pump curve, for better code handling.

- The kinematic shock phenomenon is replaced by adding a slightly greater amount of air than that recorded during the experiment. 


\section{Chapter 3. SIMULATION SCENARIOS, RESULTS AND DISCUSSION}

\subsection{Void Recirculation Experiment}

\subsubsection{Experiment Description}

The Void Recirculation System, Figure 3.1, is the experimental setup used to validate the results from the RELAP5 simulation. Unlike Figure 1.3 where the same setup was shown for the suction side of the pump, Figure 3.1 shows the experimental setup on the discharge side of the pump.

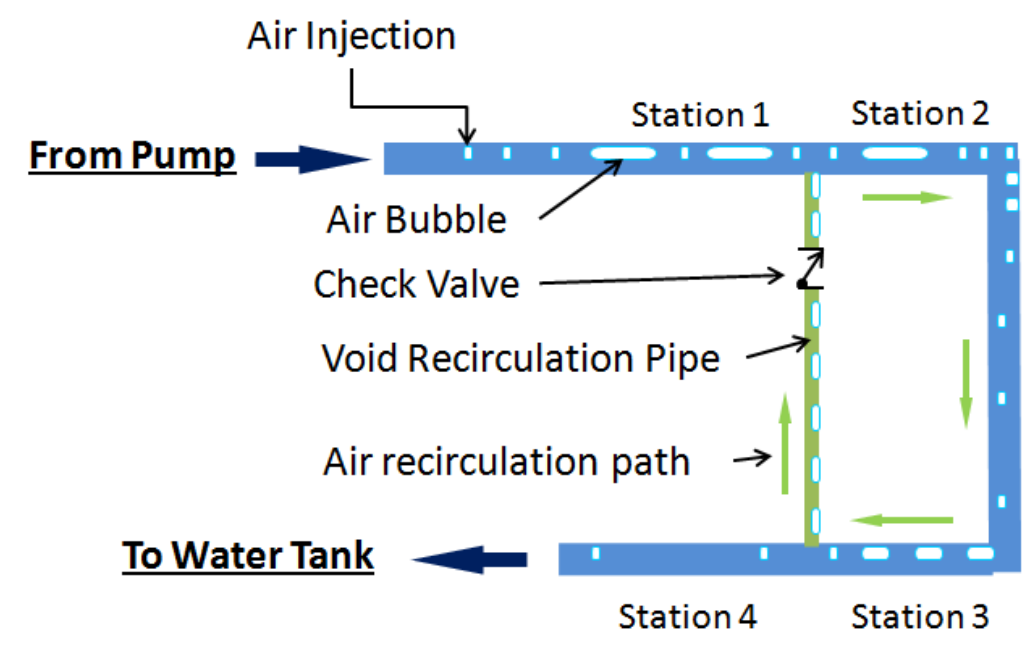

Figure 3.1. Experimental setup of the Void Recirculation System.

The water coming from the six-inch trash pump enters the upper main pipe before station one and continues its path through stations two, three and four, where it ultimately discharges into the water tank. Air was injected (after the water flow reached steady state) for a period of 15 seconds, through a 3/8-inch flexible hose. The air injection was located at the top section of the upper main pipe, approximately two feet to the left from 
station one, using an air compressor as previously described in Section 2.3.1. The air follows the path along stations one through four, with the exception that the majority of the air recirculates upwardly through the void recirculation pipe. The green colored pipe and arrows denote the void recirculation pipe and air recirculation path, respectively. Specifically, only air recirculates between stations two and three. A two-inch check valve, with a minimum opening pressure of $0.5 \mathrm{psi}$, was located on the void recirculation pipe (VRP) to prevent downward water flow, and to allow air accumulation on the bottom section of the VRP. Hence, the check valve allowed only upwards flow. The experimental setup, Figure 3.1, applies for the tested branches: four-inch and six-inch diameter pipes. A thorough dimensional description of the VRS, for both four-inch and six-inch branches, can be seen in Appendix A - VRS Piping Drawings. It is important to note that these figures only show lower pipe configurations of $4 \times 4 \times 3$-inch and $6 \times 6 \times 4-$ inch. The words 'pipe configuration' are meant to describe how the different reducing tees were used to connect each respective nominal pipe size. Figure 3.2 shows a picture of the different bottom pipe configurations that were used during the VRS experiment, ranging from four-inch to eight-inch pipes. Since the objective of the experiment was to test for pipe configurations that removed air more efficiently from the main pipe, the present study focuses on the $4 \times 4 \times 3$-inch and $6 \times 6 \times 4$-inch pipe configurations in view of the fact that these yielded a higher air removal rate with respect to the other pipe configurations tested. 


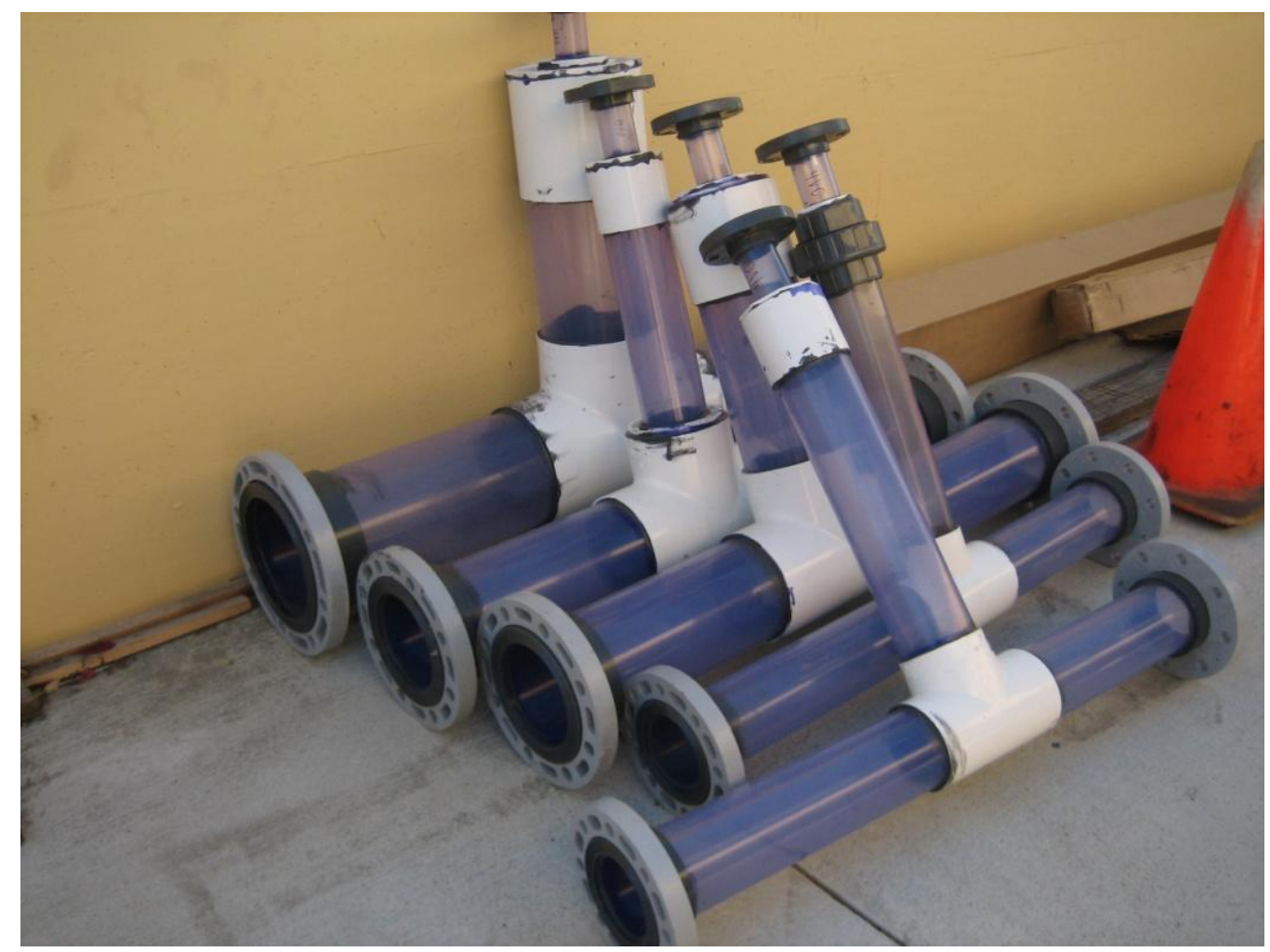

Figure 3.2. Lower pipe configurations used during the VRS experiment.

The main parameters controlled during the VRS experiment were initial void fraction and main pipe flow rate. Void fraction measurements were determined visually using square level rulers with 1/8-inch measurement resolution, located at stations one through four, where station one was used to determine the initial void fraction. The initial void fractions during the VRS experiment varied between three and 13 percent for the different pipe configurations tested. The initial void fraction to be analyzed under the present study is approximately seven percent for both pipe configurations $4 \times 4 \times 3$-inch and $6 \times 6 \times 4$-inch. The void fraction value of seven percent was carefully chosen since it appears in both pipe configuration results, allowing easy comparison. The maximum allowable void fraction in station four of the VRS model and test fixture is five percent 
for pipe diameters less than 12 inches. This five percent void fraction value is based on nuclear industry acceptability and on-going research (Institute of Nuclear Power Operations, 2010). Flow rate measurements were determined electronically using a turbine paddle flow meter, located on the main six-inch pipe after the pump as depicted in Figure 2.6. Flow rate values were then converted to Froude numbers to allow easy comparison between the different pipe diameters tested. A summary of the different flow rates tested for both pipe branches can be seen in Table 2.5 for further reference. Three different trials were measured with the same initial void fraction and Froude number. The void fraction recorded at each station was a visual average for the period of time of each trial (approximately two minutes or 120 seconds). Hence, only three void fraction values taken from each trial were reported for each scenario. Even though the experimental results were insufficient for a thorough statistical analysis, it provides an insight of the values to be expected at each station and will be used to validate the numerical results obtained from RELAP5.

The experiment setup was chosen to be in this specific way for two main reasons:

first, to have better flow rate control and second, to avoid the rather complicated vacuum running conditions. Even though air behaves differently under suction and discharge conditions, the recirculation behavior was the main objective to prove that the VRS device worked properly. 


\subsubsection{Experiment Observations}

There are several experimental observations that need to be reported for the sake of the VRS simulation validation. All observations reported under this section are based on flow regime patterns seen in all tested branches and are accompanied by pictures taken during the experiment. There are five main sections for which the flow behavior is of great interest: upper main pipe, vertical downward flow pipe or downcomer, lower elbow, lower tee and void recirculation pipe. These sections will be used to validate the results from the RELAP5 simulation. Figure 3.3 shows all the sections of experimental interest for the VRS, including the main five sections previously described, which can be seen in boxed texts.

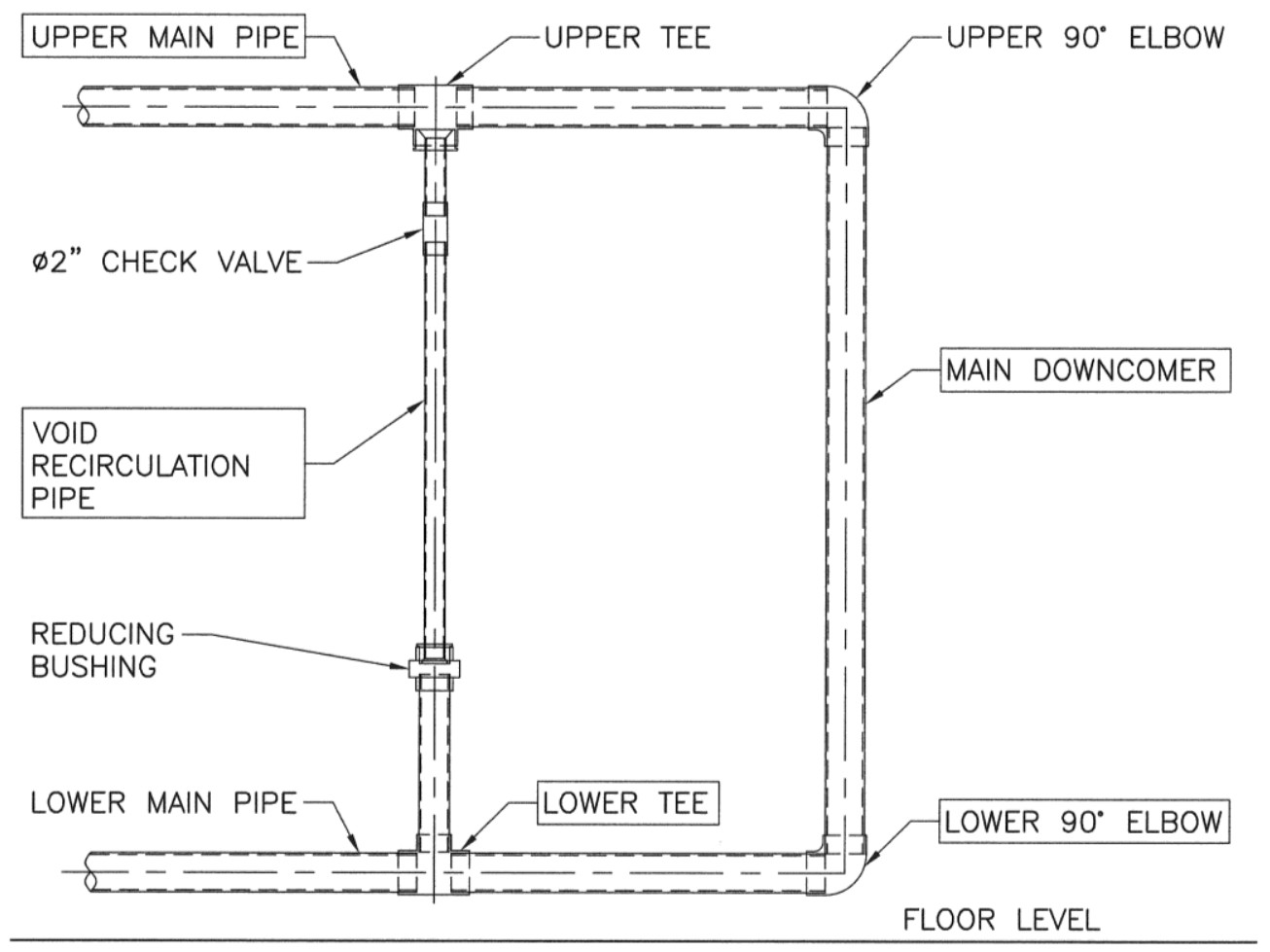

Figure 3.3. Sections of experimental interest for the Void Recirculation System. 


\subsubsection{Upper Main Pipe Observation}

The flow regime observed in all upper main pipe branches, comprising in the four-inch and six-inch pipes, was a horizontal stratified flow regime. Figure 3.4 is a picture taken on the opposite side of the pipe between the upper tee and upper elbow, showing the nature of the flow regime encountered at all tested flow rates and initial void fractions. In this picture the main pipe, square level rulers to measure the void fraction and the horizontal stratified flow regime can be appreciated. The horizontal stratified flow regime is composed of the air and water phases, which can be seen in the upper and lower parts of the main pipe, respectively.

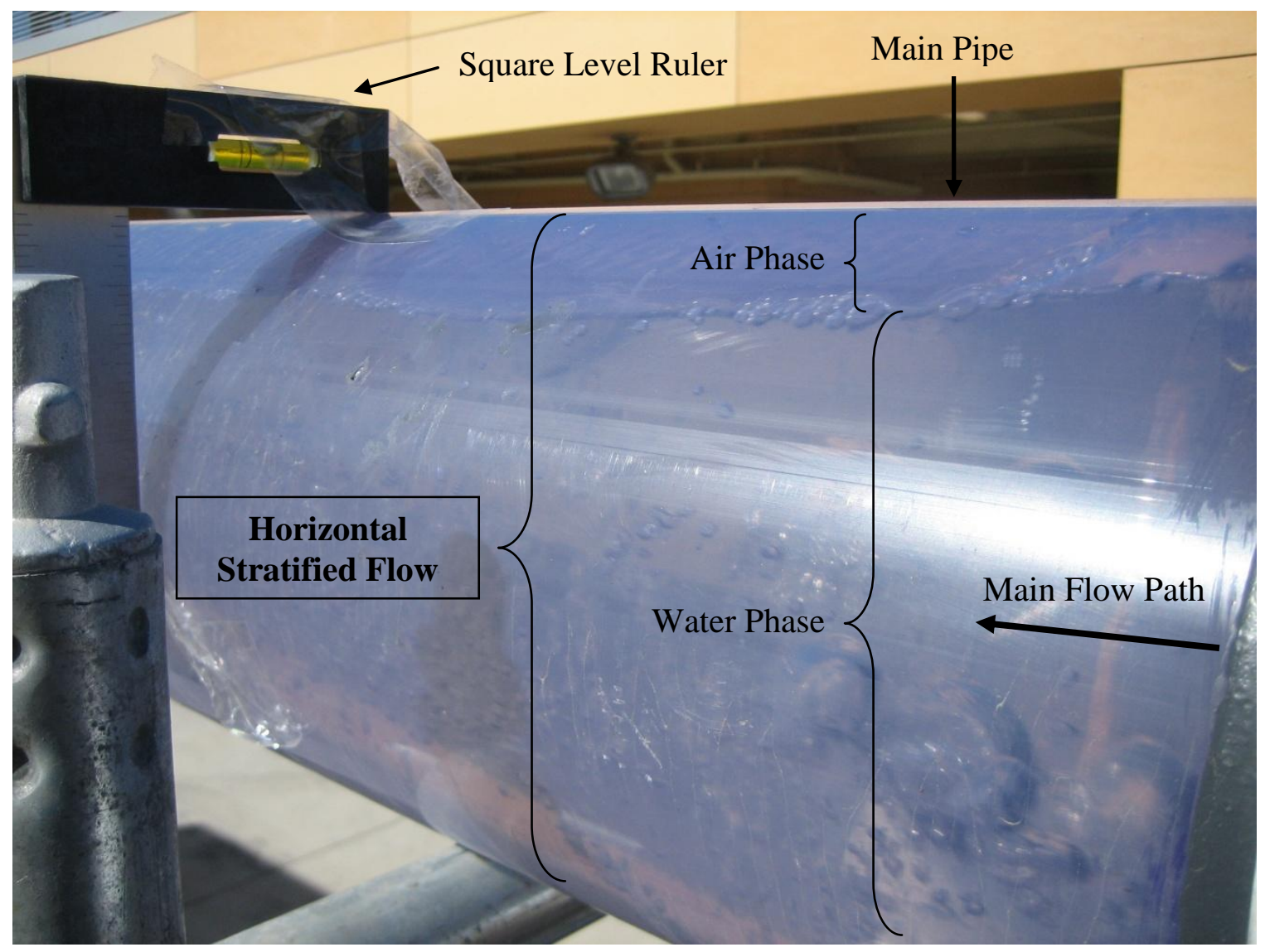

Figure 3.4. Horizontal stratified flow regime observed in the four and six-inch pipes. 
The bubbles seen near the center of the main pipe (right side of picture) originate from the void recirculation pipe, which is ultimately connected to the bottom side of the upper tee. The observed air in this picture is in fact the air that has been removed at the lower tee and proves that the VRS works properly. The bubbles, located near the center of the main pipe, eventually rise to the top of the pipe due to their lower density. Since air is being added from the bottom side of the upper tee, this specific process creates flow instability, or waves, due to variations in void fraction at different sections of the pipe. In other words, the observed flow regime is in fact wavy horizontal stratified flow and will become important as the simulation results are explained.

\subsubsection{Downcomer Observation}

The flow regime observed in all downcomers was bubbly flow as seen in Figure 3.5, which is a picture taken before the six-inch lower elbow. In some cases, slugs of air were observed travelling upwards in the opposite direction of the main flow path. This behavior was possibly due to the coalescence of air bubbles at the lower elbow, followed by an increase in buoyancy that ultimately was larger than the water inertia force. The coalescence of bubbles at the lower elbow is possibly due to a velocity gradient generated with a sharp turn in direction, hence leading to a local pressure gradient. 


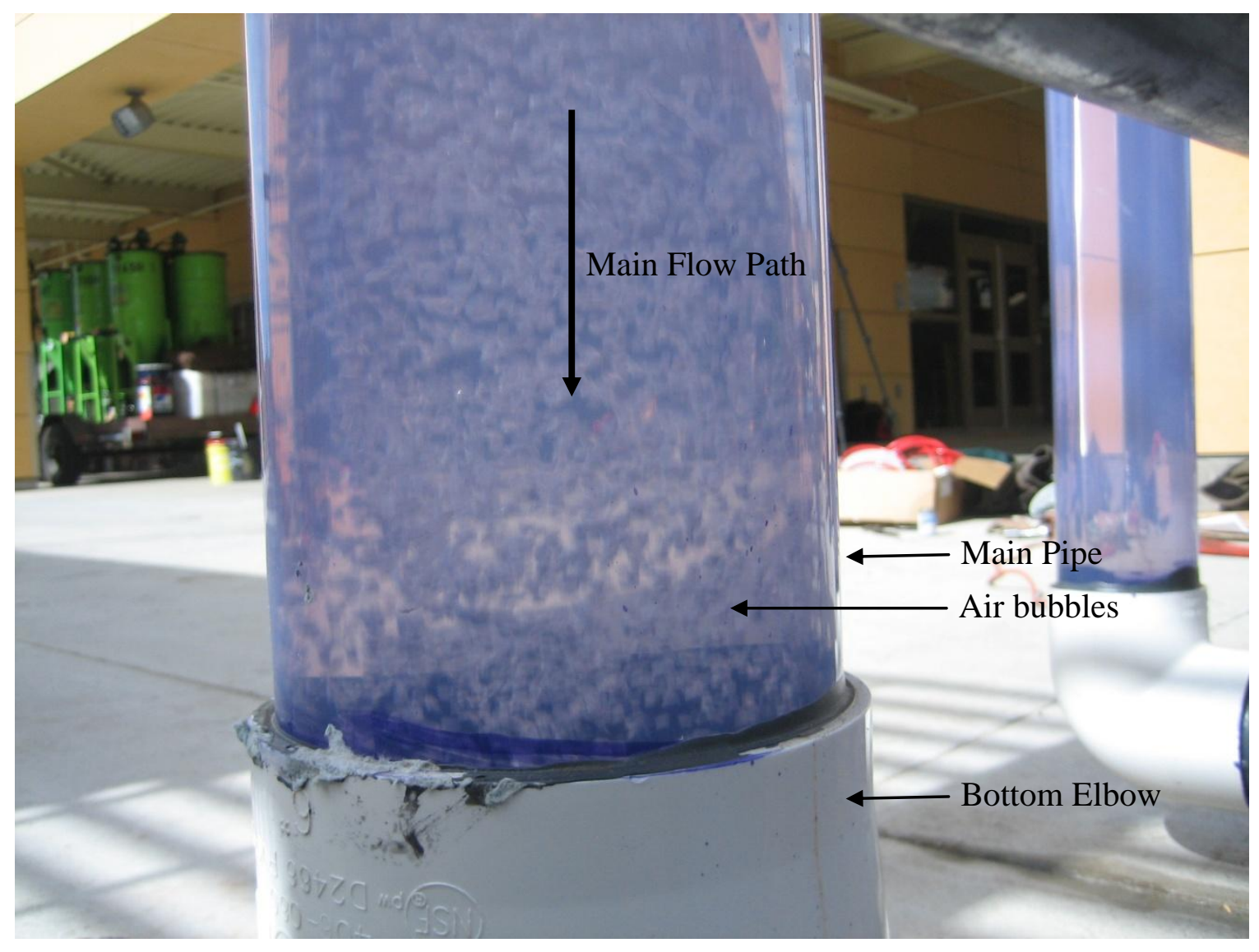

Figure 3.5. Downward bubbly flow regime observed in the four and six-inch pipes.

\subsubsection{Lower Elbow Observation}

The flow regimes observed after the lower elbow for all tested pipe branches varied between wavy horizontally stratified, slug and bubbly flow. Figure 3.6 shows the wavy horizontal stratified flow observed at one instant of time, with bubbly flow in the water phase. These bubbles, due to their lower density, eventually rise and help generate waves downstream. Figure 3.7 shows a combination between bubbly and slug flow in a short length of pipe and at a later instant of time than Figure 3.6. The bubbly flow is shown to the left, immediately after the lower elbow and the slug flow is shown to the 
right of the picture accompanied by the tail of the bubble. The behavior variation may be due to changes in velocity gradients and void fraction quantities, and is an indication that the air bubble is slowly being transported in the direction of the main flow.

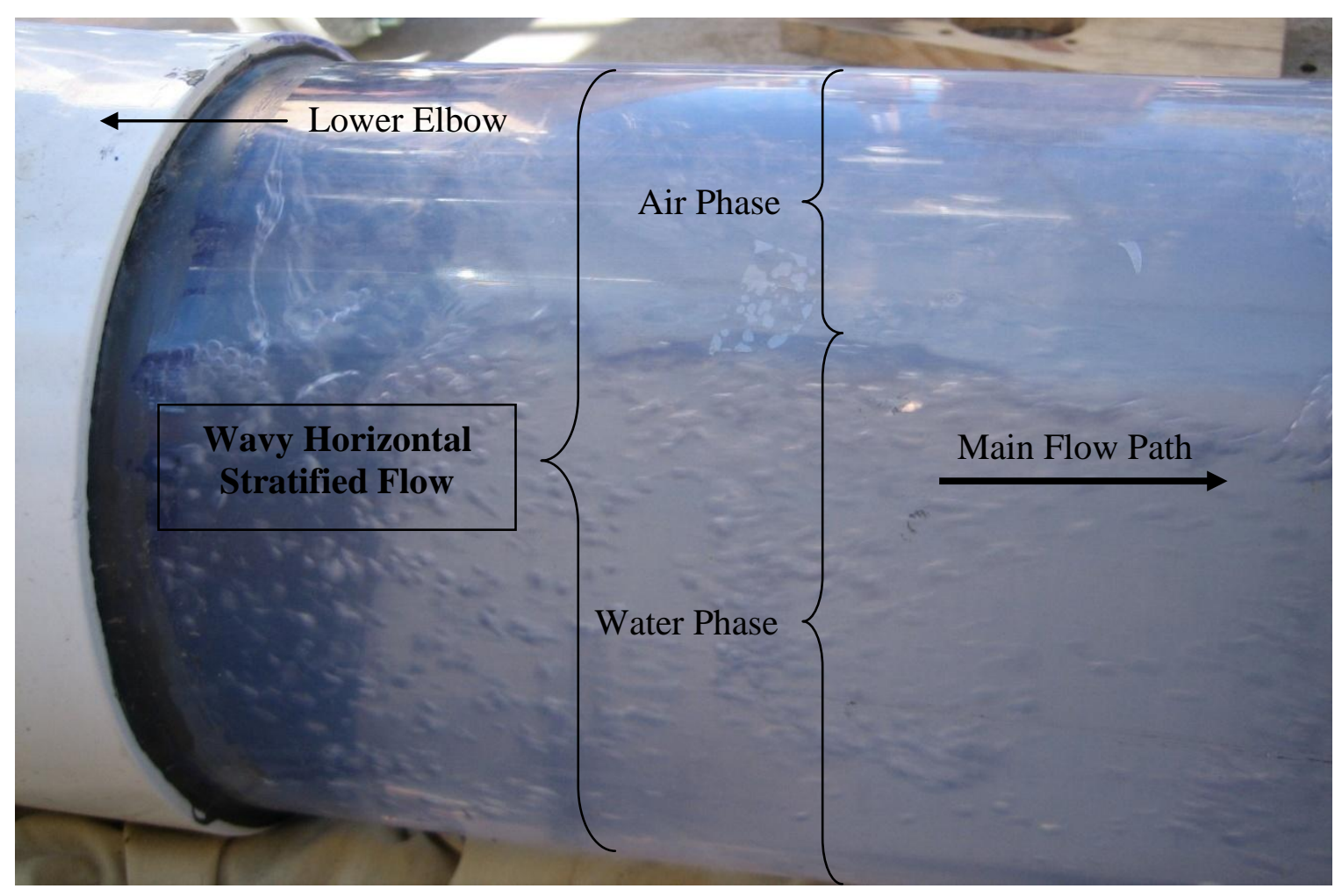

Figure 3.6. Wavy horizontal stratified flow observed in the four and six-inch pipes. 


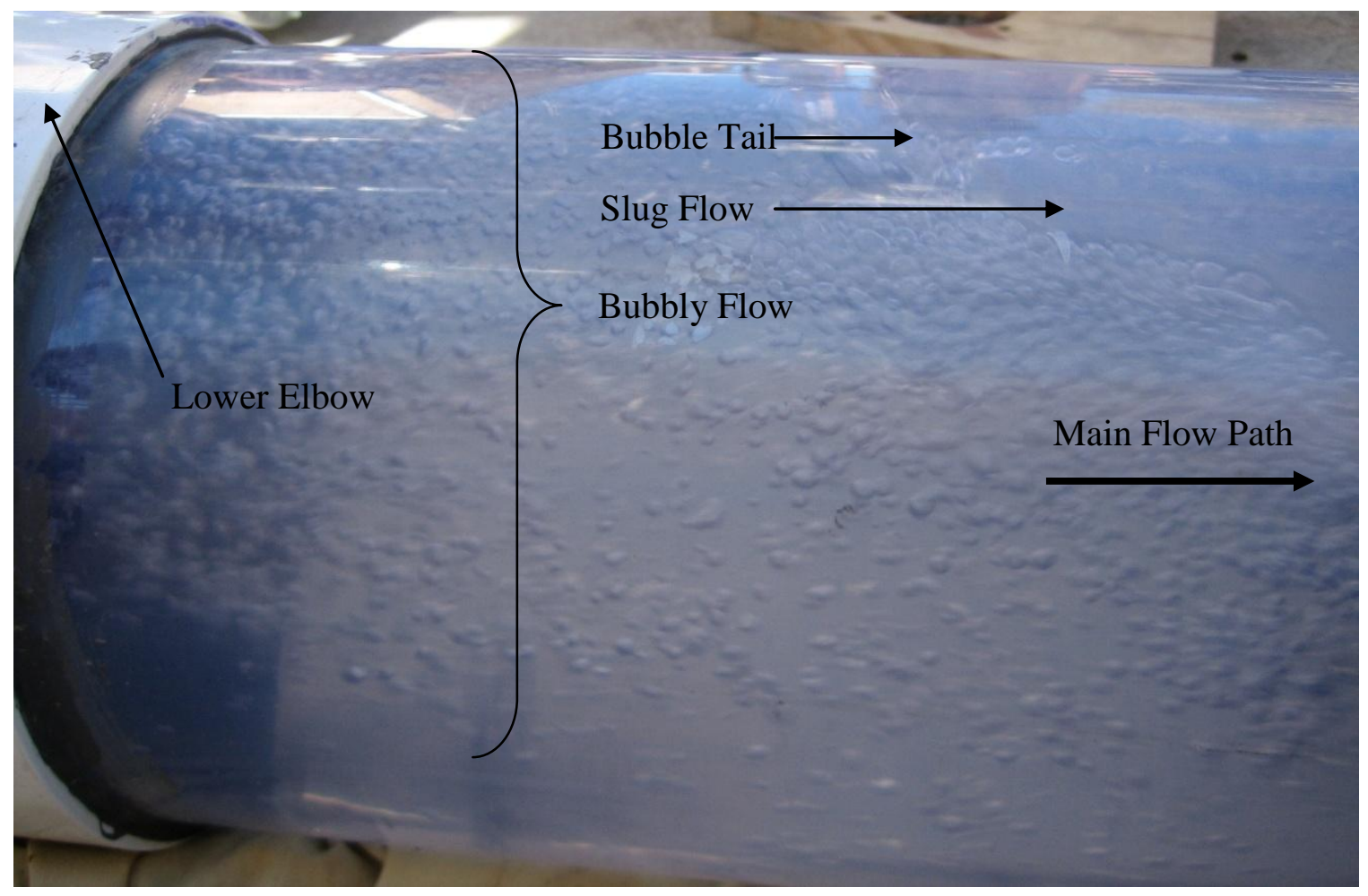

Figure 3.7 Bubbly and slug flow observed in the four and six-inch pipes.

Finally, it was observed that in many cases an air bubble would form, immediately after the lower elbow, with a defined bubble head. This bubble would move back and forth for a period of time, with a severe change in void fraction but no net velocity, until water broke the air bubble by allowing it to move in the direction of the main flow. When the breaking process happened, the air bubble accelerated until it reached the velocity of the water. This phenomenon can be clearly depicted in the following section and will become important for simulation validation. 


\subsubsection{Lower Tee Observation}

The flow regimes observed at stations three (before lower tee) and four (after lower tee) varied between bubbly and slug flow, but were significantly different in void fraction quantity since the lower tee removed the majority of the air coming from station three. Figure 3.8 shows a picture taken at station three at one instant of time, with a void fraction of approximately 50 percent. Even though the flow regime in Figure 3.8 seems to be wavy horizontally stratified, the air bubbles seen to the right of the picture is an indication that the bubble head is nearby. Thus the flow regime at this moment of time is in fact slug flow. The lower tee, though not shown in Figure 3.8, is located to the right of the square level ruler.

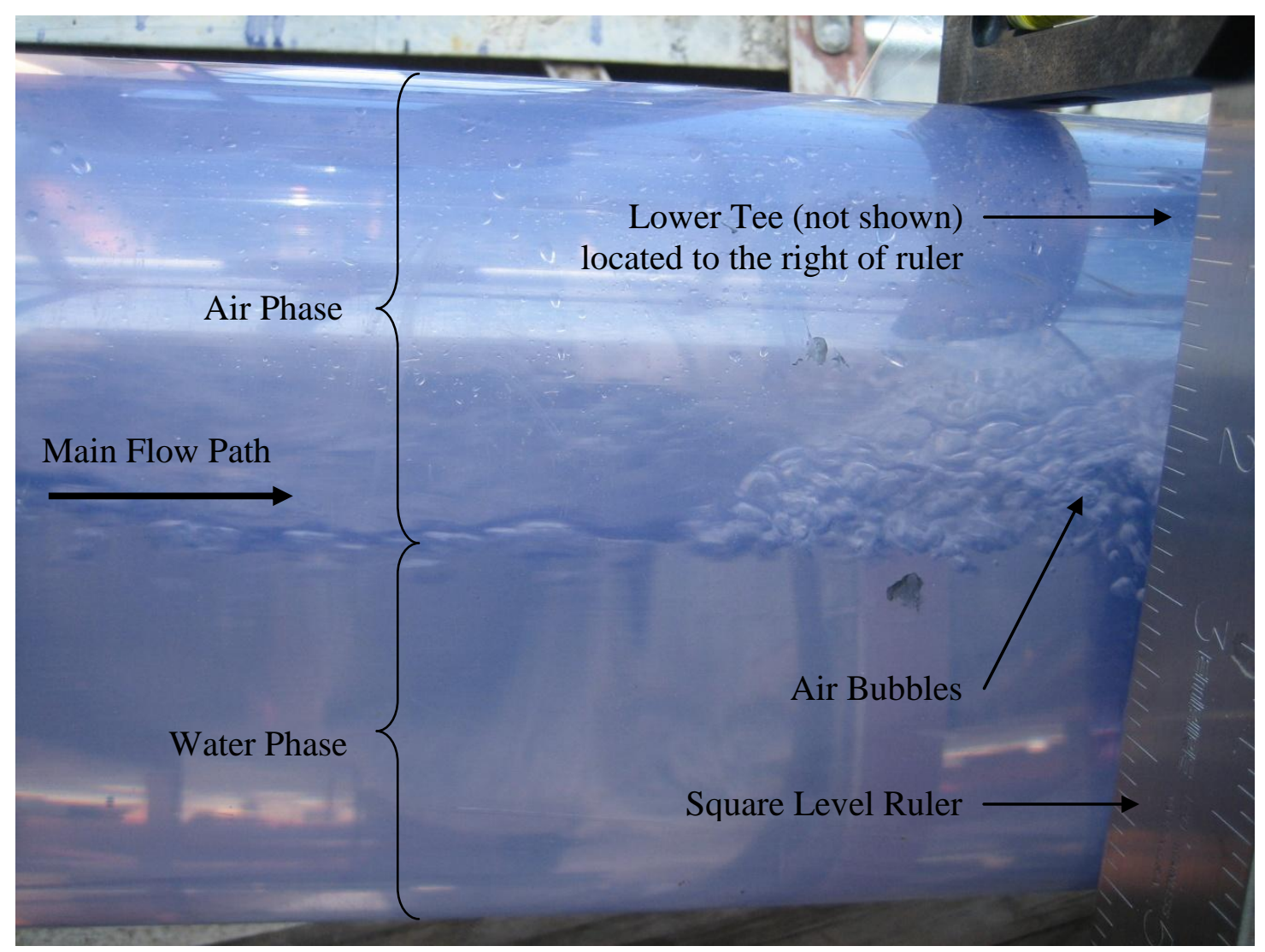

Figure 3.8. Slug flow observed at station three in the four and six-inch pipes. 
Figure 3.9 shows the same picture as before taken at a later instant of time where the bubble head, previously mentioned, is clearly depicted and is proof of the bubble slowly traveling in the direction opposite of the main flow path (i.e. right to left). The void fraction seen to the left of the picture where the slug is present is approximately 30 percent. However, the void fraction present to the right of the picture was impossible to measure with this square level ruler since the regime was bubbly flow.

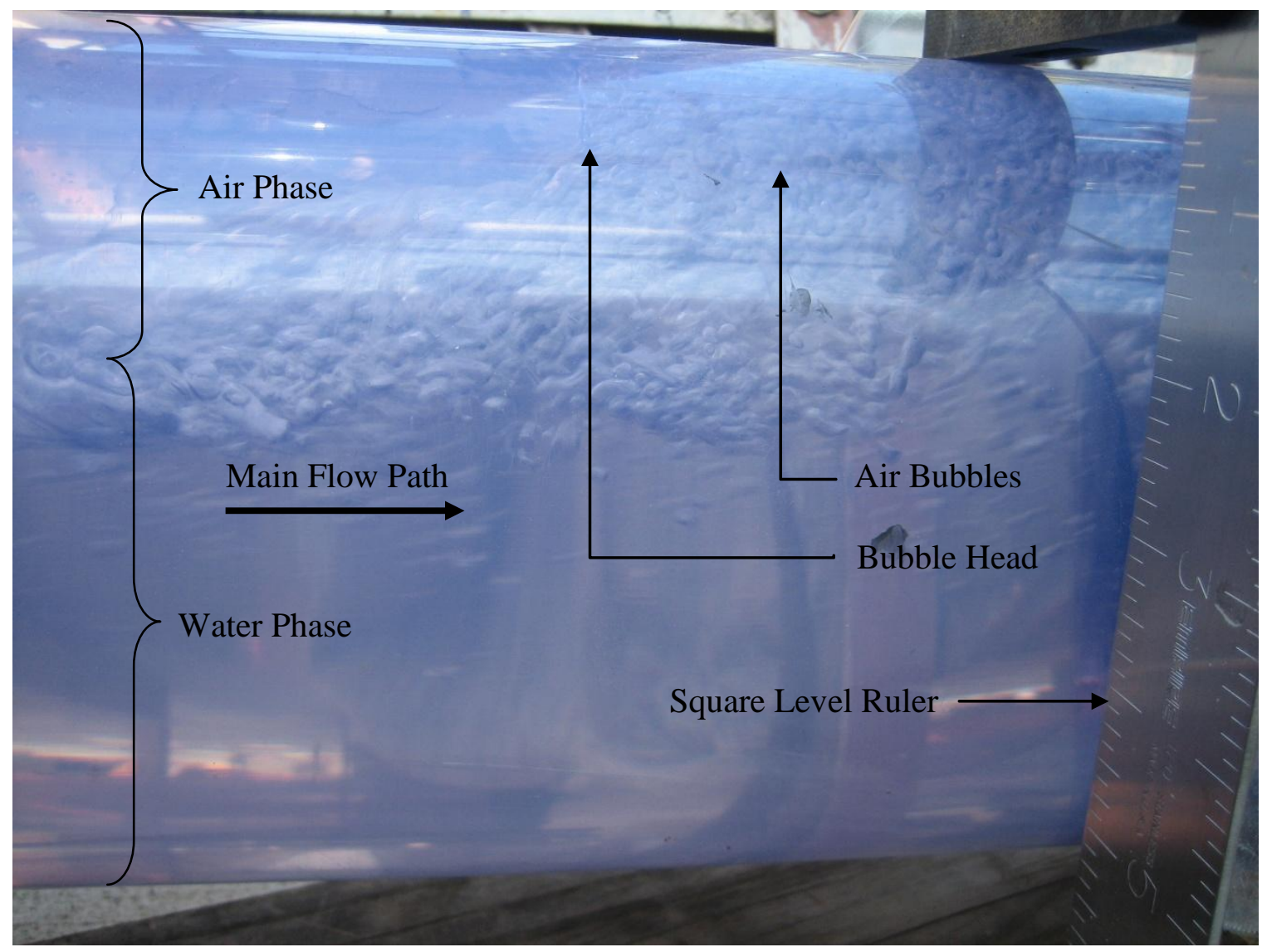

Figure 3.9. Wavy horizontal stratified and bubbly flow transition observed at station three in the four and six-inch pipes.

From Figure 3.8 and Figure 3.9, it was concluded that the void fraction decreased locally each time the bubble was moving in the direction opposite of the main flow path, 
implying that the air velocity would range between zero and negative values. In contrast, the void fraction increased locally whenever the bubble traveled in the direction of the main flow path, implying that the air velocity would range between zero and positive values. This behavior supports the discussion provided in the previous section (3.1.2.3), where the bubble moves back and forth for a period of time, until there is enough void fraction with respect to the main flow to disrupt the air bubble, allowing it to travel in the direction of the main flow path.

The flow regime observed at station four was mainly bubbly with little amount of void fraction as seen in Figure 3.10. Occasionally, slugs of air were observed with approximately 20 percent void fraction, but only for a short period of time. This behavior may be due to a flow discontinuity generated by the lower tee, which will be further discussed in the next section. 


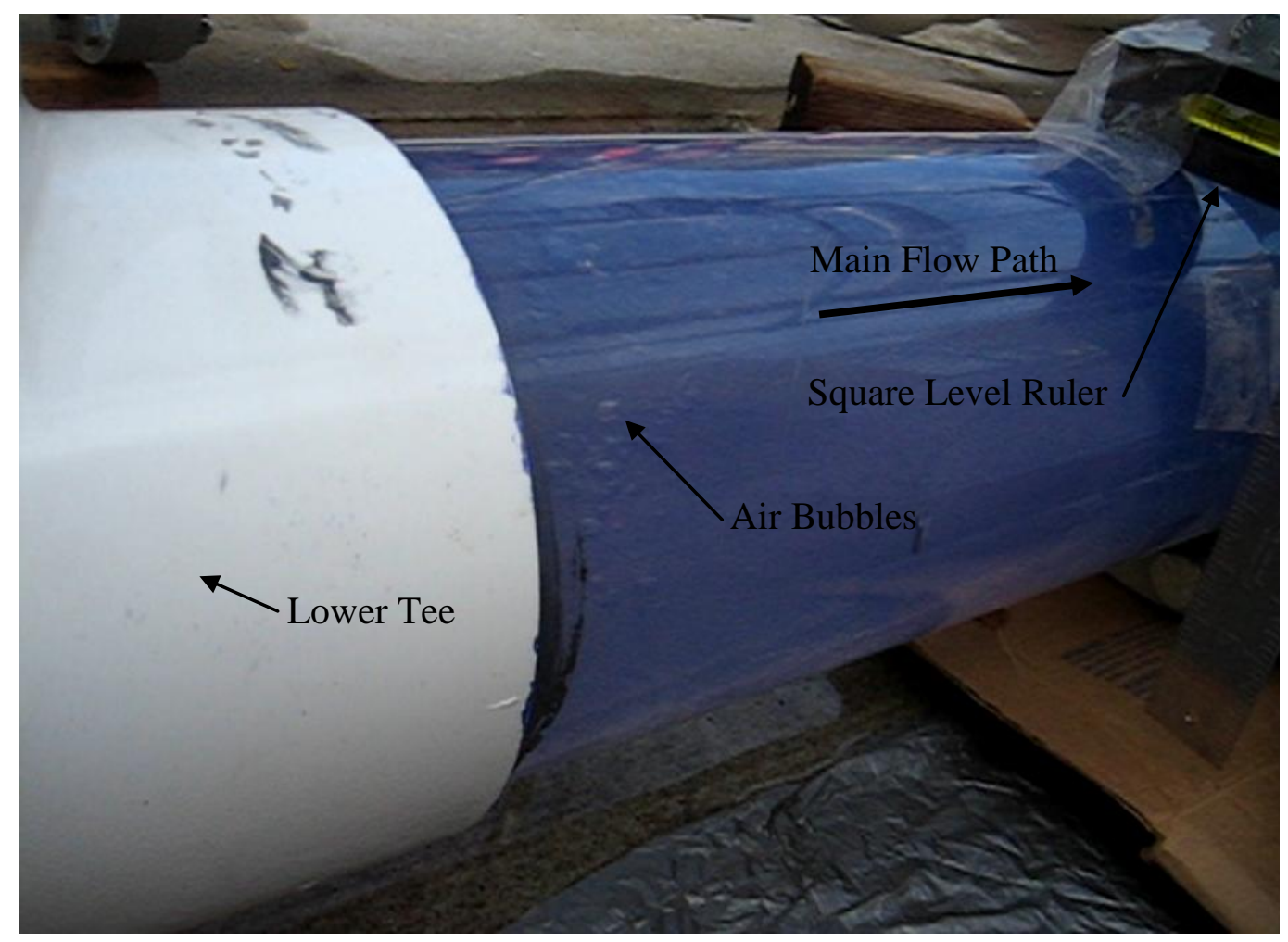

Figure 3.10. Bubbly flow observed at station four in the four and six-inch pipes.

\subsubsection{Void Recirculation Pipe Observation}

The flow regimes observed during the experiment at the void recirculation pipe varied constantly between upwards slug and upwards bubbly flow. This behavior was characteristic in the pipe section immediately before the two-inch check valve. It is worth mentioning that no total mass flow rate was seen through the VRP even though the experiment had already started, since the check valve only allowed upwards flow. Figure 3.11 shows the upwards slug flow observed when the first amount of air was transported between station three and the lower tee. 


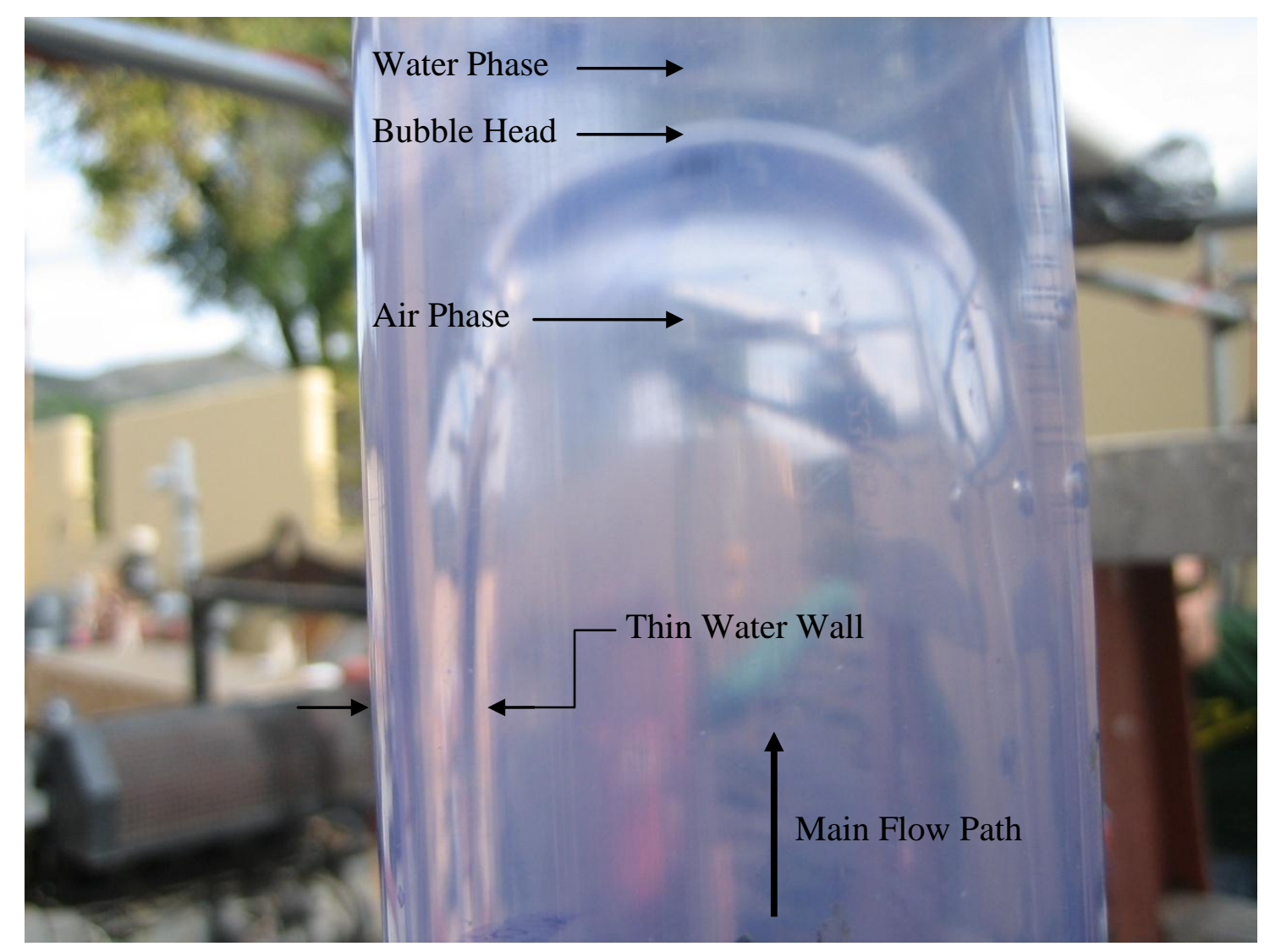

Figure 3.11. Upwards slug flow observed at the VRP for the four and six-inch pipe configurations.

The head of the bubble, which takes the form of a bullet shape, matches the description of the Taylor bubbles seen in Figure 2.3, and can be seen towards the top of the picture. The bubble head is followed by the bubble body seen in the middle of the picture, which is occupying nearly 90 percent of the inner pipe diameter. This slug of air forces the water to move sideways towards the wall (thin water wall formation) and downwards, until no more slugs are present, for which at this time bubbly flow occurs as shown in Figure 3.12. The flow regime in this section of pipe varied between slug and bubbly 
flow, thus matching the description of a Taylor Bubble Train flow regime, as seen in Figure 3.13. This behavior was typical for Froude numbers of 0.8, 1.0 and 1.3.

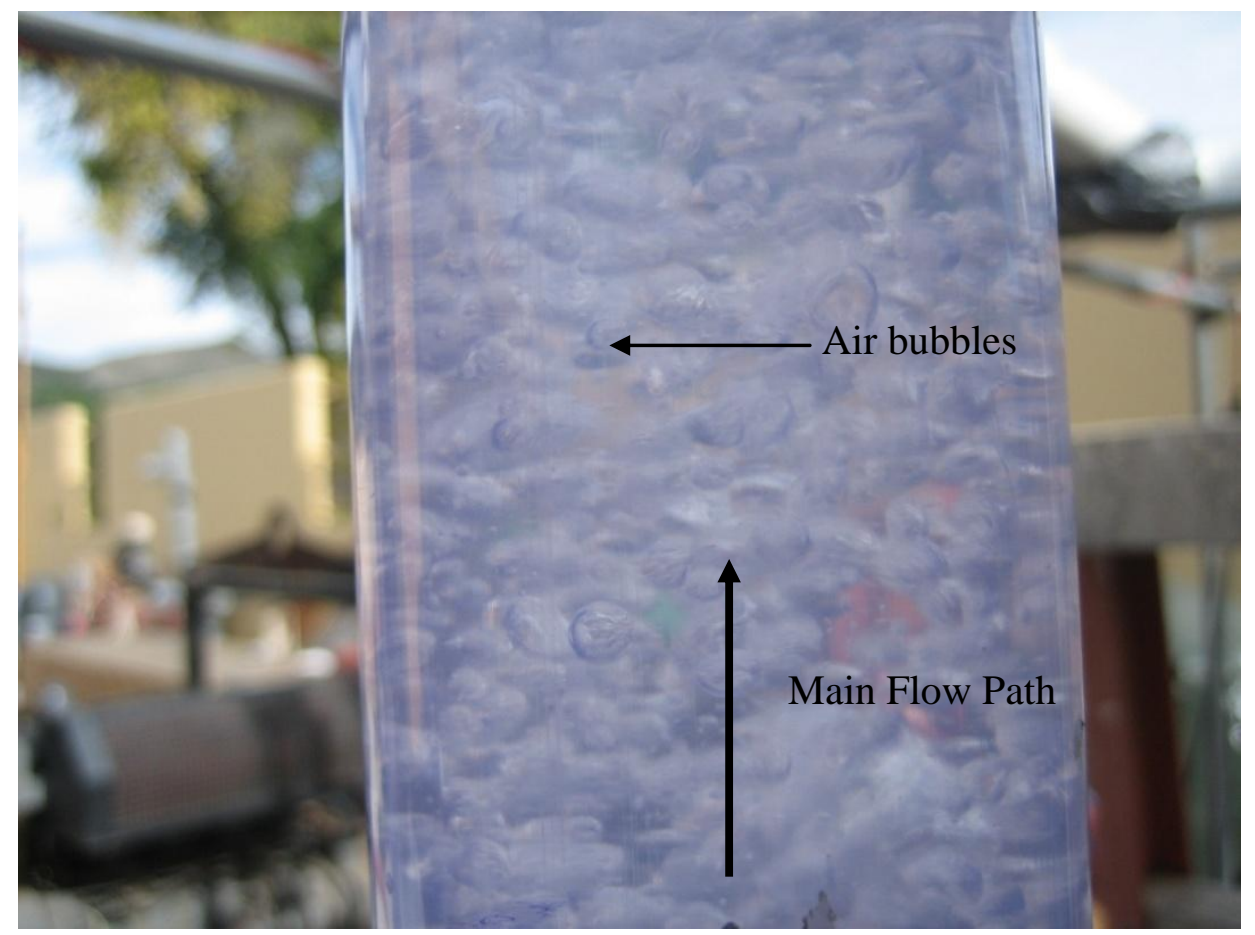

Figure 3.12. Upwards bubbly flow observed at the VRP for the four and six-inch pipe configurations.

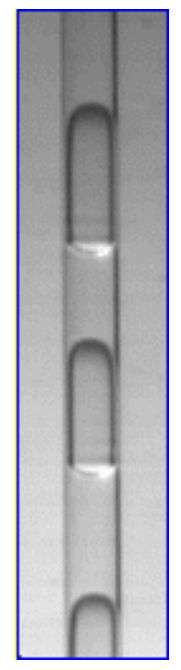

Figure 3.13. Taylor Bubble Train Flow Regime (Flow Regime Sample Movies). 
It is possible that the formation of the Taylor bubble train flow regime at the intersection between the VRP and lower tee causes a discontinuity of the air-water flow coming from station three. This discontinuity may be a reason for why the air bubble in station three moves back and forth, and why there are small slugs of air at station four throughout the experiment.

Air recirculation through the VRS stopped after approximately two minutes of testing at the highest flow rates for both four and six-inch branches, which correspond to a Froude number of 1.6. Hence, after two minutes, very little to no air was seen in stations one through four, but only a certain amount of air accumulated before the check valve as seen in Figure 3.14. Recall that air injection occurred for 15 seconds at the beginning of the experiment, thus no air was added at the time this photograph was taken. Since this amount of air was not sufficient to open the check valve, then this air bubble would settle indefinitely. Furthermore, this amount of air captured before the check valve was the total air successfully removed in the VRS at the highest flow rate.

In conclusion, the amount of air recirculated was greater at Froude numbers approximately up to 1.3 , since the check valve was continuously opening and closing throughout the experiment. This makes sense because the water travels relatively slow to allow a higher amount of upwards air flow. Conversely, a lower amount of air was removed at the highest flow rate, corresponding to a Froude number of 1.6. This also makes sense since the water travels relatively fast to carry more air past the lower tee and to station four, where it ultimately ends in the tank. 


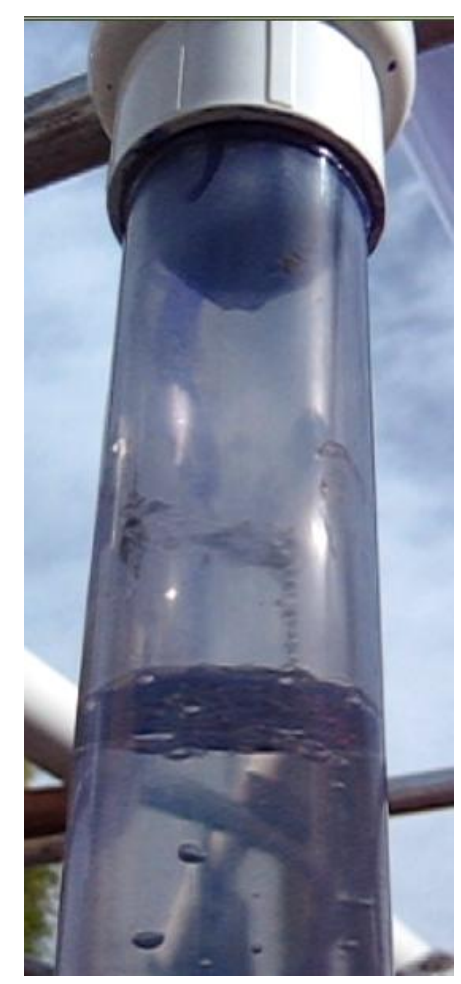

Figure 3.14. Air settling before the check valve in the six-inch branch.

\subsection{Description of Simulation Scenarios}

The simulations to be considered in the present study will apply to those selected under Section 3.1. More precisely, the pipe configurations $4 \times 4 \times 3$-inch and $6 \times 6 \times 4$-inch will be simulated in RELAP5, analyzed and validated against the experimental Void Recirculation System results. Table 3.1 shows the list of simulation scenarios to be considered for the RELAP5 VRS model. There are a total of eight simulation scenarios: four for the $4 \times 4 \times 3$-inch and $6 \times 6 \times 4$-inch pipe configurations, respectively. All eight scenarios have different volumetric flow rates and thus mass flow rates. However, only four different Froude numbers are analyzed for both pipe configurations and are approximately $0.81,1.00,1.30$ and 1.60 . These values correspond to the tested 
volumetric flow rates in the VRS experiment. Air was injected following a specific scheme as shown in Table 2.6 and Table 2.7 to ensure a minimum initial void fraction of seven percent. Each simulation scenario was modeled for a period of 150 seconds. The code built in RELAP5 for simulation scenario one can be seen in Appendix C - VRS RELAP5 Code for further reference.

Table 3.1. List of simulation scenarios for the RELAP5 VRS model.

\begin{tabular}{|c|c|c|c|c|c|}
\hline Scenario & $\begin{array}{c}\text { Main Pipe } \\
\text { Diameter } \\
\text { (in) }\end{array}$ & $\begin{array}{c}\text { Pipe } \\
\text { Configuration } \\
\text { (in) }\end{array}$ & $\begin{array}{c}q \\
(\mathrm{gpm})\end{array}$ & $\dot{m}_{l}(\mathrm{lb} / \mathrm{s})$ & $F r$ \\
\hline 1 & 4.026 & $4 \times 4 \times 3$ & 105 & 14.5 & 0.81 \\
\hline 2 & 4.026 & $4 \times 4 \times 3$ & 125 & 17.3 & 0.96 \\
\hline 3 & 4.026 & $4 \times 4 \times 3$ & 168 & 23.3 & 1.29 \\
\hline 4 & 4.026 & $4 \times 4 \times 3$ & 208 & 28.8 & 1.60 \\
\hline 5 & 6.065 & $6 \times 6 \times 4$ & 294 & 40.7 & 0.81 \\
\hline 6 & 6.065 & $6 \times 6 \times 4$ & 400 & 55.4 & 1.10 \\
\hline 7 & 6.065 & $6 \times 6 \times 4$ & 500 & 69.2 & 1.38 \\
\hline 8 & 6.065 & $6 \times 6 \times 4$ & 582 & 80.6 & 1.60 \\
\hline
\end{tabular}

\subsection{Convergence Test}

The convergence test for the VRS model consists in showing time and grid independence. For both tests, only the void fraction of simulation scenario one, at station three, will be used to evaluate the independence of the model built in RELAP5. Station three was chosen to be of particular interest since it is the section that contains the largest amounts of air to be recirculated through the VRS. Table 3.2 shows the list of convergence tests to be done for the VRS model. The time independence test consists in evaluating the void fraction at station three, using 32 nodes (finest mesh), for the following time steps: $1.0 \times 10^{-2}, 1.0 \times 10^{-3}$, and $1.0 \times 10^{-5}$ seconds. An average relative error, taken throughout the entire simulation time will be used to report time independence. 
Table 3.2. List of convergence tests for the RELAP5 VRS model.

\begin{tabular}{|c||c|c|c|}
\hline \multirow{2}{*}{ Simulation Scenario } & Test & $\begin{array}{c}\text { Time Step } \\
\text { Criterion (seconds) }\end{array}$ & $\begin{array}{c}\text { Mesh Size Criterion } \\
\text { (No. of Nodes) }\end{array}$ \\
\cline { 4 - 4 } & \multirow{3}{*}{ Time Independence } & $1 \times 10^{-2}$ & 32 \\
\cline { 4 - 4 } & & $1 \times 10^{-3}$ & 32 \\
\hline B & \multirow{3}{*}{ Grid Independence } & $1 \times 10^{-5}$ & 32 \\
\hline C & & $1 \times 10^{-3}$ & 11 \\
\hline D & $1 \times 10^{-3}$ & 20 \\
\hline E & $1 \times 10^{-3}$ & 32 \\
\hline F & &
\end{tabular}

The grid independence test consists in using a constant time step of $1 \times 10^{-3}$ seconds and changing the number of nodes in the VRS as follows:

Fine mesh, $N_{l}=32$ nodes

Medium mesh, $N_{2}=20$ nodes

Coarse mesh, $N_{3}=11$ nodes

It is important to note that the number of nodes was edited only for pipe component 320 , which encompass stations two, the main pipe downcomer and station three (which is of highest interest). The Richardson extrapolation (RE) method (Celik, Ghia, Roache, \& Freitas, 2008) will be used to estimate the discretization error and to determine grid convergence for the void fraction solution at station three. 


\subsubsection{Time Independence Test}

Figure 3.15 shows the void fraction behavior for simulation scenario one at station three for different time steps. The time steps $1.0 \times 10^{-2}, 1.0 \times 10^{-3}$, and $1.0 \times 10^{-5}$ seconds can be depicted in dashed, solid and dotted lines, respectively.

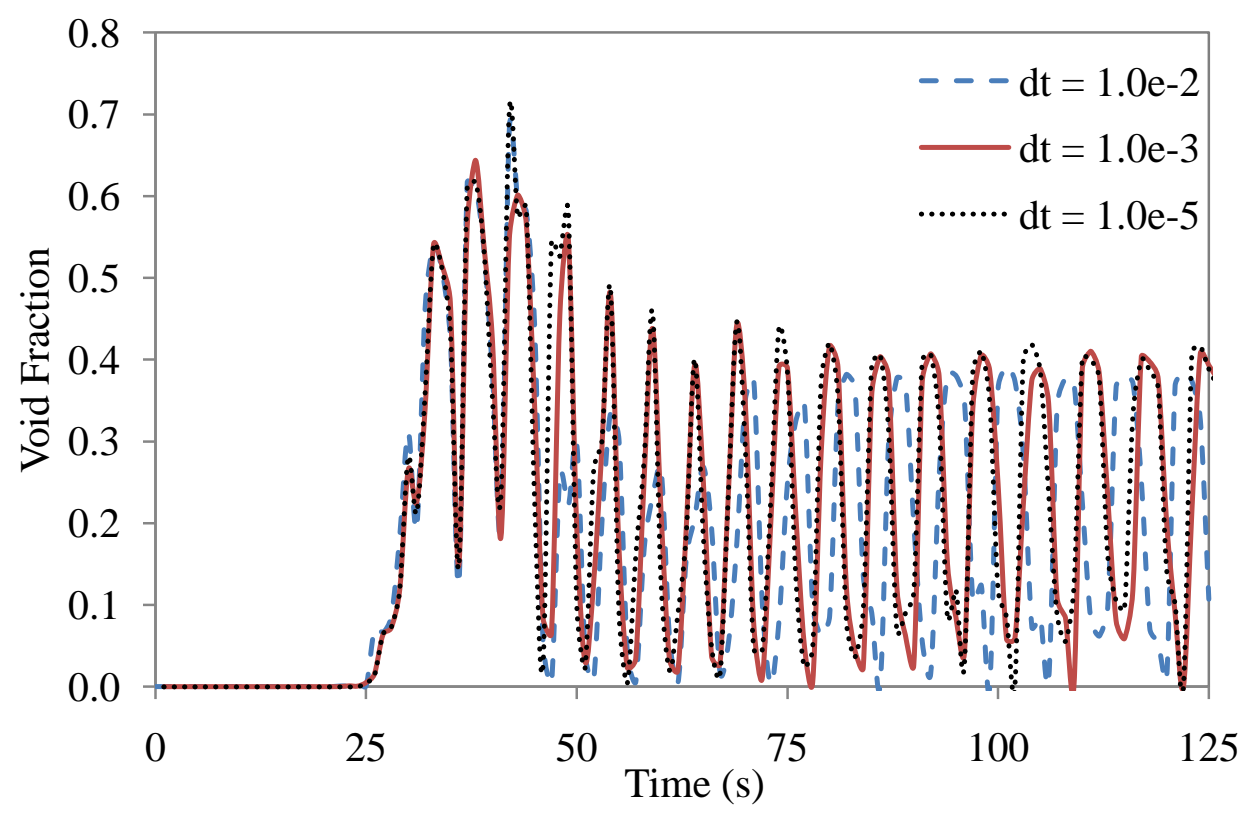

Figure 3.15. Void fraction behavior for scenario one at station three for different time steps.

During the first 65 seconds, all solutions behave similarly with an oscillatory motion, which will be later explained under the results and discussion section. The solution for the largest time step begins to be off-phase with respect to the other two solutions after 65 seconds. This behavior might be due to numerical calculations within RELAP5, since the oscillation pattern seems to be the same throughout the simulation time. The relative error was calculated using the following formula: 


$$
e_{a}^{\mathrm{AB}}=\left|\frac{V F_{\mathrm{B}}-V F_{\mathrm{A}}}{V F_{\mathrm{B}}}\right|
$$

where $V F$ is the void fraction at station three at a particular time, and the subscripts A and B correspond to the largest $\left(1.0 \times 10^{-2}\right.$ seconds $)$ and intermediate $\left(1.0 \times 10^{-3}\right.$ seconds $)$ time steps, respectively. The relative error of the void fraction was computed for every second up to 125 seconds, and an average relative error was calculated for the entire simulation time. The average relative error between convergence scenarios A and B was approximately $264 \%$. This high value is a consequence of the off-phase behavior between these two solutions. The void fraction relative error between the intermediate $\left(1.0 \times 10^{-3}\right.$ seconds) and smallest time steps $\left(1.0 \times 10^{-5}\right.$ seconds) was found by using the following:

$$
e_{a}{ }^{\mathrm{BC}}=\left|\frac{V F_{\mathrm{C}}-V F_{\mathrm{B}}}{V F_{\mathrm{C}}}\right|
$$

where the subscripts B and C correspond to the intermediate and smallest time steps, respectively. The average relative error between these convergence scenarios was found to be approximately $35 \%$. This comparatively low value makes sense because, unlike the off-phase behavior between scenarios A and B, the time step solutions between scenarios $\mathrm{B}$ and $\mathrm{C}$ are closely in phase, thus leading to a smaller relative error. In terms of computational time, scenarios $\mathrm{A}, \mathrm{B}$ and $\mathrm{C}$ took approximately 2 minutes, 30 minutes and 2 days, respectively. Because a greater relative error difference was obtained by using the intermediate time step of $1.0 \times 10^{-3}$ seconds when compared to total computational time, then it was decided to use this specific time step for all simulation scenarios. In 
addition, the results obtained for this particular time step demonstrate good convergence behavior with respect to the smallest time step.

\subsubsection{Grid Independence Test}

Figure 3.16 shows the void fraction behavior for simulation scenario one at station three for different mesh sizes. The coarse, medium and fine meshes can be depicted in dashed, solid and dotted lines.

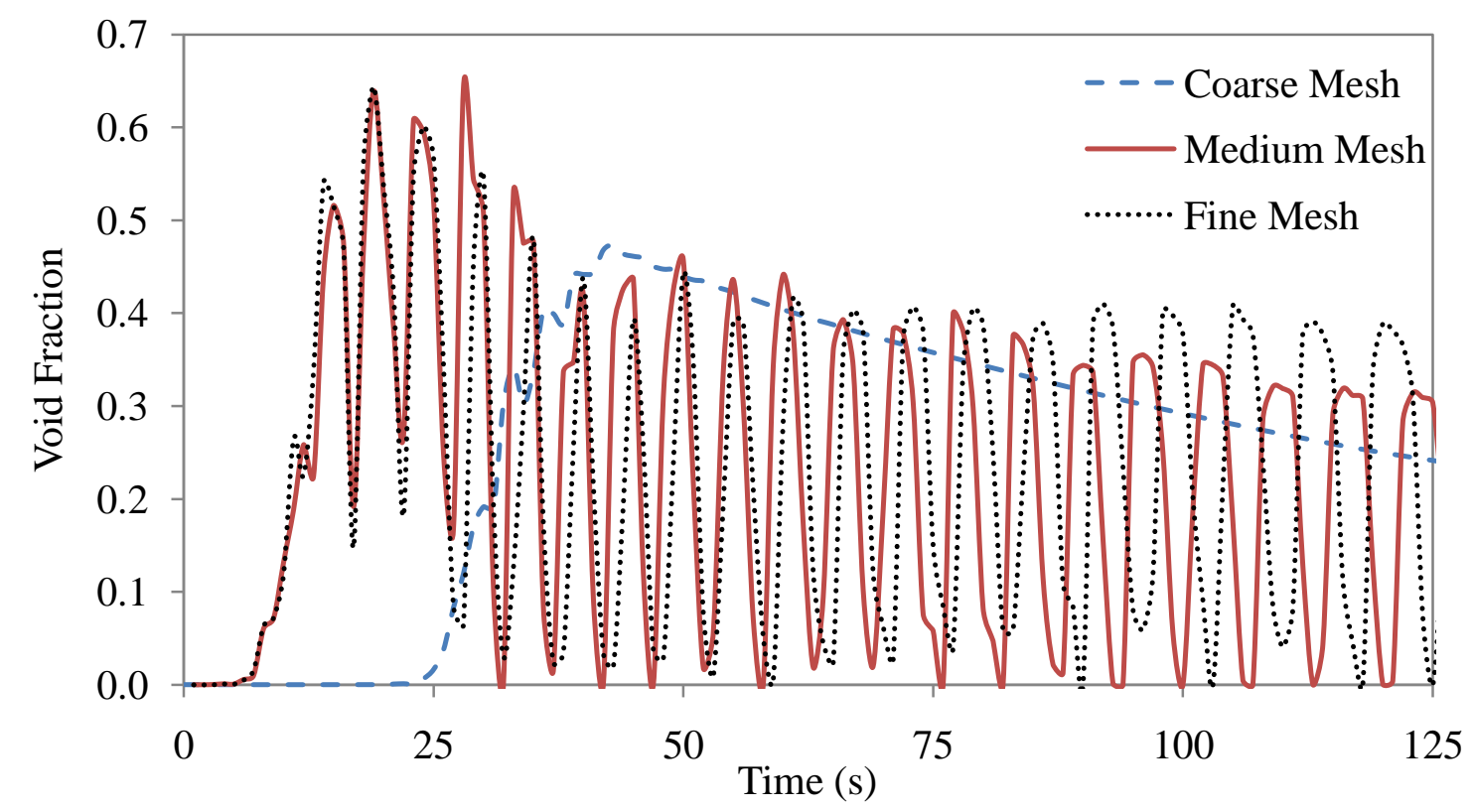

Figure 3.16. Void fraction behavior for scenario one at station three for different mesh sizes.

In this graph, the smoothest void fraction behavior can be appreciated for the coarse mesh when compared to the medium and fine meshes. However, the coarse mesh solution is in fact the least accurate since it does not describe the physical behavior of two-component 
flow for the VRS experiment. The medium and fine meshes have a similar oscillating behavior, with the exception that the solutions are not always in phase throughout the entire simulation time. Table 3.3 shows the discretization error results for scenarios D, E and F, which were based on the RE method.

Table 3.3. Discretization error results based on the RE method.

\begin{tabular}{|l|l|}
\hline \multicolumn{1}{|c|}{ Parameter } & \multicolumn{1}{c|}{ Value } \\
\hline$N_{1}, N_{2}, N_{3}$ & $32,20,11$ \\
\hline$r_{21}$ & 1.37 \\
\hline$r_{32}$ & 1.48 \\
\hline$p$ & 3.75 \\
\hline$e_{a}^{2 l}$ & $192 \%$ \\
\hline$e_{\text {ext }}^{2 l}$ & $135 \%$ \\
\hline${\text { GCI } \text { fine }^{2 l}}^{2 l}$ & $74 \%$ \\
\hline
\end{tabular}

The grid refinement factor, $r$, is a ratio of coarse to fine mesh and is a function of the number of nodes and the total pipe area of interest. This parameter was used to calculate the apparent order, $p$ using the following expressions (Celik, Ghia, Roache, \& Freitas, 2008):

$$
\begin{gathered}
p=\frac{1}{\ln \left(r_{21}\right)}|\ln | \frac{\varepsilon_{32}}{\varepsilon_{21}}|+q(p)| \\
q(p)=\ln \left(\frac{r_{21}^{p}-s}{r_{32}^{p}-s}\right) \\
s=1 \cdot \operatorname{sign}\left(\frac{\varepsilon_{32}}{\varepsilon_{21}}\right)
\end{gathered}
$$


where $\varepsilon_{32}=V F_{3}-V F_{2}, \varepsilon_{21}=V F_{2}-V F_{1}$ and the subscripts 1,2 , and 3 correspond to the fine, medium and coarse meshes, respectively. These values, along with the apparent order were calculated at each second for 125 seconds. Then, an average apparent order was calculated for the entire simulation time, in which the value was found to be approximately 3.75. This value was not in agreement with the formal order of the scheme used in RELAP5, which was unity. According to Celik et al. (2008), the RE method does not work when $\varepsilon_{32}$ or $\varepsilon_{21}$ is approximately zero, which in this case, the majority of the values were very close to zero. In addition, the authors suggest that these results might be an indication of an oscillatory convergence or that an exact solution has been achieved. For the particular VRS model, it seems that an oscillatory convergence behavior was attained by looking at Figure 3.16, which might explain the reason why the apparent order is not in agreement with the formal order of the scheme used in the simulation. The approximate relative error, extrapolated relative error and the fine-grid convergence index between medium and fine meshes were calculated using the following expressions respectively (Celik, Ghia, Roache, \& Freitas, 2008):

$$
\begin{gathered}
e_{a}{ }^{21}=\left|\frac{V F_{1}-V F_{2}}{V F_{1}}\right| \\
e_{\text {ext }}{ }^{21}=\left|\frac{V F_{\text {ext }}^{12}-V F_{1}}{V F_{\text {ext }}^{12}}\right| \\
\operatorname{GCI}_{\text {fine }}{ }^{21}=\frac{1.25 e_{a}^{21}}{r_{21}^{p}-1}
\end{gathered}
$$


Each of these values were then averaged for the simulation time of 125 seconds. The relative error was found to be $192 \%$, while the extrapolated relative error was $135 \%$. The fine-grid convergence index was found to be approximately $74 \%$. These high values are associated with the off-phase behavior seen in Figure 3.16, in addition of the high apparent order $p=3.75$. More precisely, the location of station three chosen for all convergence scenarios slightly varied between each other due to mesh refinement. Numerical results showed that the void fraction tends to drastically change from node to node for this VRS model in specific. This implies that two-component flow is extremely sensitive to pipe location and time.

As a rule of thumb, GCI should be higher than $e_{\text {ext }}$ at an apparent order of unity. Because the original apparent order $p=3.75$ yielded a lower $G C I$ value with respect to $e_{e x t}$, then it was decided to recalculate the discretization error parameters by using a modified apparent order. Both apparent orders of unity and two were tested, but it was found that the former value yielded extremely high discretization errors. Table 3.4 summarizes the results for the modified discretization error using $p=2.00$, which is the closest value to the formal order of the scheme used in RELAP5. In this case, the relative and extrapolated errors were approximately $192 \%$ and the $G C I$ is $271 \%$, which is greater than $e_{\text {ext }}$. 
Table 3.4. Modified Discretization error results based on the RE method, using $p=2.00$.

\begin{tabular}{|l|l|}
\hline \multicolumn{1}{|c|}{ Parameter } & \multicolumn{1}{c|}{ Value } \\
\hline$p$ & 2.00 \\
\hline$e_{a}^{21}$ & $192 \%$ \\
\hline$e_{\text {ext }}^{21}$ & $191 \%$ \\
\hline GCI $_{\text {fine }}^{21}$ & $271 \%$ \\
\hline
\end{tabular}

Even though the discretization errors continue to be high, the fine mesh solution demonstrates good convergence behavior, and more importantly, numerically describes the behavior linked with reality. The simulation scenarios analyzed in the present study use the finest mesh described above.

\subsection{Simulation Validation, Results and Discussion}

This thesis analyzes a simulation of two-component (air and water) flow in a Void Recirculation System, where the main parameters to be considered are mass flow rates and void fraction at stations one through four, according to Figure 3.1. Experimental results are available from VRS tests carried at Cal Poly State University (Daza, Fong, Rosas, \& Wong, 2009) and will be used to validate the VRS model developed in RELAP5. The purpose of analyzing mass flow rates obtained from the simulation results is to prove that the VRS model works properly, by showing a net positive upwards flow through the void recirculation pipe. The purpose of analyzing the void fraction is to describe the parameter's behavior at all stations with respect to time and to validate the numerical results to the VRS experiment. The simulation scenarios to be analyzed 
assume a time step of $1.0 \times 10^{-3}$ seconds with the finest mesh size as described in the convergence test section.

\subsubsection{Mass Flow Rate Analysis}

The mass flow rates of the VRS model for stations one, two, four and the void recirculation pipe, for simulation scenario one $(4 \times 4 \times 3$-inch, $F r=0.81)$ can be seen in Figure 3.17. The mass flow rate in station one behaves constantly with respect to the other sections of interest at a value of $14.5 \mathrm{lb} / \mathrm{s}$. This behavior makes sense since there is a constant source of water and air passing through station one. Air was injected between 20 and 35 seconds, where mass flow rate maximums can be seen for stations one, two and four. Even though air has not yet arrived at station four, the peaking behavior is the result of the mass conservation being calculated in RELAP5, since air is being added. 


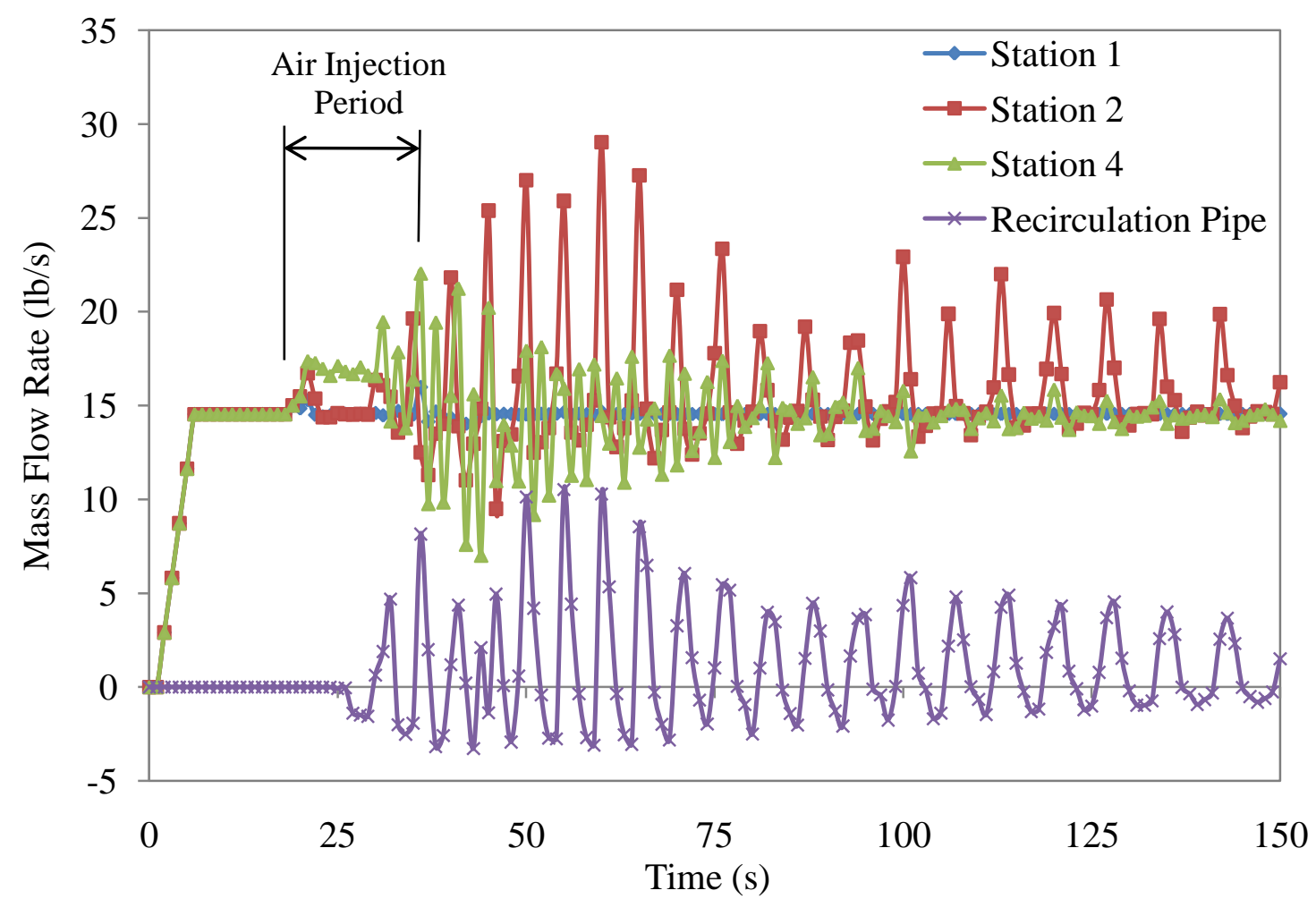

Figure 3.17. Mass flow rate behavior for simulation scenario one: $4 \times 4 \times 3$-inch, $F r=0.81$.

The oscillating behavior seen at stations two, four and the recirculation pipe is mainly due to the check valve open/close operation. Station's two mass flow rate oscillates between 12 and $30 \mathrm{lb} / \mathrm{s}$ during the first 65 seconds of the simulation time, but only after air was injected. The wide oscillating range at station two is a result of air being recirculated upwards through the VRP, which is discharged into the upper tee and ultimately transported into station two. The mass flow rate fluctuation decreases as time increases and the frequency of the oscillation decreases as well. This behavior is due to a lower quantity of air being recirculated through the VRP since a fraction of the recirculated air has been transferred to station four, where it ultimately exits the VRS by 
going back to the tank. In contrast, station four shows a lower oscillating mass flow rate range ( 7 to $22 \mathrm{lb} / \mathrm{s}$ ) with respect to station two since there is a much lower quantity of air being transported in this pipe section. This explanation will become more apparent during the next section, where void fraction behavior is discussed.

The oscillating behavior in the recirculation pipe, which is a pipe volume located immediately before the check valve, can be better explained in Figure 3.18. This figure shows a comparison between the mass flow rate and void fraction at the VRP. The mass flow rate, depicted in the solid line, can be read from the primary vertical axis on the left. The void fraction, depicted in the dashed line, can be read from the secondary vertical axis to the right.

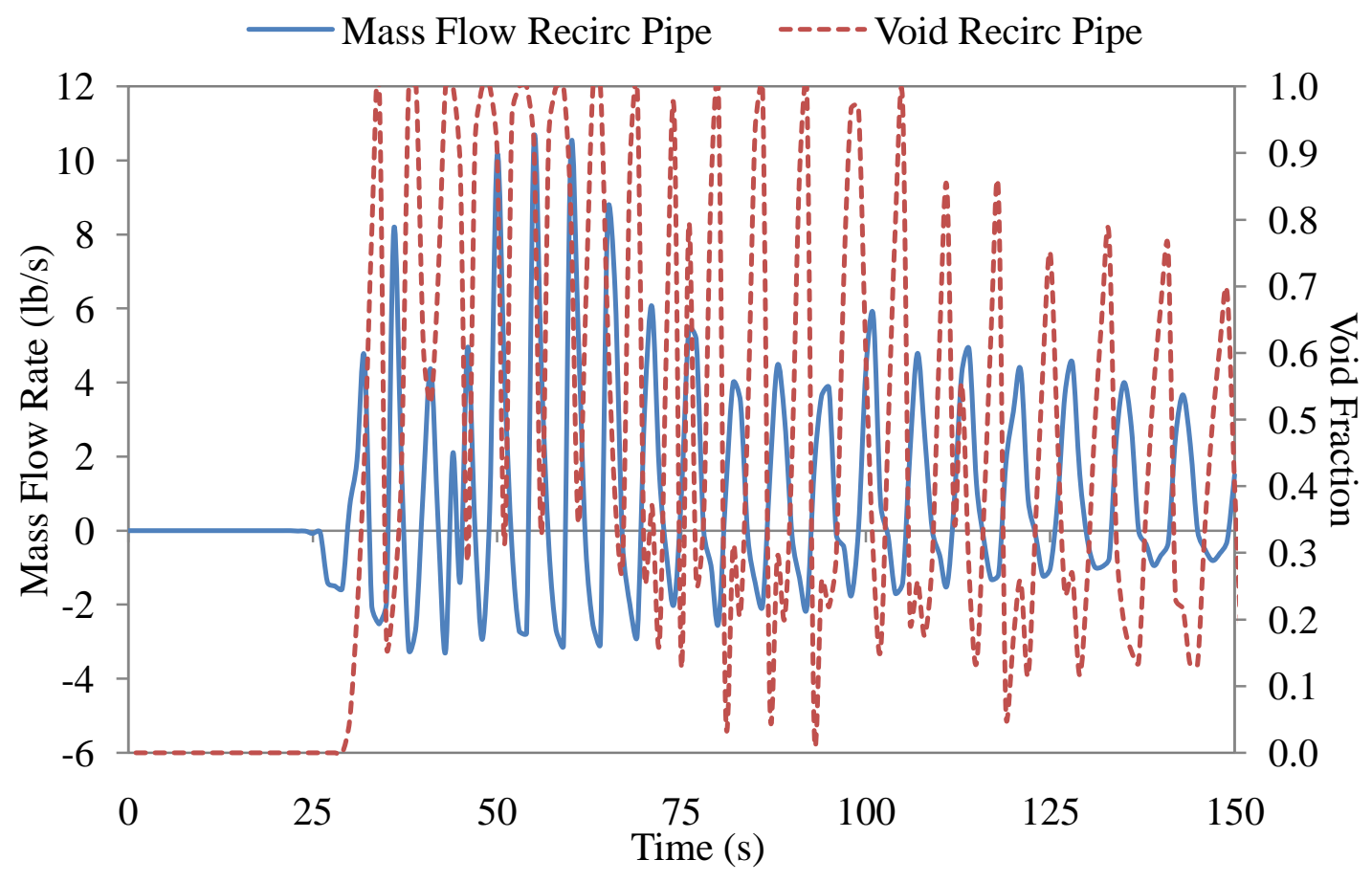

Figure 3.18. Mass flow rate and void fraction behavior at the recirculation pipe, for simulation scenario one: $4 \times 4 \times 3$-inch, $F r=0.81$. 
The mass flow rate varies between -3 and $10 \mathrm{lb} / \mathrm{s}$, where the oscillating behavior decreases as time increases. The void fraction ranges between 0.3 and 1.0 for approximately 75 seconds after air has been injected and later decreases towards the end of the simulation. Note that the decreasing behavior occurs in both mass flow rate and void fraction parameters as time increases, implying that the quantity of air recirculating through the VRP is constantly decreasing due to a portion of air being transported to station four. This behavior was also observed during the experiment as was described in Section 3.1.2.5 for Froude numbers up to 1.3. Mass flow rate maximum peaks occur when the majority of the air has passed through the check valve, resulting in a minimum void fraction peak. On the other hand, mass flow rate minimum peaks occur when the air accumulates before the check valve opens. Furthermore, the negative mass flow rate peaks are an indication that the water is being forced down, by allowing the accumulation of air until enough pressure is built to open the check valve. The simulation flow regimes for the VRP indicate a variation between slug and annular mist. The numerical results for scenarios four and eight, which had the highest Froude number simulated of 1.6, indicated that recirculation ceased towards the end of the simulation by showing zero mass flow rate and a void fraction of unity for the VRP. This settling behavior can be seen in Figure 3.19, which is a plot comparison between the mass flow rate and void fraction of the VRP with respect to time, for simulation scenario eight $(6 \times 6 \times 4$-inch, $F r=$ 1.60). This behavior makes sense since at higher Froude numbers inertia forces are high enough to transport the air bubbles past the lower tee and into station four, thus leading to a lower net amount of air being recirculated through the VRP. Section 3.1.2.5 describes a similar behavior encountered during the experiment for a Froude number of 1.6. 
Specifically, Figure 3.14 resembles the same exact air settling behavior towards the end of the experiment trial.

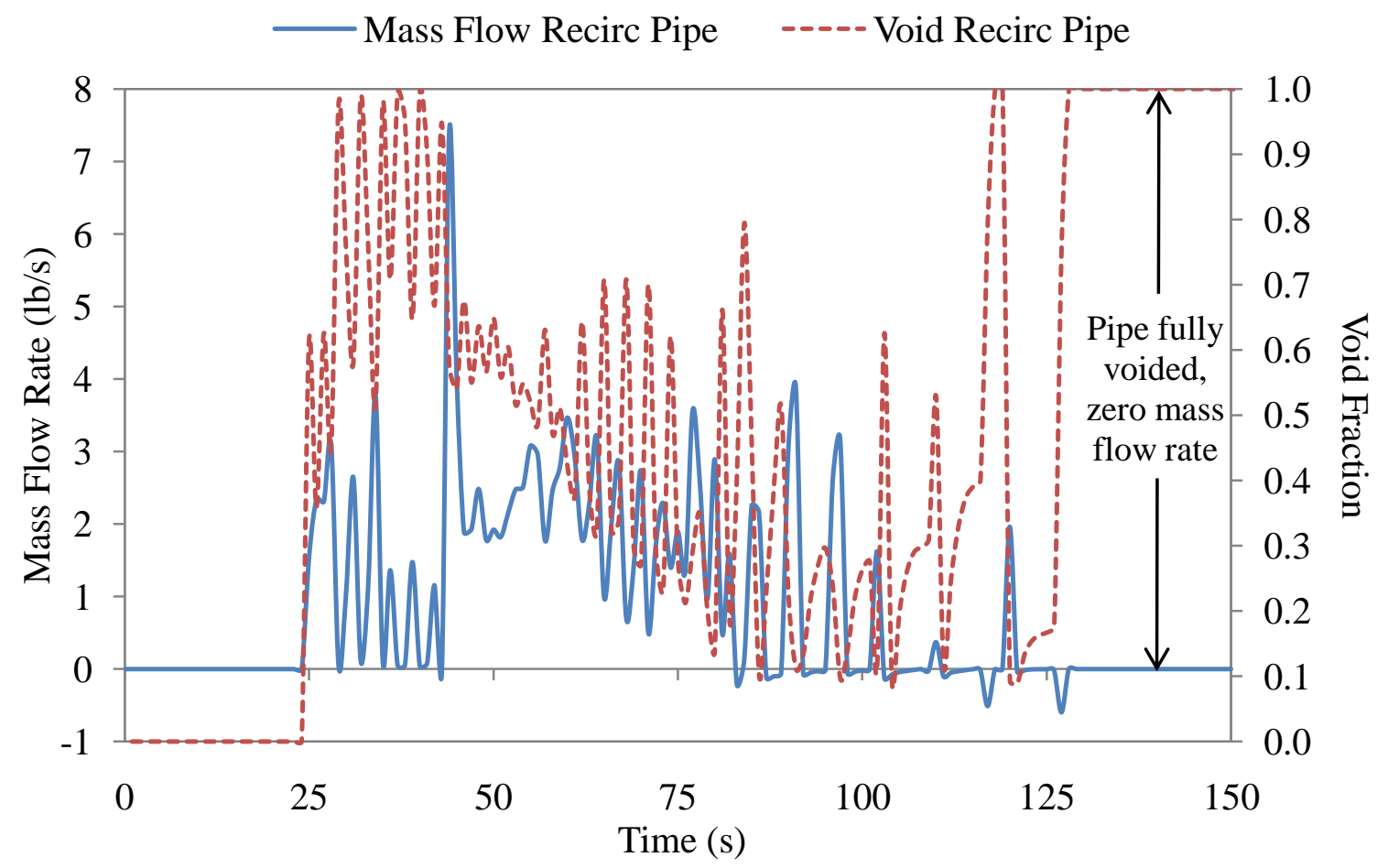

Figure 3.19. Mass flow rate and void fraction behavior at the recirculation pipe, for simulation scenario eight: $6 \times 6 \times 4-i n c h, F r=1.60$.

The oscillating mass flow rate behavior seen in simulation scenario one was common for all eight scenarios, and the results are summarized in Appendix D.1. Mass Flow Rate Results An important difference between the pipe configurations $4 \times 4 \times 3$-inch and 6x6x4-inch is discussed below. The simulation flow regime for stations one, two and four (for all scenarios) were horizontally-stratified flow for the majority of the simulation time. Bubbly flow was reached when the majority of the air had exited the system, usually at high Froude numbers of 1.3 and 1.6. 
One important difference seen in scenarios four $(4 \times 4 \times 3$-inch, $F r=1.60)$ through eight (6x6x4-inch, $0.81 \leq F r \leq 1.60)$, in addition of the oscillating behavior, was the fact that there was a steadier amount of air passing through the recirculation pipe. This effect can be clearly seen in Figure 3.20, where the mass flow rate for stations one, two, four and the recirculation pipe are plotted versus time. The steady behavior was a consequence of the check valve being continuously open for a period of time, which occurred approximately between 35 and 85 seconds for this scenario in particular. By steady, it is meant that the oscillating behavior did not occur as drastic as was the case for scenario one. Stations two and four were also affected by this constant source of air coming from the VRP, but continued to oscillate after 85 seconds, once lower amounts of air were captured in the VRP. 


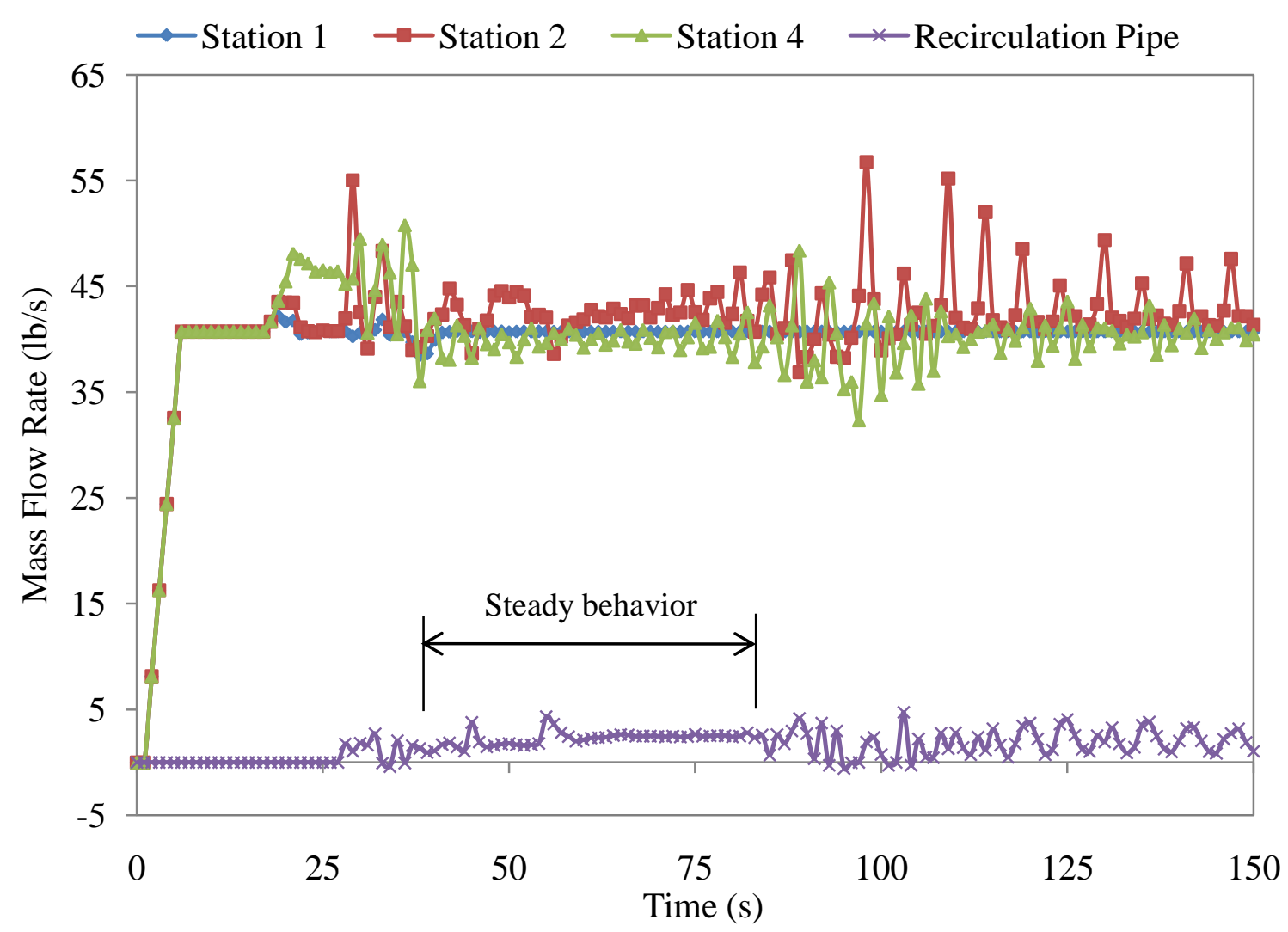

Figure 3.20. Mass flow rate behavior for simulation scenario five: $6 x 6 x 4$-inch, $F r=0.81$.

More important than the check valve operation, the steady behavior in the VRP for scenario four $(4 \times 4 \times 3$-inch, $F r=1.60)$ was probably caused by a higher Froude number, which ultimately allows the air to travel faster throughout the system, thus feeding a more constant amount of air from station three to the VRP. The mass flow rate through the VRP in simulation scenarios six $(6 \times 6 \times 4$-inch, $F r=1.10)$ and seven $(6 \times 6 \times 4$-inch, $F r=$ 1.38) presented a steady behavior for a longer period of time with respect to scenarios five $(6 \times 6 \times 4$-inch, $F r=0.81)$ and eight $(6 \times 6 \times 4$-inch, $F r=1.60)$. It is possible that the Froude numbers represented in simulation scenarios six and seven are in near-perfect combination with respect to the existing amount of air to not allow many discontinuities 
at the lower tee, resulting in a steadier upwards air flow. The fact that scenarios five through eight had a steady mass flow rate behavior through the VRP, which can be depicted in Figure D.5 through Figure D.8, was probably due to a higher cross-sectional amount of air in the six-inch pipe, when compared to the four-inch pipe. For example, a ten percent void fraction value in the four and six-inch pipes correspond to gas crosssectional areas of $1.276 \mathrm{in}^{2}$ and $2.893 \mathrm{in}^{2}$, respectively. Higher gas cross-sectional areas infer that higher amounts of air are being carried throughout the system, which in turn can prevent bubble discontinuities by allowing the air to have more surface area. This hypothesis could be the explanation for why the mass flow rate, and thus the void fraction did not oscillate as drastically as was the case for scenarios one through three, and it is strongly recommended to do a more in depth analysis of this behavior. Perhaps an analysis of the Weber number influence in horizontal flows could be performed since this parameter compares the inertial to surface tension forces.

In short, the VRS numerical results obtained from the simulation for mass flow rate, VRP void fraction and flow regime behavior seem to represent the physical behavior observed during the experiment (Section 3.1.2.), thus supporting the functionality of the VRS model.

\subsubsection{Void Fraction Analysis}

The void fraction analysis will focus on stations two, three and four, which are part of the main piping system. The purpose of analyzing the void fraction at these sections is to show the air removal effectiveness between stations three and four, and to 
prove that the VRS model in RELAP5 works properly with respect to the experimental observations provided in Section 3.1.2.4. In addition, the void fraction in the pipe volume after the lower elbow will be briefly discussed. The purpose of analyzing the void fraction in this section is to show the backward and forward motion of the air bubble with respect to the experimental observations provided in Section 3.1.2.3.

\subsubsection{Main Pipe Void Fraction}

The void fraction behavior, for simulation scenario one $(4 \times 4 \times 3$-inch, $F r=0.81)$, at stations two, three and four can be depicted in Figure 3.21. In this graph, the oscillating behavior is present, as was the case for the mass flow rate behavior discussed in the previous section. This particular behavior was also due to the check valve open/close operation, which eventually affects the entire VRS model. The air injection procedure can be clearly reflected in station two at 20 seconds, where a steady line can be seen for approximately 10 seconds until the void fraction starts to oscillate. 


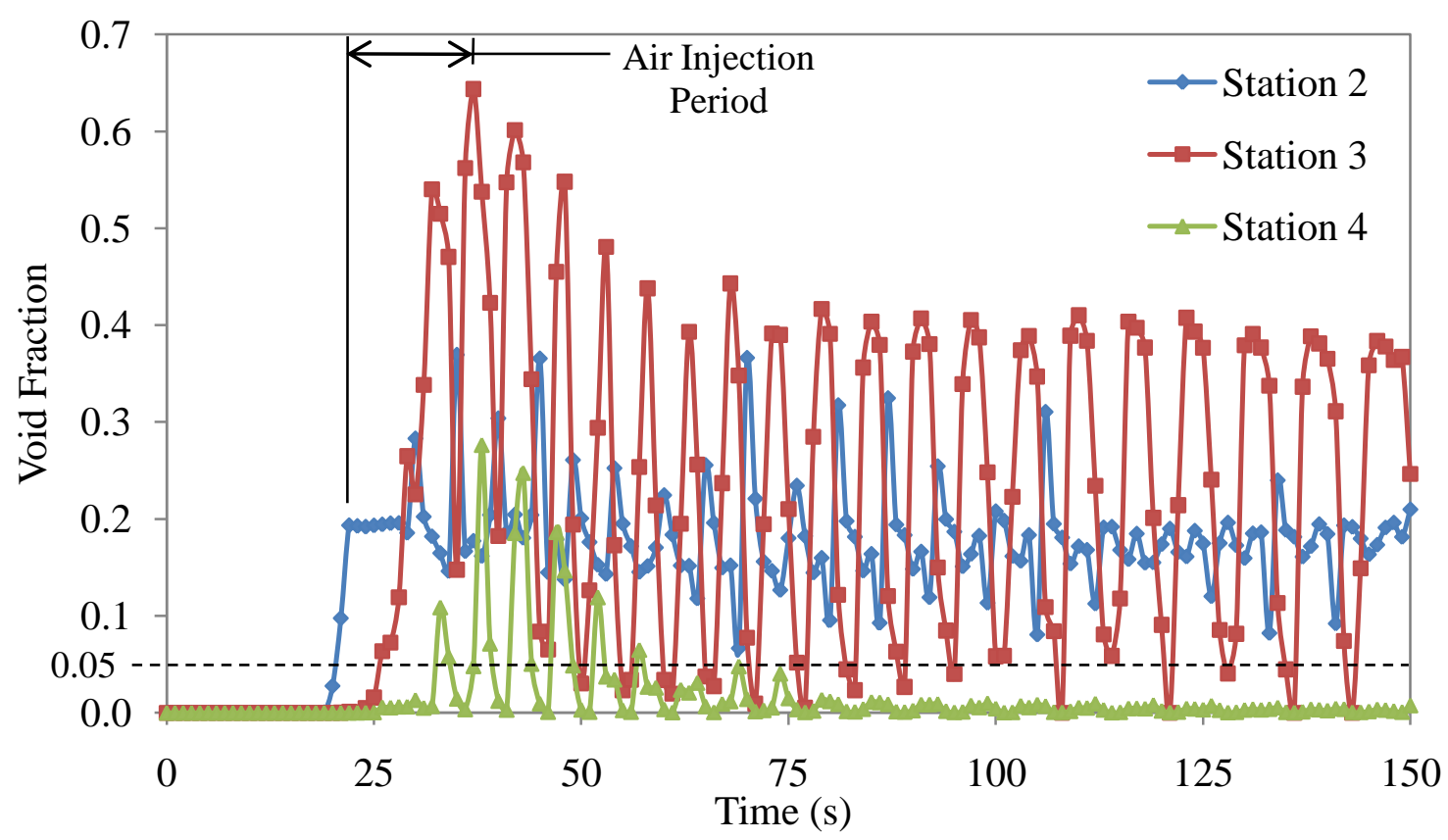

Figure 3.21. Void fraction behavior for simulation scenario one: $4 \times 4 \times 3$-inch, $F r=0.81$.

As time advances, the void fraction at station two approaches an approximate value of 0.2 , indicating that air is constantly being fed from the VRP and thus, recirculation happens indefinitely. This behavior was also common for stations three and four, with the exception that station three shows a greater oscillation, which is possibly due to the discontinuities present at the lower elbow and lower tee. A void fraction peak value of approximately 0.6 was the result of injecting air for a period of 15 seconds. Then, the void fraction started to decrease following an oscillatory motion until recirculation occurred (approximately after 75 seconds). At this time, the void fraction ranged between the extreme values of 0.05 and 0.4 . More importantly, the maximum void fraction in station four occurred at approximately 0.3 , but rapidly decreased to values less than 0.05 , which is the maximum allowable void fraction accepted by the industry for 
pipes less than 12 inches. The peaking behavior at station four was normal because of the high initial amount of air coming from station three. The pipe configurations $4 \times 4 \times 3-$ inch and 6x6x4-inch have a limited capacity to take large amounts of air, which explains this initial peaking behavior. Nonetheless, the majority of the air at station three, which is the most critical location in the VRS, was removed and recirculated throughout the system. The void fraction seen at station four is the amount of air that was not recirculated through the VRP, which ultimately returns to the tank. Table 3.5 shows the numerical results for the average percent air removed between stations three and four, for all simulation scenarios. The average amount of air for each station was measured as void fraction, and the average percent air removed for all scenarios was greater than $88 \%$, which is a highly effective air removal value. The values were averaged for the period of time until station four contained less than one percent void fraction. The percent air removed was calculated using the following expression:

$$
\text { Percent Air Removed }=1-\frac{\text { Void Fraction at Station } 4}{\text { Void Fraction at Station } 3}
$$


Table 3.5. Numerical results for the average percent air removed between stations three and four.

\begin{tabular}{|c|c|c|c|c|c|}
\hline Scenario & $\begin{array}{c}\text { Pipe } \\
\text { Configuration (in) }\end{array}$ & $F r$ & $\begin{array}{c}\text { Void Fraction } \\
\text { Station 3 }\end{array}$ & $\begin{array}{c}\text { Void Fraction } \\
\text { Station 4 }\end{array}$ & $\begin{array}{c}\text { Percent Air } \\
\text { Removed }\end{array}$ \\
\hline 1 & $4 \times 4 \times 3$ & 0.81 & 0.266 & 0.0318 & $88.0 \%$ \\
\hline 2 & $4 \times 4 \times 3$ & 0.96 & 0.237 & 0.0250 & $89.4 \%$ \\
\hline 3 & $4 \times 4 \times 3$ & 1.29 & 0.273 & 0.0467 & $82.9 \%$ \\
\hline 4 & $4 \times 4 \times 3$ & 1.60 & 0.292 & 0.0309 & $89.4 \%$ \\
\hline 5 & $6 \times 6 \times 4$ & 0.81 & 0.422 & 0.0221 & $94.8 \%$ \\
\hline 6 & $6 \times 6 \times 4$ & 1.10 & 0.350 & 0.0202 & $94.2 \%$ \\
\hline 7 & $6 \times 6 \times 4$ & 1.38 & 0.309 & 0.0278 & $91.0 \%$ \\
\hline 8 & $6 \times 6 \times 4$ & 1.60 & 0.218 & 0.0260 & $88.1 \%$ \\
\hline
\end{tabular}

The main reason why air recirculates indefinitely through the VRP is because of the relatively low Froude numbers with respect to the existing amount of air in the system. At low Froude numbers, air and water travel slower, which creates flow discontinuities between the lower elbow and lower tee. Figure 3.22 shows a comparison between the slip ratio and void fraction for simulation scenario one $(4 \times 4 \times 3$-inch, $F r=$ 0.81), at stations three and four. The purpose of showing this graph is to present the contrast of flow behavior between stations three and four. Solid lines are used to measure the slip ratio seen on the primary vertical axis to the left; and dashed lines are used to measure the void fraction on the secondary vertical axis to the right. Positive and negative slip ratios suggest that the flow is co-current and countercurrent, respectively. At the beginning of the simulation, and up to 75 seconds, the slip ratio at station three drastically varies between approximately -0.5 and 1.25 . However, the slip ratio decreases towards an average value of zero at the end of the simulation time, as the void fraction continues to vary indefinitely between 0.05 and 0.4 . 


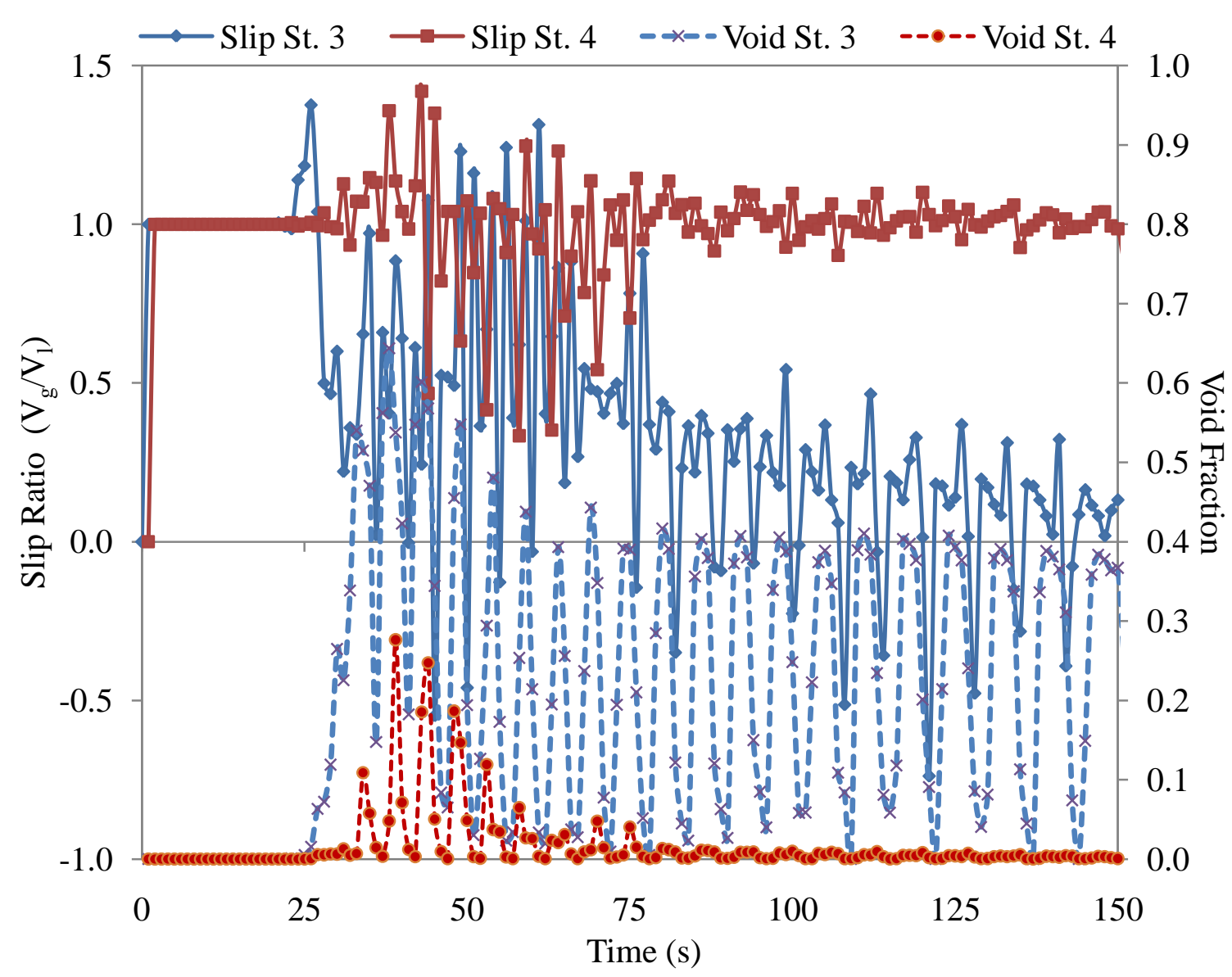

Figure 3.22. Slip ratio and void fraction behavior at stations three and four, for simulation scenario one: $4 \times 4 \times 3$-inch, $F r=0.81$.

Note that slip ratio continues to oscillate between positive and negative values even towards the end of the simulation. This behavior suggests that air bubbles are being continuously recirculated through the VRS, but more importantly, shows the forward and backward motion of the air bubbles. Maximum slip ratio and void fraction values occur at the same time, meaning that the largest possible amounts of air continue the main path flow direction (co-current); and vice versa for minimum values in that the lowest amounts of air travel against the direction of the main path flow (countercurrent). 
Conversely, station four shows that the slip ratio varies with lower magnitudes, with no negative values, and ultimately approaches unity towards the end of the simulation. This particular behavior suggests that air bubbles are continuously flowing co-currently despite the amount of air.

The void fraction, as well as the slip ratio behavior seen in simulation scenario one was common for all eight scenarios, and the results are summarized in Appendix D.2. Void Fraction Results The simulation flow regime at station three (for all scenarios) varied between horizontally stratified and bubbly flow. Even though not immediately apparent, the continuous combination between these two regimes is a product of slug flow, and matches the experimental flow regime observation previously described in Section 3.1.2.4. However, it is important to mention that the extreme void fraction oscillating behavior for simulation scenarios five through seven nearly disappeared between 35 and approximately 75 seconds of the simulation. This particular behavior, nearly disappearing oscillation, can be seen in Figure D.13 through Figure D.15, which was caused by a steadier mass flow rate through the VRP as explained in Section 3.4.1. A steady two-component mass flow rate implies a steady amount of air and water flow rates, which ultimately results in a steady void fraction. Because the check valve in the VRP remains open during this time, then a steady amount of void fraction is reflected in stations two and three. Station four is also affected by a steady void fraction behavior meaning that a constant amount of air is passing through without being recirculated and ultimately exits the VRS by returning to the tank. Though, it is important to note that the magnitudes are much lower when compared to stations two and three. 
One important distinction seen in simulation scenarios four and eight, which correspond to a Froude number of 1.6, is that air recirculation ceases towards the end of the simulation, as was described in the mass flow rate behavior. Figure 3.23 shows this particular behavior for simulation scenario eight $(6 \times 6 \times 4$-inch, $F r=1.6)$. The main reason why air recirculation ceases is probably caused by a higher Froude number that ultimately allows the air to exit the VRS at a higher rate through station four, and as a consequence travels back to the tank. At high Froude numbers, there is less time for the air, coming from station three, to rise through the vertical VRP. In other words, the air bubble at high Froude numbers is traveling so fast through station three that it basically ignores the effect of the upwards oriented lower tee, which is supposed to remove the air by recirculating it throughout the system. From this reasoning, it is recommended to avoid high Froude numbers to prevent large and continuous air bubbles from entering station four, assuming the same VRS configuration is used in practice. It is possible that other VRS configurations might have a more efficient method in recirculating the air at high Froude numbers, and it is strongly suggested to perform further analysis by trying different pipe diameters and/or other parts that do not require moving parts, such as the check valve. 


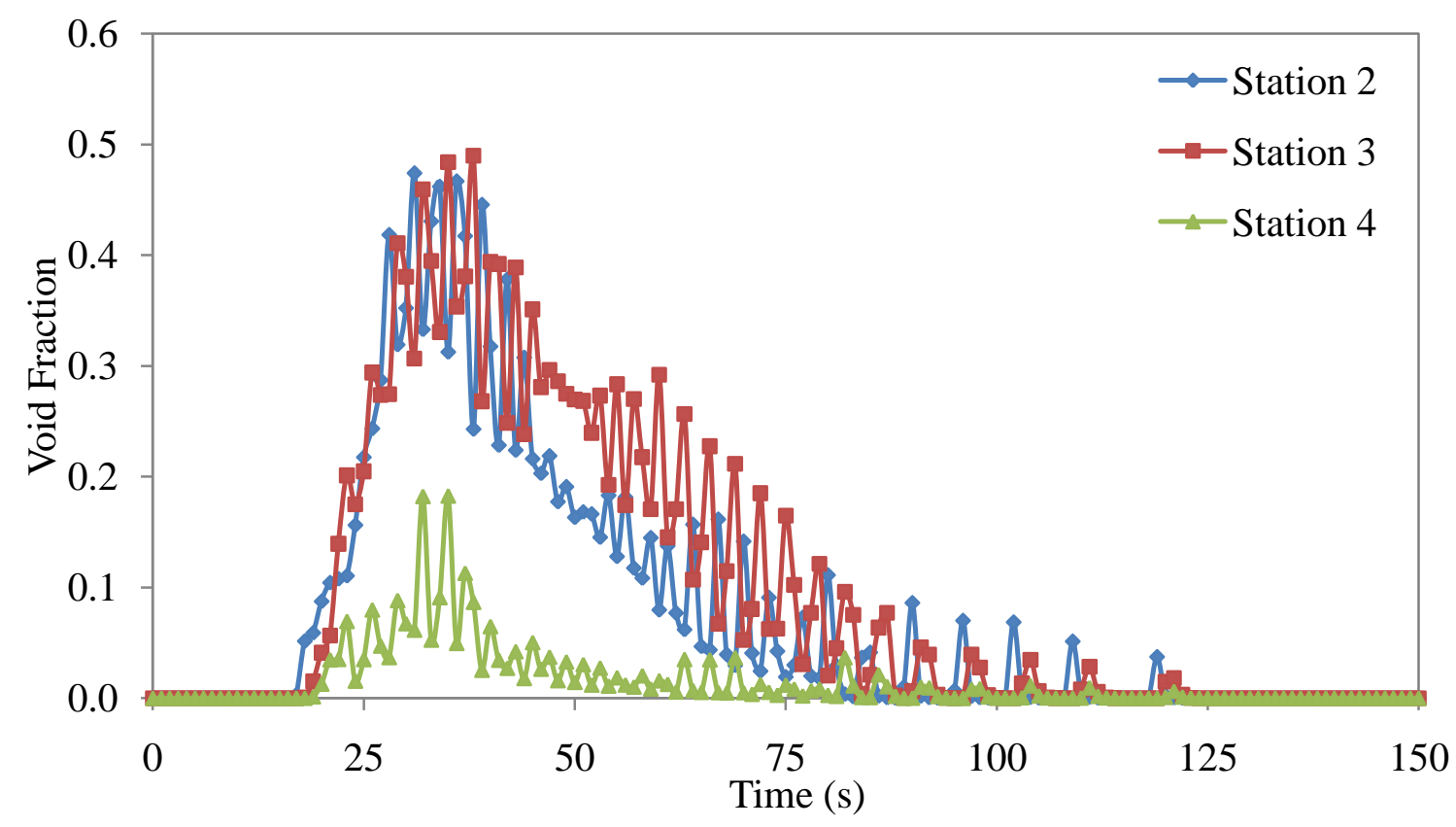

Figure 3.23. Void fraction behavior for simulation scenario eight: $6 \times 6 \times 4$-inch, $F r=1.60$.

In short, the VRS numerical results obtained from the simulation for void fraction and slip ratio seem to represent the physical behavior observed during the experiment (Section 3.1.2.), thus supporting the functionality of the VRS model. In addition, it demonstrates the effectiveness of the lower tee configuration in recirculating large amounts of air coming from station three.

\subsubsection{Lower Elbow Void Fraction}

The slip ratio and void fraction behavior at a pipe section after the lower elbow, for simulation scenarios one and eight, are depicted in Figure 3.24 and Figure 3.25, respectively. Pipe components 320-23 and 420-18 refer to the pipe section after the 
lower elbow for pipe configurations $4 \times 4 \times 3$-inch and $6 \times 6 \times 4$-inch, respectively. Solid and dashed lines are used to measure slip ratio and void fraction, respectively.

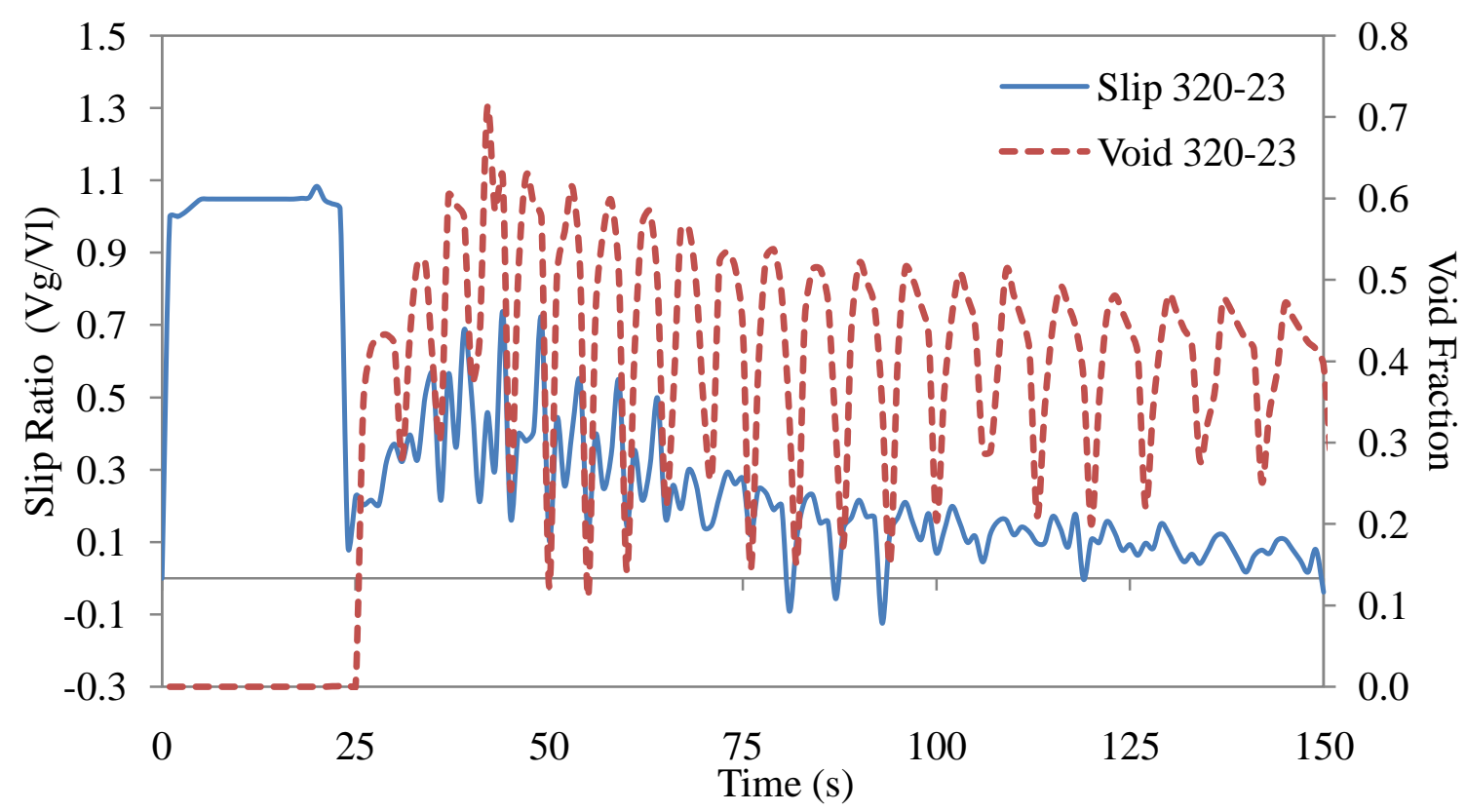

Figure 3.24. Slip ratio and void fraction behavior at pipe section after lower elbow, for simulation scenario one: $4 \times 4 \times 3$-inch, $F r=0.81$.

Figure 3.24 shows a similar behavior as Figure 3.22 in that the slip ratio approaches zero in an oscillatory motion towards the end of the simulation, while the void fraction continues to oscillate between the approximate values of 0.2 and 0.5 . This behavior, while in part triggered by the check valve open/close operation, could also be due to the relatively low Froude numbers since there is not enough flow to carry the air in a continuous manner. In addition, the change in direction at the lower elbow contributes to the formation of large voids due to a localized lower pressure. This in turn, creates a discontinuity in the flow causing a slug flow behavior. According to the numerical results, the simulated Froude numbers of $0.80,1.0$ and 1.3, indicated that the slip ratio 
and void fraction behaved similarly. In contrast, only the highest simulated Froude number of 1.6, for scenarios four and eight, indicated that air recirculation ceased towards the end of the simulation as seen in Figure 3.25. This particular behavior indicates that the majority of the air has exited the VRS through station four and has returned to the tank. These two graphs are in good agreement with the observations done in the experiment and are intended to support the bubble behavior seen at station three for all simulation scenarios.

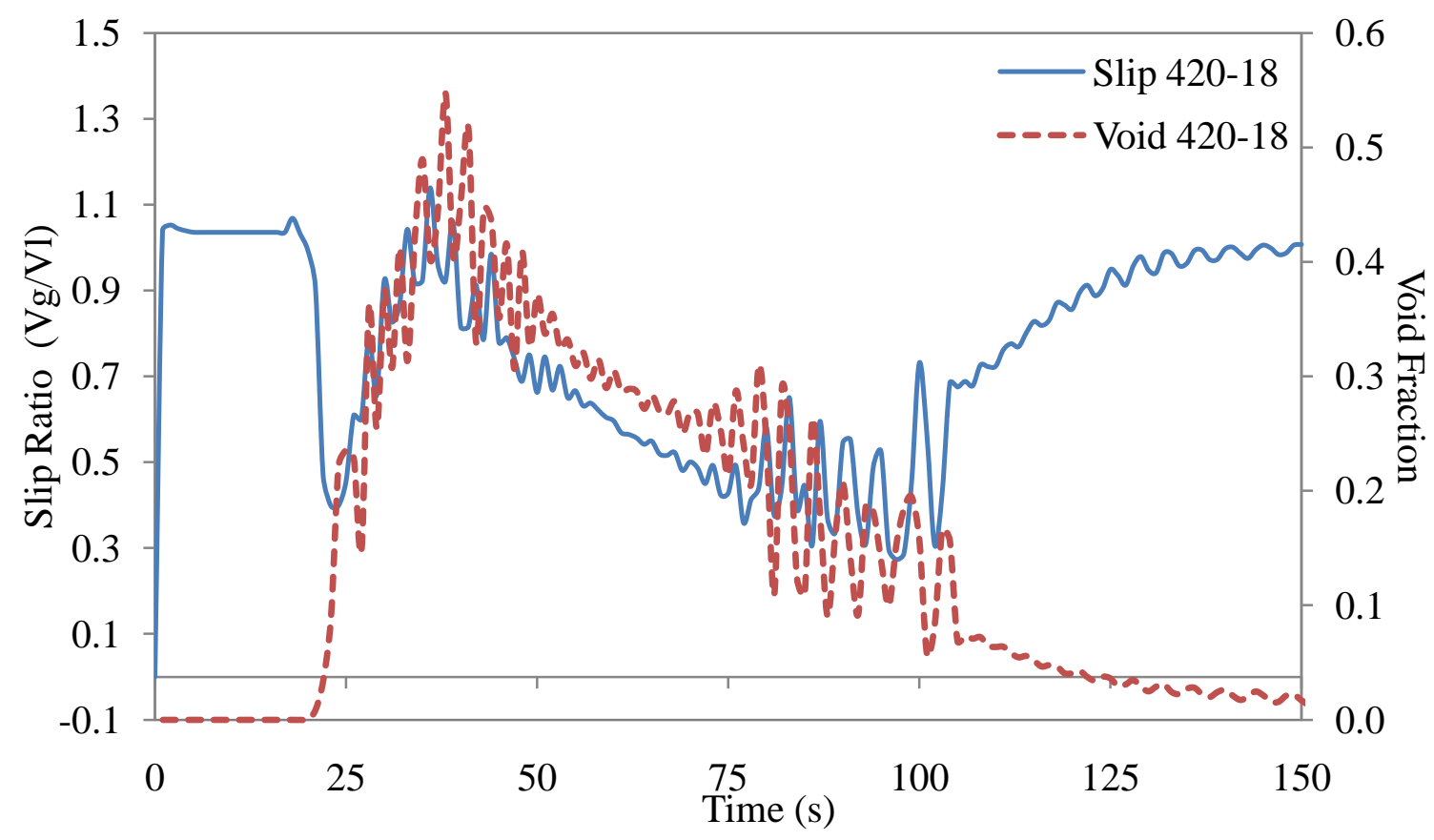

Figure 3.25. Slip ratio and void fraction behavior at pipe section after lower elbow, for simulation scenario eight: $6 \times 6 \times 4$-inch, $F r=1.6$. 


\subsubsection{Simulation and Experimental Void Fraction Validation}

Now that the VRS model has been verified with respect to experimental observations and plausible explanations for the different flow behaviors seen in the pipe sections of interest, the validation between simulation and experimental void fraction results can be analyzed. More specifically, time-averaged void fraction values will be compared in order to validate the VRS model built in RELAP5. Since the void fraction experimental results were averaged for a period of approximately 120 seconds for each scenario, which represents the time at which station four reached a void fraction less than one percent, then it makes sense to average the void fraction numerical results for the period of time that satisfies the void fraction condition at station four. Figure 3.26 shows the void fraction validation between experimental and numerical (model) results, at stations one through four, for simulation scenario one $(4 \times 4 \times 3$-inch, $F r=0.81)$. 


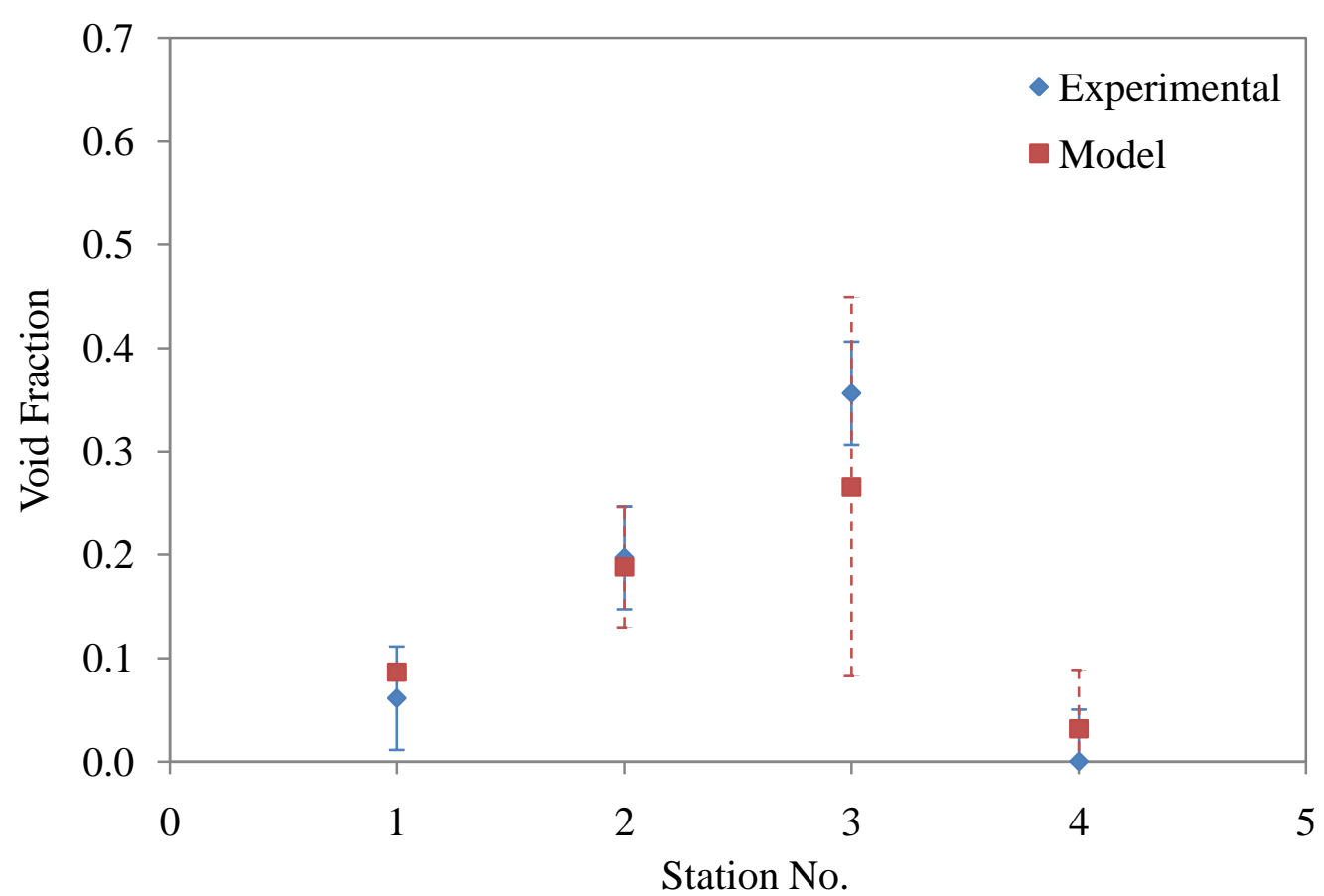

Figure 3.26. Void fraction validation of the VRS model for simulation scenario one: $4 \times 4 \times 3$-inch, $F r=0.81$.

The bars shown in this graph actually represent uncertainty ranges, rather than error bars, since insufficient experimental data was available for a thorough statistical analysis. Solid and dashed bars represent experimental and model uncertainty ranges, respectively. The experimental uncertainty associated with the void fraction at each station was approximately \pm 0.5 inches, since this value was much larger than the other parameters (length and pipe diameter uncertainty) used for general uncertainty propagation. This specific value was determined by visually inspecting the length variation (in inches) of the void fraction. Figure 3.27 shows a schematic of a pipe partially filled with water, along with the variables used to calculate the void fraction. The air phase is occupying the top portion of the inner pipe diameter, while the water phase is occupying the bottom 
portion. The variables $y, r$ and $\theta$ measure the air level from the top of the pipe, pipe radius and water contact angle, respectively.

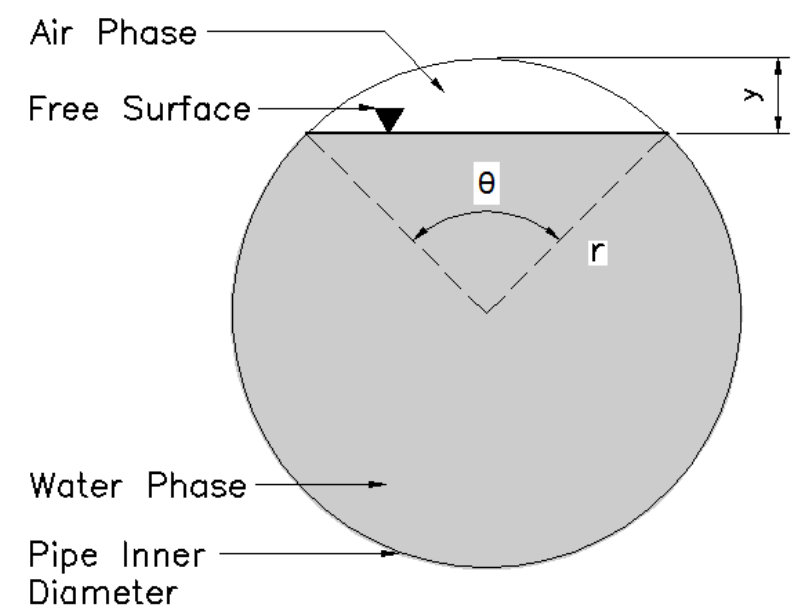

Figure 3.27. Schematic of a pipe partially filled with water.

The cross-sectional area occupied by the air phase can be calculated using the following expression:

$$
A_{g}=\frac{D^{2}}{8}[\theta-\sin \theta]
$$

where $D$ is twice the radius $r$. The water contact angle, $\theta$, can be obtained geometrically using:

$$
\theta=2 \cos ^{-1}\left(1-\frac{2 y}{D}\right)
$$

The void fraction is finally calculated using equation 2.3 . The uncertainty of \pm 0.5 inches previously mentioned was translated into void fraction by observing the total variation in $y$ and then using equations $2.3,3.2$ and 3.3. This uncertainty range corresponds to $\pm 7.2 \%$ 
and $\pm 3.9 \%$ void fration for four inch and six inch pipe diameters, respectively. As a result, all void fractions calculated for the four inch pipe had greater uncertainty values.

For this particular scenario validation, the numerical results over predicted the experimental results at stations one and four, and under predicted the experimental results at stations two and three. Nonetheless, the uncertainty ranges of both experimental and model results at each station overlap with each other, meaning that any of the values could fall in this range at any particular time. Uncertainty overlapping not only proves that the model resembles realistic behavior, but also validates the VRS model built in RELAP5.

In regards to the remaining simulation scenarios, the void fraction validation was achieved for the majority of Froude numbers and stations of interest. A summary of the validation plots can be seen in Appendix E - VRS Simulation and Experimental Void Fraction Validation for further reference. However, it is important to note that the validation at station three, which is of highest significance, was not achieved in the following three scenarios: four, seven and eight. It is believed that the apparent underprediction of the numerical results for these scenarios was not the cause for a nonnumerical validation. On the contrary, it is believed the all void fraction values obtained from the experiment were too conservative and thus over-predicted the actual value. 


\section{Chapter 4. CONCLUSIONS AND RECOMMENDATIONS}

\subsection{Conclusions}

In conclusion, the objectives of this thesis were accomplished by (1) simulating a Void Recirculation System model using RELAP5 and investigating the behavior of twocomponent flow by means of analyzing mass flow rates, void fraction and slip ratios; and (2) successfully validating its results with respect to experimental results and observations.

The Void Recirculation System model, simulated in RELAP5, was successfully validated against experimental results using the void fraction parameter. A total of eight simulation scenarios were analyzed using two different pipe configurations $(4 \times 4 \times 3$-inch and 6x6x4-inch), and four Froude numbers $(0.80,1.0,1.3$ and 1.6). The void fraction numerical results obtained from RELAP5 were in good agreement with experimental results and represent the physical behavior seen during the Void Recirculation System experiment.

The numerical results confirmed that air recirculation is more effective at Froude numbers of $0.80,1.0$ and 1.3, which resemble experimental observations. At these Froude numbers, recirculation occurs indefinitely, or for a long period of time, since air does not travel fast enough to exit the Void Recirculation System. Conversely, the numerical results showed that air recirculation occurs for a short period of time, and ceases towards the end of the simulation at the highest Froude number simulated of 1.6. For this reason, high Froude numbers, and thus high flow rates, should be avoided if air is to be recirculated more effectively. The void fraction and mass flow rate oscillating 
motion observed in the numerical results were associated with both the check valve open/close operation, as well as with the flow discontinuities produced by the lower elbow and lower tee.

The air reduction effectiveness due to the use of the $4 \times 4 \times 3$-inch and $6 \times 6 \times 4$-inch pipe configurations was approximately $90 \%$ for all simulation scenarios. Even though this Void Recirculation System model was analyzed on the discharge side of the pump, it can be potentially used as a computational tool to solve the problem of large voids in suction piping at nuclear power plants, or wherever this problem is encountered.

\subsection{Recommendations}

In the attempt of validating the Void Recirculation System model, the lack of accurate experimental results along with a poor statistical analysis did not contribute in a more detailed explanation of the numerical results. For this, it is recommended to design a better experiment with higher precision instruments that entail all parameters of interest. Furthermore, the experiment should be performed under suction conditions to fully grasp the air behavior due to the Void Recirculation System.

The question of scalability for two-component flow in a Void Recirculation System was raised when the pipe configurations $4 \times 4 \times 3$-inch and $6 \times 6 \times 4$-inch were compared. Even though simulation initial conditions were the same for both pipe configurations, including the same initial void fraction, the air had a tendency to behave differently. A study of the Weber number influence for wavy horizontally stratified flow 
at elbows and tees is recommended to better understand the scalability of the Void Recirculation System for different pipe diameters.

Finally, the modeling of other pipe configurations (using the VRS model) that recirculate air is strongly suggested, since it could help to decide what diameters are appropriate for each application. In addition, it is recommended to model other VRS ideas that could improve air recirculation by not having to use moving parts, such as a check valve. These recommended computational efforts can expand the validity of the VRS model, lower experiment expenses and could help identify if the VRS solution is suitable for a particular application. 


\section{Bibliography}

Baker, G., Clark, W. W., Azzopardi, B. J., \& Wilson, J. A. (2008). Transient effects in gasliquid phase separation at a pair of T-junctions. Chemical Engineering Science , 63, 968976.

Celik, I. B., Ghia, U., Roache, P. J., \& Freitas, C. J. (2008). Procedure for Estimation and Reporting of Uncertainty Due to Discretization in CFD Applications. Journal of Fluids Engineering , 1-15.

Chisholm, D. (1968). Prediction of pressure losses at changes of section, bends and throttling devices. NEL Report No 388. Glasgow: National Engineering Laboratory.

Chisholm, D. (1983). Two-Phase flow in pipelines and heat exchangers. New York: Longman Inc.

Crane Corporation. (1988). Flow of Fluids through Valves, Fittings, and Pipe. Stamford: Crane Corporation.

Daza, O. E., Fong, M. J., Rosas, R., \& Wong, B. S. (2009). Void Recirculation system. San Luis Obispo: Cal Poly State University.

de Sampaio, P. A., Faccini, J. L., \& Su, J. (2008). Modeling of stratified gas-liquid two-phase flow in horizontal circular pipes. International Journal of Heat and Mass Transfer , 51, 2752-2761.

Diablo Canyon Power Plant, PG\&E. (2009, January 24). Void Recirculation Device. Avila Beach, CA.

Flow Regime Sample Movies. (n.d.). Retrieved April 19, 2011, from http://ctcr4.chem.uva.nl/SingleCapillary/sample_videos_flow_regime.html

Fox, R. W., McDonald, A. T., \& Pritchard, P. J. (2006). Introduction to Fluid Mechanics. John Wiley \& Sons, Inc.

Ghiaasiaan, S. M. (2008). Two-Phase Flow, Boiling, and Condensation in Conventional and Miniature Systems. New York: Cambridge University Press.

Groudev, P. P., \& Gencheva, R. V. (2004). Relap5/mod3.2 investigation of main loop isolating valves in case of SGTR in VVER440/V230. Annals of Nuclear Energy, 31, 1583-1613.

Institute of Nuclear Power Operations. (2010). How Engineering can Manage Gas Accumulation. Training Module 2 . United States of America: INPO.

Ishii, M. (1975). Thermo-Fluid Dynamic Theory of Two-Phase Flow. Paris: Eyrolles.

Ishii, M., \& Mishima, K. (1984). Two-Fluid model and hydrodynamic constitutive relations. Nuclear Engineering and Design , 82 (2-3), 107-126. 
Jain, S. C. (2001). Open-Channel Flow. New York, New York, USA: John Wiley \& Sons.

Kadri, U., Mudde, R. F., Oliemans, R., Bonizzi, M., \& Andreussi, P. (2009). Prediction of the transition from stratified to slug flow or roll-waves in gas-liquid horizontal pipes. International Journal of Multiphase Flow 35 , 1001-1010.

Kaliatka, A., \& Uspuras, E. (2008). Development and testing of RBMK-1500 model for BDBA analysis employing RELAP/SCDAPSIM code. Annals of Nuclear Energy, 35, 997-992.

Margaris, D. P. (2007). T-junction separation modelling in gas-liquid two-phase flow. Chemical Engineering and Processing , 46, 150-158.

Marshall, J. (2003). Two-Phase Flow. San Luis Obispo: Cal Poly State University.

Newton, C., \& Behnia, M. (2001). A numerical model of stratified wavy gas-liquid pipe flow. Chemical Engineering Science, 56, 6851-6861.

Nuclear Regulatory Commission. (2010). Resolution of Generic Safety Issues: Issue 193: BWR ECCS Suction Concerns Description (NUREG-0933, Main Report with Supplements 133). Washington: Nuclear Regulatory Commission.

Nuclear Regulatory Commission. (2006, September 21). U.S. NRC Information Notices. Retrieved from U.S. NRC: http://www.nrc.gov/reading-rm/doc-collections/gencomm/info-notices/2006/in200621.pdf

Ottens, M., Hoefsloot, H. C., \& Hamersma, P. J. (2001). Transient gas \}liquid \#ow in horizontal T-junctions. Chemical Engineering Science, 56, 43-55.

Phillips, B. E. (2003). RHR Water Hammer Simulation and Evaluation. San Luis Obispo: Cal Poly State University.

RELAP5/MOD3.2. (1995). Code Manual Volume I: Code Structure, System Models, and Solution Methods (Vol. I). Idaho Falls: NUREG/CR-5535.

RELAP5/MOD3.2. (1995). Code Manual Volume II: User's Guide and Input Requirements. Idaho Falls: NUREG/CR-5535.

Sarrette, C., \& Bestion, D. (2003). Study of release of nitrogen gas dissolved in water during depressurisation-application to primary circuit of PWR. Nuclear Engineering and Design , 224, 337-358.

Sidi-Ali, K., \& Gatignol, R. (2010). Interfacial friction factor determination using CFD simulations in a horizontal stratified two-phaseflow. Chemical Engineering Science , 65, 5160-5169.

Spears Manufacturing Company. (2010, February 1). PVC White Schedule 40 Fittings, Unions, $\&$ Saddles. Technical Information Weights \& Dimensions . Spears Manufacturing Company. 
Taitel, Y., \& Dukler, A. E. (1976). A theoretical approach to the Lockhart-Martinelli correlation for stratified flow. International Journal of Multiphase flow , 2, 591-595.

Wallis, G. B. (1969). One-Dimensional Two-Phase Flow. New York: McGraw-Hill, Inc.

Westinghouse Electric Company LLC. (2011). Investigation of Simplified Equation for Gas Transport. Cranberry Township: Westinghouse Electric Company LLC.

Westinghouse Electric Company, LLC. (2010). Technical Basis for Gas Transport to the Pump Suction. Cranberry Township: Westinghouse Electric Company, LLC.

Woods, B. D., \& Hanratty, T. J. (1999). Influence of Froude number on physical processes determining frequency of slugging in horizontal gas-liquid flows. International Journal of Multiphase Flow 25 , 1195-1223. 


\section{Appendix A - VRS Piping Drawings}

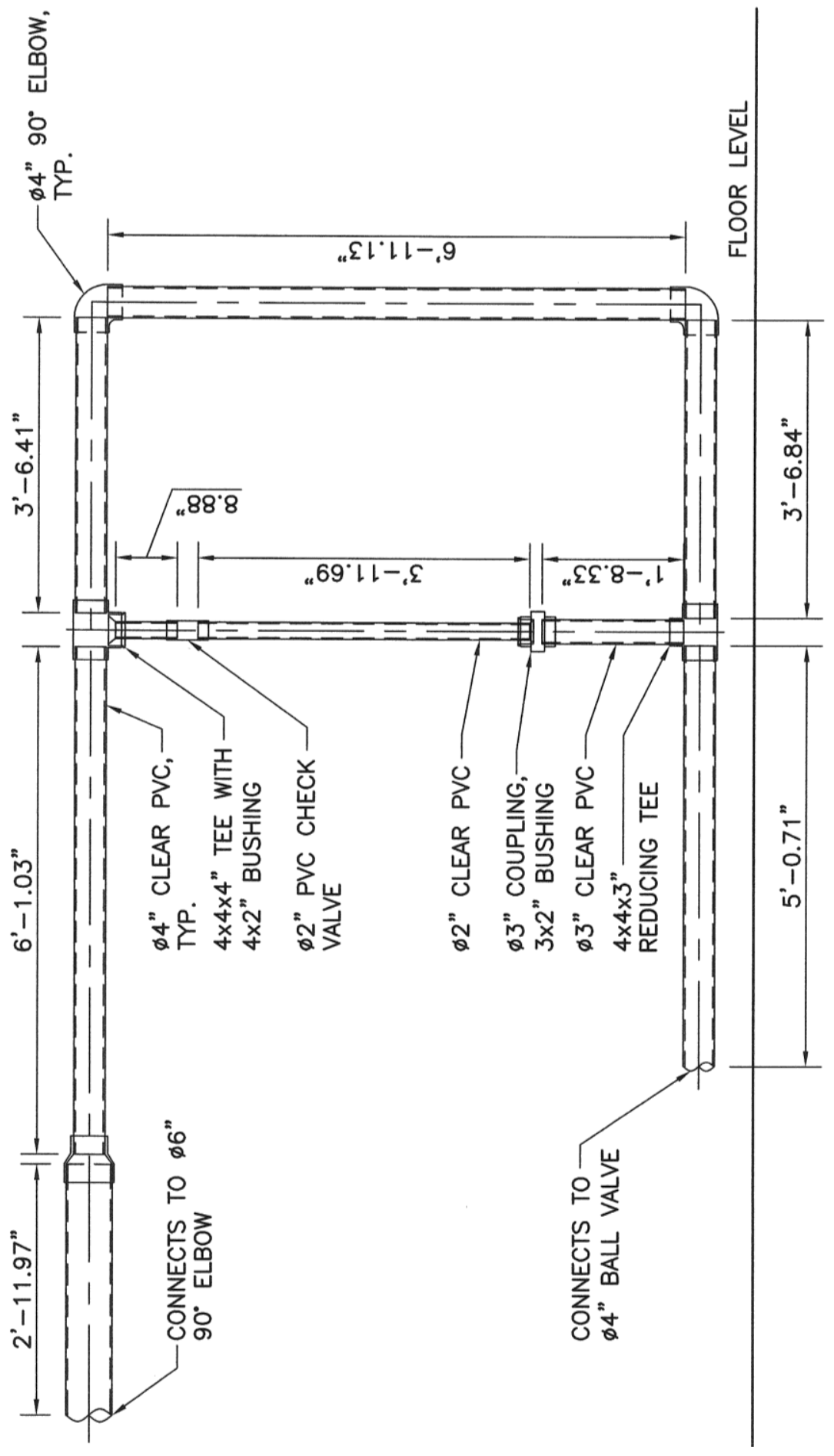

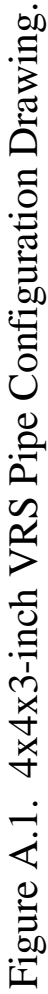




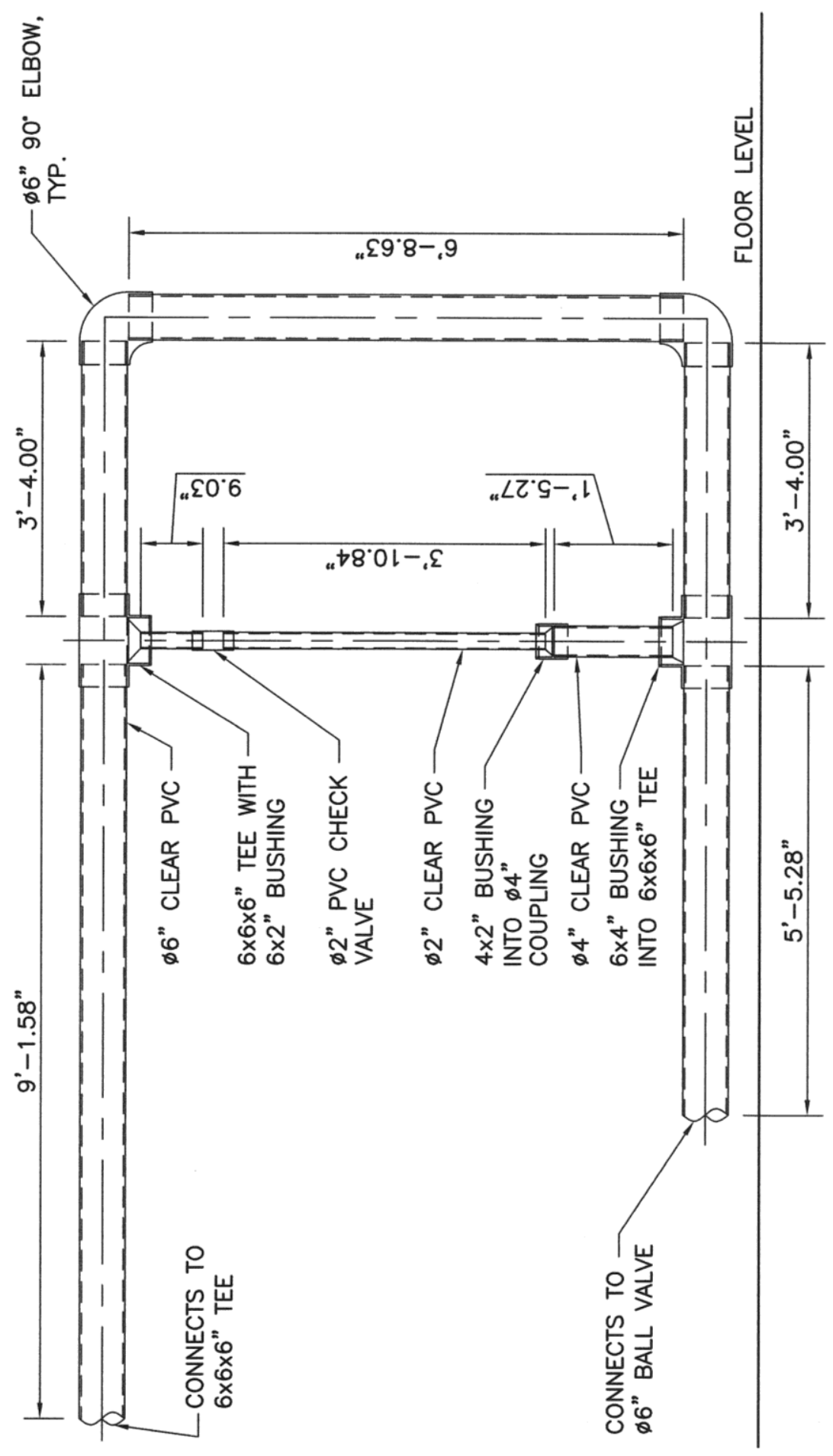

O0 
Appendix B - VRS Pipe Data

\begin{tabular}{|c|c|c|c|c|c|c|c|c|}
\hline Comp Name & SubComp & $\begin{array}{c}\text { Length } \\
\text { (ft) }\end{array}$ & $\begin{array}{l}\text { Dia } \\
\text { (in) }\end{array}$ & $\begin{array}{l}\text { Flow } \\
\text { Area } \\
\left(\mathbf{f t}^{\wedge} \mathbf{2}\right)\end{array}$ & $\mathbf{K}$ & $\begin{array}{c}\text { Vol } \\
\text { Angle } \\
\text { (deg) }\end{array}$ & $\begin{array}{l}\text { Centroid } \\
\text { Elev (ft) }\end{array}$ & $\begin{array}{c}\text { Centroid } \\
\text { (PSIA) }\end{array}$ \\
\hline TMDPVOL 200 & 200 & & & & & 0 & & \\
\hline TMDJUN205 & 205 & & 6.065 & 0.2006 & & 0 & & \\
\hline \multirow[t]{4}{*}{ Pipe 210} & $210-1$ & 1.000 & 6.065 & 0.2006 & 0 & 0 & 3.768 & 14.584 \\
\hline & $210-2$ & 1.000 & 6.065 & 0.2006 & 0 & 0 & 3.768 & 14.584 \\
\hline & $210-3$ & 1.000 & 6.065 & 0.2006 & 0 & 0 & 3.768 & 14.584 \\
\hline & $210-4$ & 1.000 & 6.065 & 0.2006 & 0 & 0 & 3.768 & 14.584 \\
\hline \multirow[t]{4}{*}{90 Elbow } & $210-5$ & 1.000 & 6.065 & 0.2006 & 0.45 & -90 & 3.268 & 14.800 \\
\hline & $210-6$ & 1.000 & 6.065 & 0.2006 & 0 & -90 & 2.268 & 15.233 \\
\hline & $210-7$ & 1.000 & 6.065 & 0.2006 & 0 & -90 & 1.268 & 15.666 \\
\hline & $210-8$ & 1.000 & 6.065 & 0.2006 & 0 & -90 & 0.268 & 16.099 \\
\hline \multirow[t]{19}{*}{90 Elbow } & $210-9$ & 1.000 & 6.065 & 0.2006 & 0.45 & 0 & 0.268 & 16.099 \\
\hline & $210-10$ & 1.000 & 6.065 & 0.2006 & 0 & 0 & 0.268 & 16.099 \\
\hline & $210-11$ & 1.000 & 6.065 & 0.2006 & 0 & 0 & 0.268 & 16.099 \\
\hline & $210-12$ & 1.000 & 6.065 & 0.2006 & 0 & 0 & 0.268 & 16.099 \\
\hline & $210-13$ & 1.000 & 6.065 & 0.2006 & 0 & 0 & 0.268 & 16.099 \\
\hline & $210-14$ & 1.000 & 6.065 & 0.2006 & 0 & 0 & 0.268 & 16.099 \\
\hline & $210-15$ & 1.000 & 6.065 & 0.2006 & 0 & 0 & 0.268 & 16.099 \\
\hline & $210-16$ & 1.000 & 6.065 & 0.2006 & 0 & 0 & 0.268 & 16.099 \\
\hline & $210-17$ & 1.000 & 6.065 & 0.2006 & 0 & 0 & 0.268 & 16.099 \\
\hline & 210-18 & 1.000 & 6.065 & 0.2006 & 0 & 0 & 0.268 & 16.099 \\
\hline & 210-19 & 1.000 & 6.065 & 0.2006 & 0 & 0 & 0.268 & 16.099 \\
\hline & $210-20$ & 1.000 & 6.065 & 0.2006 & 0 & 0 & 0.268 & 16.099 \\
\hline & $210-21$ & 1.000 & 6.065 & 0.2006 & 0 & 0 & 0.268 & 16.099 \\
\hline & $210-22$ & 1.000 & 6.065 & 0.2006 & 0 & 0 & 0.268 & 16.099 \\
\hline & $210-23$ & 1.000 & 6.065 & 0.2006 & 0 & 0 & 0.268 & 16.099 \\
\hline & $210-24$ & 1.000 & 6.065 & 0.2006 & 0 & 0 & 0.268 & 16.099 \\
\hline & $210-25$ & 1.000 & 6.065 & 0.2006 & 0 & 0 & 0.268 & 16.099 \\
\hline & $210-26$ & 0.506 & 6.065 & 0.2006 & 0 & 0 & 0.268 & 16.099 \\
\hline & $210-27$ & 0.506 & 6.065 & 0.2006 & 0 & 0 & 0.268 & 16.099 \\
\hline \multirow[t]{6}{*}{ 6" x 4" } & $210-28$ & 0.500 & 4.026 & 0.0884 & 0.931 & 0 & 0.268 & 16.099 \\
\hline & $210-29$ & 0.500 & 4.026 & 0.0884 & 0 & 0 & 0.268 & 16.099 \\
\hline & $210-30$ & 0.500 & 4.026 & 0.0884 & 0 & 0 & 0.268 & 16.099 \\
\hline & $210-31$ & 0.500 & 4.026 & 0.0884 & 0 & 0 & 0.268 & 16.099 \\
\hline & $210-32$ & 0.500 & 4.026 & 0.0884 & 0 & 0 & 0.268 & 16.099 \\
\hline & $210-33$ & 0.500 & 4.026 & 0.0884 & 0 & 0 & 0.268 & 16.099 \\
\hline \multirow[t]{8}{*}{ 4" x 6" } & 210-34 & 0.506 & 6.065 & 0.2006 & 0.309 & 0 & 0.268 & 16.099 \\
\hline & $210-35$ & 0.506 & 6.065 & 0.2006 & 0 & 0 & 0.268 & 16.099 \\
\hline & $210-36$ & 0.506 & 6.065 & 0.2006 & 0 & 0 & 0.268 & 16.099 \\
\hline & $210-37$ & 0.506 & 6.065 & 0.2006 & 0 & 0 & 0.268 & 16.099 \\
\hline & $210-38$ & 0.506 & 6.065 & 0.2006 & 0 & 0 & 0.268 & 16.099 \\
\hline & $210-39$ & 0.506 & 6.065 & 0.2006 & 0 & 0 & 0.268 & 16.099 \\
\hline & $210-40$ & 0.506 & 6.065 & 0.2006 & 0 & 0 & 0.268 & 16.099 \\
\hline & $210-41$ & 0.506 & 6.065 & 0.2006 & 0 & 0 & 0.268 & 16.099 \\
\hline
\end{tabular}




\begin{tabular}{|c|c|c|c|c|c|c|c|c|}
\hline & 210-42 & 0.506 & 6.065 & 0.2006 & 0 & 0 & 0.268 & 16.099 \\
\hline \multirow[t]{16}{*}{90 Elbow } & $210-43$ & 0.506 & 6.065 & 0.2006 & 0.45 & 90 & 0.774 & 15.880 \\
\hline & $210-44$ & 0.506 & 6.065 & 0.2006 & 0 & 90 & 1.280 & 15.661 \\
\hline & $210-45$ & 0.506 & 6.065 & 0.2006 & 0 & 90 & 1.786 & 15.442 \\
\hline & $210-46$ & 0.506 & 6.065 & 0.2006 & 0 & 90 & 2.292 & 15.223 \\
\hline & $210-47$ & 0.506 & 6.065 & 0.2006 & 0 & 90 & 2.798 & 15.004 \\
\hline & $210-48$ & 0.506 & 6.065 & 0.2006 & 0 & 90 & 3.304 & 14.785 \\
\hline & $210-49$ & 0.506 & 6.065 & 0.2006 & 0 & 90 & 3.810 & 14.565 \\
\hline & $210-50$ & 0.506 & 6.065 & 0.2006 & 0 & 90 & 4.316 & 14.346 \\
\hline & $210-51$ & 0.506 & 6.065 & 0.2006 & 0 & 90 & 4.822 & 14.127 \\
\hline & $210-52$ & 0.506 & 6.065 & 0.2006 & 0 & 90 & 5.328 & 13.908 \\
\hline & $210-53$ & 0.506 & 6.065 & 0.2006 & 0 & 90 & 5.834 & 13.689 \\
\hline & $210-54$ & 0.506 & 6.065 & 0.2006 & 0 & 90 & 6.340 & 13.470 \\
\hline & $210-55$ & 0.506 & 6.065 & 0.2006 & 0 & 90 & 6.846 & 13.251 \\
\hline & $210-56$ & 0.506 & 6.065 & 0.2006 & 0 & 90 & 7.352 & 13.032 \\
\hline & $210-57$ & 0.506 & 6.065 & 0.2006 & 0 & 90 & 7.858 & 12.813 \\
\hline & $210-58$ & 0.506 & 6.065 & 0.2006 & 0 & 90 & 8.364 & 12.594 \\
\hline \multirow[t]{5}{*}{90 Elbow } & $210-59$ & 0.506 & 6.065 & 0.2006 & 0.45 & 0 & 8.364 & 12.594 \\
\hline & $210-60$ & 0.506 & 6.065 & 0.2006 & 0 & 0 & 8.364 & 12.594 \\
\hline & $210-61$ & 0.506 & 6.065 & 0.2006 & 0 & 0 & 8.364 & 12.594 \\
\hline & $210-62$ & 0.506 & 6.065 & 0.2006 & 0 & 0 & 8.364 & 12.594 \\
\hline & $210-63$ & 0.506 & 6.065 & 0.2006 & 0 & 0 & 8.364 & 12.594 \\
\hline Branch 220 & $220-1$ & 1.000 & 6.065 & 0.2006 & & 0 & 8.000 & 12.594 \\
\hline \multirow[t]{5}{*}{ Pipe 230 } & 230-1 & 0.506 & 6.065 & 0.2006 & 0 & 0 & 8.000 & 12.594 \\
\hline & $230-2$ & 0.506 & 6.065 & 0.2006 & 0 & 0 & 8.000 & 12.594 \\
\hline & $230-3$ & 0.506 & 6.065 & 0.2006 & 0 & 0 & 8.000 & 12.594 \\
\hline & $230-4$ & 0.506 & 6.065 & 0.2006 & 0 & 0 & 8.000 & 12.594 \\
\hline & $230-5$ & 0.643 & 6.065 & 0.2006 & 0 & 0 & 8.000 & 12.594 \\
\hline \multirow[t]{5}{*}{ Pipe 500} & $500-1$ & 0.506 & 6.065 & 0.2006 & 0 & 0 & 8.000 & 12.594 \\
\hline & $500-2$ & 0.506 & 6.065 & 0.2006 & 0 & 0 & 8.000 & 12.594 \\
\hline & $500-3$ & 0.506 & 6.065 & 0.2006 & 0 & 0 & 8.000 & 12.594 \\
\hline & $500-4$ & 0.506 & 6.065 & 0.2006 & 0 & 0 & 8.000 & 12.594 \\
\hline & $500-5$ & 0.506 & 6.065 & 0.2006 & 0 & 0 & 8.000 & 12.594 \\
\hline \multirow[t]{9}{*}{$6 " \times 8 "$} & $500-6$ & 0.700 & 7.981 & 0.3474 & 0.191 & 0 & 8.000 & 12.594 \\
\hline & $500-7$ & 0.700 & 7.981 & 0.3474 & 0 & 0 & 8.000 & 12.594 \\
\hline & $500-8$ & 0.700 & 7.981 & 0.3474 & 0 & 0 & 8.000 & 12.594 \\
\hline & $500-9$ & 0.700 & 7.981 & 0.3474 & 0 & 0 & 8.000 & 12.594 \\
\hline & $500-10$ & 0.700 & 7.981 & 0.3474 & 0 & 0 & 8.000 & 12.594 \\
\hline & 500-11 & 0.700 & 7.981 & 0.3474 & 0 & 0 & 8.000 & 12.594 \\
\hline & $500-12$ & 0.700 & 7.981 & 0.3474 & 0 & 0 & 8.000 & 12.594 \\
\hline & 500-13 & 0.700 & 7.981 & 0.3474 & 0 & 0 & 8.000 & 12.594 \\
\hline & 500-14 & 0.900 & 7.981 & 0.3474 & 0 & 0 & 8.000 & 12.594 \\
\hline Branch 240 & $240-1$ & 1.000 & 6.065 & 0.2006 & 0 & 0 & 8.000 & 12.594 \\
\hline \multirow{5}{*}{ Pipe 400 } & $400-1$ & 0.506 & 6.065 & 0.2006 & 0 & 0 & 8.000 & 12.594 \\
\hline & $400-2$ & 0.506 & 6.065 & 0.2006 & 0 & 0 & 8.000 & 12.594 \\
\hline & $400-3$ & 0.506 & 6.065 & 0.2006 & 0 & 0 & 8.000 & 12.594 \\
\hline & $400-4$ & 0.506 & 6.065 & 0.2006 & 0 & 0 & 8.000 & 12.594 \\
\hline & $400-5$ & 0.506 & 6.065 & 0.2006 & 0 & 0 & 8.000 & 12.594 \\
\hline
\end{tabular}




\begin{tabular}{|c|c|c|c|c|c|c|c|c|}
\hline & $400-6$ & 0.506 & 6.065 & 0.2006 & 0 & 0 & 8.000 & 12.594 \\
\hline & $400-7$ & 0.506 & 6.065 & 0.2006 & 0 & 0 & 8.000 & 12.594 \\
\hline & $400-8$ & 0.506 & 6.065 & 0.2006 & 0 & 0 & 8.000 & 12.594 \\
\hline & $400-9$ & 0.535 & 6.065 & 0.2006 & 0 & 0 & 8.000 & 12.594 \\
\hline \multirow[t]{9}{*}{ Pipe 401} & $401-1$ & 0.506 & 6.065 & 0.2006 & 0 & 0 & 8.000 & 12.594 \\
\hline & $401-2$ & 0.506 & 6.065 & 0.2006 & 0 & 0 & 8.000 & 12.594 \\
\hline & $401-3$ & 0.506 & 6.065 & 0.2006 & 0 & 0 & 8.000 & 12.594 \\
\hline & $401-4$ & 0.506 & 6.065 & 0.2006 & 0 & 0 & 8.000 & 12.594 \\
\hline & $401-5$ & 0.506 & 6.065 & 0.2006 & 0 & 0 & 8.000 & 12.594 \\
\hline & $401-6$ & 0.506 & 6.065 & 0.2006 & 0 & 0 & 8.000 & 12.594 \\
\hline & $401-7$ & 0.506 & 6.065 & 0.2006 & 0 & 0 & 8.000 & 12.594 \\
\hline & $401-8$ & 0.506 & 6.065 & 0.2006 & 0 & 0 & 8.000 & 12.594 \\
\hline & $401-9$ & 0.535 & 6.065 & 0.2006 & 0 & 0 & 8.000 & 12.594 \\
\hline TMDPVOL 402 & 402 & & & & & 0 & & 60.000 \\
\hline TMDJUN 403 & 403 & & 6.065 & 0.2006 & & 0 & & \\
\hline SNGLVOL 404 & 404 & 5.000 & 0.364 & 0.0007 & 0 & 0 & 8.000 & 12.594 \\
\hline CHCKVLV 405 & 405 & & 0.364 & 0.0007 & 3 & 0 & 8.000 & 12.594 \\
\hline SNGLVOL 406 & 406 & 5.000 & 0.364 & 0.0007 & 0 & 0 & 8.000 & 12.594 \\
\hline BRANCH 407 & 407 & 1.000 & 6.065 & 0.2006 & 0 & 0 & 8.000 & 12.594 \\
\hline Branch 410 & $410-1$ & 1.000 & 6.065 & 0.2006 & 0 & 0 & 8.000 & 12.594 \\
\hline \multirow[t]{6}{*}{ Pipe 420 } & $420-1$ & 0.556 & 6.065 & 0.2006 & 0 & 0 & 8.000 & 12.594 \\
\hline & $420-2$ & 0.556 & 6.065 & 0.2006 & 0 & 0 & 8.000 & 12.594 \\
\hline & $420-3$ & 0.556 & 6.065 & 0.2006 & 0 & 0 & 8.000 & 12.594 \\
\hline & $420-4$ & 0.556 & 6.065 & 0.2006 & 0 & 0 & 8.000 & 12.594 \\
\hline & $420-5$ & 0.556 & 6.065 & 0.2006 & 0 & 0 & 8.000 & 12.594 \\
\hline & $420-6$ & 0.506 & 6.065 & 0.2006 & 0.45 & -45 & 7.821 & 12.671 \\
\hline \multirow[t]{10}{*}{45 elbow } & $420-7$ & 0.743 & 6.065 & 0.2006 & 0 & -90 & 7.629 & 12.755 \\
\hline & $420-8$ & 0.743 & 6.065 & 0.2006 & 0 & -90 & 6.886 & 13.076 \\
\hline & $420-9$ & 0.743 & 6.065 & 0.2006 & 0 & -90 & 6.144 & 13.398 \\
\hline & $420-10$ & 0.743 & 6.065 & 0.2006 & 0 & -90 & 5.401 & 13.719 \\
\hline & $420-11$ & 0.743 & 6.065 & 0.2006 & 0 & -90 & 4.658 & 14.041 \\
\hline & $420-12$ & 0.743 & 6.065 & 0.2006 & 0 & -90 & 3.916 & 14.362 \\
\hline & $420-13$ & 0.743 & 6.065 & 0.2006 & 0 & -90 & 3.173 & 14.684 \\
\hline & $420-14$ & 0.743 & 6.065 & 0.2006 & 0 & -90 & 2.431 & 15.005 \\
\hline & $420-15$ & 0.743 & 6.065 & 0.2006 & 0 & -90 & 1.688 & 15.327 \\
\hline & $420-16$ & 1.184 & 6.065 & 0.2006 & 0 & -90 & 0.504 & 15.839 \\
\hline \multirow[t]{6}{*}{45 elbow } & $420-17$ & 0.506 & 6.065 & 0.2006 & 0.45 & -45 & 0.072 & 16.026 \\
\hline & $420-18$ & 0.556 & 6.065 & 0.2006 & 0 & 0 & -0.206 & 16.147 \\
\hline & $420-19$ & 0.556 & 6.065 & 0.2006 & 0 & 0 & -0.206 & 16.147 \\
\hline & $420-20$ & 0.556 & 6.065 & 0.2006 & 0 & 0 & -0.206 & 16.147 \\
\hline & $420-21$ & 0.556 & 6.065 & 0.2006 & 0 & 0 & -0.206 & 16.147 \\
\hline & $420-22$ & 0.556 & 6.065 & 0.2006 & 0 & 0 & -0.206 & 16.147 \\
\hline Branch 430 & $430-1$ & 1.000 & 6.065 & 0.2006 & & 0 & -0.206 & 16.147 \\
\hline \multirow[t]{4}{*}{ Pipe 800} & $800-1$ & 0.326 & 4.026 & 0.0513 & 0 & 90 & -0.043 & 16.076 \\
\hline & $800-2$ & 0.326 & 4.026 & 0.0513 & 0 & 90 & 0.282 & 15.935 \\
\hline & $800-3$ & 0.326 & 4.026 & 0.0513 & 0 & 90 & 0.608 & 15.794 \\
\hline & $800-4$ & 0.326 & 4.026 & 0.0513 & 0 & 90 & 0.934 & 15.653 \\
\hline
\end{tabular}




\begin{tabular}{|c|c|c|c|c|c|c|c|c|}
\hline \multirow[t]{18}{*}{$4 \times 2$ reducer } & $800-5$ & 0.326 & 2.067 & 0.0233 & 0.992 & 90 & 1.260 & 15.512 \\
\hline & $800-6$ & 0.326 & 2.067 & 0.0233 & 0 & 90 & 1.585 & 15.371 \\
\hline & $800-7$ & 0.326 & 2.067 & 0.0233 & 0 & 90 & 1.911 & 15.230 \\
\hline & $800-8$ & 0.326 & 2.067 & 0.0233 & 0 & 90 & 2.237 & 15.089 \\
\hline & $800-9$ & 0.326 & 2.067 & 0.0233 & 0 & 90 & 2.563 & 14.948 \\
\hline & $800-10$ & 0.326 & 2.067 & 0.0233 & 0 & 90 & 2.888 & 14.807 \\
\hline & $800-11$ & 0.326 & 2.067 & 0.0233 & 0 & 90 & 3.214 & 14.666 \\
\hline & $800-12$ & 0.326 & 2.067 & 0.0233 & 0 & 90 & 3.540 & 14.525 \\
\hline & $800-13$ & 0.326 & 2.067 & 0.0233 & 0 & 90 & 3.866 & 14.384 \\
\hline & $800-14$ & 0.326 & 2.067 & 0.0233 & 0 & 90 & 4.192 & 14.243 \\
\hline & $800-15$ & 0.326 & 2.067 & 0.0233 & 0 & 90 & 4.517 & 14.102 \\
\hline & $800-16$ & 0.326 & 2.067 & 0.0233 & 0 & 90 & 4.843 & 13.961 \\
\hline & $800-17$ & 0.326 & 2.067 & 0.0233 & 0 & 90 & 5.169 & 13.820 \\
\hline & $800-18$ & 0.326 & 2.067 & 0.0233 & 0 & 90 & 5.495 & 13.679 \\
\hline & $800-19$ & 0.326 & 2.067 & 0.0233 & 0 & 90 & 5.820 & 13.537 \\
\hline & $800-20$ & 0.326 & 2.067 & 0.0233 & 0 & 90 & 6.146 & 13.396 \\
\hline & $800-21$ & 0.326 & 2.067 & 0.0233 & 0 & 90 & 6.472 & 13.255 \\
\hline & $800-22$ & 0.326 & 2.067 & 0.0233 & 0 & 90 & 6.798 & 13.114 \\
\hline Chkvalve 810 & $810-1$ & 1.000 & 2.067 & 0.0233 & 0.95 & 0 & 6.798 & 13.114 \\
\hline \multirow[t]{4}{*}{ Pipe 820 } & $820-1$ & 0.200 & 2.067 & 0.0233 & 0 & 90 & 6.898 & 13.071 \\
\hline & $820-2$ & 0.200 & 2.067 & 0.0233 & 0 & 90 & 7.098 & 12.984 \\
\hline & $820-3$ & 0.200 & 2.067 & 0.0233 & 0 & 90 & 7.298 & 12.898 \\
\hline & $820-4$ & 0.311 & 2.067 & 0.0233 & 0 & 90 & 7.453 & 12.831 \\
\hline \multirow[t]{10}{*}{ Pipe 440} & $440-1$ & 0.506 & 6.065 & 0.2006 & 0 & 0 & -0.206 & 16.147 \\
\hline & $440-2$ & 0.506 & 6.065 & 0.2006 & 0 & 0 & -0.206 & 16.147 \\
\hline & $440-3$ & 0.506 & 6.065 & 0.2006 & 0 & 0 & -0.206 & 16.147 \\
\hline & $440-4$ & 0.506 & 6.065 & 0.2006 & 0 & 0 & -0.206 & 16.147 \\
\hline & $440-5$ & 0.506 & 6.065 & 0.2006 & 0 & 0 & -0.206 & 16.147 \\
\hline & $440-6$ & 0.506 & 6.065 & 0.2006 & 0 & 0 & -0.206 & 16.147 \\
\hline & $440-7$ & 0.506 & 6.065 & 0.2006 & 0 & 0 & -0.206 & 16.147 \\
\hline & $440-8$ & 0.506 & 6.065 & 0.2006 & 0 & 0 & -0.206 & 16.147 \\
\hline & $440-9$ & 0.506 & 6.065 & 0.2006 & 0 & 0 & -0.206 & 16.147 \\
\hline & $440-10$ & 0.506 & 6.065 & 0.2006 & 0 & 0 & -0.206 & 16.147 \\
\hline Valve 450 & $450-1$ & 0.000 & 6.065 & 0.2006 & 0.019 & & -0.206 & 16.147 \\
\hline \multirow[t]{4}{*}{ Pipe 460 } & $460-1$ & 0.890 & 6.065 & 0.2006 & 0 & 0 & -0.206 & 16.147 \\
\hline & $460-2$ & 0.890 & 6.065 & 0.2006 & 0 & 0 & -0.206 & 16.147 \\
\hline & $460-3$ & 0.890 & 6.065 & 0.2006 & 0 & 0 & -0.206 & 16.147 \\
\hline & $460-4$ & 0.890 & 6.065 & 0.2006 & 0 & 0 & -0.206 & 16.147 \\
\hline Branch 630 & 630-1 & 1.000 & 6.065 & 0.2006 & 0 & 0 & -0.206 & 16.147 \\
\hline \multirow[t]{5}{*}{ Pipe 640} & 640-1 & 0.506 & 6.065 & 0.2006 & 0 & 0 & -0.206 & 16.147 \\
\hline & $640-2$ & 0.506 & 6.065 & 0.2006 & 0 & 0 & -0.206 & 16.147 \\
\hline & $640-3$ & 0.506 & 6.065 & 0.2006 & 0 & 0 & -0.206 & 16.147 \\
\hline & $640-4$ & 0.506 & 6.065 & 0.2006 & 0 & 0 & -0.206 & 16.147 \\
\hline & $640-5$ & 0.506 & 6.065 & 0.2006 & 0 & 0 & -0.206 & 16.147 \\
\hline \multirow[t]{3}{*}{90 Elbow } & $640-6$ & 0.506 & 6.065 & 0.2006 & 0.45 & 0 & -0.206 & 16.147 \\
\hline & $640-7$ & 0.506 & 6.065 & 0.2006 & 0 & 0 & -0.206 & 16.147 \\
\hline & $640-8$ & 0.506 & 6.065 & 0.2006 & 0 & 0 & -0.206 & 16.147 \\
\hline
\end{tabular}




\begin{tabular}{|c|c|c|c|c|c|c|c|c|}
\hline & $640-9$ & 0.506 & 6.065 & 0.2006 & 0 & 0 & -0.206 & 16.147 \\
\hline & $640-10$ & 0.506 & 6.065 & 0.2006 & 0 & 0 & -0.206 & 16.147 \\
\hline & $640-11$ & 0.506 & 6.065 & 0.2006 & 0 & 0 & -0.206 & 16.147 \\
\hline & 640-12 & 0.506 & 6.065 & 0.2006 & 0 & 0 & -0.206 & 16.147 \\
\hline \multirow[t]{5}{*}{ Pipe 620} & $620-1$ & 0.506 & 6.065 & 0.2006 & 0 & 0 & -0.206 & 16.147 \\
\hline & $620-2$ & 0.506 & 6.065 & 0.2006 & 0 & 0 & -0.206 & 16.147 \\
\hline & $620-3$ & 0.506 & 6.065 & 0.2006 & 0 & 0 & -0.206 & 16.147 \\
\hline & $620-4$ & 0.574 & 6.065 & 0.2006 & 0 & 0 & -0.206 & 16.147 \\
\hline & $620-5$ & 0.574 & 6.065 & 0.2006 & 0 & 0 & -0.206 & 16.147 \\
\hline Branch 610 & $610-1$ & 1.000 & 6.065 & 0.2006 & 0 & 0 & -0.206 & 16.147 \\
\hline \multirow[t]{28}{*}{ Pipe 600 } & $600-1$ & 0.506 & 6.065 & 0.2006 & 0 & 0 & -0.206 & 16.147 \\
\hline & $600-2$ & 0.506 & 6.065 & 0.2006 & 0 & 0 & -0.206 & 16.147 \\
\hline & $600-3$ & 0.506 & 6.065 & 0.2006 & 0 & 0 & -0.206 & 16.147 \\
\hline & $600-4$ & 0.506 & 6.065 & 0.2006 & 0 & 0 & -0.206 & 16.147 \\
\hline & $600-5$ & 0.506 & 6.065 & 0.2006 & 0 & 0 & -0.206 & 16.147 \\
\hline & $600-6$ & 0.506 & 6.065 & 0.2006 & 0 & 0 & -0.206 & 16.147 \\
\hline & $600-7$ & 0.506 & 6.065 & 0.2006 & 0 & 0 & -0.206 & 16.147 \\
\hline & $600-8$ & 0.506 & 6.065 & 0.2006 & 0 & 0 & -0.206 & 16.147 \\
\hline & $600-9$ & 0.506 & 6.065 & 0.2006 & 0 & 0 & -0.206 & 16.147 \\
\hline & $600-10$ & 0.506 & 6.065 & 0.2006 & 0 & 0 & -0.206 & 16.147 \\
\hline & $600-11$ & 0.506 & 6.065 & 0.2006 & 0 & 0 & -0.206 & 16.147 \\
\hline & $600-12$ & 0.506 & 6.065 & 0.2006 & 0 & 0 & -0.206 & 16.147 \\
\hline & 600-13 & 0.506 & 6.065 & 0.2006 & 0 & 0 & -0.206 & 16.147 \\
\hline & $600-14$ & 0.506 & 6.065 & 0.2006 & 0 & 0 & -0.206 & 16.147 \\
\hline & $600-15$ & 0.506 & 6.065 & 0.2006 & 0 & 0 & -0.206 & 16.147 \\
\hline & $600-16$ & 0.506 & 6.065 & 0.2006 & 0 & 0 & -0.206 & 16.147 \\
\hline & $600-17$ & 0.506 & 6.065 & 0.2006 & 0 & 0 & -0.206 & 16.147 \\
\hline & $600-18$ & 0.506 & 6.065 & 0.2006 & 0 & 0 & -0.206 & 16.147 \\
\hline & $600-19$ & 0.506 & 6.065 & 0.2006 & 0 & 0 & -0.206 & 16.147 \\
\hline & $600-20$ & 0.506 & 6.065 & 0.2006 & 0 & 0 & -0.206 & 16.147 \\
\hline & $600-21$ & 0.506 & 6.065 & 0.2006 & 0 & 0 & -0.206 & 16.147 \\
\hline & $600-22$ & 0.506 & 6.065 & 0.2006 & 0 & 0 & -0.206 & 16.147 \\
\hline & $600-23$ & 0.506 & 6.065 & 0.2006 & 0 & 0 & -0.206 & 16.147 \\
\hline & $600-24$ & 0.506 & 6.065 & 0.2006 & 0 & 0 & -0.206 & 16.147 \\
\hline & $600-25$ & 0.506 & 6.065 & 0.2006 & 0 & 0 & -0.206 & 16.147 \\
\hline & $600-26$ & 0.506 & 6.065 & 0.2006 & 0 & 0 & -0.206 & 16.147 \\
\hline & $600-27$ & 0.506 & 6.065 & 0.2006 & 0 & 0 & -0.206 & 16.147 \\
\hline & $600-28$ & 0.506 & 6.065 & 0.2006 & 0 & 0 & -0.206 & 16.147 \\
\hline \multirow[t]{10}{*}{90 Elbow } & $600-29$ & 0.506 & 6.065 & 0.2006 & 0.45 & 90 & 0.300 & 15.928 \\
\hline & $600-30$ & 0.506 & 6.065 & 0.2006 & 0 & 90 & 0.806 & 15.709 \\
\hline & $600-31$ & 0.506 & 6.065 & 0.2006 & 0 & 90 & 1.312 & 15.490 \\
\hline & $600-32$ & 0.506 & 6.065 & 0.2006 & 0 & 90 & 1.818 & 15.270 \\
\hline & 600-33 & 0.506 & 6.065 & 0.2006 & 0 & 90 & 2.324 & 15.051 \\
\hline & $600-34$ & 0.506 & 6.065 & 0.2006 & 0 & 90 & 2.830 & 14.832 \\
\hline & $600-35$ & 0.506 & 6.065 & 0.2006 & 0 & 90 & 3.336 & 14.613 \\
\hline & $600-36$ & 0.506 & 6.065 & 0.2006 & 0 & 90 & 3.842 & 14.394 \\
\hline & $600-37$ & 0.506 & 6.065 & 0.2006 & 0 & 90 & 4.348 & 14.175 \\
\hline & 600-38 & 0.506 & 6.065 & 0.2006 & 0 & 90 & 4.854 & 13.956 \\
\hline
\end{tabular}




\begin{tabular}{|c|c|c|c|c|c|c|c|c|}
\hline \multirow[t]{8}{*}{90 Elbow } & $600-39$ & 0.506 & 6.065 & 0.2006 & 0.45 & 0 & 4.854 & 13.956 \\
\hline & $600-40$ & 0.506 & 6.065 & 0.2006 & 0 & 0 & 4.854 & 13.956 \\
\hline & $600-41$ & 0.506 & 6.065 & 0.2006 & 0 & 0 & 4.854 & 13.956 \\
\hline & $600-42$ & 0.506 & 6.065 & 0.2006 & 0 & 0 & 4.854 & 13.956 \\
\hline & $600-43$ & 0.506 & 6.065 & 0.2006 & 0 & 0 & 4.854 & 13.956 \\
\hline & $600-44$ & 0.506 & 6.065 & 0.2006 & 0 & 0 & 4.854 & 13.956 \\
\hline & $600-45$ & 0.506 & 6.065 & 0.2006 & 0 & 0 & 4.854 & 13.956 \\
\hline & $600-46$ & 0.506 & 6.065 & 0.2006 & 0 & 0 & 4.854 & 13.956 \\
\hline \multirow[t]{4}{*}{90 Elbow } & $600-47$ & 0.506 & 6.065 & 0.2006 & 0.45 & -90 & 4.348 & 14.175 \\
\hline & $600-48$ & 0.506 & 6.065 & 0.2006 & 0 & -90 & 3.842 & 14.394 \\
\hline & $600-49$ & 0.506 & 6.065 & 0.2006 & 0 & -90 & 3.336 & 14.613 \\
\hline & $600-50$ & 0.506 & 6.065 & 0.2006 & 0 & -90 & 2.830 & 14.832 \\
\hline SNGLJUN605 & 105.000 & & 6.065 & 0.2006 & 1.000 & 0.000 & & \\
\hline \multirow[t]{5}{*}{ Pipe 250 } & $250-1$ & 0.506 & 6.065 & 0.2006 & 0 & 0 & 8.000 & 12.594 \\
\hline & $250-2$ & 0.506 & 6.065 & 0.2006 & 0 & 0 & 8.000 & 12.594 \\
\hline & $250-3$ & 0.506 & 6.065 & 0.2006 & 0 & 0 & 8.000 & 12.594 \\
\hline & $250-4$ & 0.506 & 6.065 & 0.2006 & 0 & 0 & 8.000 & 12.594 \\
\hline & $250-5$ & 0.506 & 6.065 & 0.2006 & 0 & 0 & 8.000 & 12.594 \\
\hline \multirow[t]{6}{*}{90 Elbow } & $250-6$ & 0.506 & 6.065 & 0.2006 & 0.45 & 0 & 8.000 & 12.594 \\
\hline & $250-7$ & 0.506 & 6.065 & 0.2006 & 0 & 0 & 8.000 & 12.594 \\
\hline & $250-8$ & 0.506 & 6.065 & 0.2006 & 0 & 0 & 8.000 & 12.594 \\
\hline & $250-9$ & 0.506 & 6.065 & 0.2006 & 0 & 0 & 8.000 & 12.594 \\
\hline & $250-10$ & 0.506 & 6.065 & 0.2006 & 0 & 0 & 8.000 & 12.594 \\
\hline & $250-11$ & 0.506 & 6.065 & 0.2006 & 0 & 0 & 8.000 & 12.594 \\
\hline \multirow[t]{7}{*}{ 6" x 4" } & $250-12$ & 0.506 & 6.065 & 0.2006 & 0.931 & 0 & 8.000 & 12.594 \\
\hline & $250-13$ & 0.500 & 4.026 & 0.0884 & 0 & 0 & 8.000 & 12.594 \\
\hline & $250-14$ & 0.500 & 4.026 & 0.0884 & 0 & 0 & 8.000 & 12.594 \\
\hline & $250-15$ & 0.500 & 4.026 & 0.0884 & 0 & 0 & 8.000 & 12.594 \\
\hline & $250-16$ & 0.500 & 4.026 & 0.0884 & 0 & 0 & 8.000 & 12.594 \\
\hline & $250-17$ & 0.500 & 4.026 & 0.0884 & 0 & 0 & 8.000 & 12.594 \\
\hline & $250-18$ & 0.500 & 4.026 & 0.0884 & 0 & 0 & 8.000 & 12.594 \\
\hline \multirow[t]{10}{*}{ Pipe 300} & $300-1$ & 0.340 & 4.026 & 0.0884 & 0 & 0 & 8.000 & 12.594 \\
\hline & $300-2$ & 0.340 & 4.026 & 0.0884 & 0 & 0 & 8.000 & 12.594 \\
\hline & $300-3$ & 0.340 & 4.026 & 0.0884 & 0 & 0 & 8.000 & 12.594 \\
\hline & $300-4$ & 0.340 & 4.026 & 0.0884 & 0 & 0 & 8.000 & 12.594 \\
\hline & $300-5$ & 0.340 & 4.026 & 0.0884 & 0 & 0 & 8.000 & 12.594 \\
\hline & $300-6$ & 0.340 & 4.026 & 0.0884 & 0 & 0 & 8.000 & 12.594 \\
\hline & $300-7$ & 0.340 & 4.026 & 0.0884 & 0 & 0 & 8.000 & 12.594 \\
\hline & $300-8$ & 0.340 & 4.026 & 0.0884 & 0 & 0 & 8.000 & 12.594 \\
\hline & $300-9$ & 0.340 & 4.026 & 0.0884 & 0 & 0 & 8.000 & 12.594 \\
\hline & $300-10$ & 0.340 & 4.026 & 0.0884 & 0 & 0 & 8.000 & 12.594 \\
\hline Branch 310 & $310-1$ & 1.000 & 4.026 & 0.0884 & & 0 & 8.000 & 12.594 \\
\hline \multirow[t]{6}{*}{ Pipe 320 } & $320-1$ & 0.340 & 4.026 & 0.0884 & 0 & 0 & 8.000 & 12.594 \\
\hline & $320-2$ & 0.340 & 4.026 & 0.0884 & 0 & 0 & 8.000 & 12.594 \\
\hline & $320-3$ & 0.340 & 4.026 & 0.0884 & 0 & 0 & 8.000 & 12.594 \\
\hline & $320-4$ & 0.340 & 4.026 & 0.0884 & 0 & 0 & 8.000 & 12.594 \\
\hline & $320-5$ & 0.340 & 4.026 & 0.0884 & 0 & 0 & 8.000 & 12.594 \\
\hline & $320-6$ & 0.340 & 4.026 & 0.0884 & 0 & 0 & 8.000 & 12.594 \\
\hline
\end{tabular}




\begin{tabular}{|c|c|c|c|c|c|c|c|c|}
\hline & $320-7$ & 0.340 & 4.026 & 0.0884 & 0 & 0 & 8.000 & 12.594 \\
\hline & $320-8$ & 0.340 & 4.026 & 0.0884 & 0 & 0 & 8.000 & 12.594 \\
\hline & $320-9$ & 0.340 & 4.026 & 0.0884 & 0 & 0 & 8.000 & 12.594 \\
\hline & $320-10$ & 0.340 & 4.026 & 0.0884 & 0 & 0 & 8.000 & 12.594 \\
\hline \multirow[t]{11}{*}{45 elbow } & $320-11$ & 0.340 & 4.026 & 0.0884 & 0.51 & -45 & 7.880 & 12.646 \\
\hline & $320-12$ & 0.657 & 4.026 & 0.0884 & 0 & -90 & 7.672 & 12.736 \\
\hline & $320-13$ & 0.657 & 4.026 & 0.0884 & 0 & -90 & 7.015 & 13.021 \\
\hline & $320-14$ & 0.657 & 4.026 & 0.0884 & 0 & -90 & 6.358 & 13.305 \\
\hline & $320-15$ & 0.657 & 4.026 & 0.0884 & 0 & -90 & 5.701 & 13.589 \\
\hline & $320-16$ & 0.657 & 4.026 & 0.0884 & 0 & -90 & 5.044 & 13.874 \\
\hline & $320-17$ & 0.657 & 4.026 & 0.0884 & 0 & -90 & 4.387 & 14.158 \\
\hline & $320-18$ & 0.657 & 4.026 & 0.0884 & 0 & -90 & 3.730 & 14.443 \\
\hline & $320-19$ & 0.657 & 4.026 & 0.0884 & 0 & -90 & 3.073 & 14.727 \\
\hline & $320-20$ & 0.657 & 4.026 & 0.0884 & 0 & -90 & 2.416 & 15.012 \\
\hline & $320-21$ & 0.657 & 4.026 & 0.0884 & 0 & -90 & 1.759 & 15.296 \\
\hline \multirow[t]{11}{*}{45 elbow } & $320-22$ & 0.340 & 4.026 & 0.0884 & 0.51 & -45 & 1.468 & 15.422 \\
\hline & $320-23$ & 0.340 & 4.026 & 0.0884 & 0 & 0 & 1.348 & 15.474 \\
\hline & $320-24$ & 0.340 & 4.026 & 0.0884 & 0 & 0 & 1.348 & 15.474 \\
\hline & $320-25$ & 0.340 & 4.026 & 0.0884 & 0 & 0 & 1.348 & 15.474 \\
\hline & $320-26$ & 0.340 & 4.026 & 0.0884 & 0 & 0 & 1.348 & 15.474 \\
\hline & $320-27$ & 0.340 & 4.026 & 0.0884 & 0 & 0 & 1.348 & 15.474 \\
\hline & $320-28$ & 0.340 & 4.026 & 0.0884 & 0 & 0 & 1.348 & 15.474 \\
\hline & $320-29$ & 0.340 & 4.026 & 0.0884 & 0 & 0 & 1.348 & 15.474 \\
\hline & $320-30$ & 0.340 & 4.026 & 0.0884 & 0 & 0 & 1.348 & 15.474 \\
\hline & $320-31$ & 0.340 & 4.026 & 0.0884 & 0 & 0 & 1.348 & 15.474 \\
\hline & $320-32$ & 0.340 & 4.026 & 0.0884 & 0 & 0 & 1.348 & 15.474 \\
\hline Branch 330 & $330-1$ & 1.000 & 6.065 & 0.2006 & & 0 & 1.348 & 15.474 \\
\hline \multirow[t]{6}{*}{ Pipe 700} & $700-1$ & 0.260 & 3.068 & 0.0513 & 0 & 90 & 1.478 & 15.417 \\
\hline & $700-2$ & 0.260 & 3.068 & 0.0513 & 0 & 90 & 1.738 & 15.305 \\
\hline & $700-3$ & 0.260 & 3.068 & 0.0513 & 0 & 90 & 1.998 & 15.192 \\
\hline & $700-4$ & 0.260 & 3.068 & 0.0513 & 0 & 90 & 2.258 & 15.080 \\
\hline & $700-5$ & 0.260 & 3.068 & 0.0513 & 0 & 90 & 2.518 & 14.967 \\
\hline & $700-6$ & 0.260 & 3.068 & 0.0513 & 0 & 90 & 2.778 & 14.855 \\
\hline \multirow[t]{15}{*}{$3 \times 2$ reducer } & $700-7$ & 0.263 & 2.067 & 0.0233 & 0.992 & 90 & 3.041 & 14.741 \\
\hline & $700-8$ & 0.263 & 2.067 & 0.0233 & 0 & 90 & 3.303 & 14.627 \\
\hline & $700-9$ & 0.263 & 2.067 & 0.0233 & 0 & 90 & 3.566 & 14.514 \\
\hline & $700-10$ & 0.263 & 2.067 & 0.0233 & 0 & 90 & 3.828 & 14.400 \\
\hline & $700-11$ & 0.263 & 2.067 & 0.0233 & 0 & 90 & 4.091 & 14.286 \\
\hline & $700-12$ & 0.263 & 2.067 & 0.0233 & 0 & 90 & 4.353 & 14.173 \\
\hline & $700-13$ & 0.263 & 2.067 & 0.0233 & 0 & 90 & 4.616 & 14.059 \\
\hline & $700-14$ & 0.263 & 2.067 & 0.0233 & 0 & 90 & 4.878 & 13.945 \\
\hline & $700-15$ & 0.263 & 2.067 & 0.0233 & 0 & 90 & 5.141 & 13.832 \\
\hline & $700-16$ & 0.263 & 2.067 & 0.0233 & 0 & 90 & 5.403 & 13.718 \\
\hline & $700-17$ & 0.263 & 2.067 & 0.0233 & 0 & 90 & 5.666 & 13.605 \\
\hline & $700-18$ & 0.263 & 2.067 & 0.0233 & 0 & 90 & 5.928 & 13.491 \\
\hline & $700-19$ & 0.263 & 2.067 & 0.0233 & 0 & 90 & 6.191 & 13.377 \\
\hline & $700-20$ & 0.263 & 2.067 & 0.0233 & 0 & 90 & 6.453 & 13.264 \\
\hline & $700-21$ & 0.263 & 2.067 & 0.0233 & 0 & 90 & 6.716 & 13.150 \\
\hline
\end{tabular}




\begin{tabular}{|l|l|r|r|r|r|r|r|r|}
\hline & $700-22$ & 0.263 & 2.067 & 0.0233 & 0 & 90 & 6.978 & 13.036 \\
\hline Chkvalve 710 & $\mathbf{7 1 0 - 1}$ & 1.000 & 2.067 & 0.0233 & 0.95 & 0 & 6.978 & 13.036 \\
\hline Pipe 720 & $720-1$ & 0.200 & 2.067 & 0.0233 & 0 & 90 & 7.078 & 12.993 \\
\hline & $720-2$ & 0.200 & 2.067 & 0.0233 & 0 & 90 & 7.278 & 12.906 \\
\hline & $720-3$ & 0.200 & 2.067 & 0.0233 & 0 & 90 & 7.478 & 12.820 \\
\hline & $720-4$ & 0.311 & 2.067 & 0.0233 & 0 & 90 & 7.634 & 12.752 \\
\hline Pipe 340 & $340-1$ & 0.350 & 4.026 & 0.0884 & 0 & 0 & 1.348 & 15.474 \\
\hline & $340-2$ & 0.350 & 4.026 & 0.0884 & 0 & 0 & 1.348 & 15.474 \\
\hline & $340-3$ & 0.350 & 4.026 & 0.0884 & 0 & 0 & 1.348 & 15.474 \\
\hline & $340-4$ & 0.350 & 4.026 & 0.0884 & 0 & 0 & 1.348 & 15.474 \\
\hline & $340-5$ & 0.350 & 4.026 & 0.0884 & 0 & 0 & 1.348 & 15.474 \\
\hline & $340-6$ & 0.350 & 4.026 & 0.0884 & 0 & 0 & 1.348 & 15.474 \\
\hline & $340-7$ & 0.350 & 4.026 & 0.0884 & 0 & 0 & 1.348 & 15.474 \\
\hline & $340-8$ & 0.350 & 4.026 & 0.0884 & 0 & 0 & 1.348 & 15.474 \\
\hline & $340-9$ & 0.350 & 4.026 & 0.0884 & 0 & 0 & 1.348 & 15.474 \\
\hline & $340-10$ & 0.350 & 4.026 & 0.0884 & 0 & 0 & 1.348 & 15.474 \\
\hline & $340-11$ & 0.350 & 4.026 & 0.0884 & 0 & 0 & 1.348 & 15.474 \\
\hline & $340-12$ & 0.350 & 4.026 & 0.0884 & 0 & 0 & 1.348 & 15.474 \\
\hline & $340-13$ & 0.350 & 4.026 & 0.0884 & 0 & 0 & 1.348 & 15.474 \\
\hline & $340-14$ & 0.350 & 4.026 & 0.0884 & 0 & 0 & 1.348 & 15.474 \\
\hline & $\mathbf{3 5 0 - 1}$ & 0.000 & 4.026 & 0.0884 & 0.019 & & 1.348 & 15.474 \\
\hline & $360-1$ & 0.506 & 4.026 & 0.0884 & 0 & 0 & 0.000 & 16.147 \\
\hline & $360-2$ & 0.506 & 4.026 & 0.0884 & 0 & 0 & 0.000 & 16.147 \\
\hline & $360-3$ & 0.506 & 4.026 & 0.0884 & 0 & 0 & 0.000 & 16.147 \\
\hline & $360-4$ & 0.506 & 4.026 & 0.0884 & 0.931 & 0 & 0.000 & 16.147 \\
\hline & $360-5$ & 0.900 & 6.065 & 0.2006 & 0 & 0 & 0.000 & 16.147 \\
\hline & $360-6$ & 0.900 & 6.065 & 0.2006 & 0 & 0 & 0.000 & 16.147 \\
\hline & $360-7$ & 0.900 & 6.065 & 0.2006 & & 0 & 0.000 & 16.147 \\
\hline
\end{tabular}




\section{Appendix C - VRS RELAP5 Code}

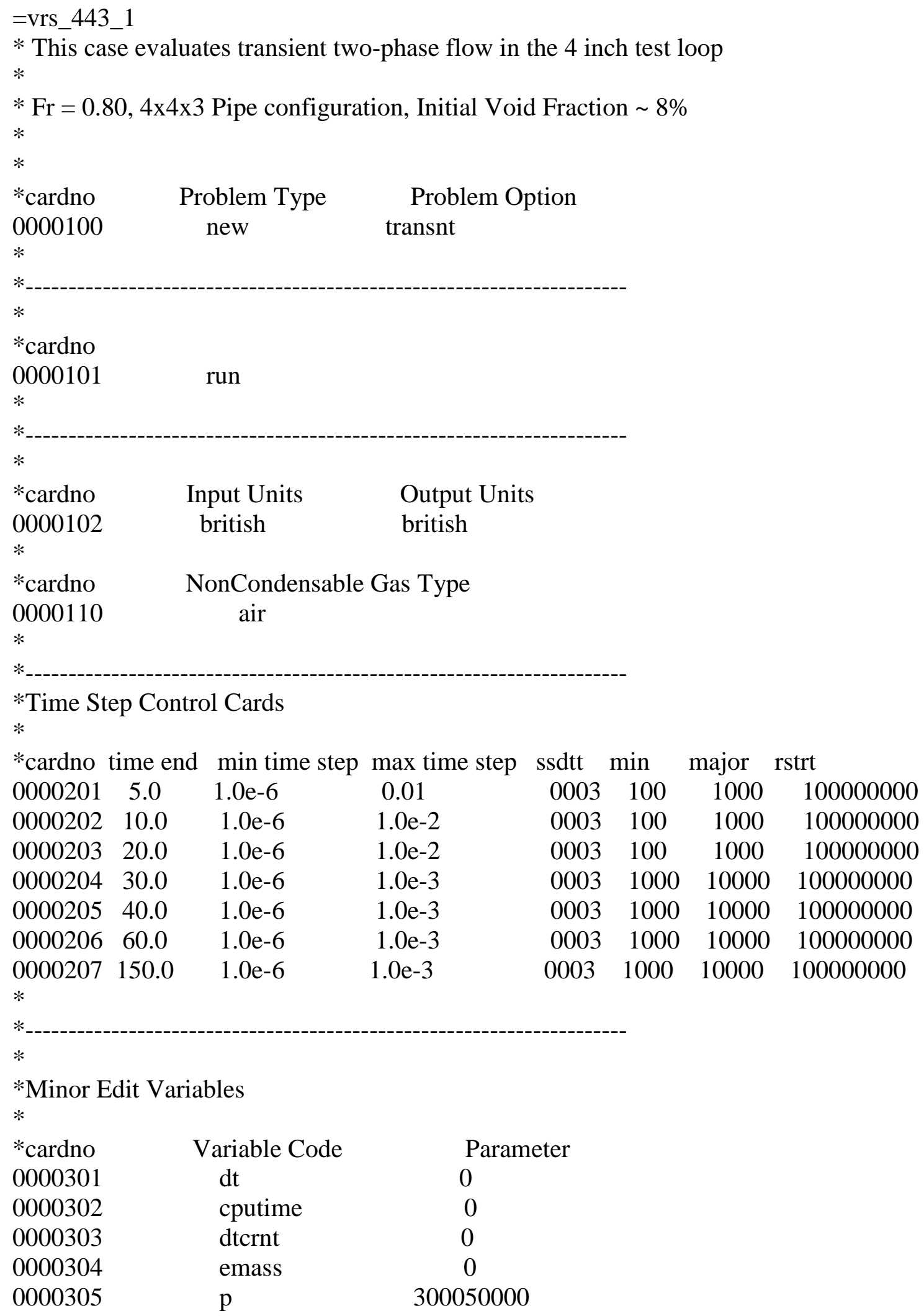

Variable Code

$\mathrm{dt}$

cputime dtcrnt emass $\mathrm{p}$

Parameter

0

0

0

0 300050000 


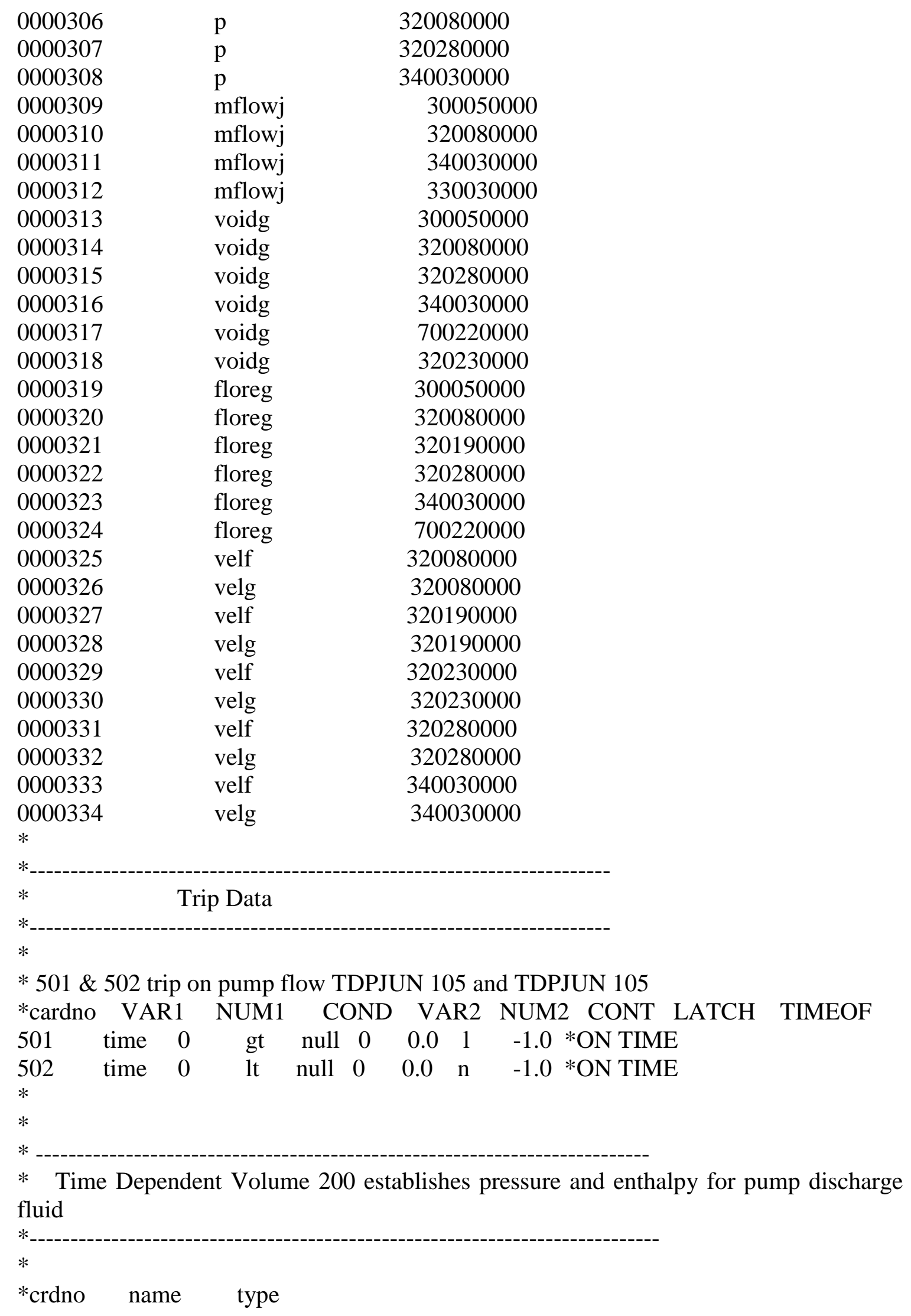




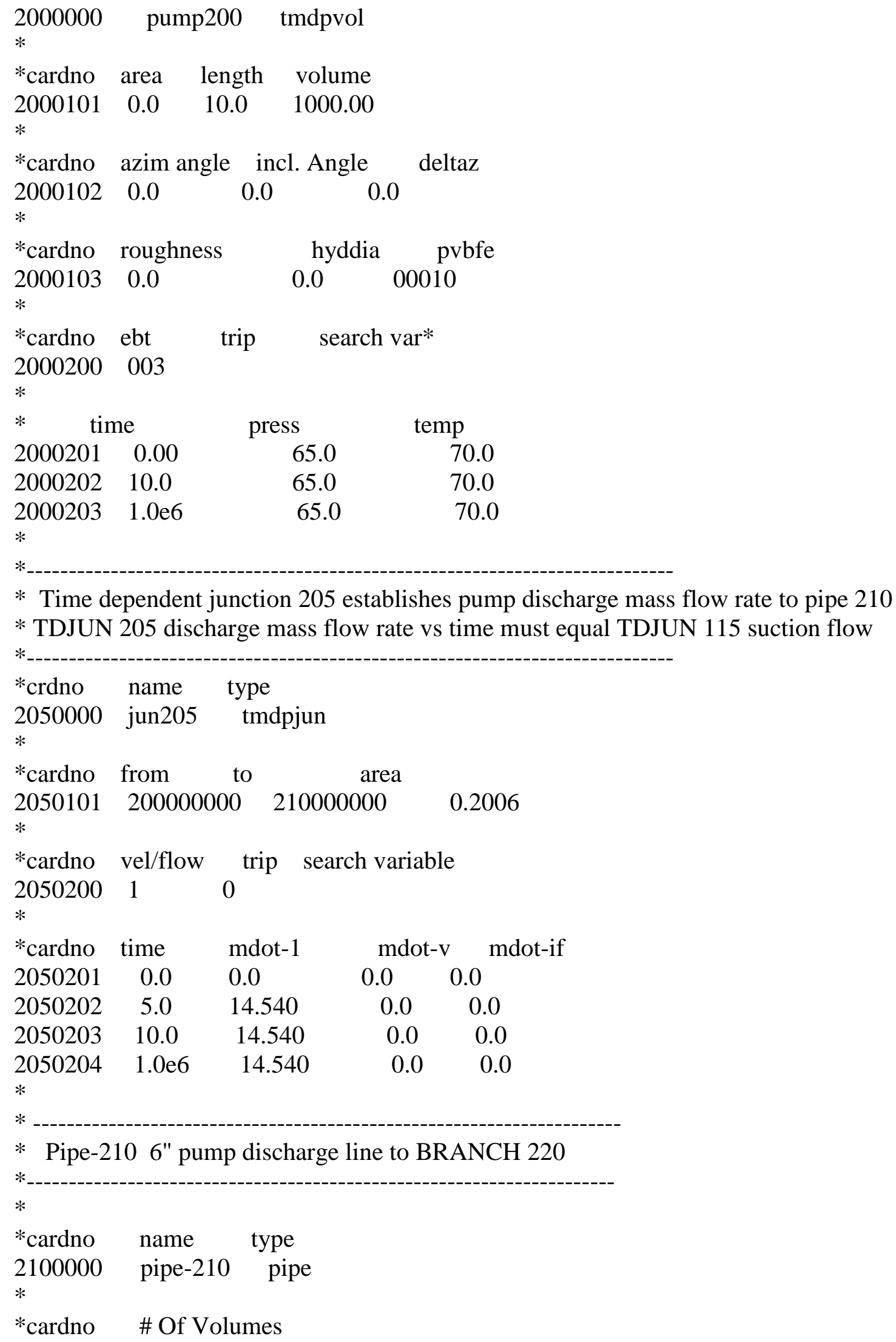




\begin{tabular}{|c|c|c|c|}
\hline $\begin{array}{l}2100001 \\
*\end{array}$ & \multicolumn{2}{|l|}{63} & \\
\hline *cardno & \multicolumn{2}{|c|}{ Volume Flow Area } & Volume Number \\
\hline 2100101 & \multicolumn{2}{|c|}{0.2006} & 27 \\
\hline 2100102 & \multicolumn{2}{|l|}{0.0884} & 33 \\
\hline $\begin{array}{l}2100103 \\
*\end{array}$ & \multicolumn{2}{|l|}{0.2006} & 63 \\
\hline *cardno & \multicolumn{2}{|c|}{ Junction Flow Area } & Junction Number \\
\hline 2100201 & \multicolumn{2}{|c|}{0.2006} & 26 \\
\hline 2100202 & \multicolumn{2}{|l|}{0.0884} & 32 \\
\hline $\begin{array}{l}2100203 \\
*\end{array}$ & \multicolumn{2}{|l|}{0.2006} & 62 \\
\hline *cardno & \multicolumn{2}{|c|}{ volume lengths } & Volume Number \\
\hline 2100301 & \multicolumn{2}{|c|}{1.0} & 25 \\
\hline 2100302 & \multicolumn{2}{|l|}{0.506} & 27 \\
\hline 2100303 & \multicolumn{2}{|l|}{0.5} & 33 \\
\hline $\begin{array}{l}2100304 \\
*\end{array}$ & \multicolumn{2}{|l|}{0.506} & 63 \\
\hline *cardno & \multicolumn{2}{|l|}{ Volume } & Volume Number \\
\hline $\begin{array}{l}2100401 \\
*\end{array}$ & \multicolumn{2}{|l|}{0.0} & 63 \\
\hline *cardno & \multicolumn{2}{|c|}{ Vertical Angle } & Volume Number \\
\hline 2100601 & \multicolumn{2}{|c|}{0.0} & 4 \\
\hline 2100602 & \multicolumn{2}{|l|}{-90.0} & 8 \\
\hline 2100603 & \multicolumn{2}{|l|}{0.0} & 42 \\
\hline 2100604 & \multicolumn{2}{|l|}{90.0} & 58 \\
\hline $\begin{array}{l}2100605 \\
*\end{array}$ & \multicolumn{2}{|l|}{0.0} & 63 \\
\hline *cardno & rough & dhyd & Volume Number \\
\hline 2100801 & 0.00015 & 0.5054 & 27 \\
\hline 2100802 & 0.00015 & 0.3355 & 33 \\
\hline $\begin{array}{l}2100803 \\
*\end{array}$ & 0.00015 & 0.5054 & 63 \\
\hline *cardno & kfor & krev & Junction Number \\
\hline 2100901 & 0.0 & 0.0 & 3 \\
\hline 2100902 & 0.45 & 0.45 & 4 \\
\hline 2100903 & 0.0 & 0.0 & 7 \\
\hline 2100904 & 0.45 & 0.45 & 8 \\
\hline 2100905 & 0.0 & 0.0 & 26 \\
\hline 2100906 & 0.931 & 0.30 & 27 \\
\hline 2100907 & 0.0 & 0.0 & 32 \\
\hline 2100908 & 0.309 & 0.931 & 33 \\
\hline 2100909 & 0.0 & 0.0 & 36 \\
\hline 2100910 & 0.0 & 0.0 & 37 \\
\hline 2100911 & 0.0 & 0.0 & 41 \\
\hline 2100912 & 0.45 & 0.45 & 42 \\
\hline
\end{tabular}




$\begin{array}{llll}2100913 & 0.0 & 0.0 & 57 \\ 2100914 & 0.45 & 0.45 & 58 \\ 2100915 & 0.0 & 0.0 & 62\end{array}$

*

*cardno tlpvbfe Volume Number

$2101001 \quad 0010000 \quad 63$

$*$

*cardno efvchas Junction Number

$2101101 \quad 0001000 \quad 62$

*

*cardno ic press temp qual vol.

$\begin{array}{llllllll}2101201 & 3 & 14.584 & 70.0 & 0.0 & 0.0 & 0.0 & 4\end{array}$

$\begin{array}{llllllll}2101202 & 3 & 14.800 & 70.0 & 0.0 & 0.0 & 0.0 & 5\end{array}$

$\begin{array}{llllllll}2101203 & 3 & 15.233 & 70.0 & 0.0 & 0.0 & 0.0 & 6\end{array}$

$\begin{array}{llllllll}2101204 & 3 & 15.666 & 70.0 & 0.0 & 0.0 & 0.0 & 7\end{array}$

$\begin{array}{llllllll}2101205 & 3 & 16.099 & 70.0 & 0.0 & 0.0 & 0.0 & 42\end{array}$

$\begin{array}{llllllll}2101206 & 3 & 15.880 & 70.0 & 0.0 & 0.0 & 0.0 & 43\end{array}$

$\begin{array}{llllllll}2101207 & 3 & 15.661 & 70.0 & 0.0 & 0.0 & 0.0 & 44\end{array}$

$\begin{array}{llllllll}2101208 & 3 & 15.442 & 70.0 & 0.0 & 0.0 & 0.0 & 45\end{array}$

$\begin{array}{llllllll}2101209 & 3 & 15.223 & 70.0 & 0.0 & 0.0 & 0.0 & 46\end{array}$

$\begin{array}{llllllll}2101210 & 3 & 15.004 & 70.0 & 0.0 & 0.0 & 0.0 & 47\end{array}$

$\begin{array}{llllllll}2101211 & 3 & 14.785 & 70.0 & 0.0 & 0.0 & 0.0 & 48\end{array}$

$\begin{array}{llllllll}2101212 & 3 & 14.565 & 70.0 & 0.0 & 0.0 & 0.0 & 49\end{array}$

$\begin{array}{llllllll}2101213 & 3 & 14.346 & 70.0 & 0.0 & 0.0 & 0.0 & 50\end{array}$

$\begin{array}{llllllll}2101214 & 3 & 14.127 & 70.0 & 0.0 & 0.0 & 0.0 & 51\end{array}$

$\begin{array}{llllllll}2101215 & 3 & 14.908 & 70.0 & 0.0 & 0.0 & 0.0 & 52\end{array}$

$\begin{array}{llllllll}2101216 & 3 & 13.689 & 70.0 & 0.0 & 0.0 & 0.0 & 53\end{array}$

$\begin{array}{llllllll}2101217 & 3 & 13.470 & 70.0 & 0.0 & 0.0 & 0.0 & 54\end{array}$

$\begin{array}{llllllll}2101218 & 3 & 13.251 & 70.0 & 0.0 & 0.0 & 0.0 & 55\end{array}$

$\begin{array}{llllllll}2101219 & 3 & 13.032 & 70.0 & 0.0 & 0.0 & 0.0 & 56\end{array}$

$\begin{array}{llllllll}2101220 & 3 & 12.813 & 70.0 & 0.0 & 0.0 & 0.0 & 57\end{array}$

$\begin{array}{llllllll}2101221 & 3 & 12.594 & 70.0 & 0.0 & 0.0 & 0.0 & 63\end{array}$

*

*cardno vel/flow

$2101300 \quad 1$

$*$

*cardno liqflow vaporf interv jun

$\begin{array}{lllll}2101301 & 0.0 & 0.0 & 0.0 & 62\end{array}$

$*$

*cardno jet dh beta c m jun

$\begin{array}{llllll}2101401 & 0.0 & 0.0 & 1.0 & 1.0 & 62\end{array}$

*

$*$

$*$

* Branch 220 6"х6"x6" branch tee connecting pipe-210, pipe-500, and pipe-230 


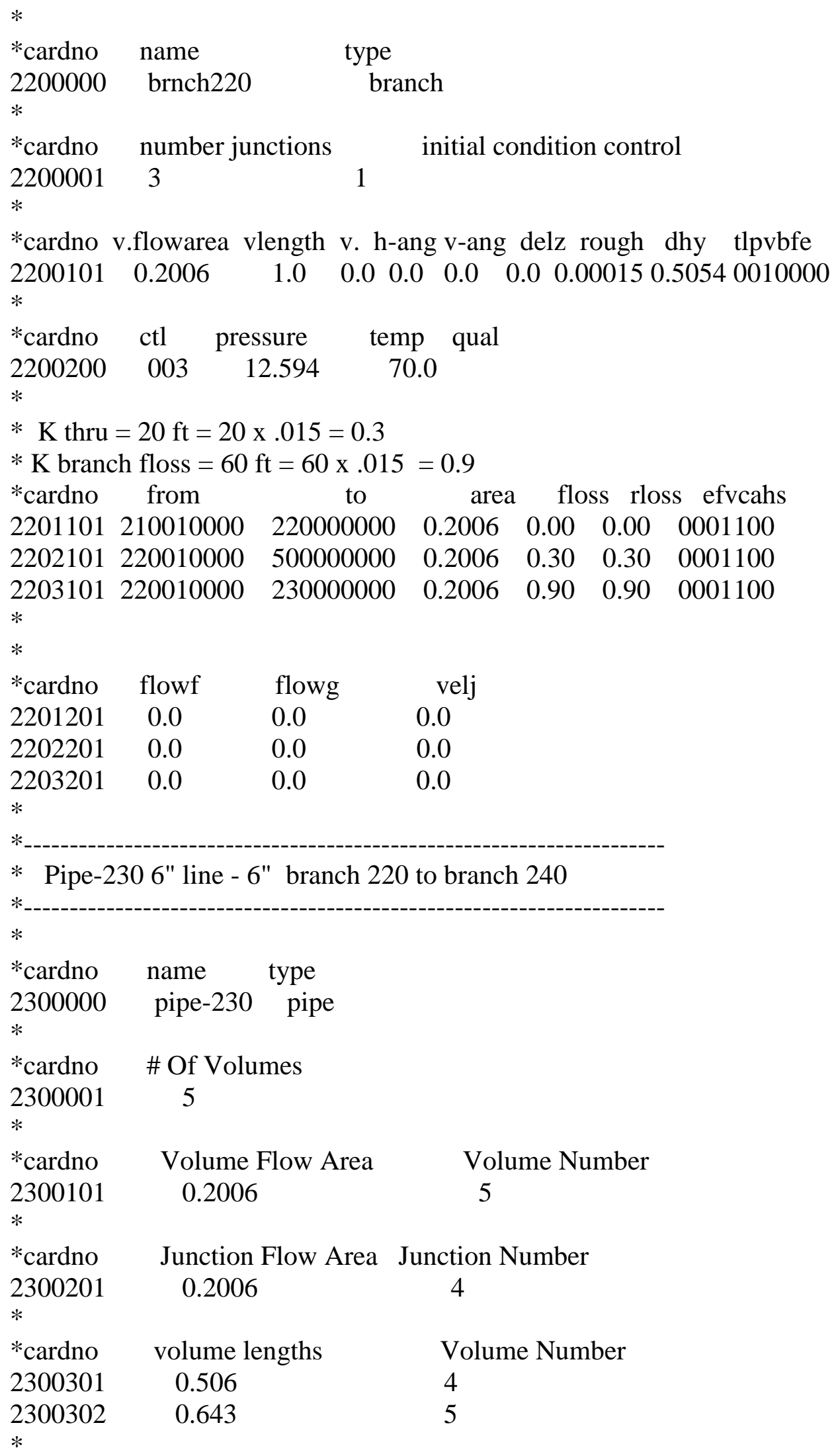




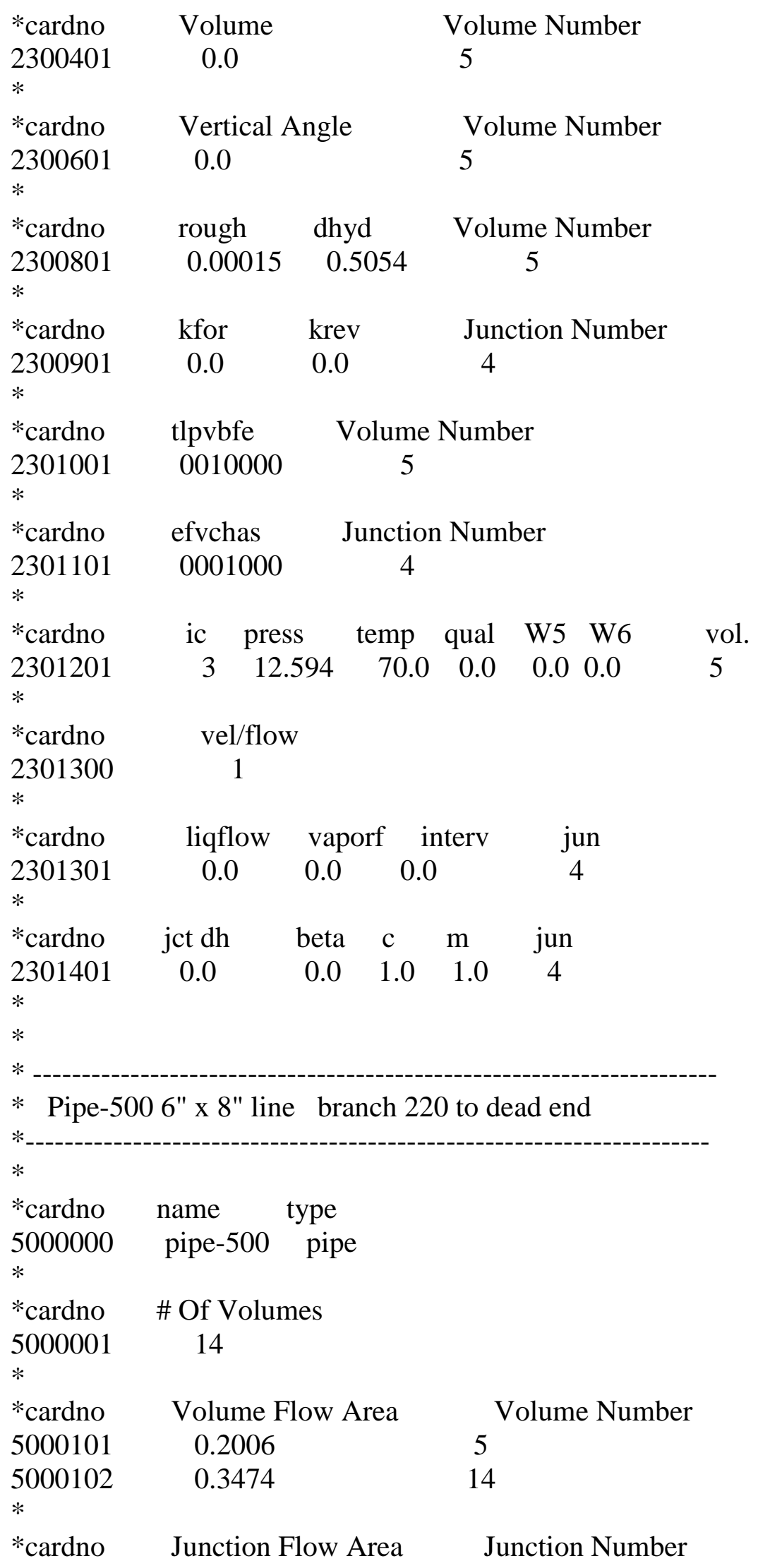




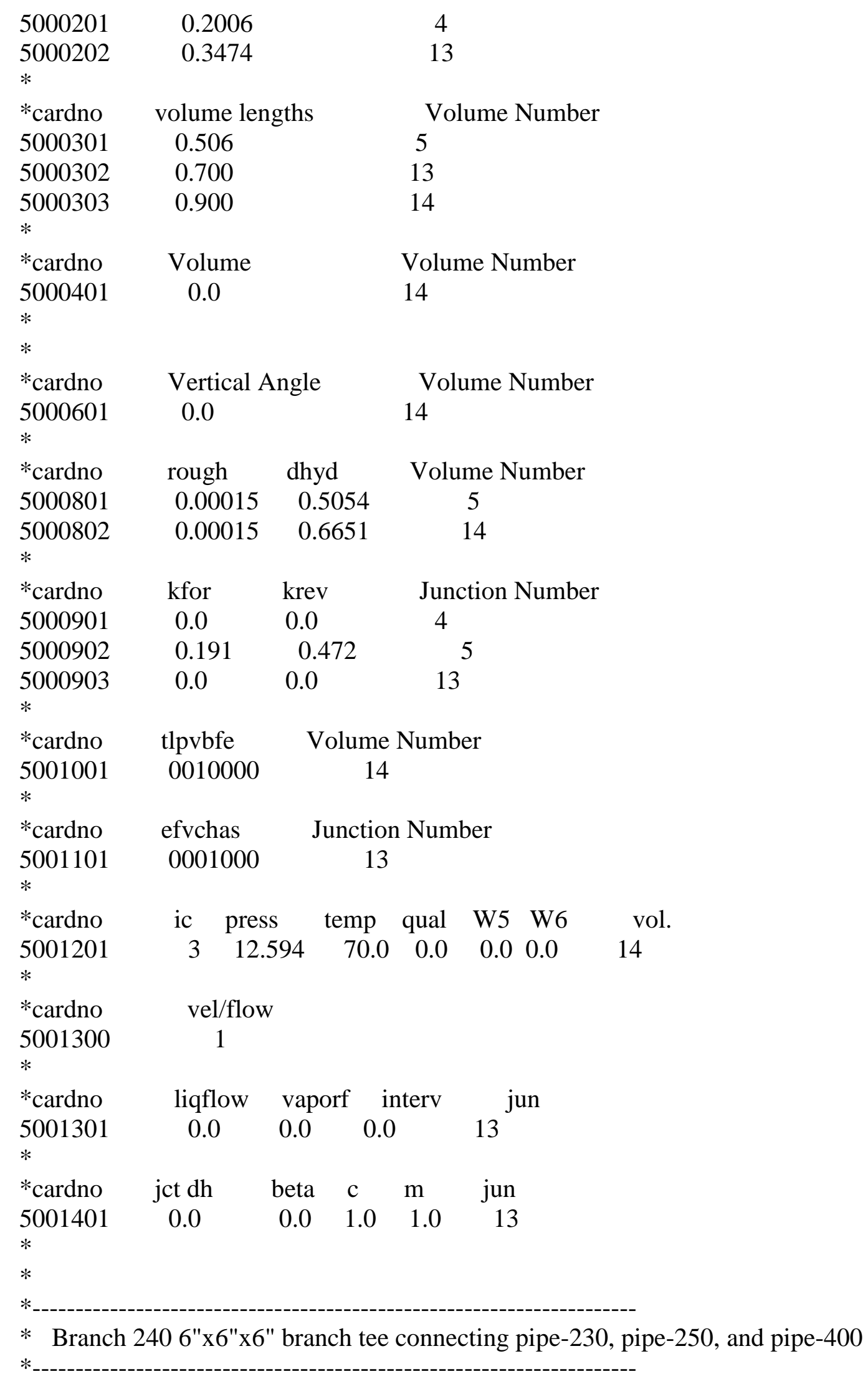




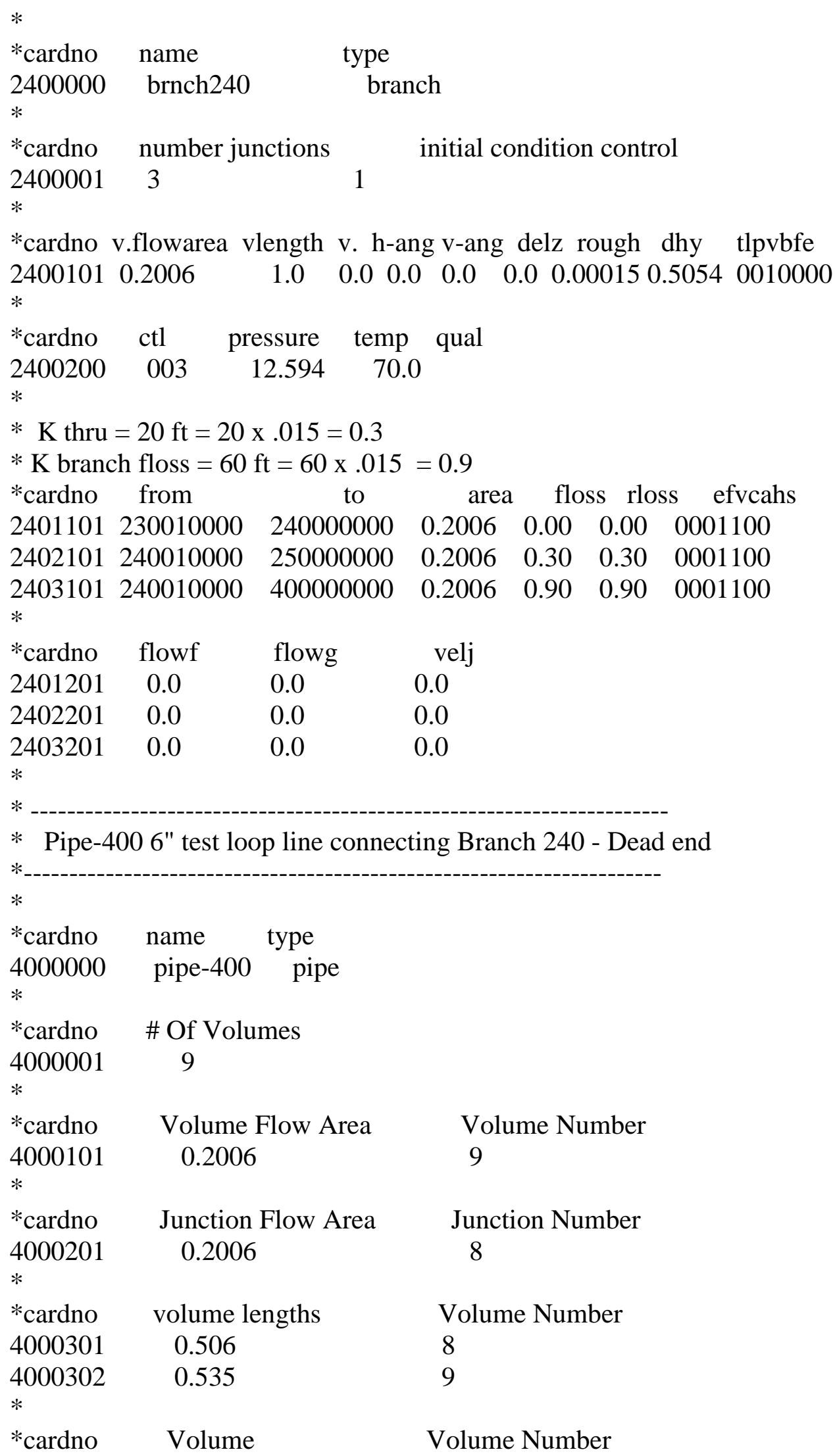




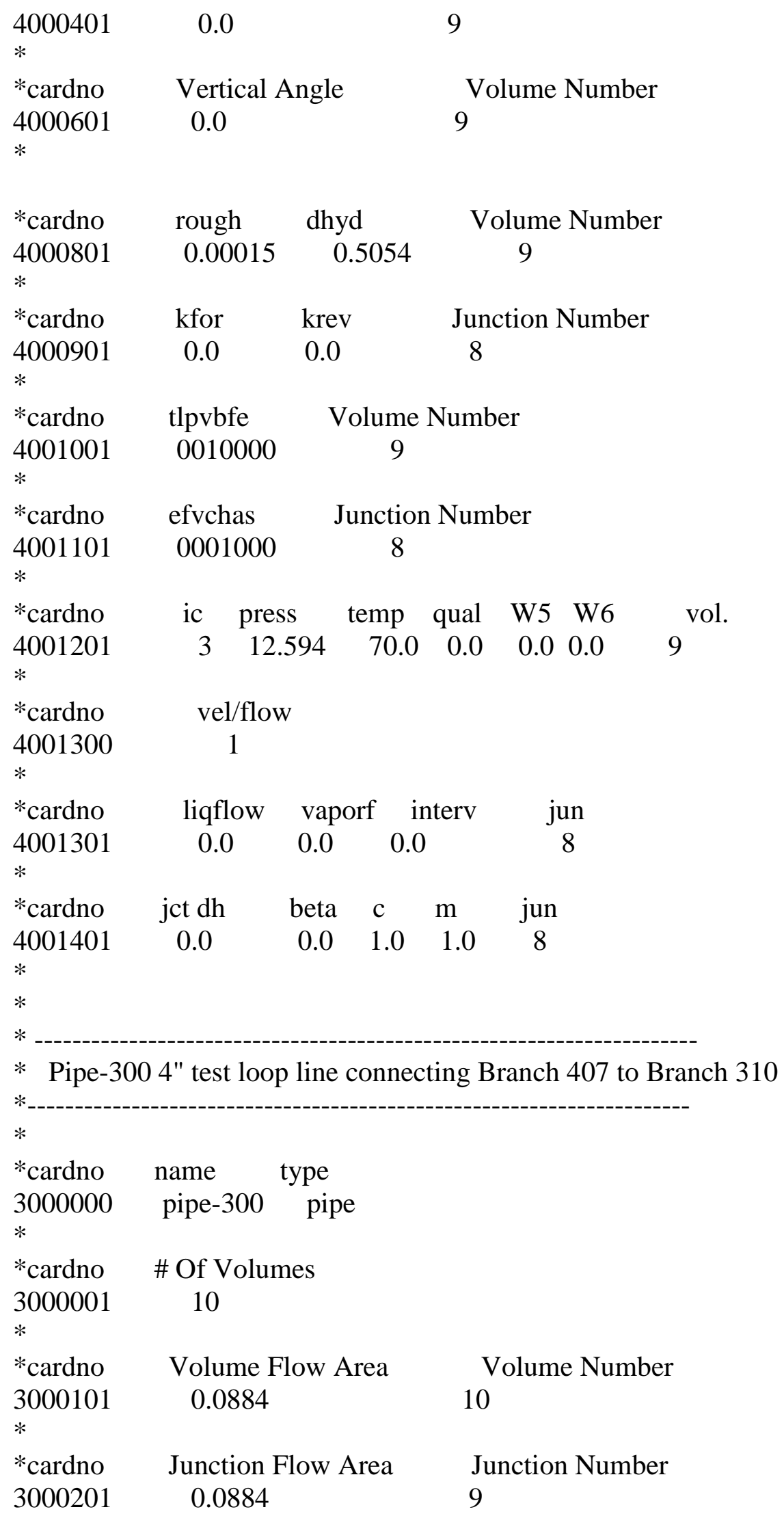




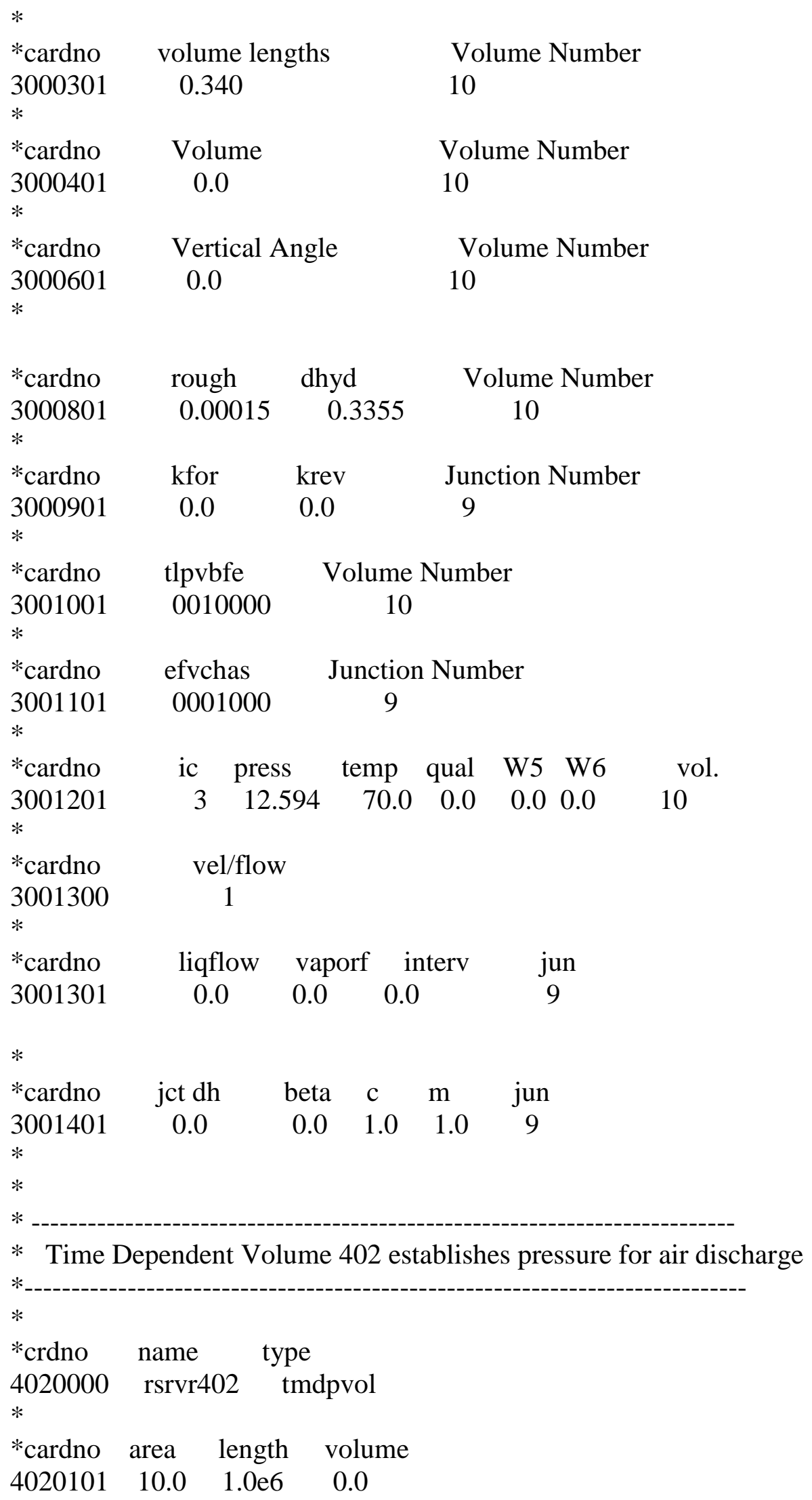




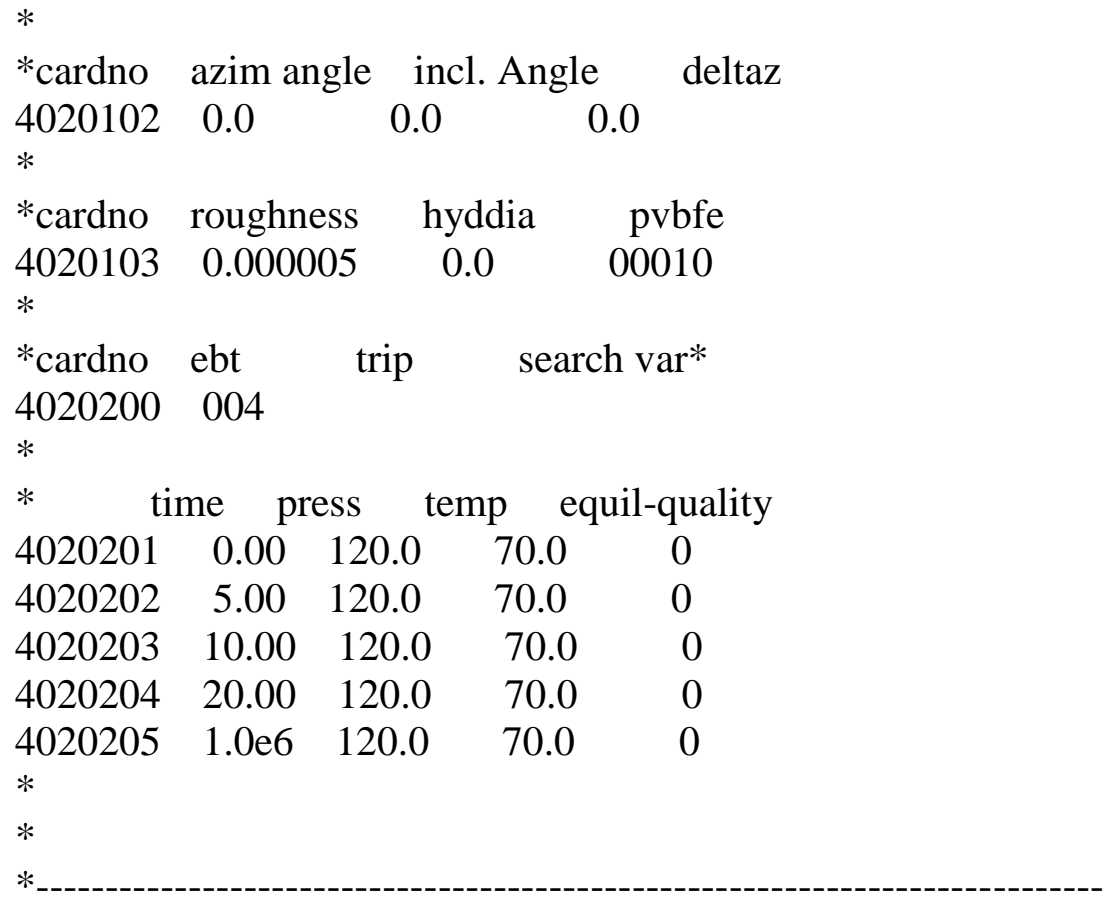

* Time dependent junction 403 establishes air compressor discharge flowrate to SNGLVOL 404

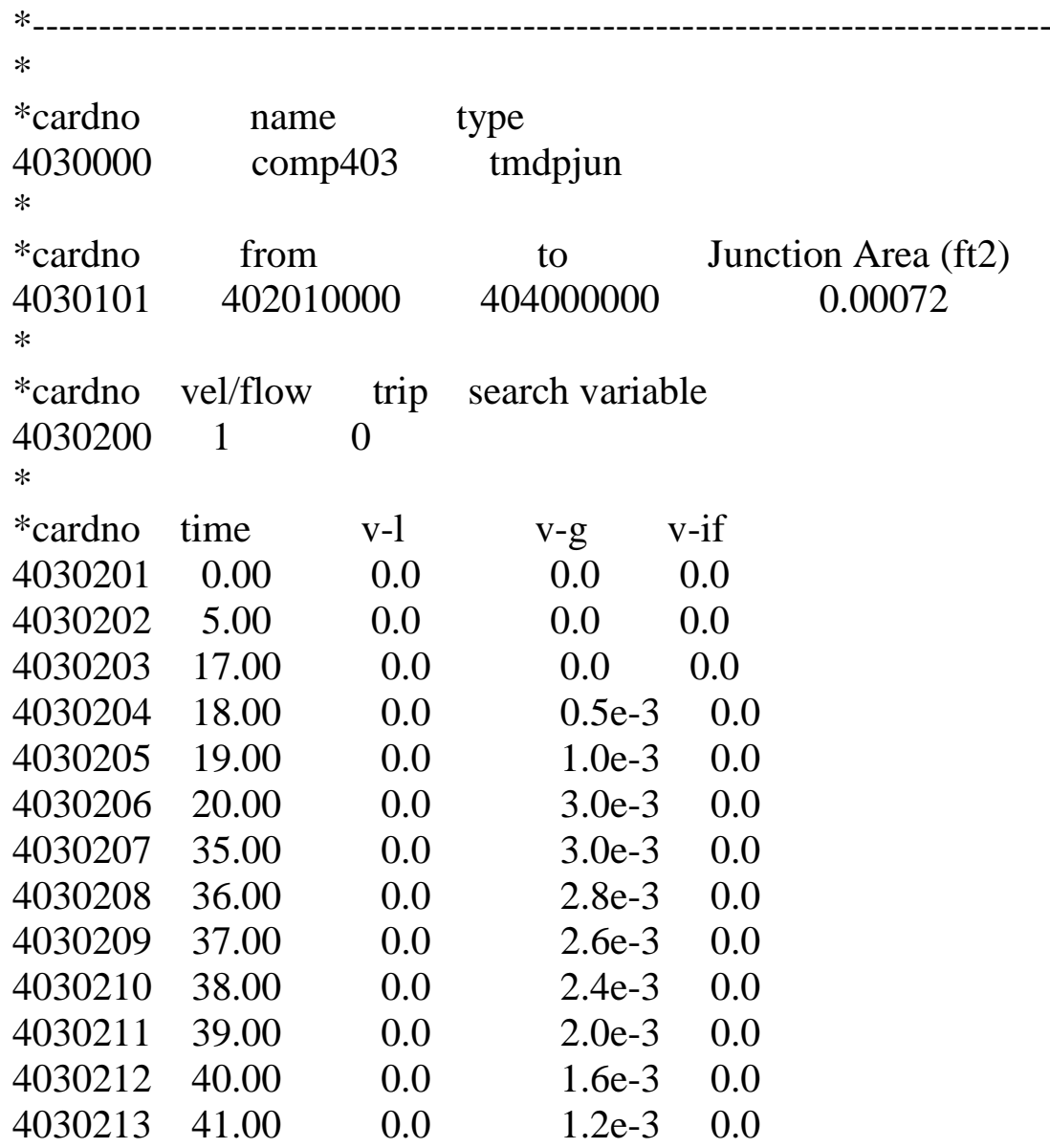




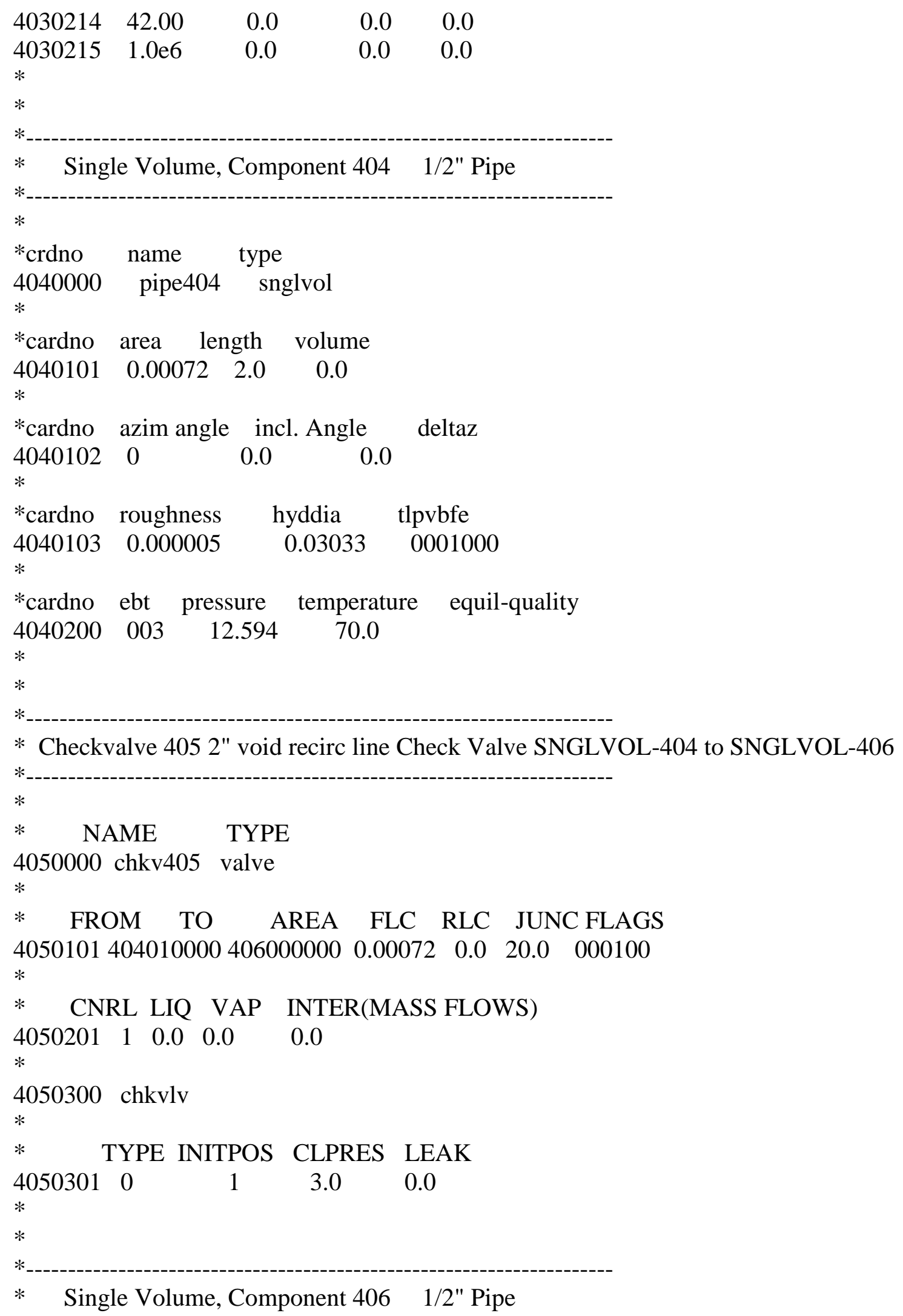




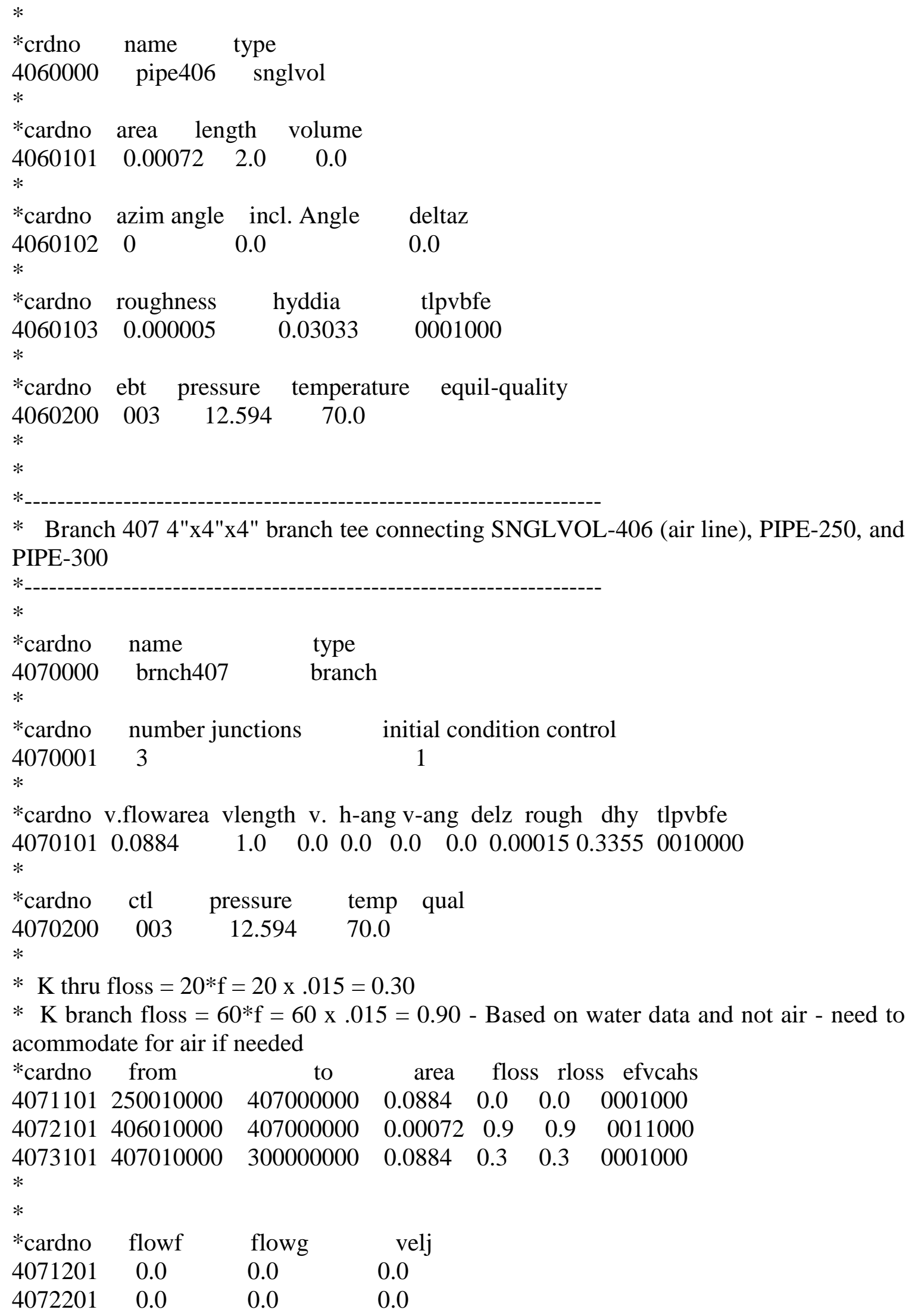




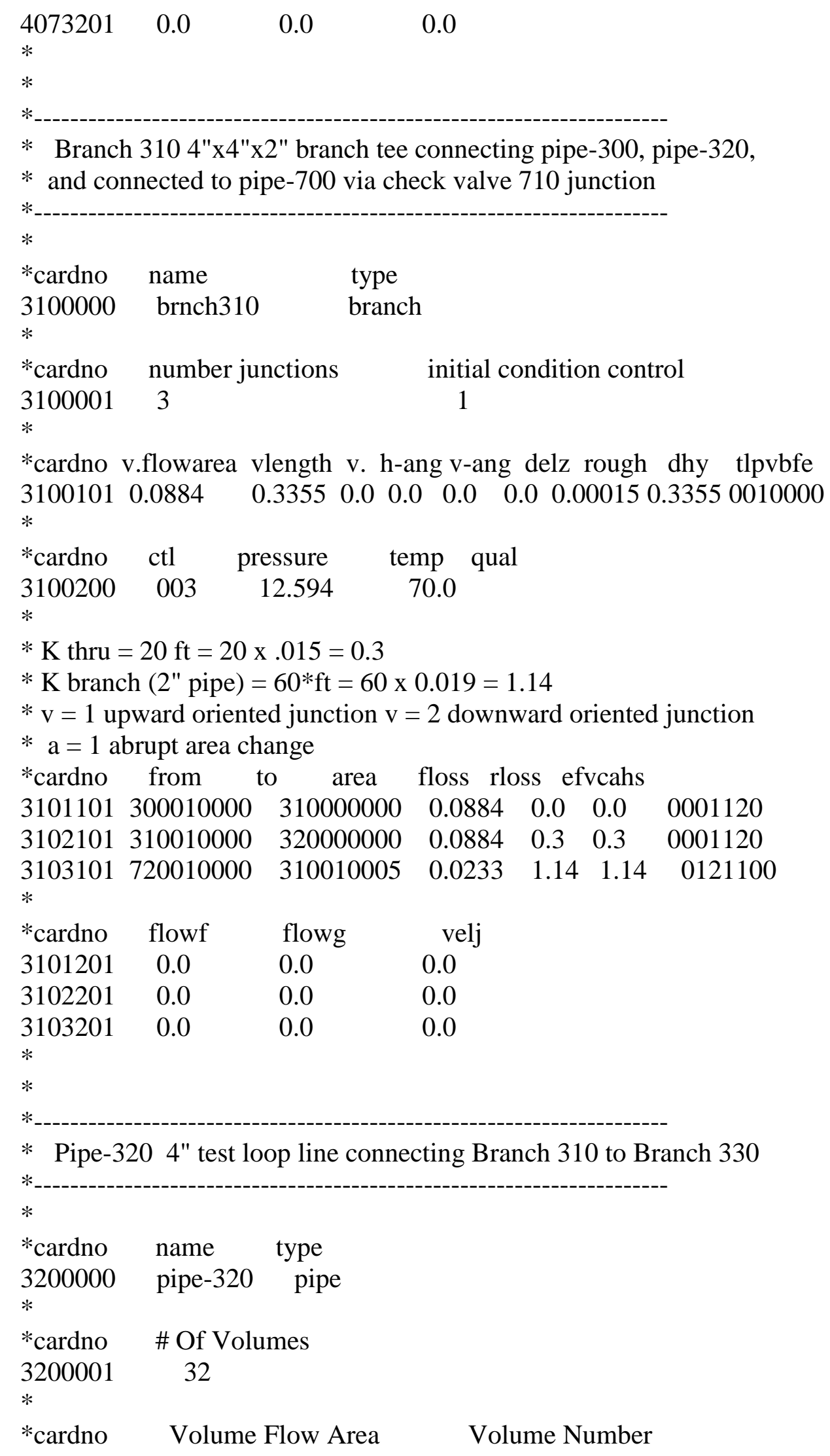




\begin{tabular}{|c|c|c|c|c|c|c|}
\hline $\begin{array}{l}3200101 \\
*\end{array}$ & \multicolumn{4}{|c|}{0.0884} & \multicolumn{2}{|l|}{32} \\
\hline $\begin{array}{l}* \text { cardno } \\
3200201 \\
*\end{array}$ & \multicolumn{4}{|c|}{0.2006} & \multicolumn{2}{|c|}{31} \\
\hline *cardno & \multicolumn{4}{|c|}{ volume lengths } & \multicolumn{2}{|c|}{ Volume Number } \\
\hline 3200301 & \multicolumn{4}{|c|}{0.340} & \multicolumn{2}{|c|}{10} \\
\hline 3200302 & \multicolumn{4}{|c|}{0.500} & \multicolumn{2}{|l|}{11} \\
\hline 3200303 & \multicolumn{4}{|c|}{0.657} & \multicolumn{2}{|l|}{21} \\
\hline 3200304 & \multicolumn{4}{|c|}{0.500} & \multicolumn{2}{|l|}{22} \\
\hline $\begin{array}{l}3200305 \\
*\end{array}$ & \multicolumn{4}{|c|}{0.340} & \multicolumn{2}{|l|}{32} \\
\hline *cardno & \multicolumn{4}{|c|}{ Volume } & \multicolumn{2}{|c|}{ Volume Number } \\
\hline $\begin{array}{l}3200401 \\
*\end{array}$ & \multicolumn{4}{|c|}{0.0} & \multicolumn{2}{|c|}{32} \\
\hline *cardno & \multicolumn{4}{|c|}{ Vertical Angle } & \multicolumn{2}{|c|}{ Volume Number } \\
\hline 3200601 & \multicolumn{4}{|c|}{0.0} & \multicolumn{2}{|c|}{10} \\
\hline 3200602 & \multicolumn{4}{|c|}{-45.0} & \multicolumn{2}{|l|}{11} \\
\hline 3200603 & & 90.0 & & & 21 & \\
\hline 3200604 & & 45.0 & & & 22 & \\
\hline $\begin{array}{l}3200605 \\
*\end{array}$ & & 0.0 & & & 32 & \\
\hline *cardno & & ough & dhyd & & Volume $\mathrm{N}$ & Number \\
\hline $\begin{array}{l}3200801 \\
*\end{array}$ & & 0.00015 & 0.335 & & 32 & \\
\hline *cardno & & xfor & krev & & Junction $\mathrm{N}$ & Number \\
\hline 3200901 & & 0.00 & 0.00 & & 9 & \\
\hline 3200902 & & 0.51 & 0.51 & & 10 & \\
\hline 3200903 & & 0.00 & 0.00 & & 20 & \\
\hline 3200904 & & 0.51 & 0.51 & & 21 & \\
\hline $\begin{array}{l}3200905 \\
*\end{array}$ & & 0.00 & 0.00 & & 31 & \\
\hline *cardno & & pvbfe & Volu & Ime $\mathrm{N}$ & Number & \\
\hline $\begin{array}{l}3201001 \\
*\end{array}$ & & 0010000 & & 32 & & \\
\hline *cardno & & fvcahs & Junc & ction & Number & \\
\hline 3201101 & & 0001000 & & 20 & & \\
\hline $\begin{array}{l}3201102 \\
*\end{array}$ & & 0000000 & & 31 & & \\
\hline *cardno & ic & press & temp & qual & & ol. \\
\hline 3201201 & 3 & 12.594 & 70.0 & 0.0 & $\begin{array}{lll}0.0 & 0.0\end{array}$ & 10 \\
\hline 3201202 & 3 & 12.646 & 70.0 & 0.0 & $\begin{array}{lll}0.0 & 0.0\end{array}$ & 11 \\
\hline 3201203 & 3 & 12.752 & 70.0 & 0.0 & $\begin{array}{lll}0.0 & 0.0\end{array}$ & 12 \\
\hline 3201204 & 3 & 13.068 & 70.0 & 0.0 & $\begin{array}{lll}0.0 & 0.0\end{array}$ & 13 \\
\hline 3201205 & 3 & 13.384 & 70.0 & 0.0 & $\begin{array}{lll}0.0 & 0.0\end{array}$ & 14 \\
\hline 3201206 & 3 & 13.700 & 70.0 & 0.0 & $0.0 \quad 0.0$ & 15 \\
\hline
\end{tabular}




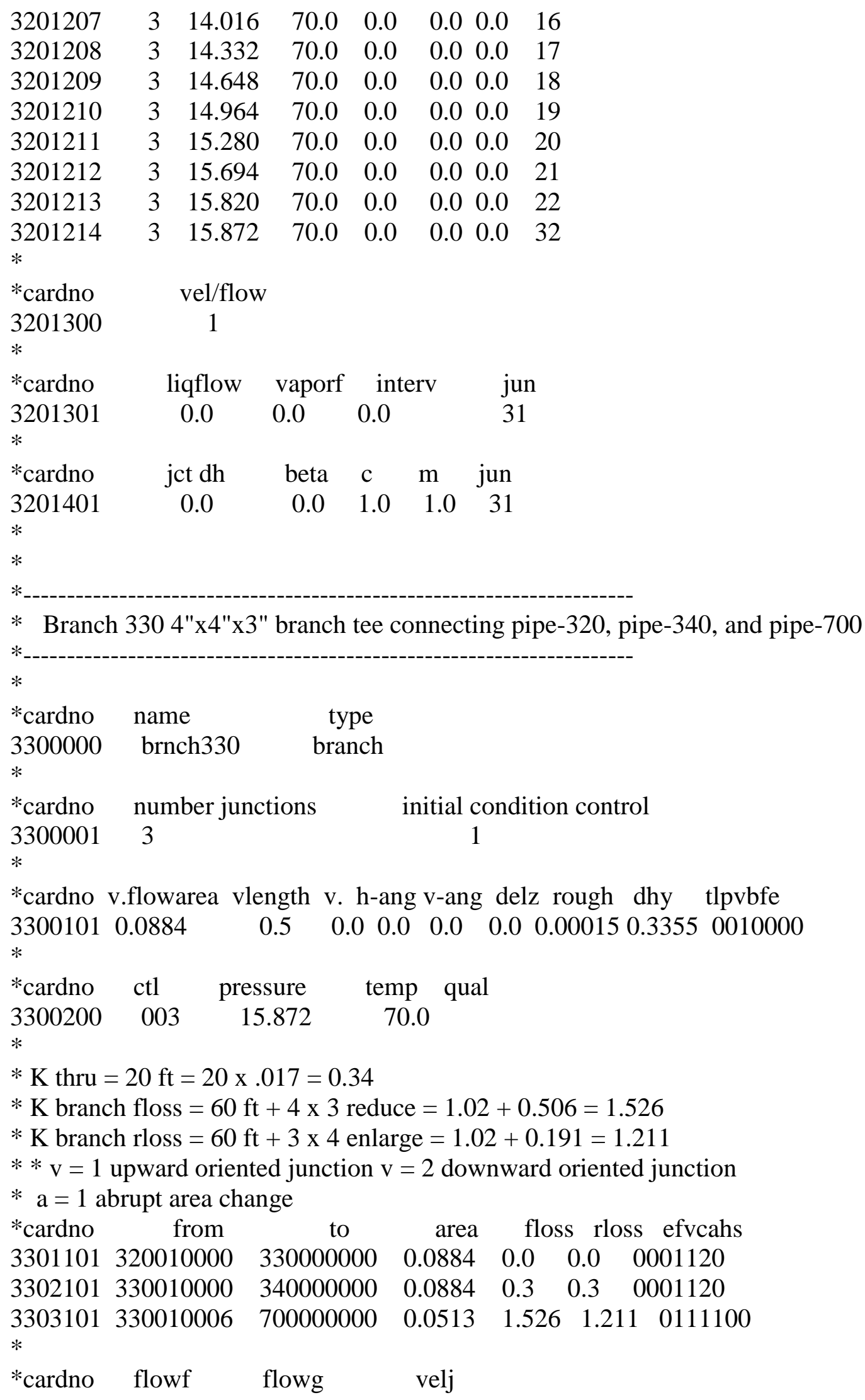




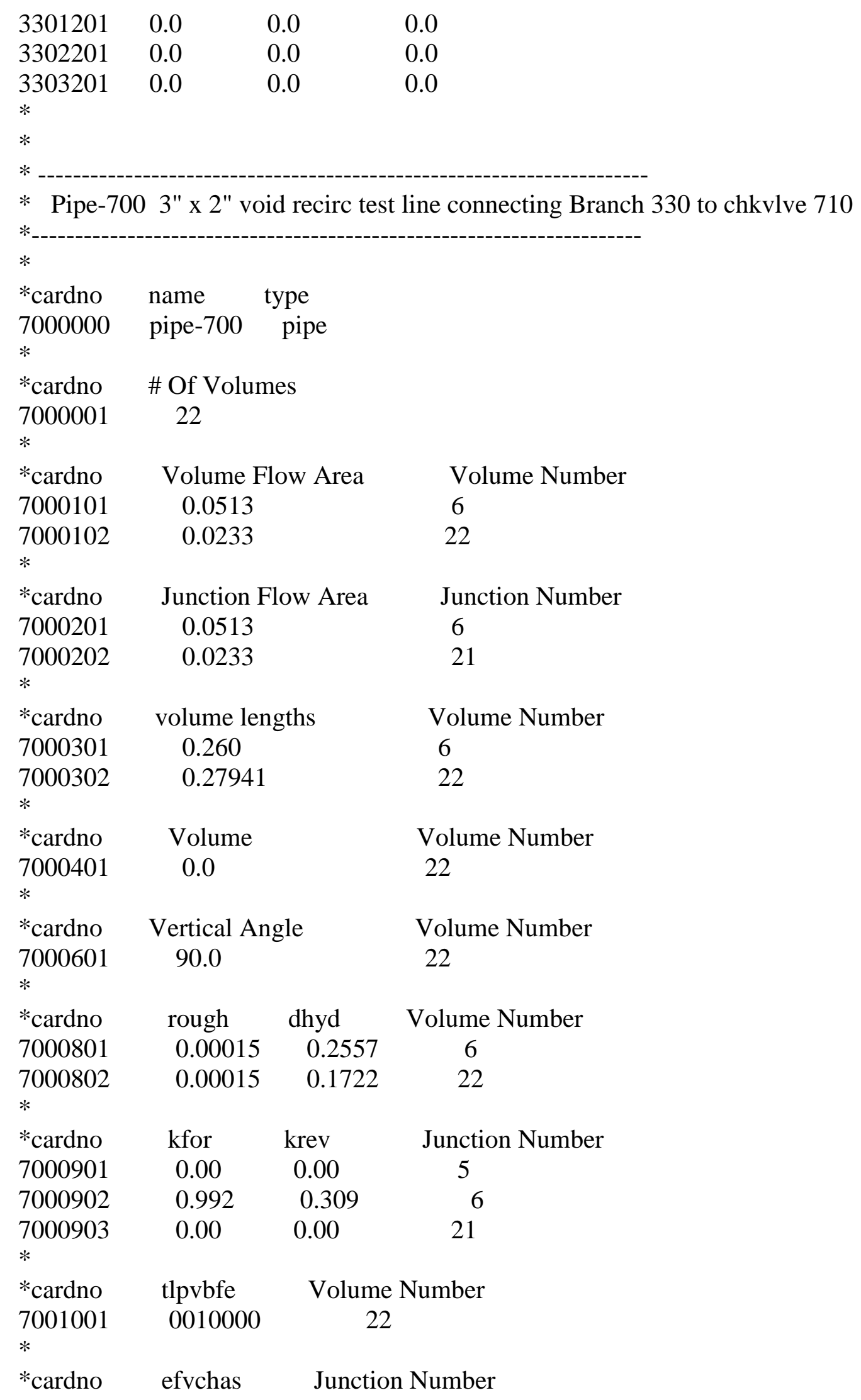




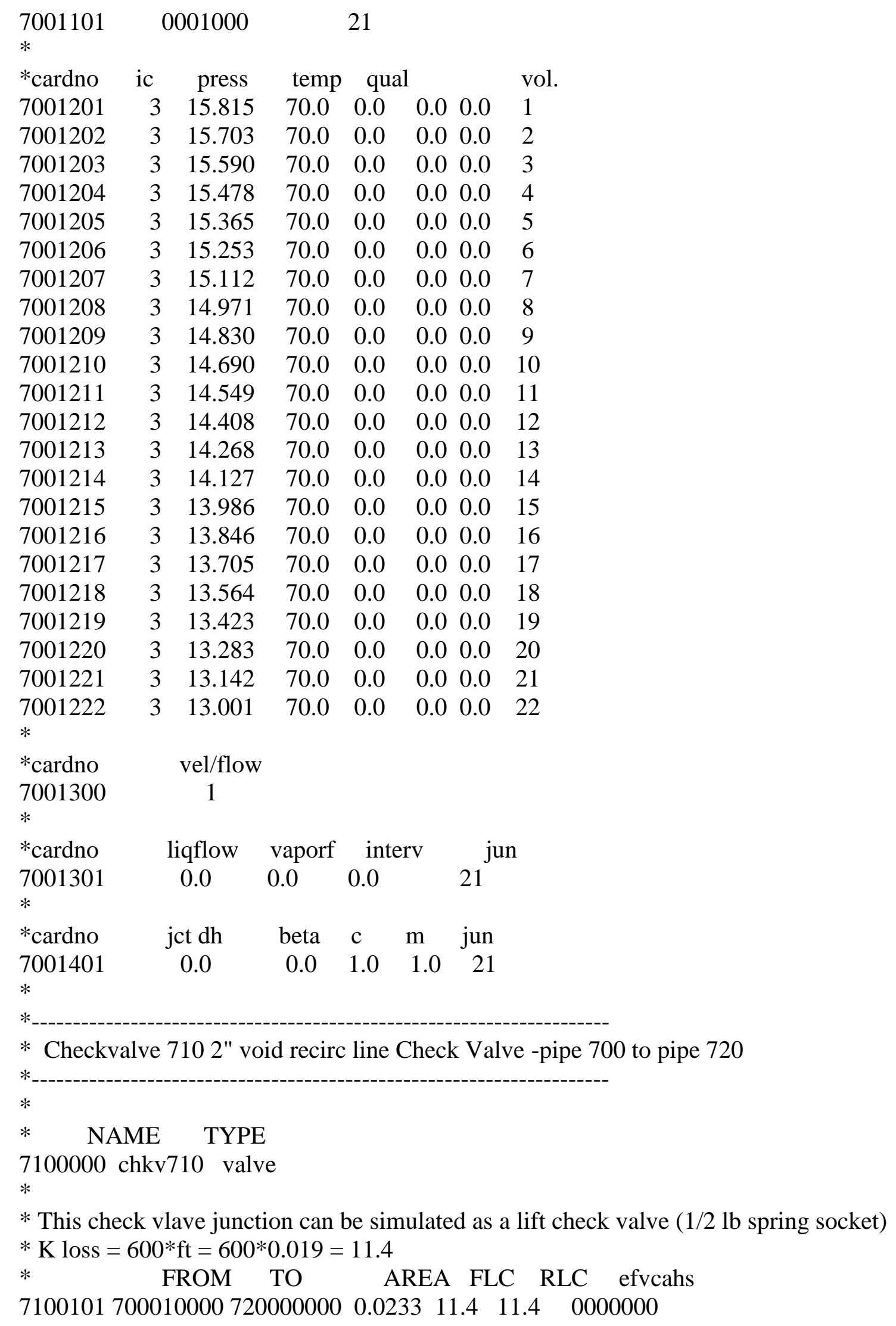




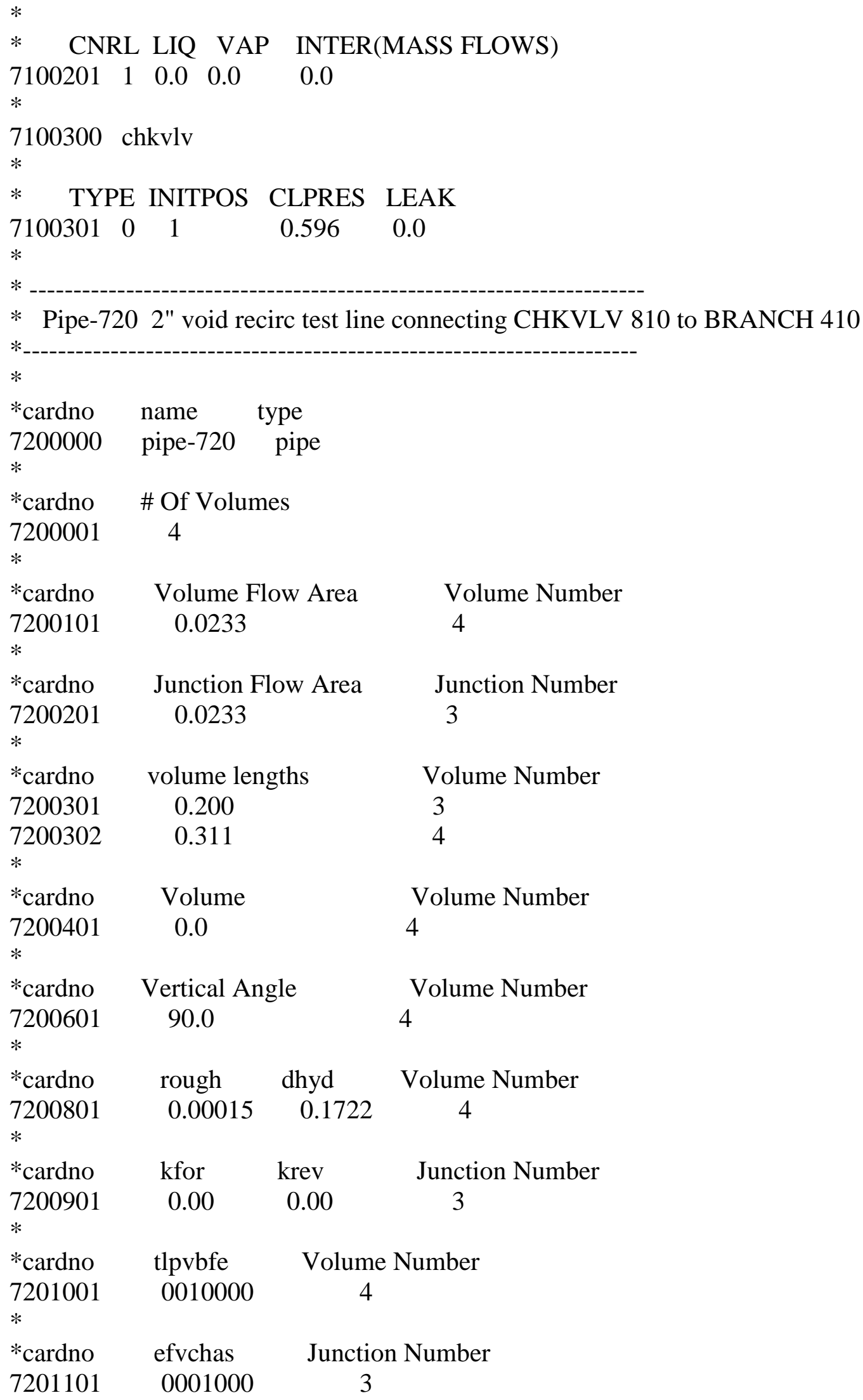




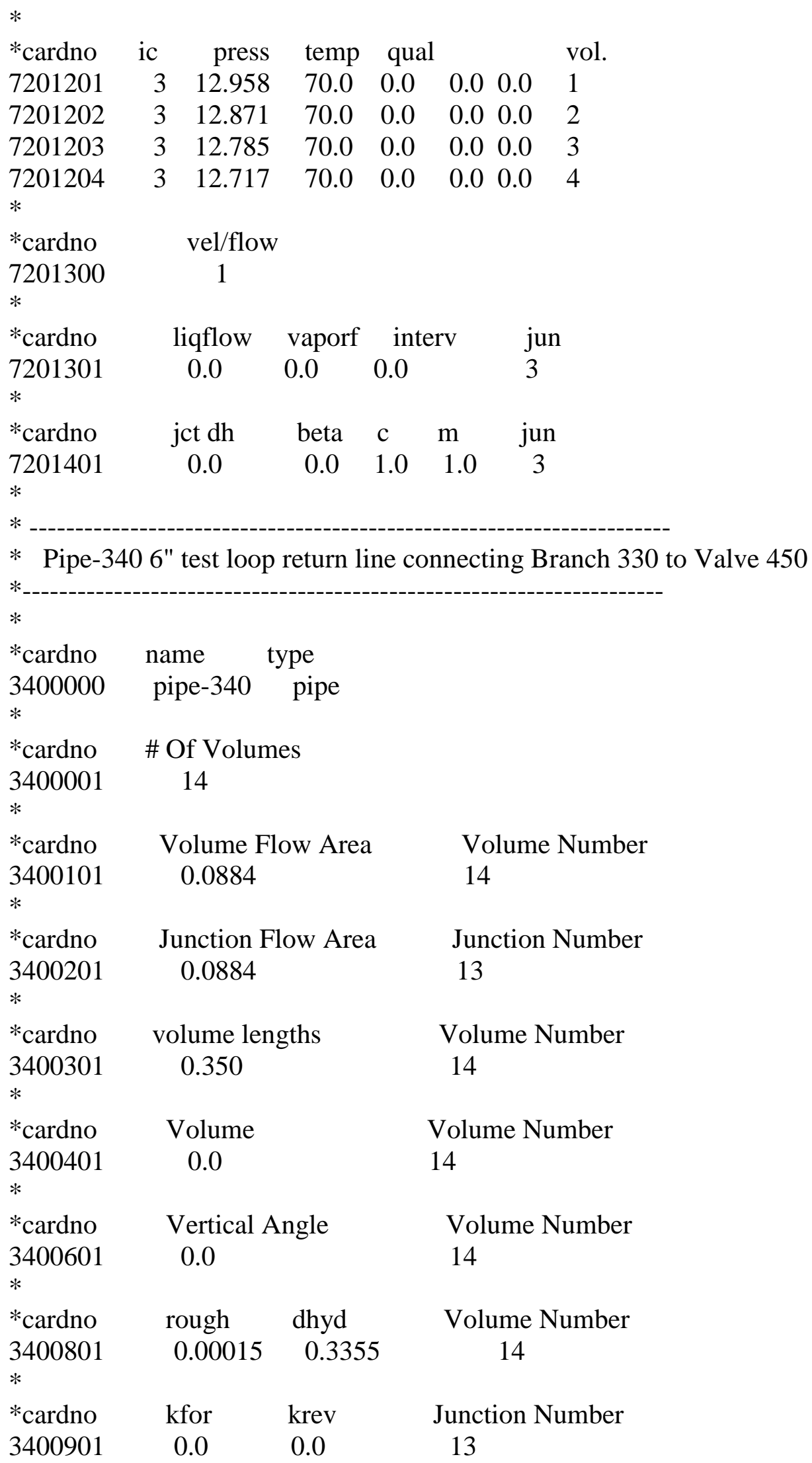




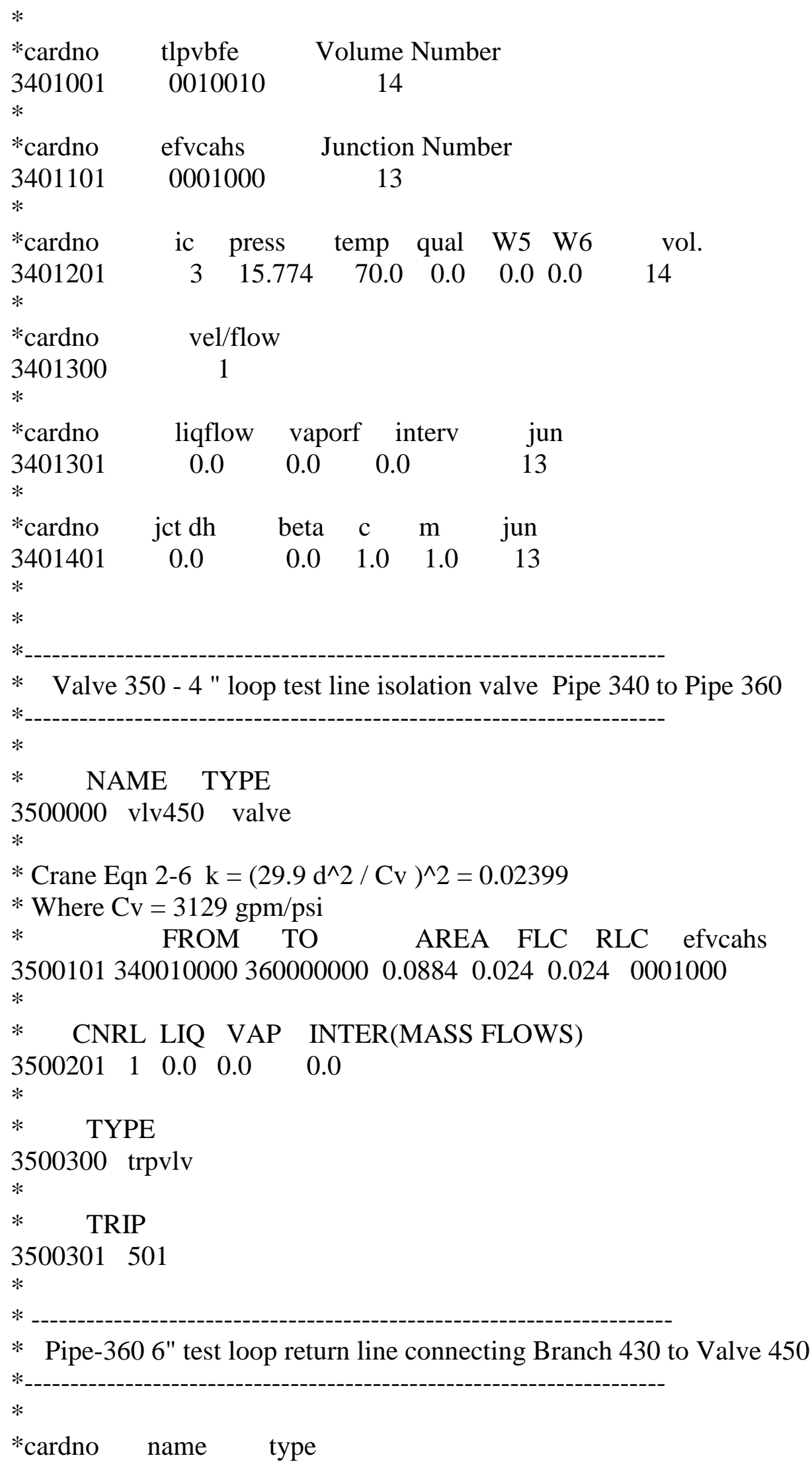




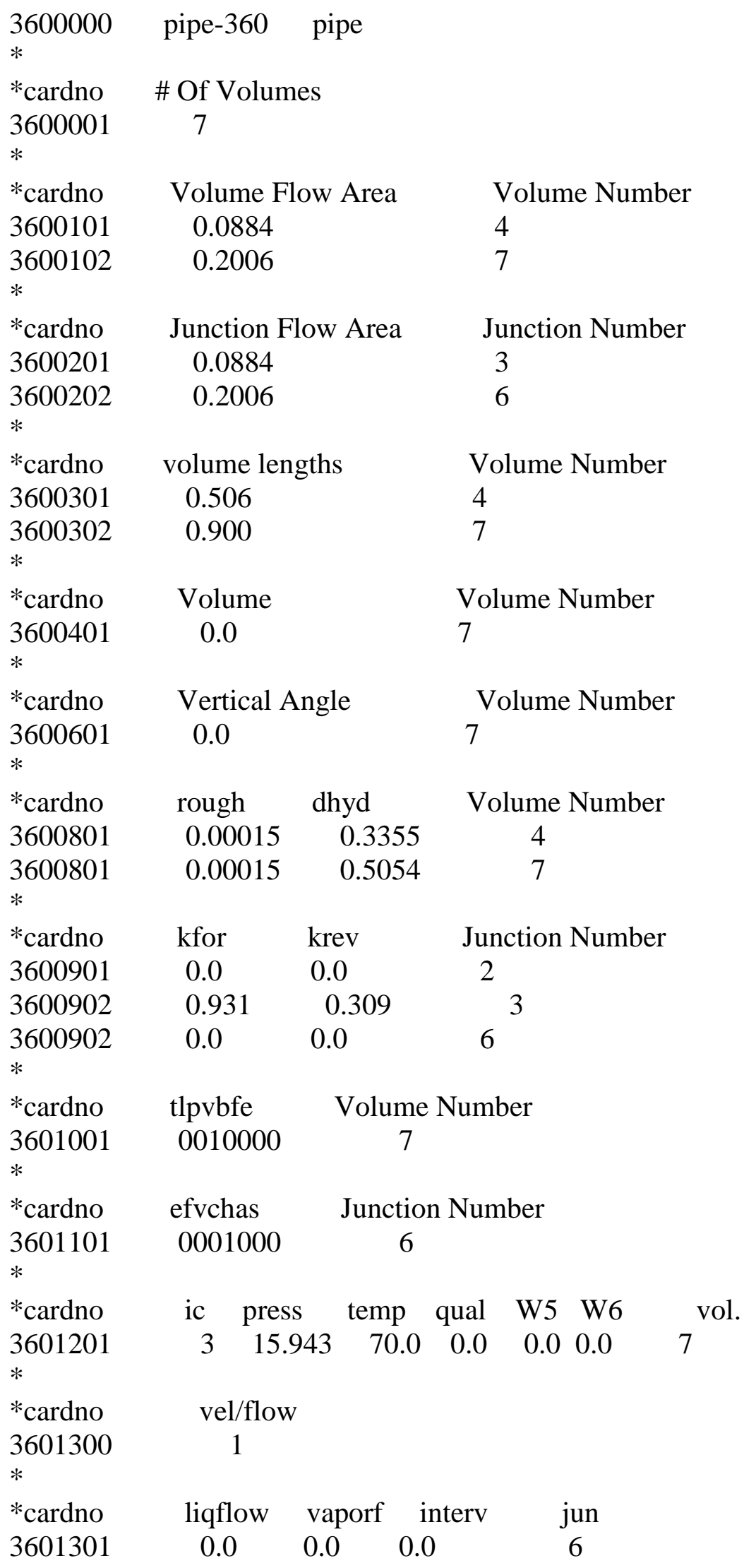




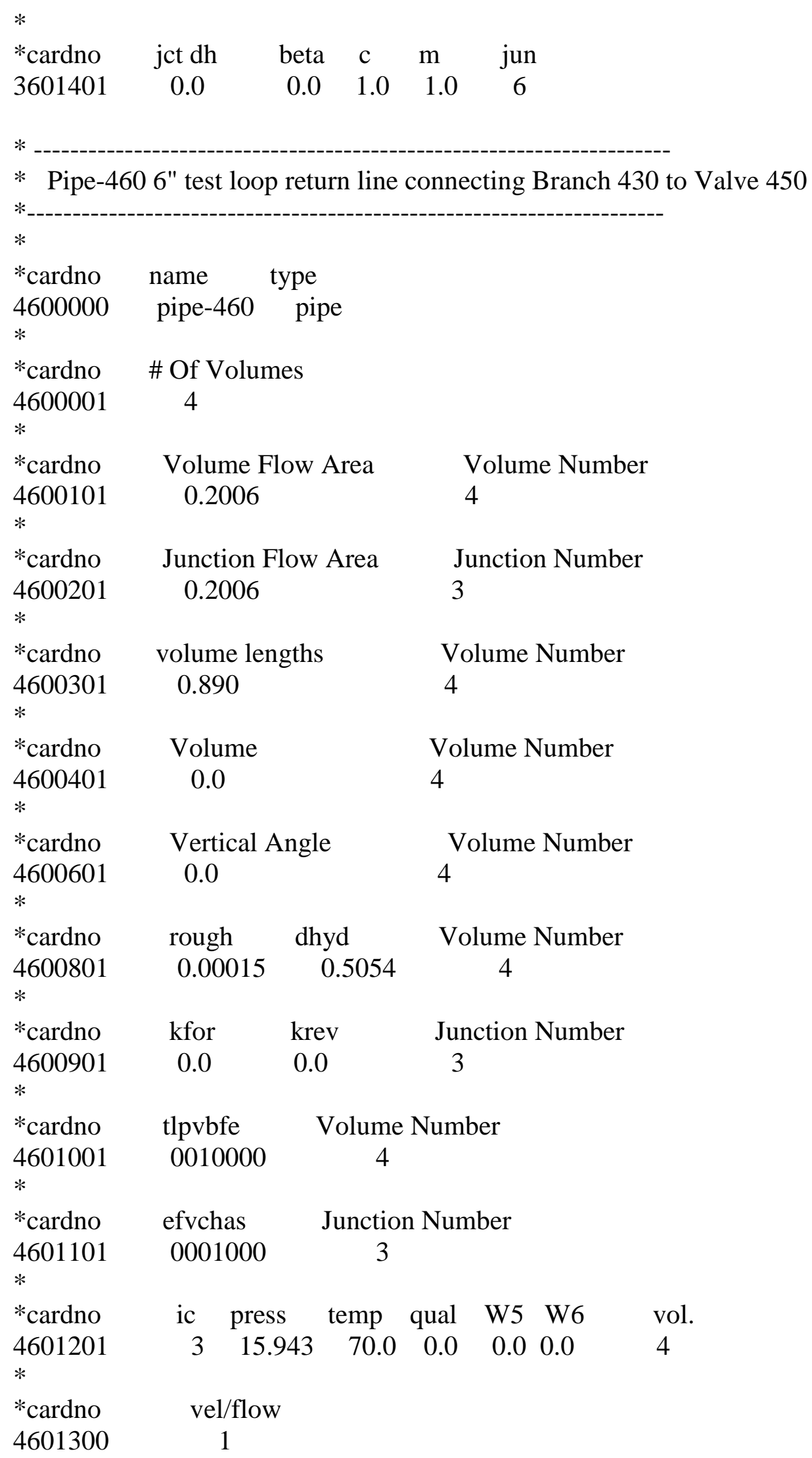




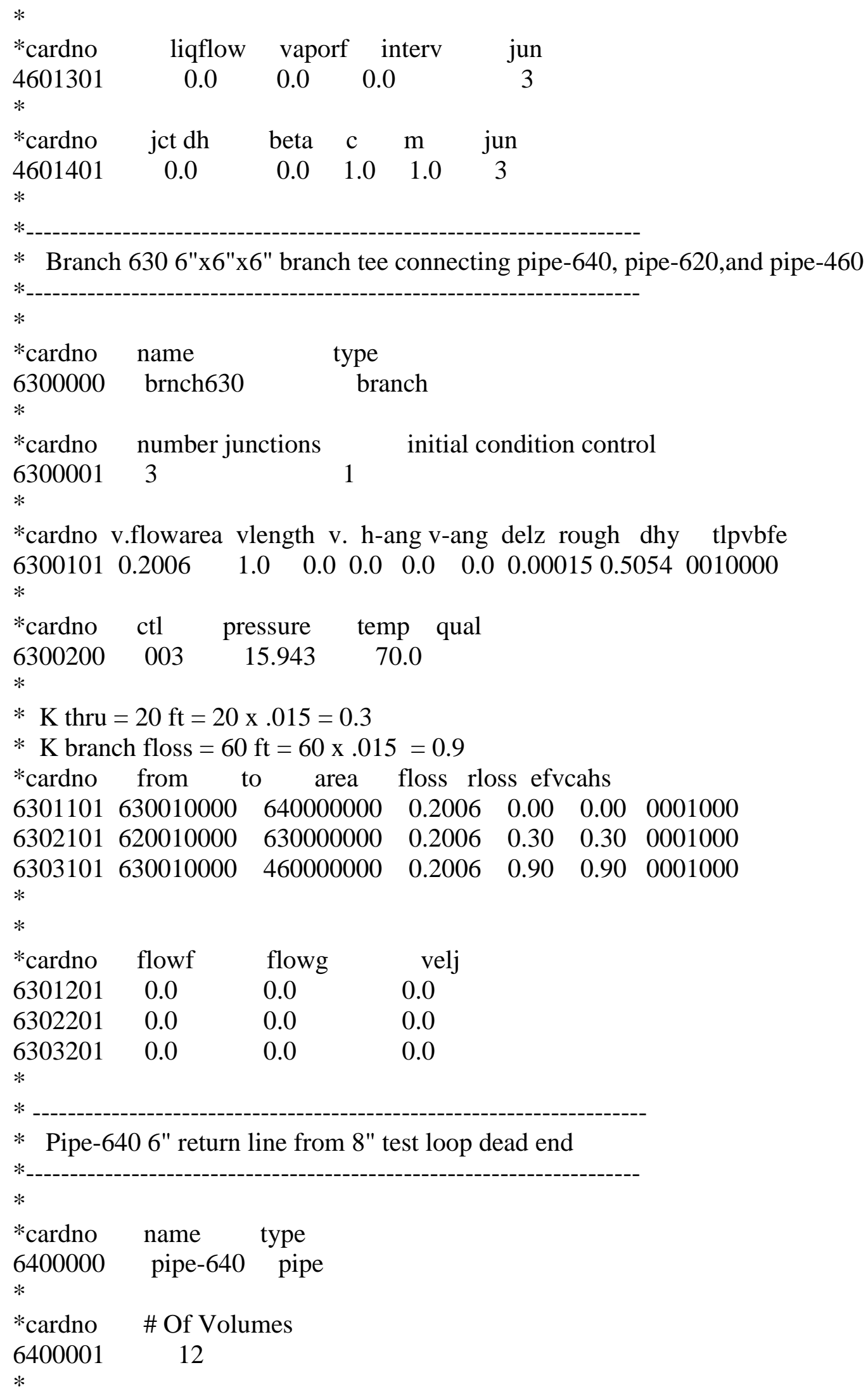




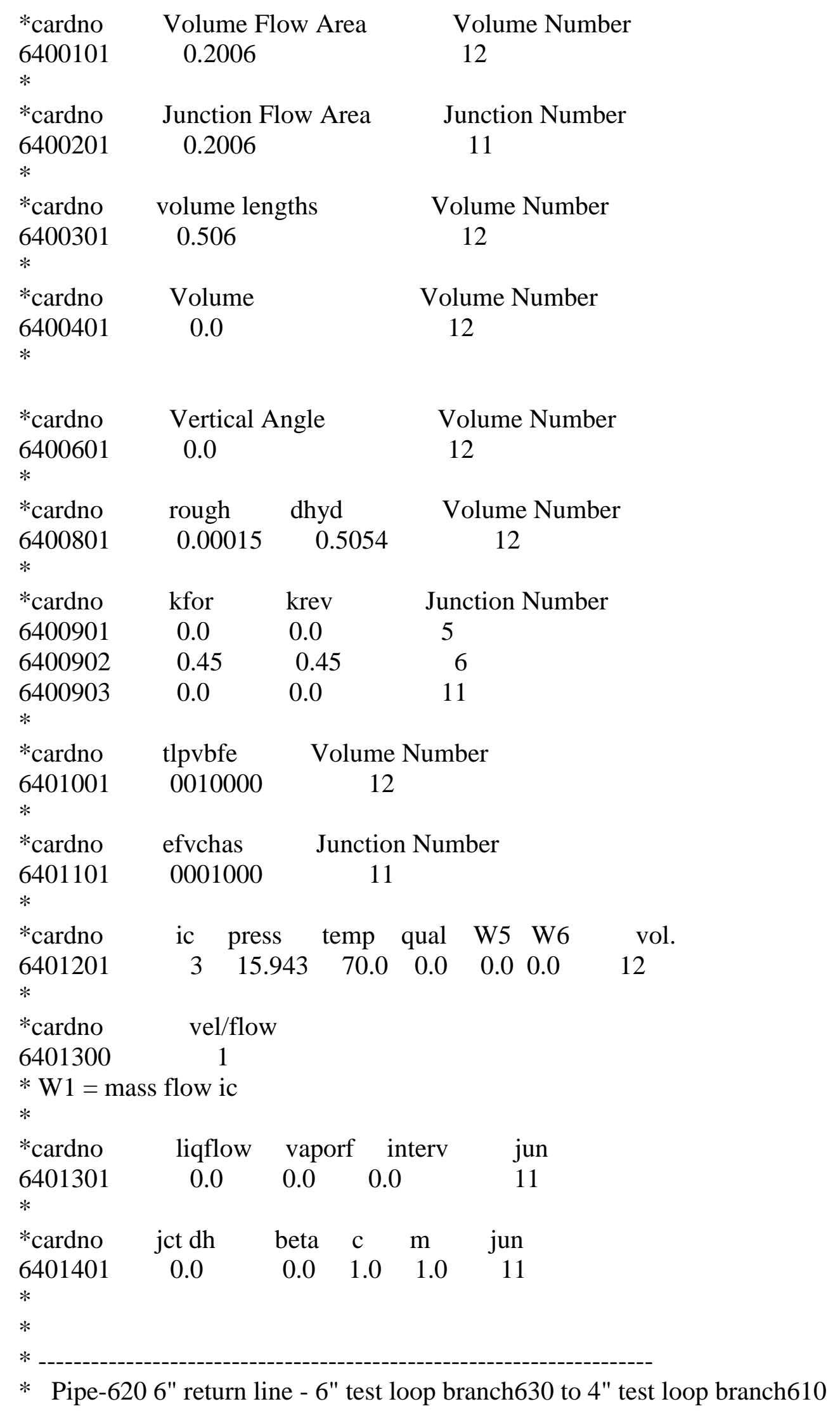




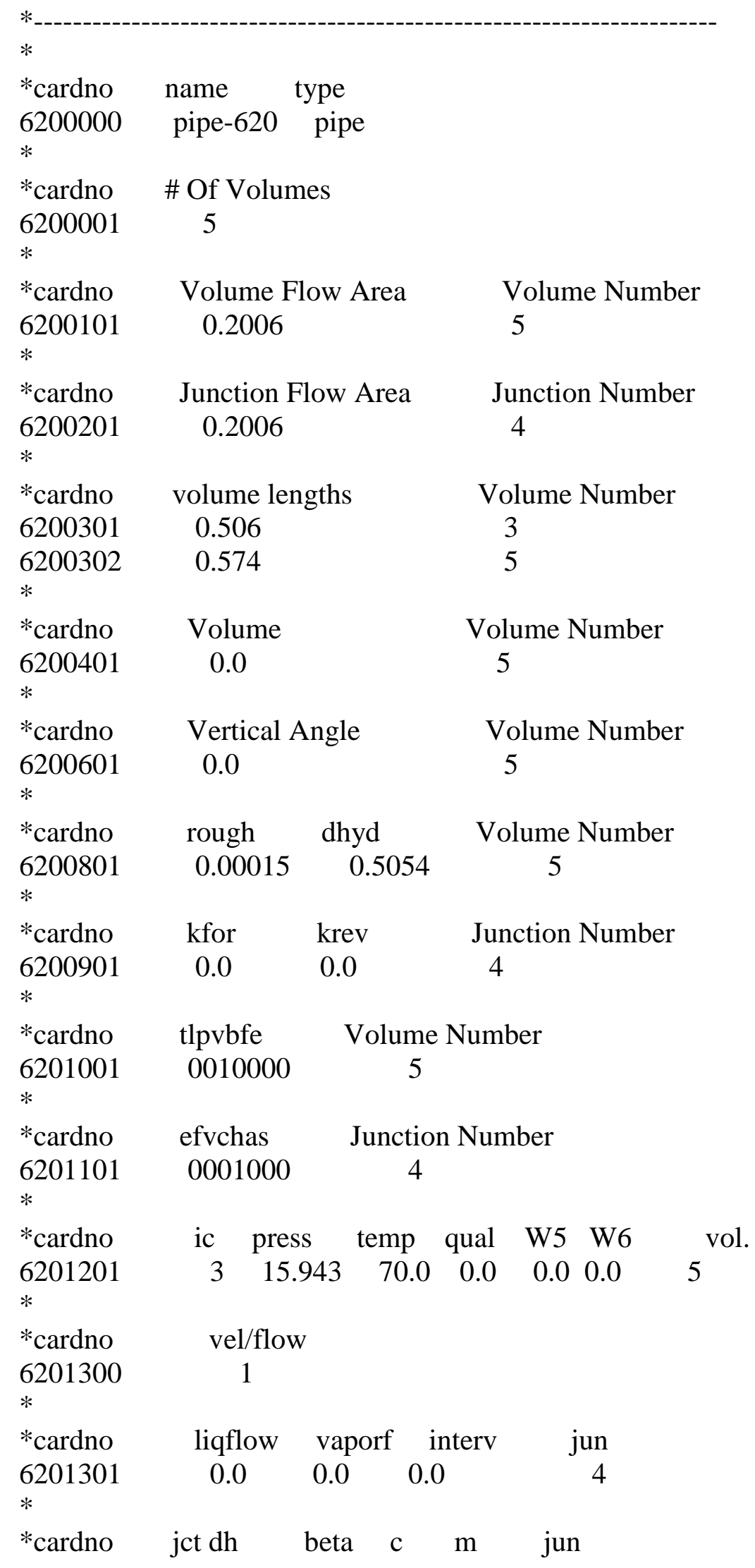




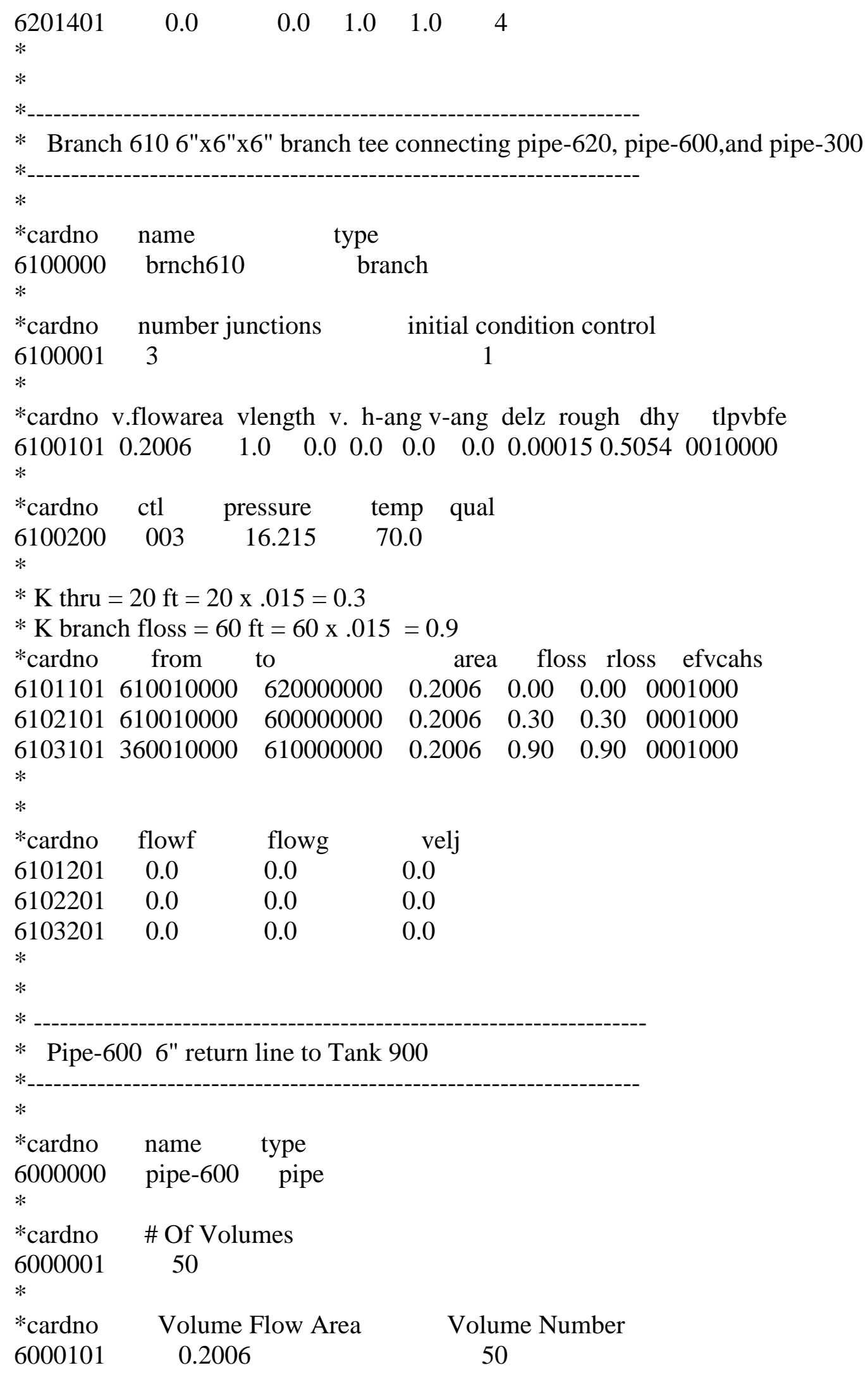




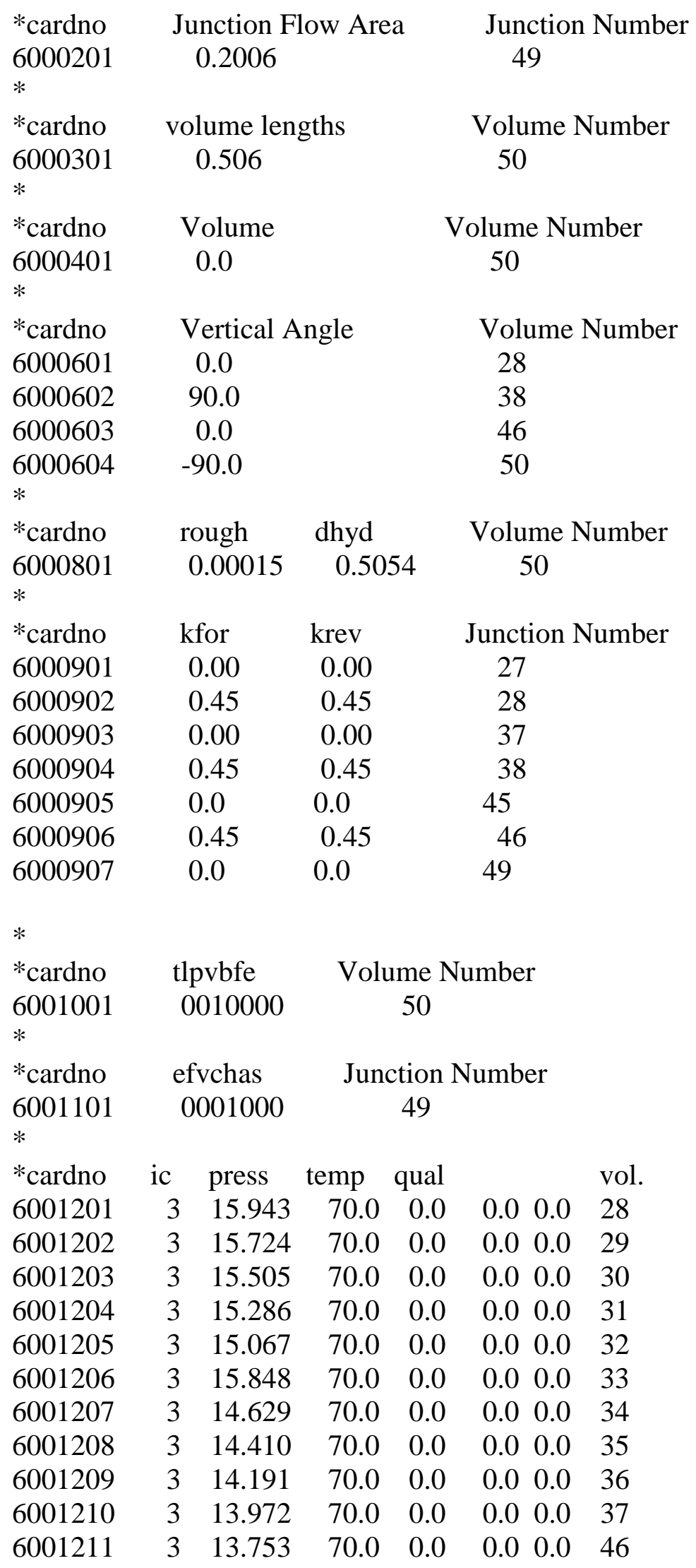




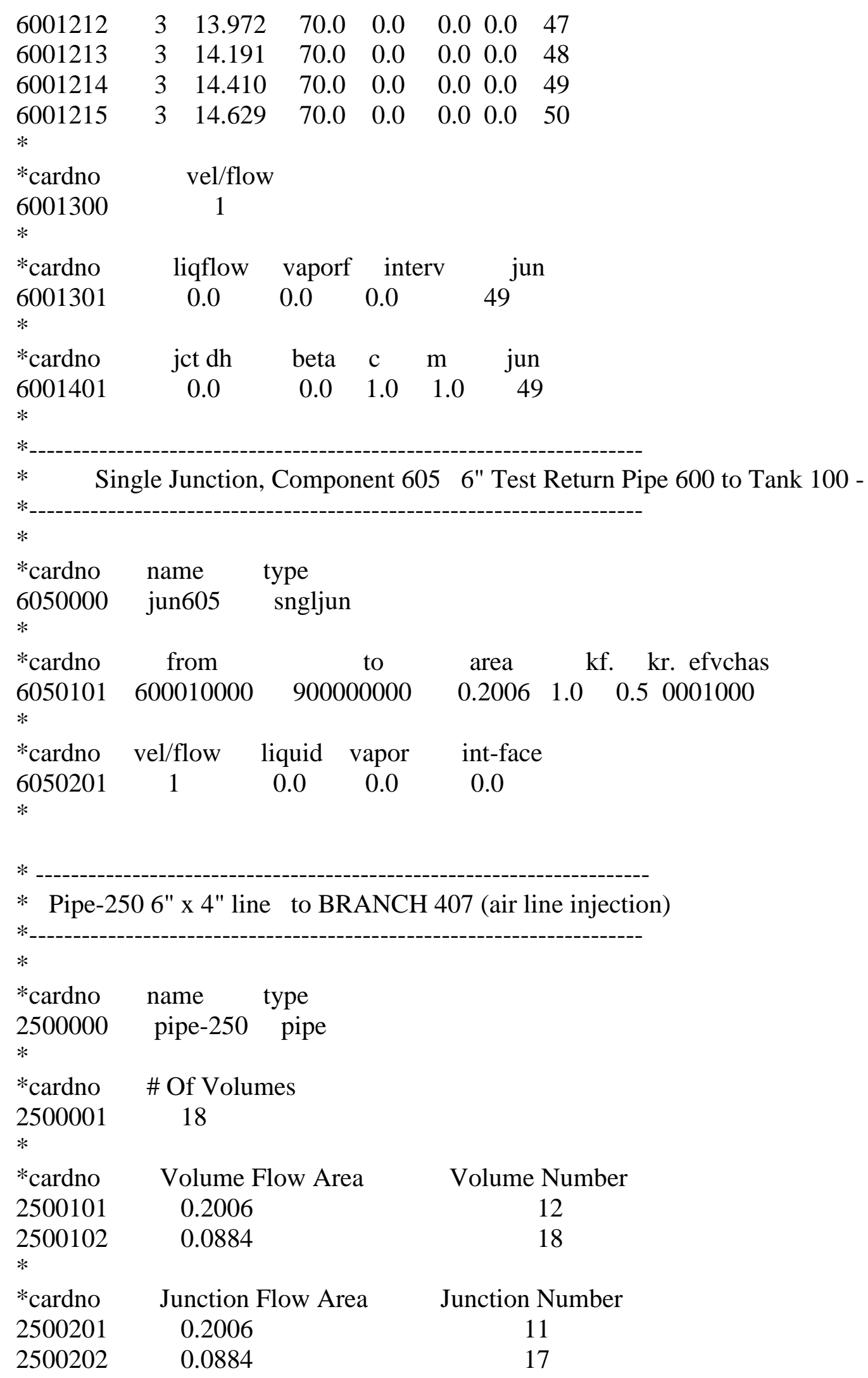




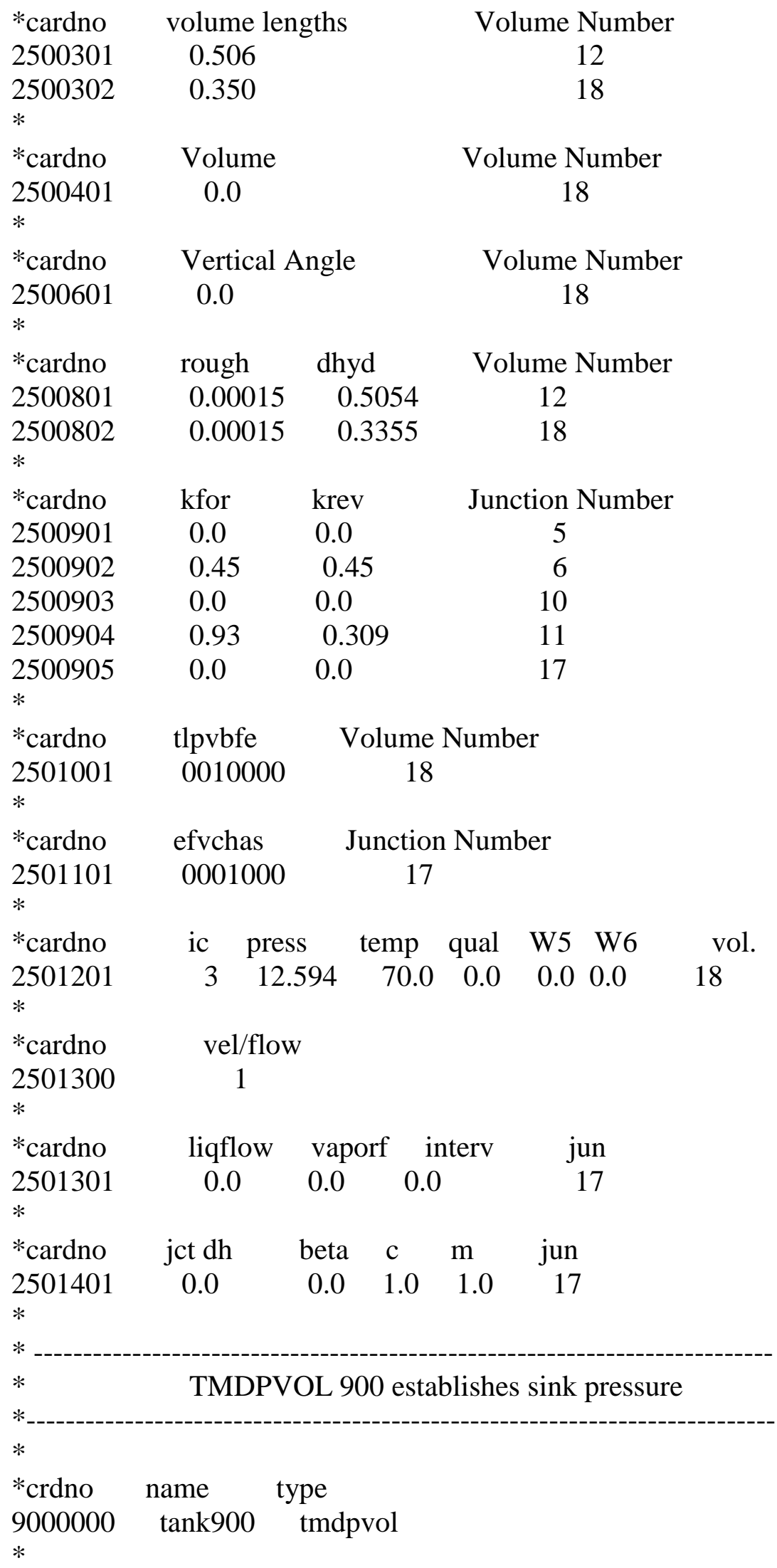




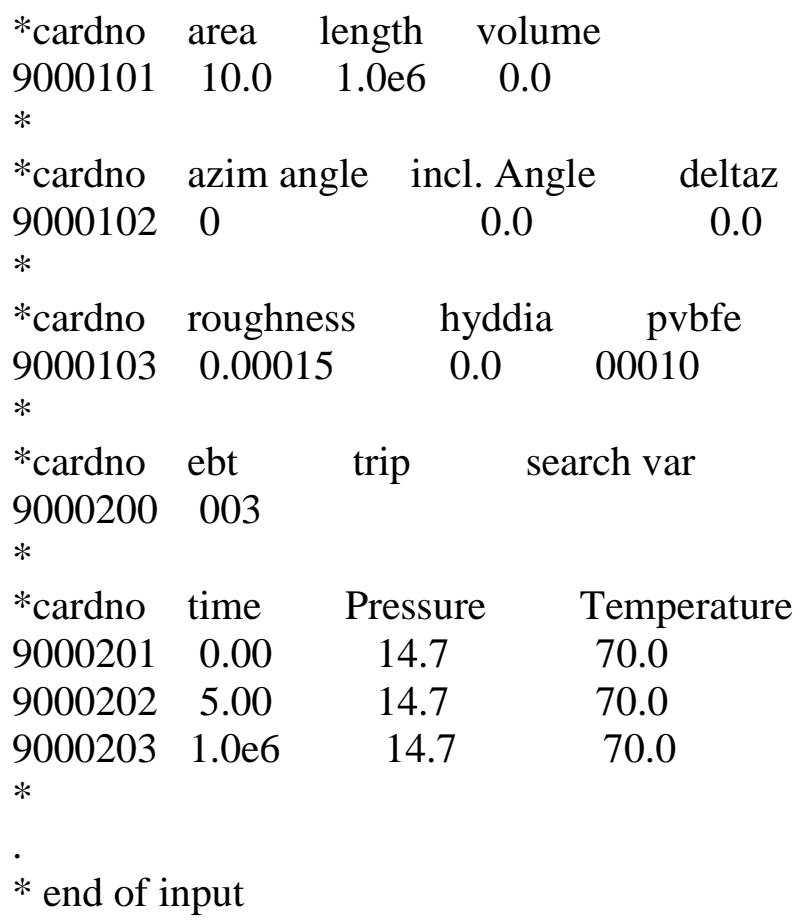




\section{Appendix D - VRS Model Results}

\section{Appendix D.1. Mass Flow Rate Results}

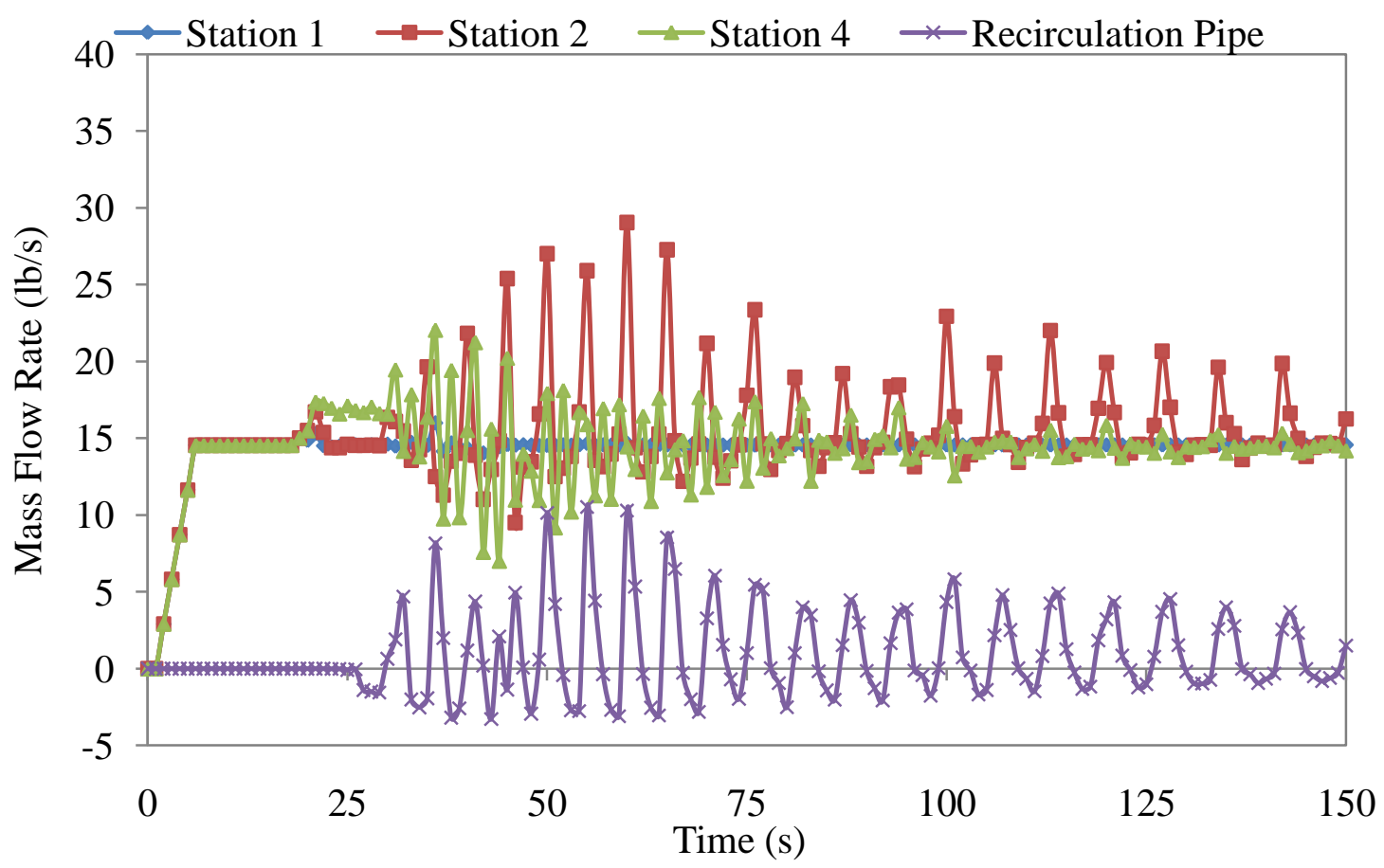

Figure D.1. Mass flow rate behavior for scenario one $(4 \times 4 \times 3$-inch, $F r=0.81)$.

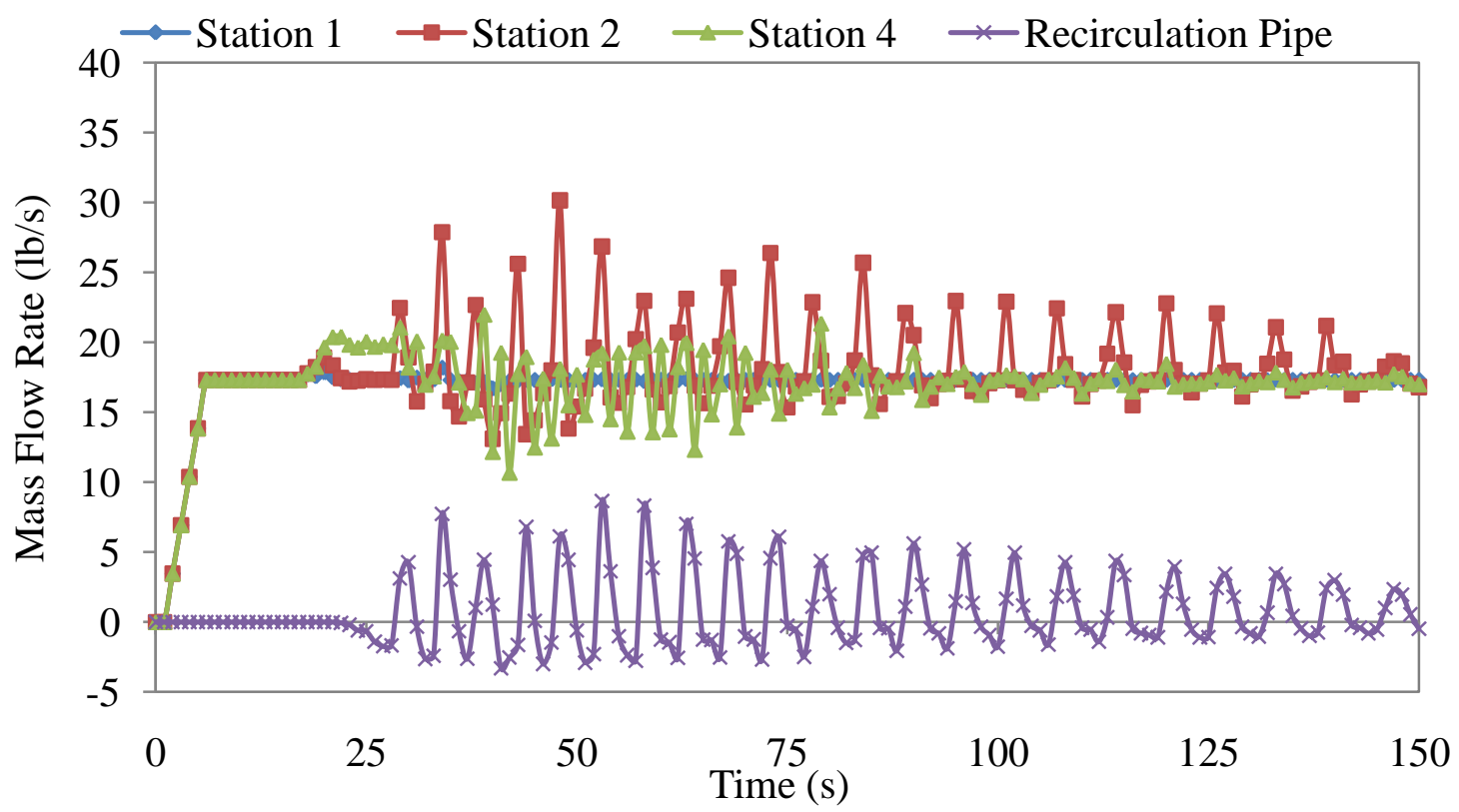

Figure D.2. Mass flow rate behavior for scenario two $(4 \times 4 \times 3$-inch, $F r=0.96)$. 


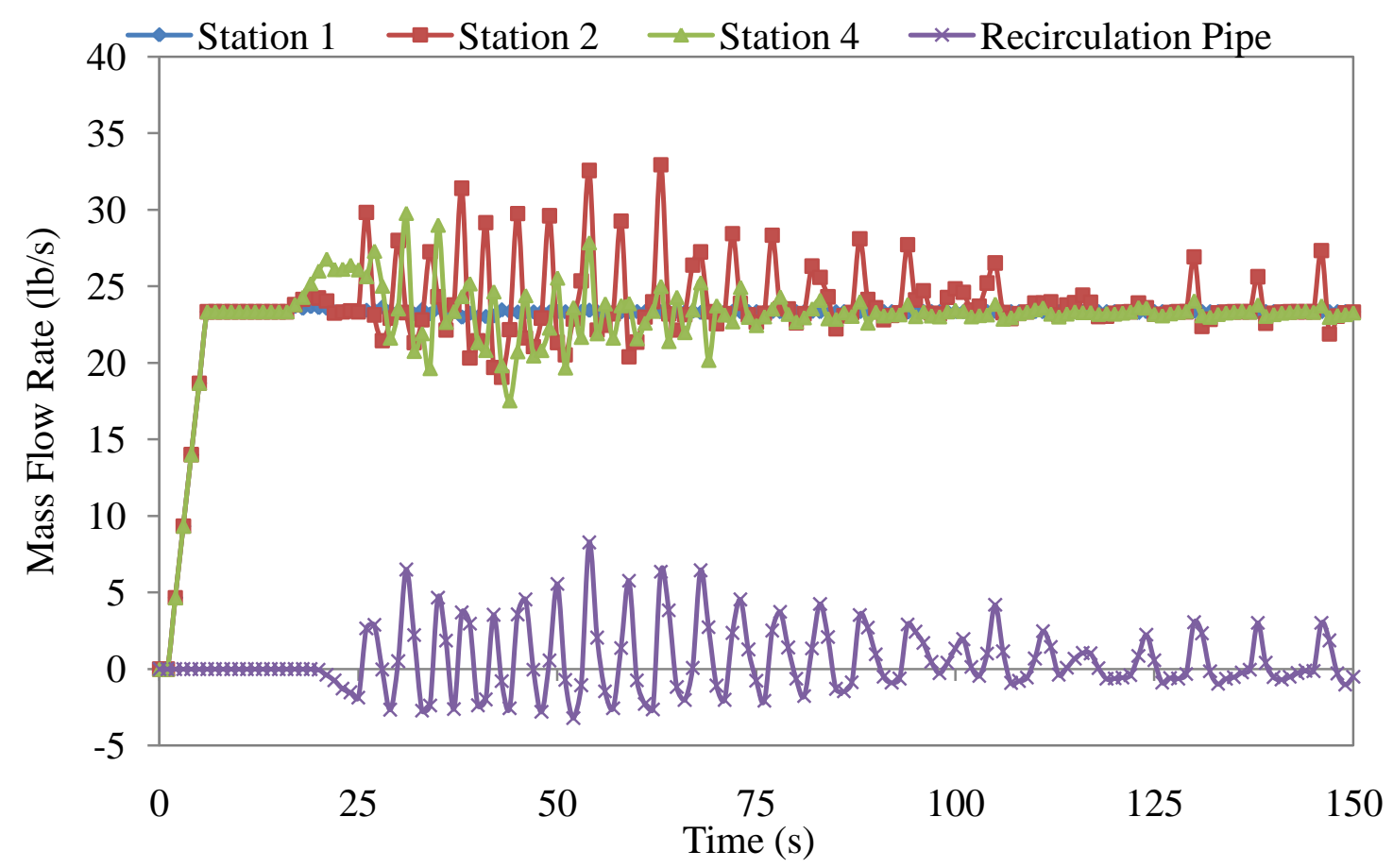

Figure D.3. Mass flow rate behavior for scenario three $(4 \times 4 \times 3$-inch, $F r=1.29)$.

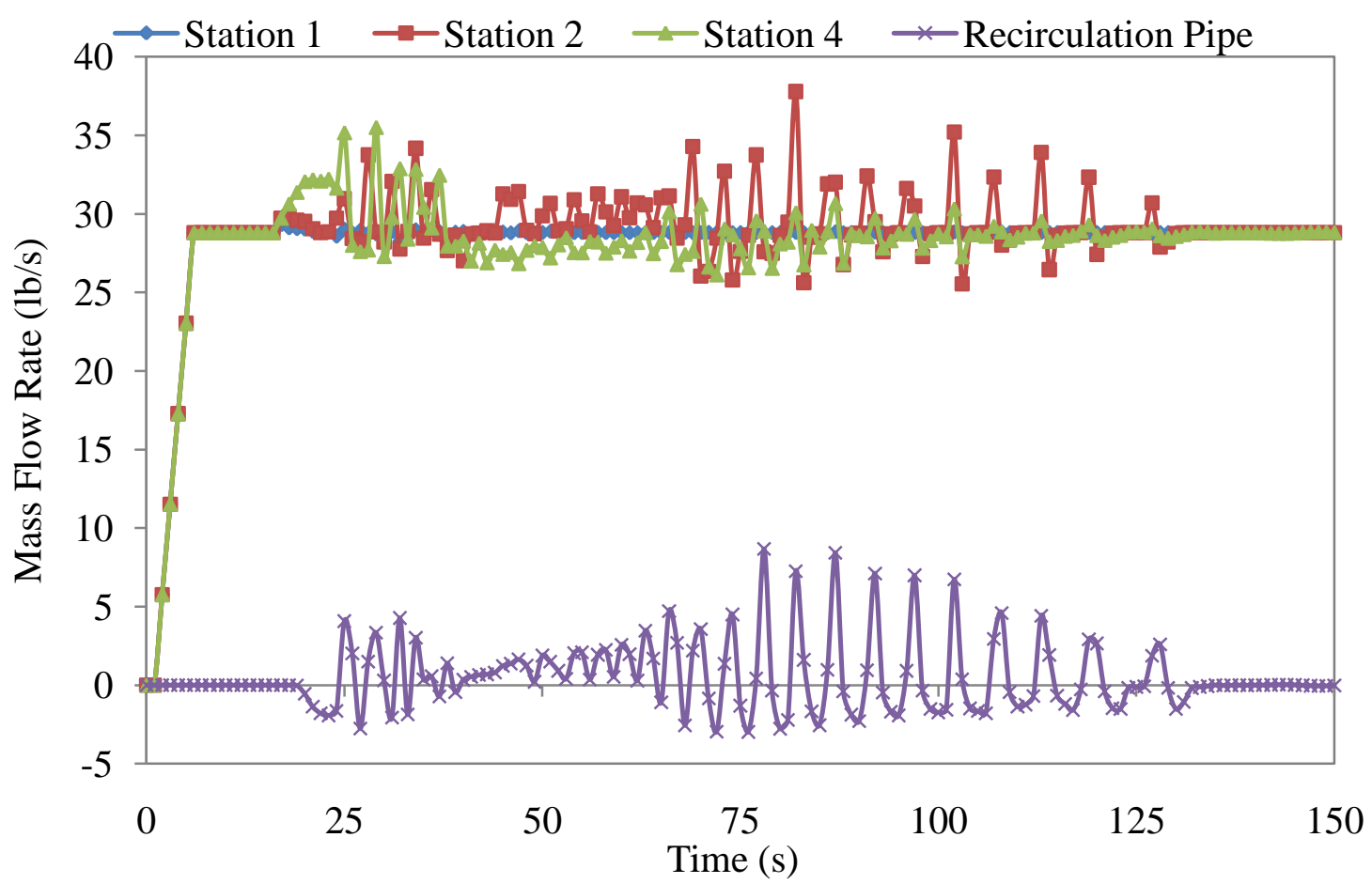

Figure D.4. Mass flow rate behavior for scenario four $(4 \times 4 \times 3$-inch, $F r=1.60)$. 


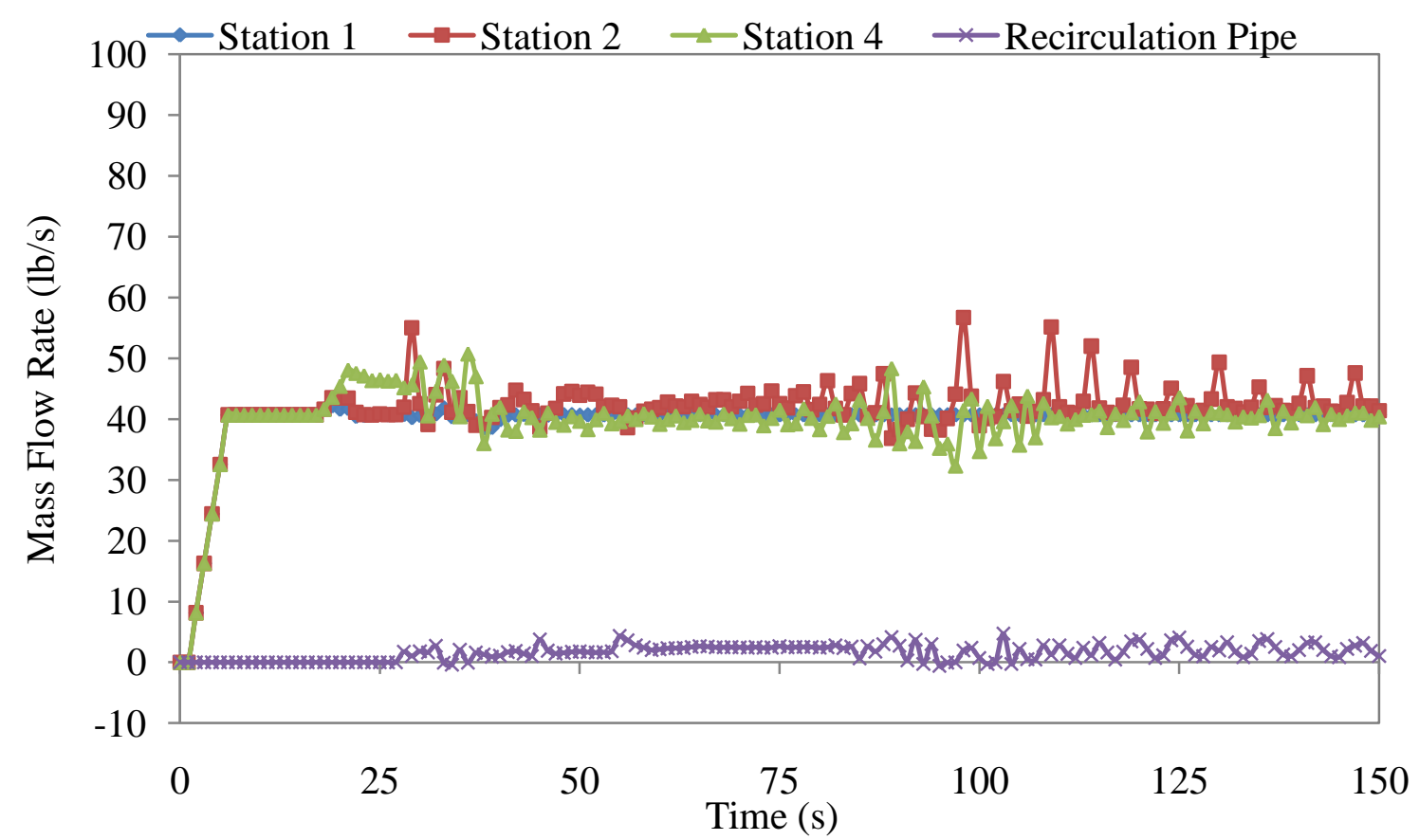

Figure D.5. Mass flow rate behavior for scenario five $(6 \times 6 \times 4$-inch, $F r=0.81)$.

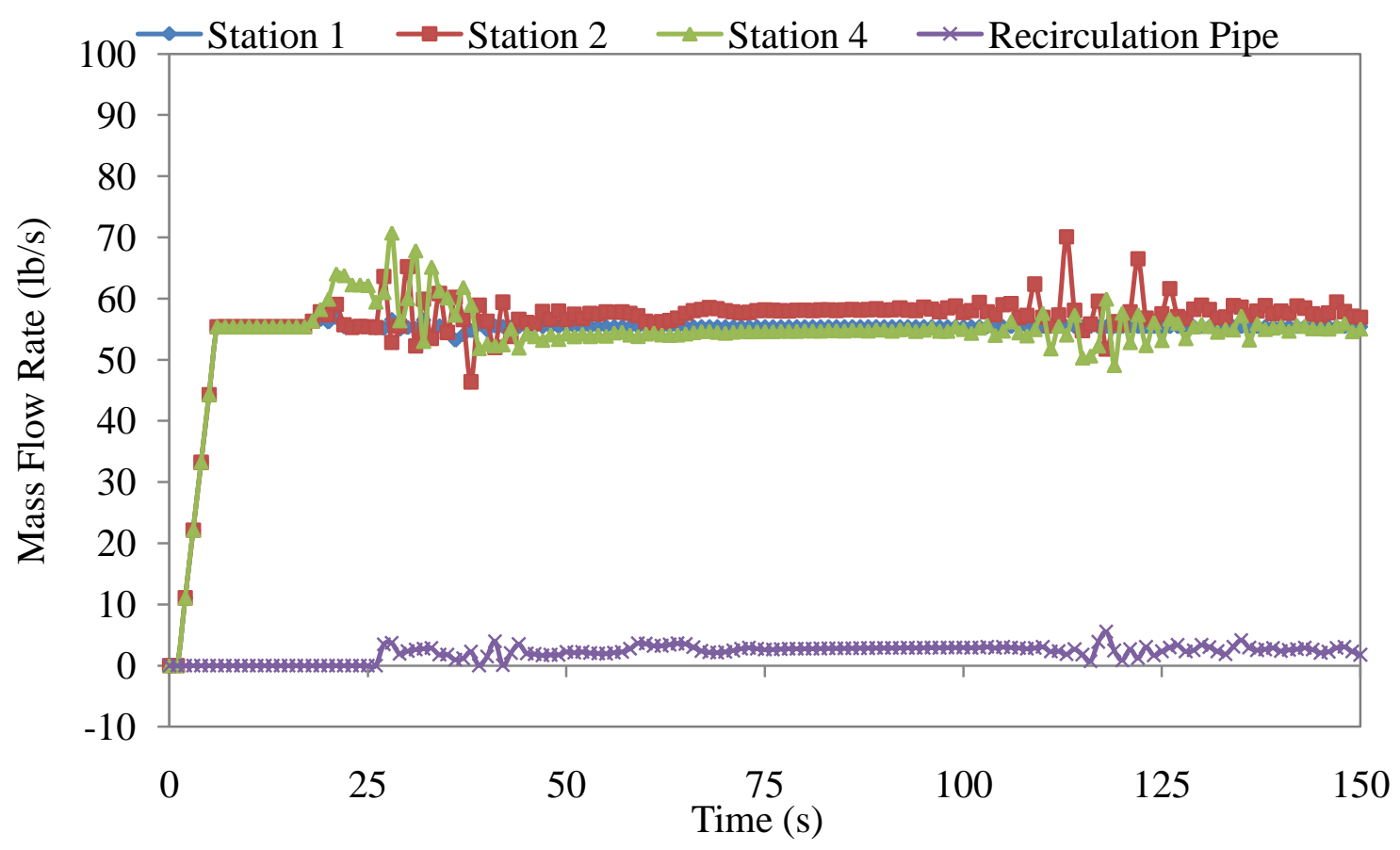

Figure D.6. Mass flow rate behavior for scenario six $(6 \mathrm{x} 6 \mathrm{x} 4$-inch, $F r=1.10)$. 


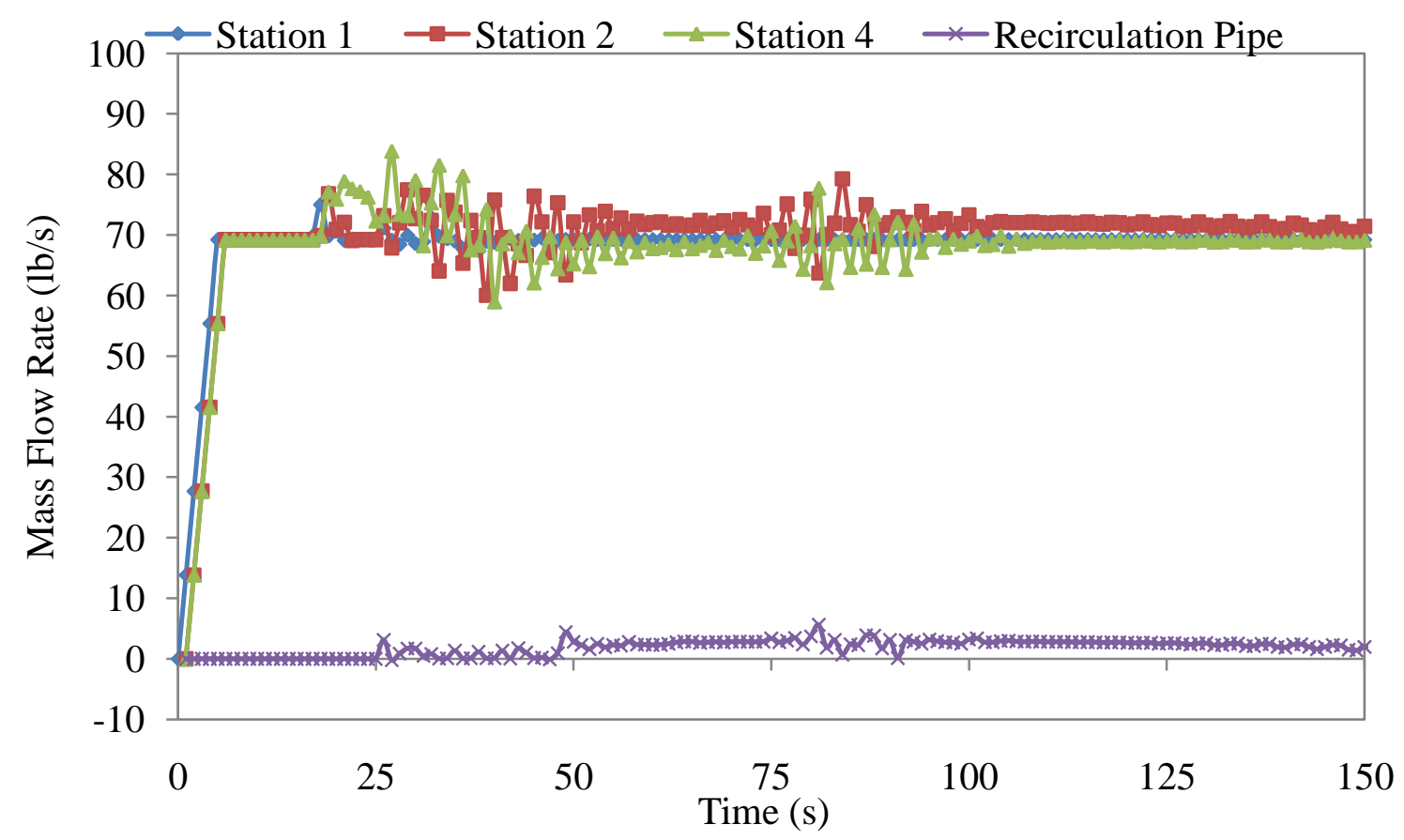

Figure D.7. Mass flow rate behavior for scenario seven (6x6x4-inch, $F r=1.38)$.

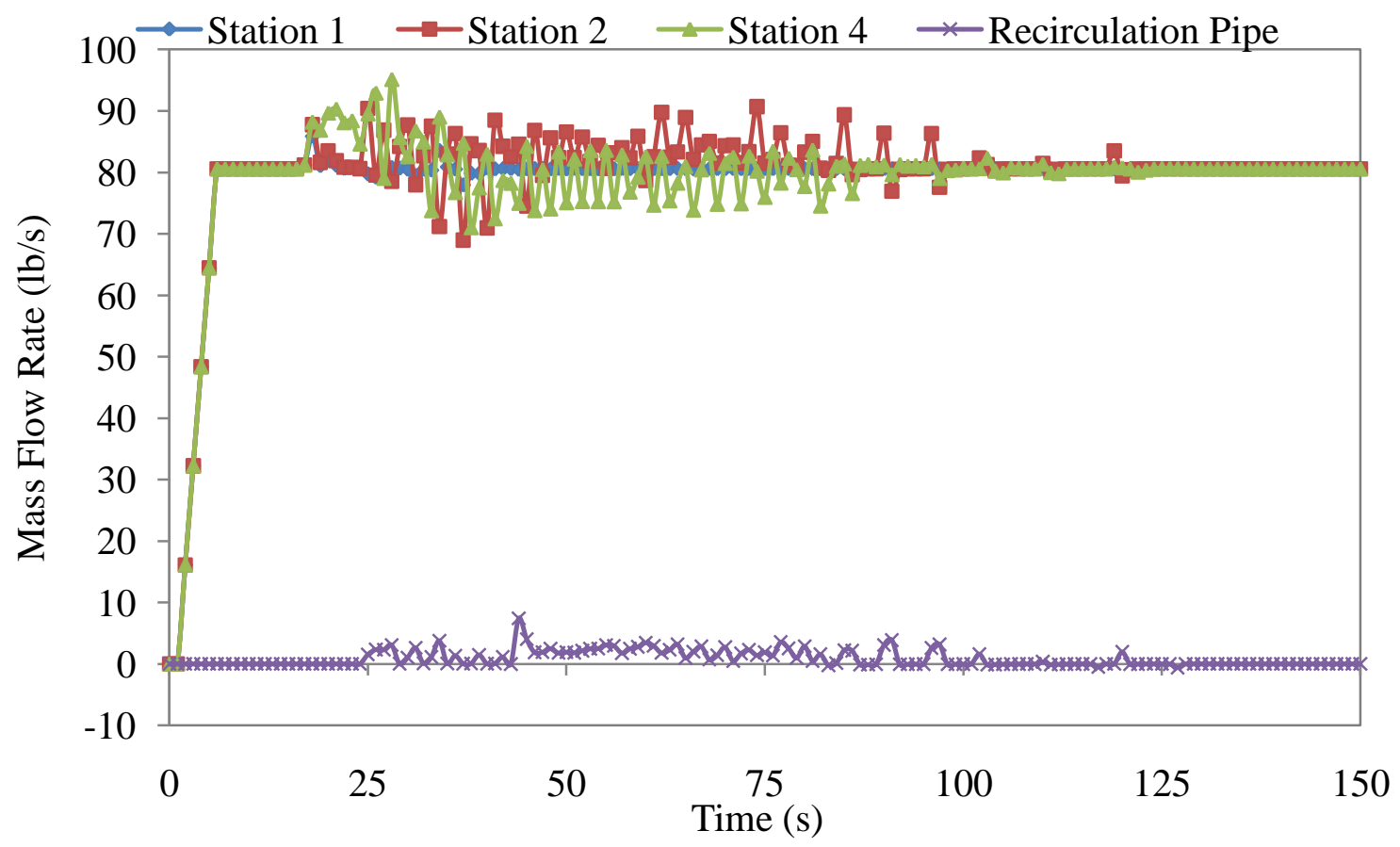

Figure D.8. Mass flow rate behavior for scenario eight $(6 x 6 x 4$-inch, $F r=1.60)$. 


\section{Appendix D.2. Void Fraction Results}

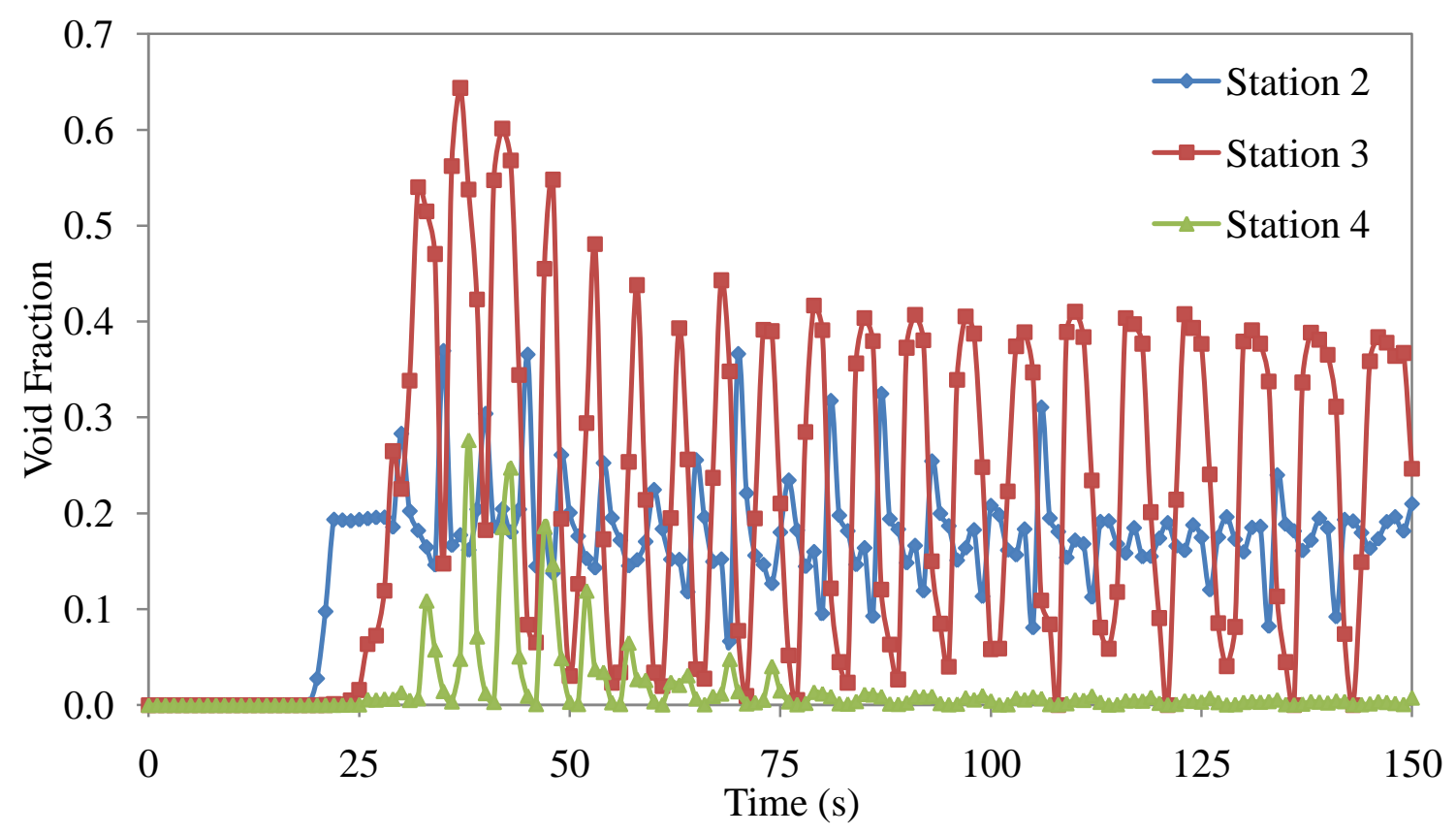

Figure D.9. Void fraction behavior for scenario one ( $4 \times 4 \times 3$-inch, $F r=0.81)$.

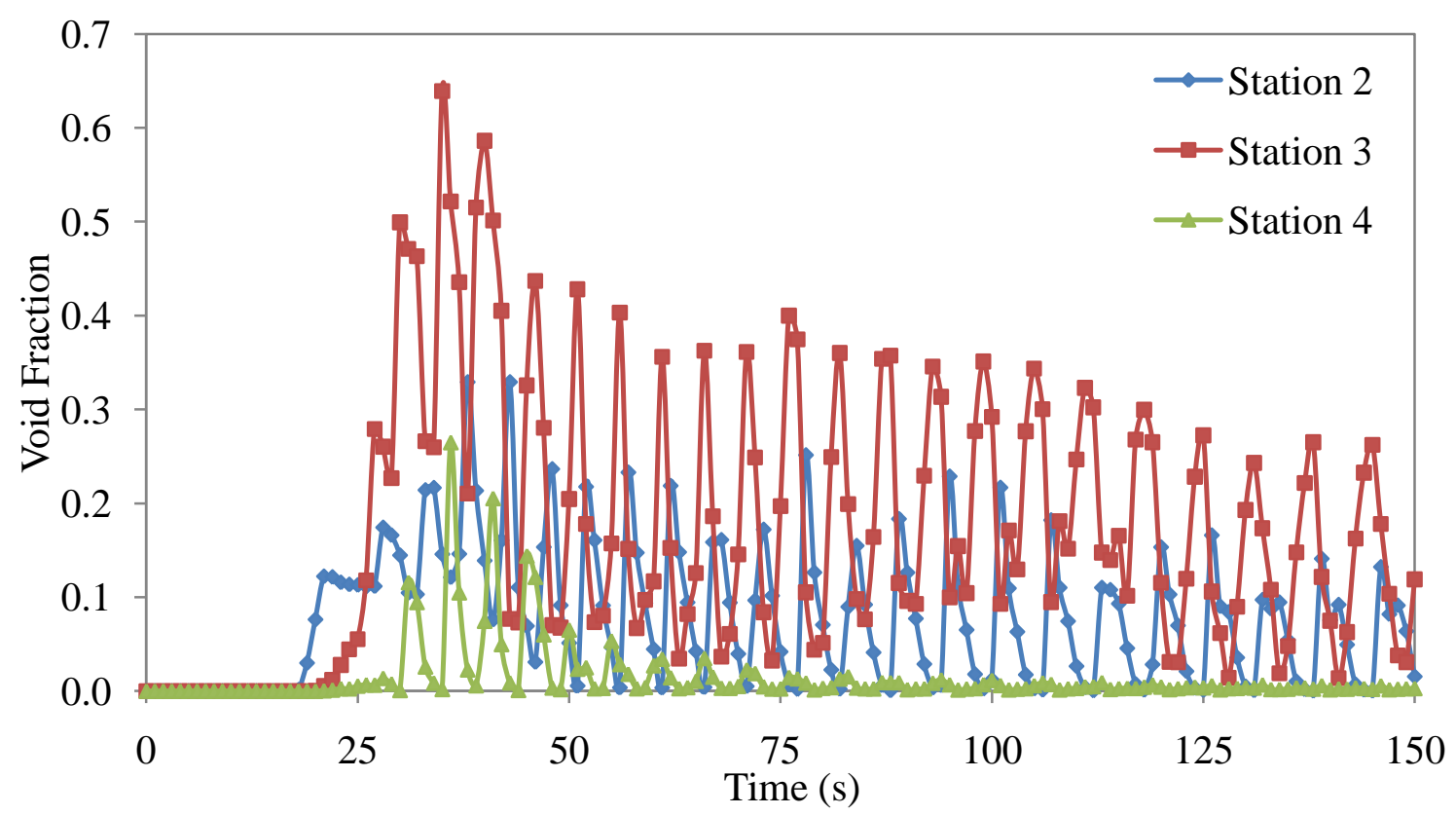

Figure D.10. Void fraction behavior for scenario two (4x4x3-inch, $F r=0.96)$. 


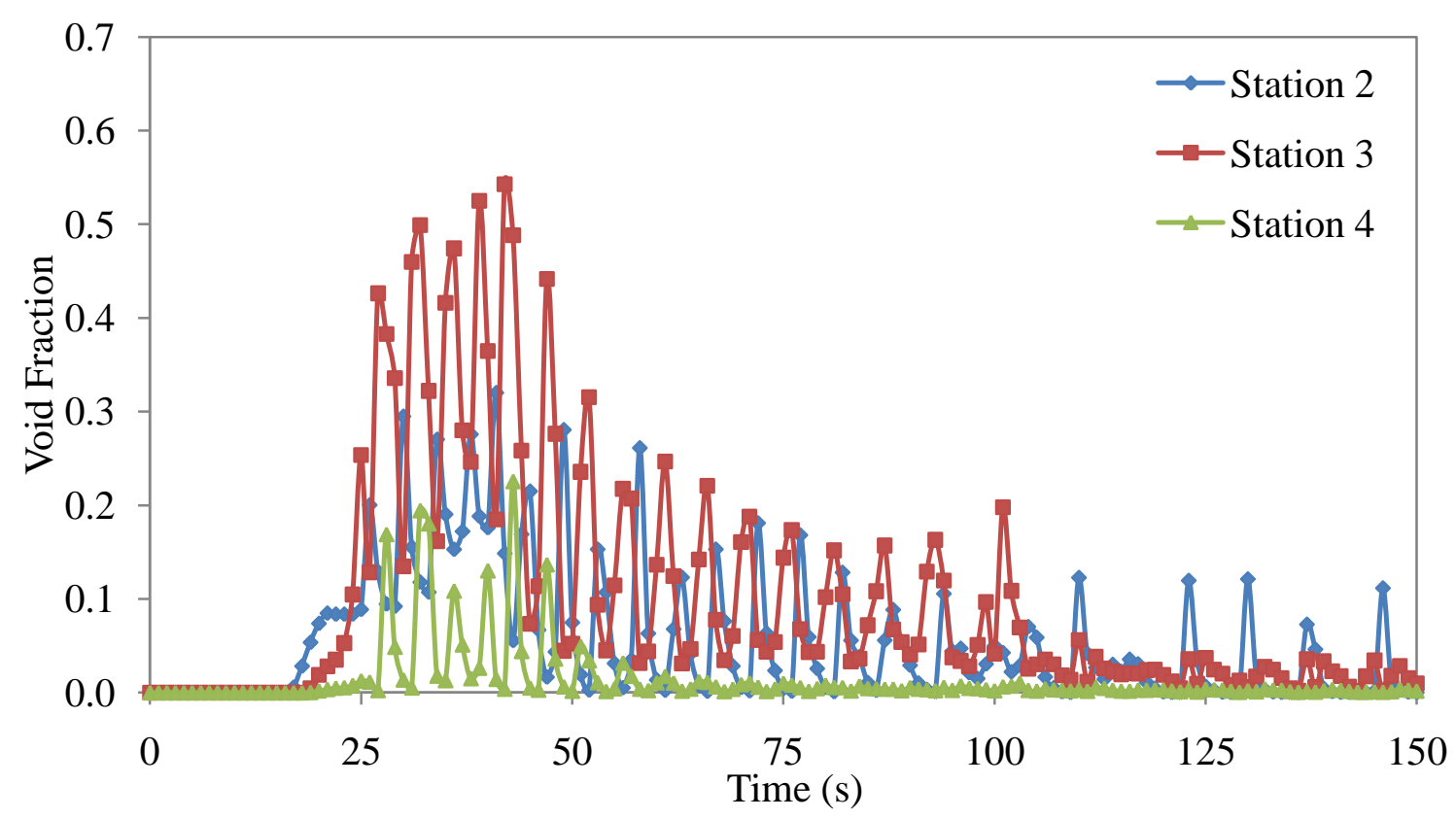

Figure D.11. Void fraction behavior for scenario three $(4 \times 4 \times 3$-inch, $F r=1.29)$.

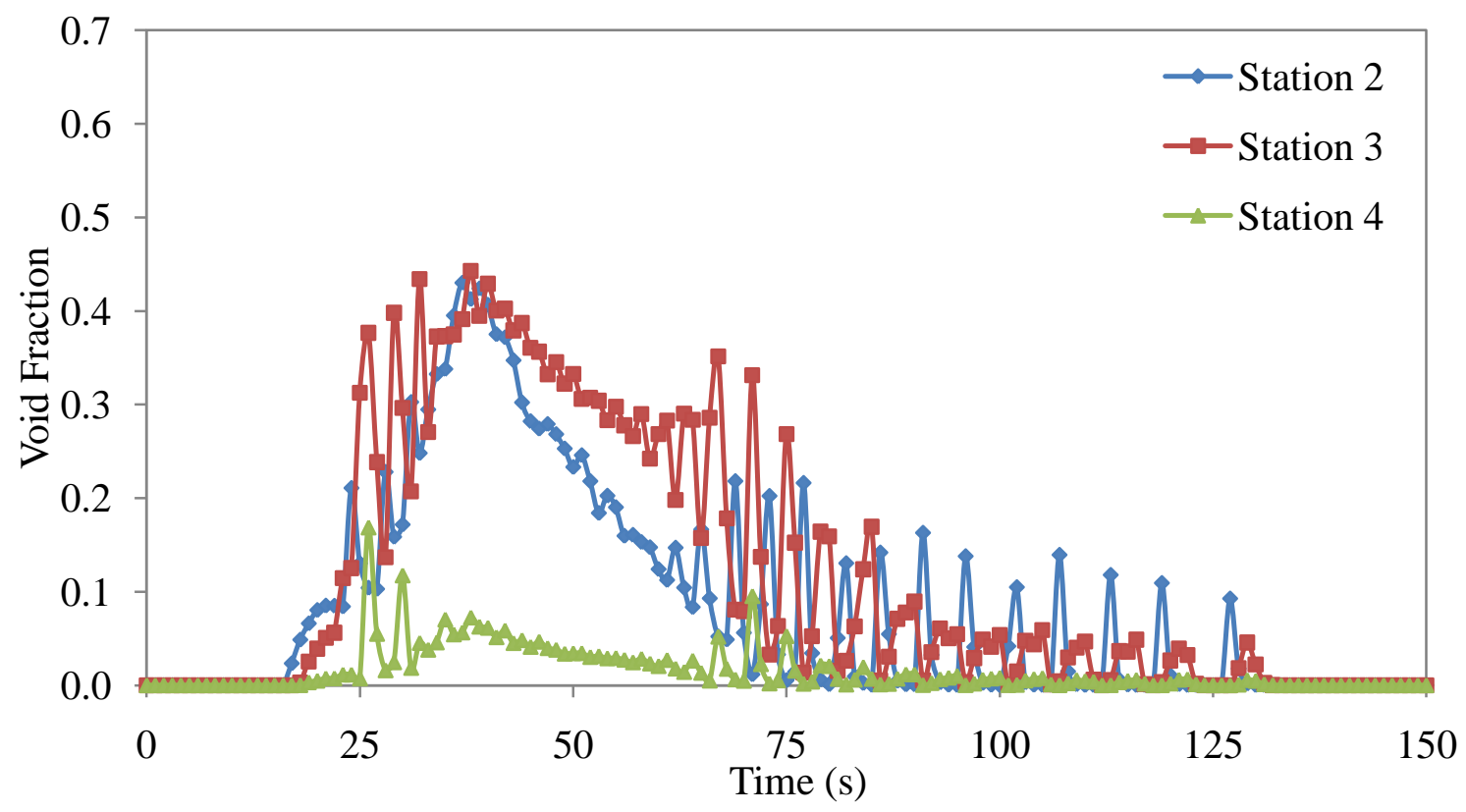

Figure D.12. Void fraction behavior for scenario four $(4 \times 4 \times 3$-inch, $F r=1.60)$. 


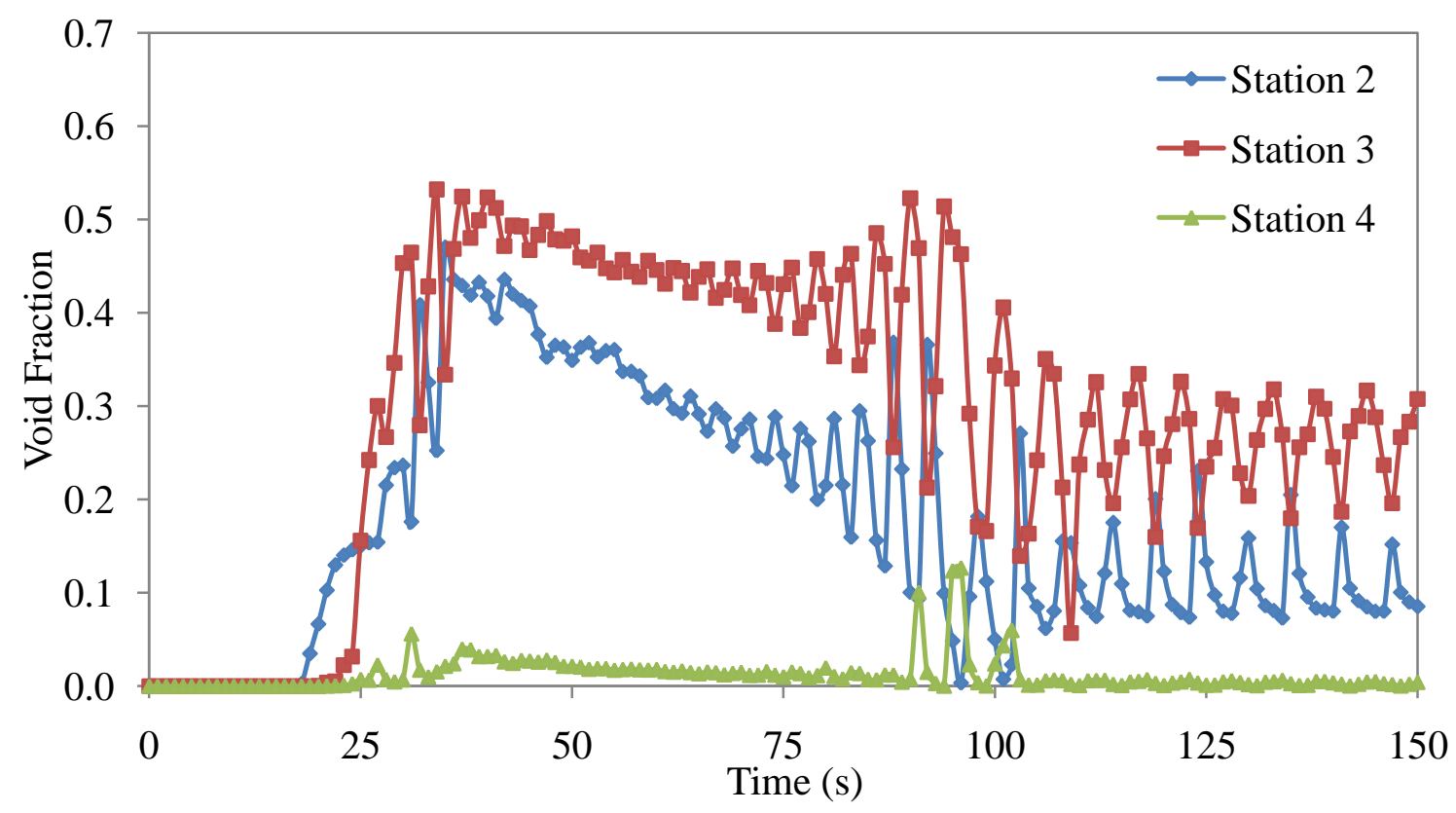

Figure D.13. Void fraction behavior for scenario five (6x6x4-inch, $F r=0.81)$.

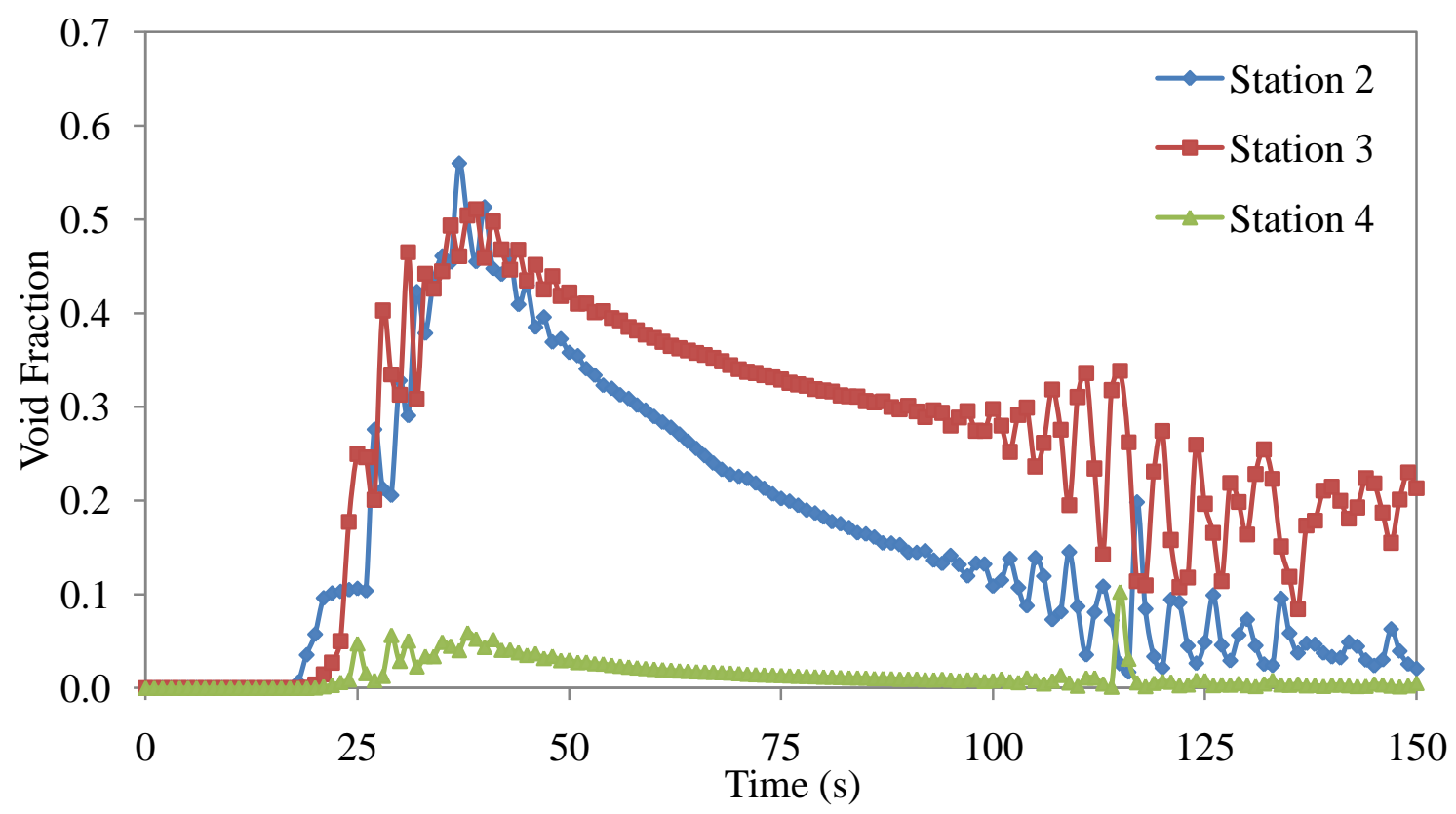

Figure D.14. Void fraction behavior for scenario six (6x6x4-inch, $F r=1.10)$. 


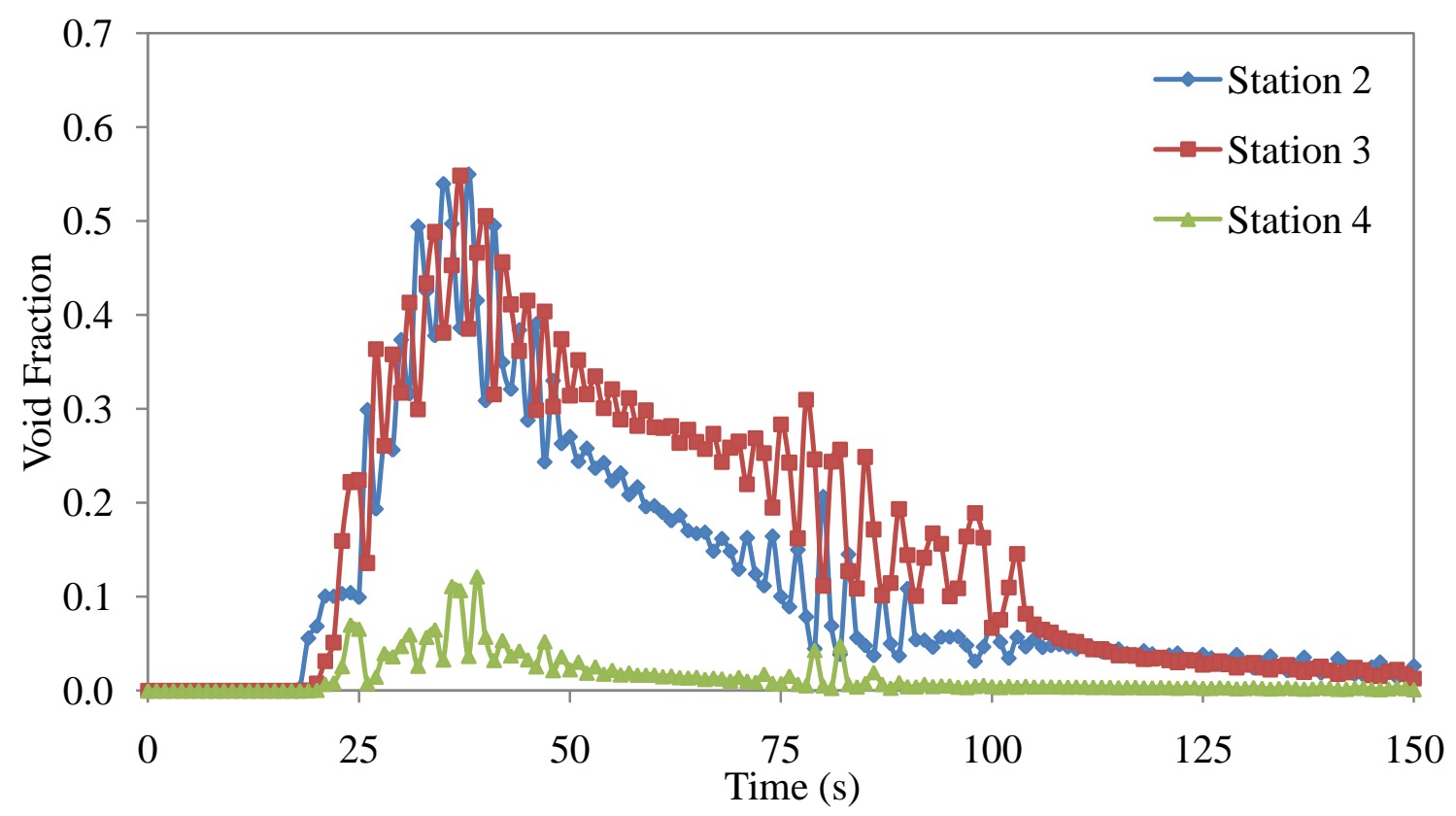

Figure D.15. Void fraction behavior for scenario seven (6x6x4-inch, $F r=1.38)$.

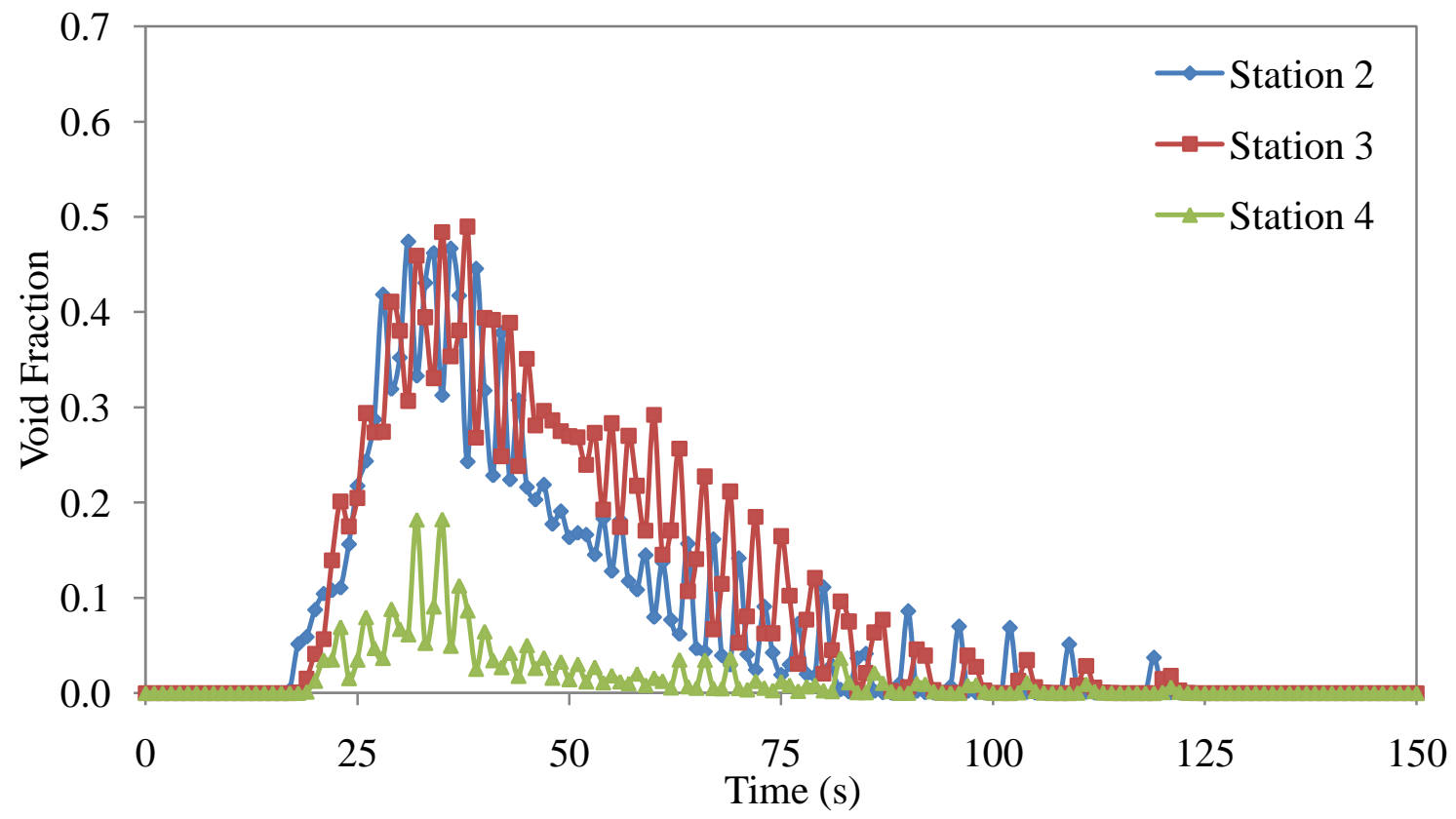

Figure D.16. Void fraction behavior for scenario eight $(6 \times 6 \times 4$-inch, $F r=1.60)$. 


\section{Appendix E - VRS Simulation and Experimental Void Fraction Validation}

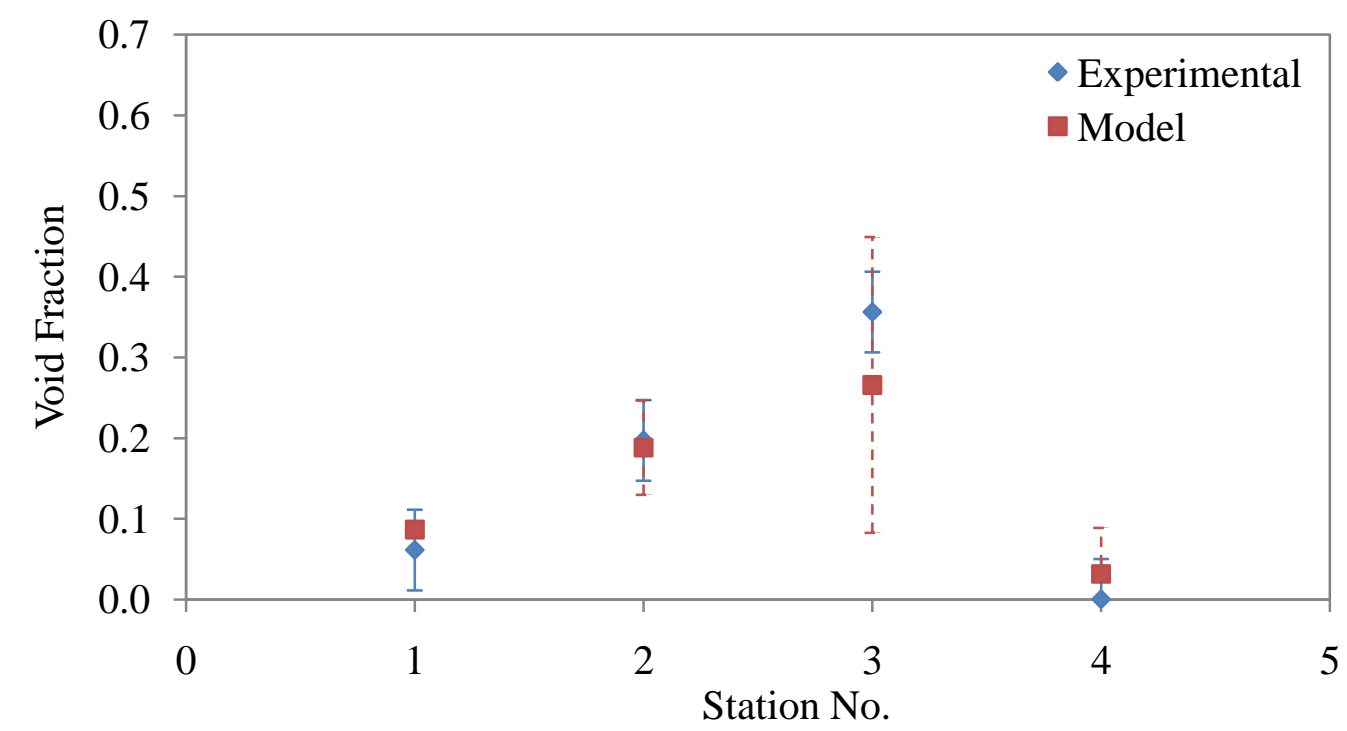

Figure E.1. Void fraction validation for scenario one (4x4x3-inch, $F r=0.81)$.

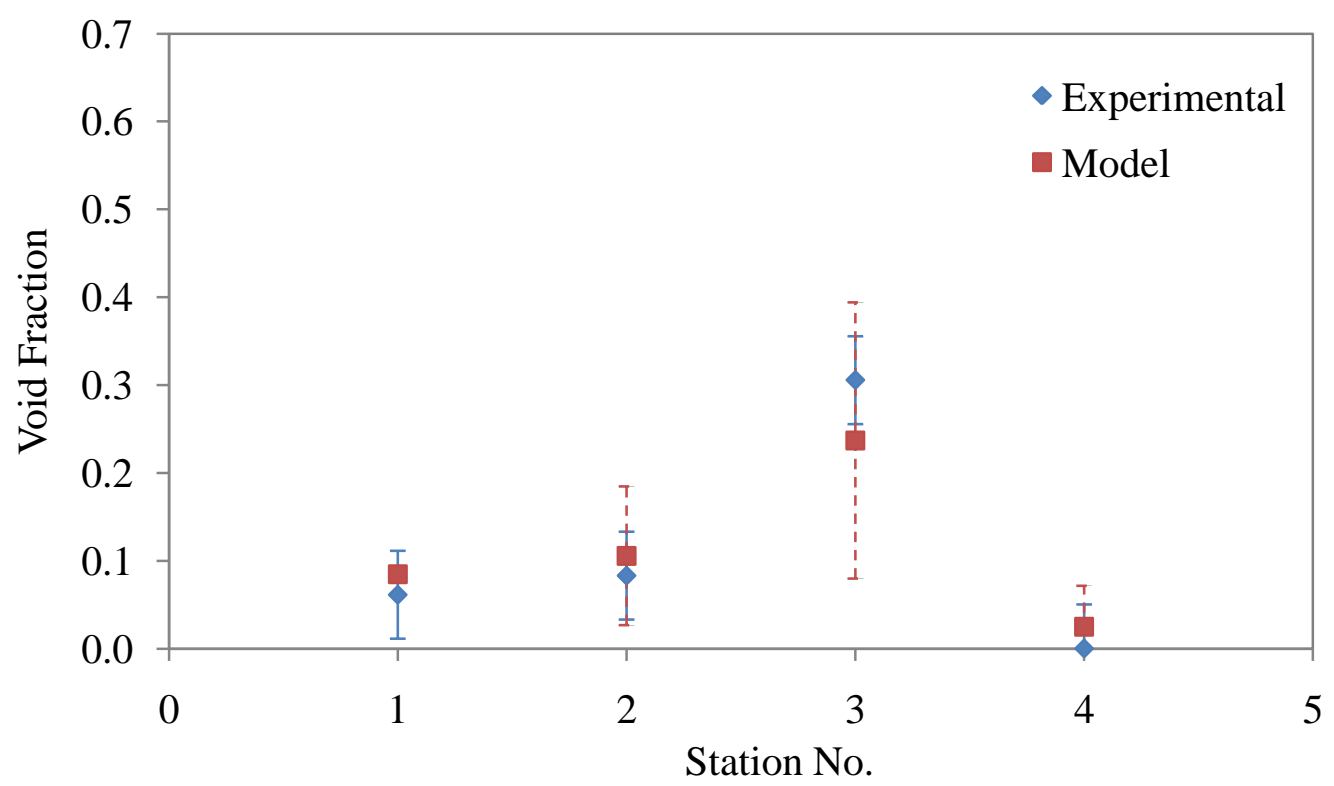

Figure E.2. Void fraction validation for scenario two $(4 \times 4 \times 3$-inch, $F r=0.96)$. 


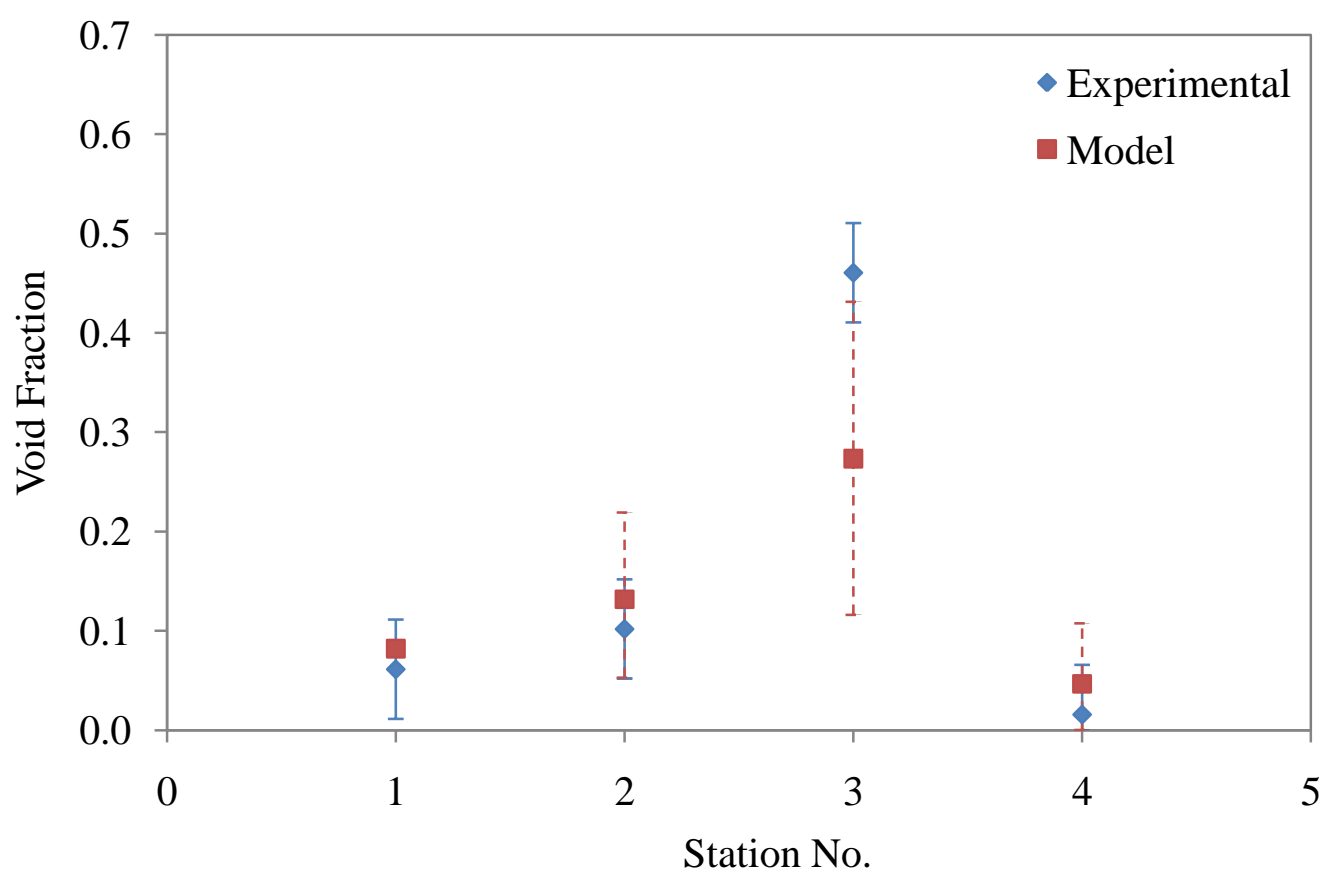

Figure E.3. Void fraction validation for scenario three $(4 \times 4 \times 3$-inch, $F r=1.29)$.

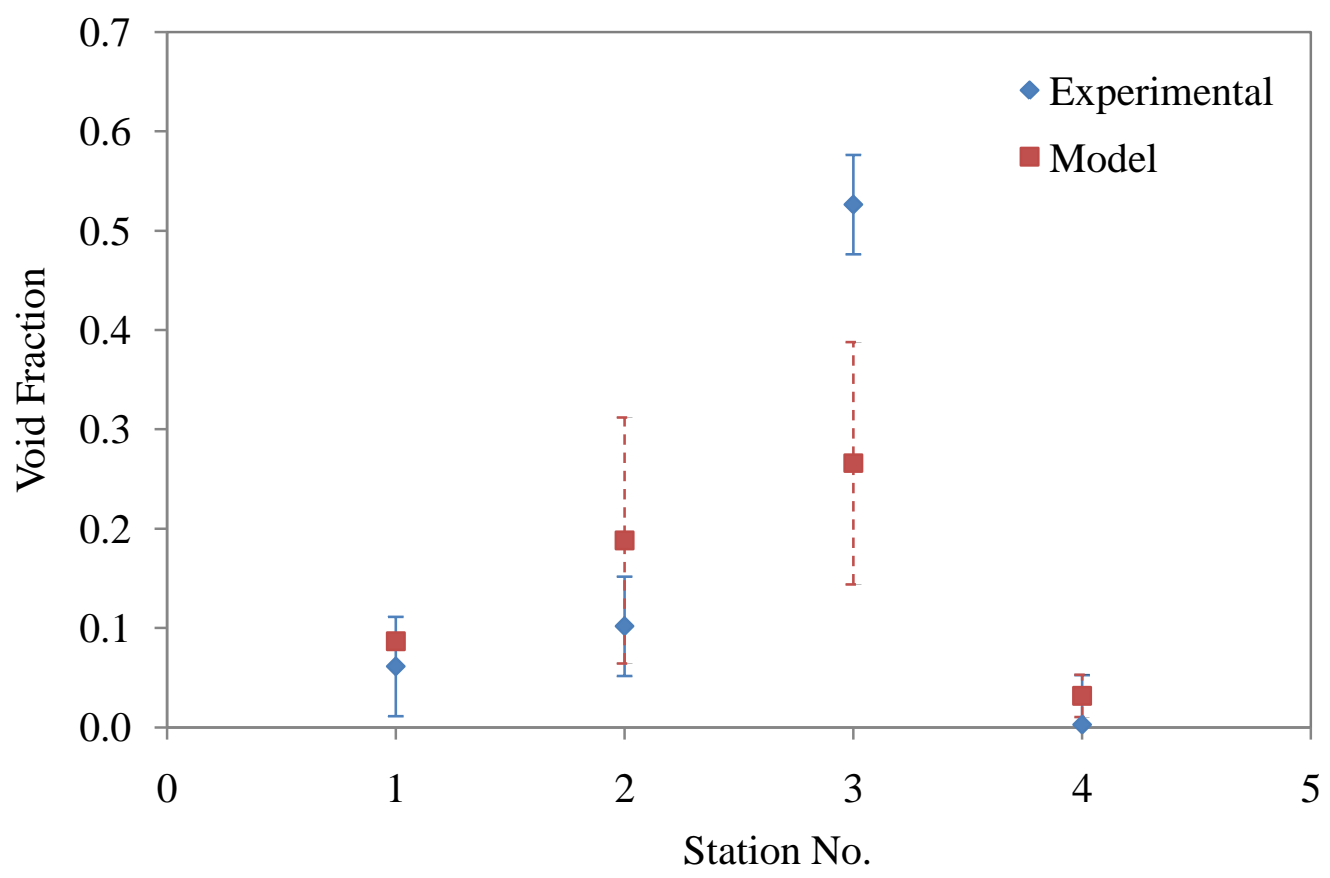

Figure E.4. Void fraction validation for scenario four $(4 \times 4 \times 3$-inch, $F r=1.60)$. 


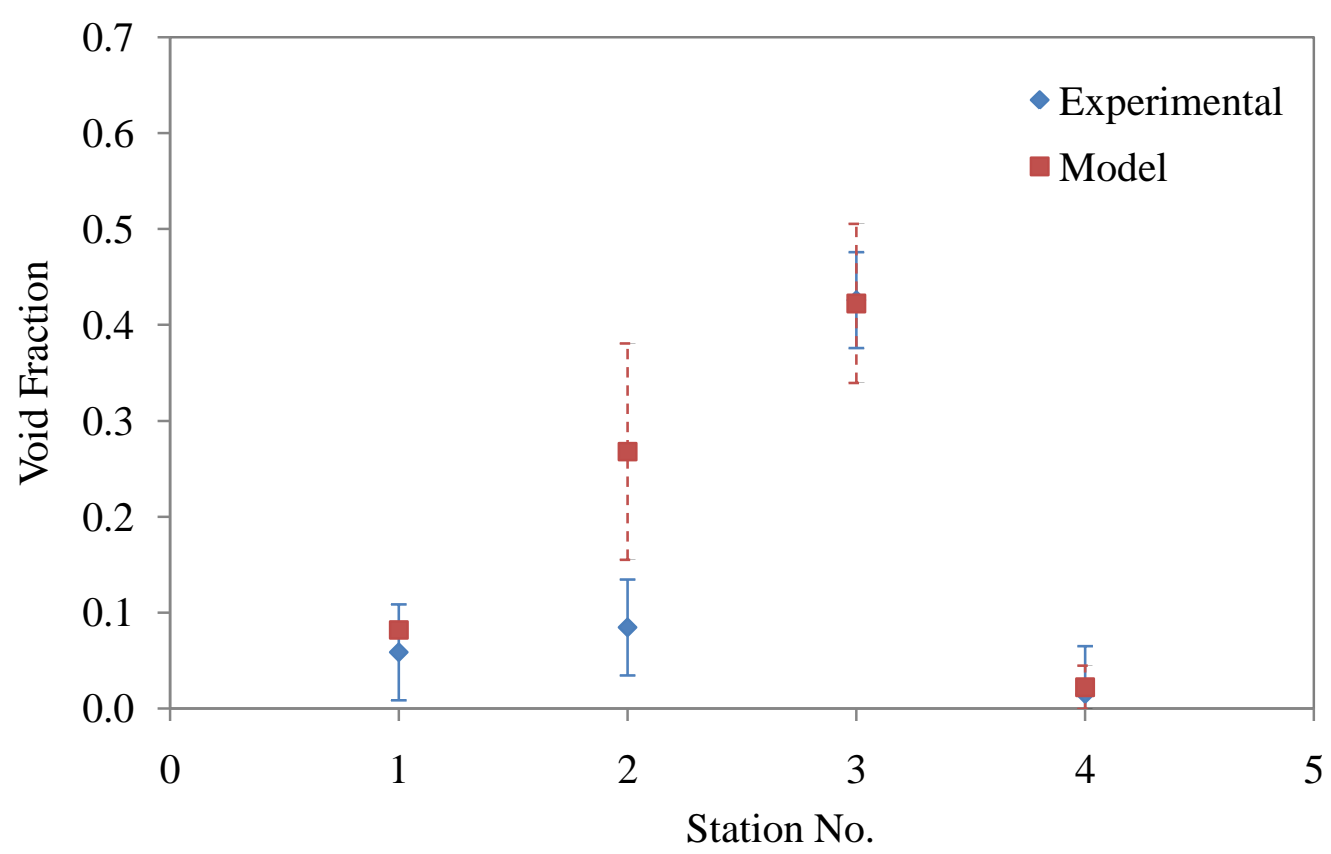

Figure E.5. Void fraction validation for scenario five $(6 \times 6 \times 4$-inch, $F r=0.81)$.

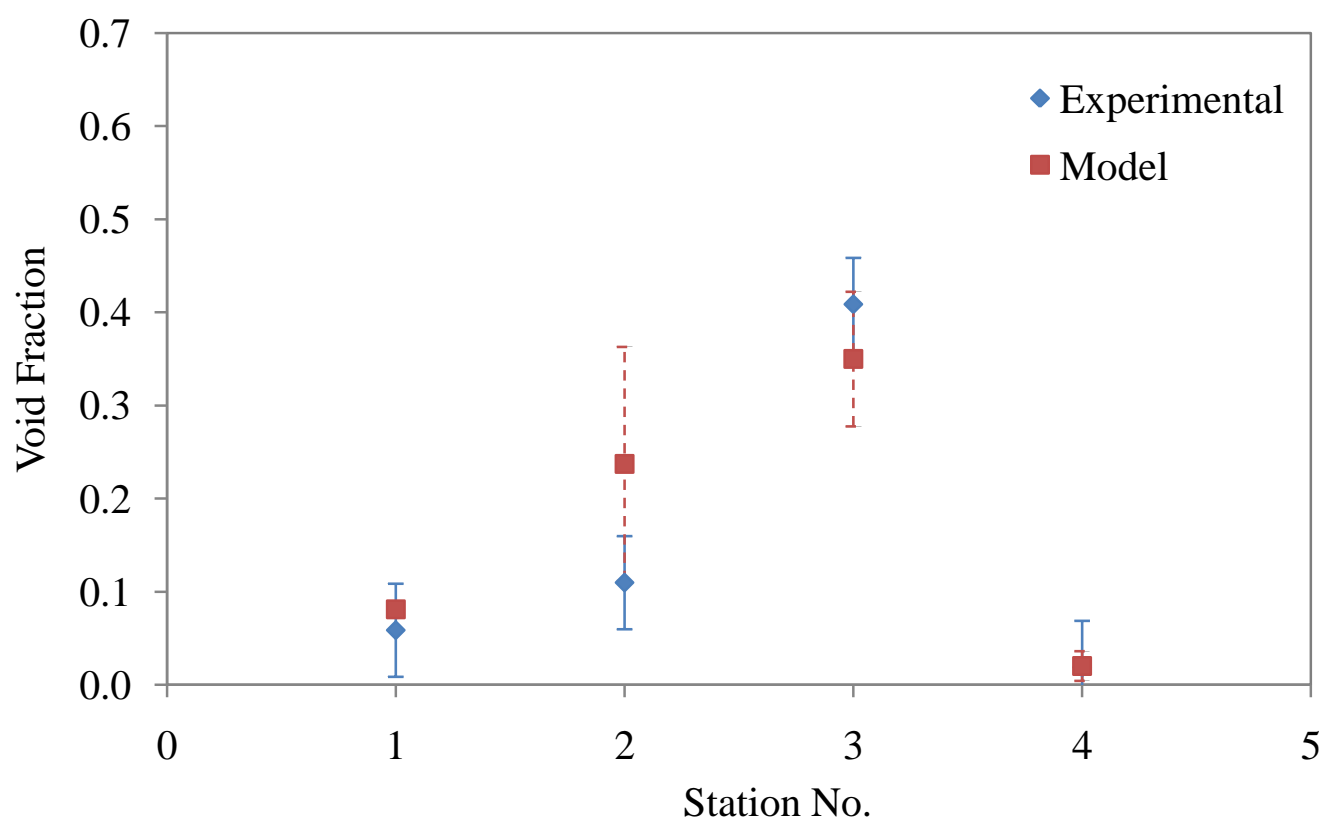

Figure E.6. Void fraction validation for scenario six (6x6x4-inch, $F r=1.10)$. 


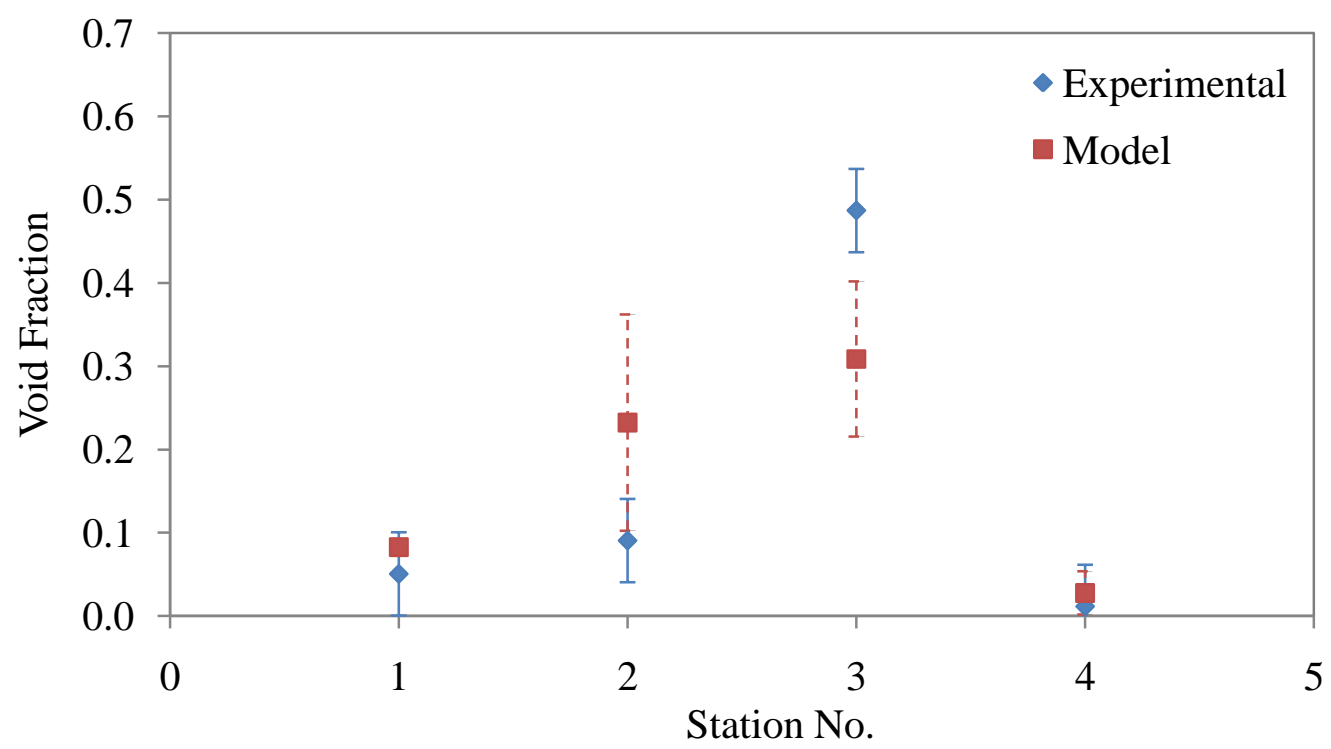

Figure E.7. Void fraction validation for scenario seven $(6 \times 6 \times 4$-inch, $F r=1.38)$.

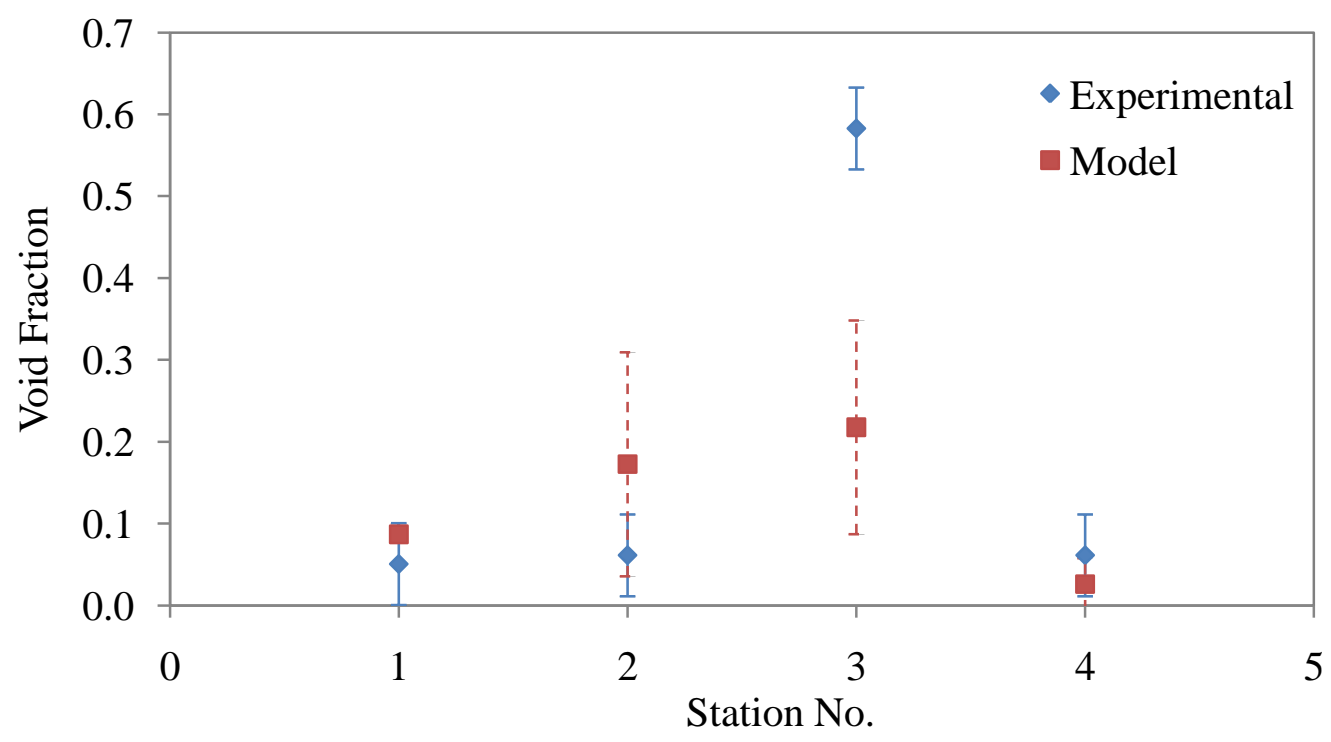

Figure E.8. Void fraction validation for scenario eight ( $6 \times 6 \times 4$-inch, $F r=1.60)$. 